\title{
S
}

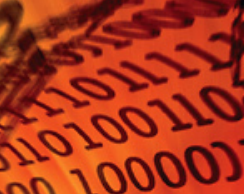

86010100110

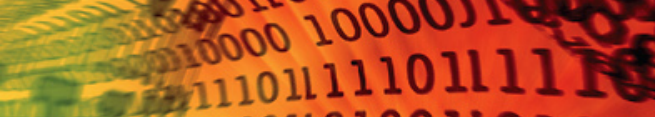

8

filo1001101001101007

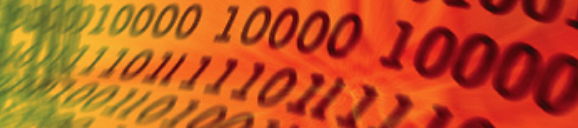

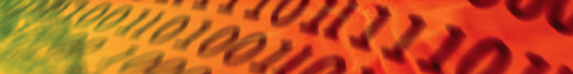

\section{Global Political Economy in the Information Age}

Power and inequality

\section{Gillian Youngs}




\section{Global Political Economy in the Information Age}

We are living in an unparalleled era of globalization; a world of Internet connectivity and emerging markets in which borders are becoming ever more permeable and trade increasingly global.

From technology and change to knowledge and power, Global Political Economy in the Information Age examines how established theoretical traditions of international relations and global political economy are shifting in the information age. Written from a critical perspective, the purpose of this book is to examine how information and technology are becoming of greater structural relevance to our understanding of globalization. By addressing the linkages between these two together with current socioeconomic developments, Gillian Youngs argues that technology is one of the key ways in which we can study how power is attained and maintained in global political economy.

This book is divided into three sections:

- Time/Space Frameworks

- Borders and Inequality

- Technofutures and Power

Global Political Economy in the Information Age is an insightful, fresh and broad-ranging evaluation of the conceptual challenges of globalization and the new information era. As such it will be of interest to and offer a diverse readership useful material when thinking about the future, both theoretically and practically.

Gillian Youngs is Senior Lecturer in the Department of Media and Communication, University of Leicester, UK. 



\section{Global Political Economy in the Information Age \\ Power and inequality}

Gillian Youngs

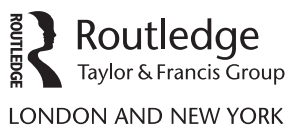


First published 2007

by Routledge

2 Park Square, Milton Park, Abingdon, Oxon OX14 4RN

Simultaneously published in the USA and Canada

by Routledge

270 Madison Ave, New York, NY 10016

Routledge is an imprint of the Taylor \& Francis Group, an informa business

This edition published in the Taylor \& Francis e-Library, 2006.

"To purchase your own copy of this or any of Taylor \& Francis or Routledge's collection of thousands of eBooks please go to www.eBookstore.tandf.co.uk."

\section{C) 2007 Gillian Youngs}

All rights reserved. No part of this book may be reprinted or reproduced or utilised in any form or by any electronic, mechanical, or other means, now known or hereafter invented, including photocopying and recording, or in any information storage or retrieval system, without permission in writing from the publishers.

\section{British Library Cataloguing in Publication Data}

A catalogue record for this book is available from the British Library

Library of Congress Cataloging in Publication Data

ISBN 0-203-96406-3 Master e-book ISBN

ISBN10: 0-415-38406-0 (hbk)

ISBN10: 0-415-38407-9 (pbk)

ISBN10: 0-203-96406-3 (ebk)

ISBN13: 978-0-415-38406-3 (hbk)

ISBN13: 978-0-415-38407-0 (pbk)

ISBN13: 978-0-203-96406-3 (ebk) 
For my students and colleagues, past and present, with whom I have shared the journey of learning, and who have made it so inspiring and hopeful 



\section{Contents}

Preface $\quad$ xi

Acknowledgements $\quad \mathrm{xv}$

Abbreviations and Acronyms xvii

Introduction: twentieth- to twenty-first-century imaginings 1 and realities - a long view of information society

Technology and change: continuities and discontinuities 3

Knowledge and power: production and consumption 7 From geospatial to sociospatial GPE: within and beyond the states/markets framework 10

Industrial and electronic utopias and ghettos: power and inequality in the information age 14

\section{PART I}

Time/space frameworks

1 States and markets: understanding geospatial time

The political economy of locatedness: national economies and currencies 24

The pre-eminent dollar 27

The euro as historic challenge? 30

The symbology of fixity: geospatiality 33

2 Virtual realities: exploring sociospatiality

Technology: thinking inside and outside the box 41

Virtual or real: overcoming a crucial binary trap 45

From cityscapes to cyberscapes: the new world of digital economy 49

Cybercitizens to cyborgs: some micro considerations 53 


\section{viii Contents}

3 The political economy of time: historical time, speed and mobility

From clock time to digital time: speed as the new imperative 66

The new global political economy of access: neoliberal ideology and universal aims 69

Moving through time and space: the new economics of mobility 73

\section{PART II}

Borders and inequality

4 Transcendence and communication

Vertical communication, globalization and new public sphere issues 77

Horizontal communication: sociospatial versus geospatial contexts 81

The political economy of interactivity: state and market in the virtual sphere 90

5 Inequality as driver

Inequality as long-term trend: exclusion over inclusion 94

The realities of inequalities: beyond neoliberalism? 105

6 Embedded patriarchy: feminism and inequality in the

Internet era

Global gender inequalities 109

Time and the experience of it 110

The gender matrix of time and embodied political economy 112

The rationalizing of time and patriarchal constructions of time 115

Time in the service of others and gendered technologies 119

Women on the Net (WoN) and women's online empowerment 122 
PART III

Technofutures and power

7 Complex hegemony in the twenty-first century: power and inequality

US hegemony in the information age 128

Inequality and leapfrogging in the knowledge economy 133

Mediated political economy: geospatial and sociospatial contexts 137

Conclusion: Contradictions between connectivity and inequality

Notes

Bibliography

165

Index

179 



\section{Preface}

I have been living a network life, like more and more of us around the world, for more than a decade, and teaching on the subject of the Internet and global change for a few years less than that. The origin of this book is in the daily practice and meanings of the virtual lives we are beginning to lead. It began in a very personal way and, as things often do, a little by chance of circumstances, when life took me to Hong Kong from my home in England, and thanks to the wonders of the Internet, much more advanced in use there than in the UK at that time, I found that the distances between 'here' and 'there' were no longer as important as they used to be. My network life began to take off, developing and expanding the face-to-face connections I had around the world, and allowing me to continue to strengthen existing contacts and make new academic and other contacts. I found that virtual collaboration in putting together a scholarly collection on globalization was pretty straightforward, and all the diverse tasks of editing and communicating with contributors efficient and effective, with distance being the most minimal of factors to consider, reduced usually to the need to be aware of time zone differences.

The speed of the Internet seemed completely in tune with the pace of life in Hong Kong, which already boasted pretty much a round the clock work ethic. Thanks in large part to my virtual life and the professional developments it nurtured, I found my way back to the UK after a few years, taking up a position at the Centre for Mass Communication Research (now incorporated in the Department of Media and Communication) at Leicester University. It was in part a result of the shift in orientation of my work on globalization and technology to incorporate the Internet and its relevance for macro and micro change, that I was offered this lecturing post, and I began teaching on these areas straight away. I was soon involved in developing an MA course on Globalization and Communications intended to appeal to students with varied backgrounds from business and computing studies, to media and political science. The main purpose of the MA was to offer a theoretically informed and interdisciplinary approach to globalization and information age issues. 
The post at the Centre was also a kind of closing of the circle for me, as I had started my professional life as a journalist, worked for a number of years in news and feature journalism and newsroom management in weekly and then daily media, before returning to higher education and establishing my own communications consultancy, working for a range of global and local enterprises including BAA plc and Rediffusion Simulation. Much of my consultancy work on internal and external communications developed a journalism specialization in civil aviation and associated technological sectors as well as my interests in innovative local media projects and approaches. I had not planned a full-time career in academia, but in pursuing my Ph.D. and accepting some part-time teaching, initially at my alma mater University of Sussex, I was encouraged into the profession by tutors I respected, who were positive about the way I interacted with students and my feedback to them.

Well, as the cliché goes, the rest is history. I took up my first full-time position at Nottingham Trent University before spending some time in Hong Kong. I taught at a new centre established by Syracuse University (New York) and had interesting times with American students who were experiencing China for the first time, and sharing their discoveries with me from their visits to the mainland, as we studied the global economy with Hong Kong as our concrete example. I completed my Ph.D., which I had been following parttime, and published it in amended form as International Relations in a Global Age: A Conceptual Challenge (Polity Press, 1999). The book was a critical consideration of the conceptual limitations of state-centred mainstream international relations (IR) in the context of globalization, drawing on critiques mainly from international/global political economy (IPE/GPE), Foucaultian and feminist IR. The collection on globalization, co-edited with Eleonore Kofman, had already been published by Pinter in 1996 and came out in a second edition a few years ago, Globalization: Theory and Practice (Continuum, 2003).

This book on GPE in the information age is both a continuation of my work on globalization and an integration of my research and teaching over recent years on technology in broad terms, and more specifically Internet-related developments and macro and micro change. It draws on my intellectual location in two interdisciplinary areas: IR and IPE/GPE; and media and communications. So this book attempts to incorporate insights from both and offer what I hope is a readable and interesting case for interdisciplinary navigation of the conceptual and concrete challenges of the new information era.

I am interested to investigate how theoretical perspectives on GPE are shifting in the information age, how communications are becoming of greater structural relevance for our understanding of it, and how this connects to established theoretical traditions, particularly of a critical kind. My focus throughout all my academic work has been on issues of inequality. Globalization has been simultaneously a story of both growing development 
and increasing inequality gaps across the world. As a global community at the beginning of the twenty-first century, we are related to each other as much by what divides us, in power and wealth, as by what connects us.

While there are many political and policy efforts to make information society developments a positive force for change, it is far from clear yet how much that will be the case. So readers will find a mix of positive, negative and cautionary messages in the pages that follow, details of the deep inequalities, including gendered ones, which persist, and hopes about the possibilities for the future that many research, political, policy and activist processes are directed towards.

There is much that is new in the information age and I want to explore that here, but I am also keen that we hold onto the insights of the past, and visit them afresh to see how they link to what is happening in the contemporary world. My sense is that this is the best route to historically grounded insights into what may lie ahead. The main aim of this book is to offer to as diverse a readership as possible some useful (and, I hope, stimulating) material for thinking about that future, theoretically and practically.

Gillian Youngs Grantham, UK 



\section{Acknowledgements}

I worked on this book during research leave granted by University of Leicester, UK, and wish to record my thanks for this support. Earlier versions of sections of Chapters 3, 4 and 6 appeared in the following three of my articles respectively, and I am grateful for permission to include this material: (2005) 'Ethics of Access: Globalization, Feminism and Information Society', Journal of Global Ethics 1, 1: 69-84; (2001) 'Globalization, Communication and Technology: Making the Democratic Links', Politica Internazionale, 1-2 (January-April): 217-26; (2001) 'The Political Economy of Time in the Internet Era: Feminist Perspectives and Challenges', Information, Communication and Society 4, 1: 14-33. I am also grateful to a number of individuals who gave me time in their busy schedules to discuss some of the areas I cover in the following pages. Some of these discussions were formal and others more in the nature of ongoing conversations. While I appreciate how these have helped my thinking about the information age, the arguments that follow and any inadequacies in them are of course mine. 



\section{Abbreviations and acronyms}

AI

APC

APC WNSP

AWID

B2B

$\mathrm{B} 2 \mathrm{C}$

CIS

DAWN

EU

FDI

GDI

GEM

GNP

GPE

GDP

HDI

ICANN

ICTs

IMF

IPE

IR

ISP

IT

ITU

MDGs

NGO

OECD

PC

SIPRI

TNC

TRIPS
Amnesty International

Association for Progressive Communications

Association for Progressive Communications Women's

Networking Support Programme

Association for Women's Rights in Development

Business to Business

Business to Customer

Commonwealth of Independent States

Development Alternatives with Women for a New Era

European Union

Foreign Direct Investment

Gender Development Index

Gender Empowerment Measure

Gross National Product

Global Political Economy

Gross Domestic Product

Human Development Index

Internet Corporation for Assigned Names and Numbers

Information and Communication Technologies

International Monetary Fund

International Political Economy

International Relations

Internet Service Provider

Information Technology

International Telecommunication Union

Millennium Development Goals

Non-governmental Organization

Organization for Economic Co-operation and Development

Personal Computer

Stockholm International Peace Research Institute

Transnational Corporation

Trade-related Intellectual Property Rights 
xviii Abbreviations and acronyms

UNAIDS The Joint United Nations Programme on HIV/AIDS

UNCTAD UN Conference on Trade and Development

UNDP United Nations Development Programme

WC3 World Wide Web Consortium

WEF World Economic Forum

WSF World Social Forum

WoN Women on the Net

WSIS World Summit on Information Society

WTO World Trade Organization 


\section{Introduction}

\section{Twentieth- to twenty-first-century imaginings and realities - a long view of information society}

A scene in the second film in the turn of the century postmodern trilogy The Matrix finds the lead character Neo ('The One') in the mechanical bowels of the city of Zion - defined in truly modern terms as 'the engineering level'. $\mathrm{Neo}$ and one of the city councillors engage in a philosophical conversation touching on some fundamentals of machine-dependent life, the machine war that is raging, and the simulated existence of those plugged into the computergenerated realities of the matrix:

Councillor: Almost no one comes down here unless there's a problem. That's how it is with people. Nobody cares how it works as long as it works. I like it down here. I like to be reminded this city survives because of these machines. These machines are keeping us alive while other machines are coming to kill us. Interesting isn't it: the power to give life and the power to end it.

Neo: $\quad$ We have the same power.

Councillor: Ah I suppose we do but down here sometimes I think about all those people still plugged into the matrix and when I look at these machines I can't help thinking that in a way we are plugged into them too.

Neo: $\quad$ But we control these machines. They don't control us.

Councillor: Course not. How could they? The idea is pure nonsense but does make one wonder just what is control.

Neo: $\quad$ If we wanted we could shut these machines down.

Councillor: Well of course. That's it. You've hit it. That's control isn't it. If we wanted we could smash them to bits, although if we did we would have to consider what would happen to our lights, our heat, our air.

Neo: $\quad$ So we need machines and they need us....

This scene in Matrix Reloaded (Wachowski and Wachowski 2003) is a vast machine room with huge mechanisms working away and wheels turning, with the protagonists distanced from it on a raised platform, surveying it from a position of control as they talk about the questions of control. This 


\section{Introduction}

early twenty-first-century imagining has echoes of a scene in an equally iconic film of the early twentieth century, namely Fritz Lang's Metropolis (1926). This futuristic fable in silent film form also centrally concerns the relationship of people to machines, but in primarily modern rather than postmodern terms focusing explicitly on differences between the destinies of 'workers' and 'owners'. A scene early in the film once again shows a vast machine room to which workers in robotic, head-down formation have descended from the city above.

The men are operating a great multi-level wall of machines in exaggerated jerky mechanical movements as if to emphasize the inhumanity of their functions. Smoke is pouring out, levers are turning and at the centre of it all the giant arms of the machine are going round and round. The observer this time is Feder, the son of the owner. He is distanced from the machines, just like Neo and the Councillor, observing, when an exhausted worker loses control of his machine and it blows, bodies of workers are flying, and then once the incident is over work begins again as normal. When a concerned Feder talks to his father about it afterwards, the latter is dismissive on the basis that accidents happen.

Matrix Reloaded and Metropolis even in their own filmic form depict ages distinct from one another: the former displaying all the slick, high-speed, colour-filled complexities of digital film-making at the end of the twentieth century, and the latter, a grainy black and white, fuzzy silent film. As pieces of technology in themselves they are indeed worlds apart. But in the themes they address, as illustrated in the two scenes described above, they are strikingly close to one another. The central place of machines in modern/ postmodern life, questions about the extent to which people control machines or they control them, the role of machines in relations of power between different groups of people, these are all pivotal issues in similar as well as distinct ways for both films. They pay broad attention to how human and machine destinies are interwoven. The comparison helps to remind us that continuities over the past century are as important as discontinuities: the mechanical age and the computer age both concern the intensification of interdependence between human and machine activity and factors of power and inequality related to it. There is a continuity of focus on the city, across both films, as the historically established locus of human power, activity and imagining.

The depiction of machines underground, out of sight, captures a truth as pertinent for social analysis as for science fiction. One of the problems in analysing the role of such technologies is their background (supporting) function that has enormous symbolic as well as practical implications. Anyone who has found themselves shouting furiously at their malfunctioning car, computer, or mobile gadget (the list is endless of course) knows the truth of the claim that people, as the Councillor in Matrix Reloaded points out, only care that things work and only attend to them when there is a problem. It seems such a simple point - that we effectively don't notice these objects 
as long as they are serving the purposes to which we wish to put them; they become an integrated part of our life experience so much so that they become a natural part of it. However, there is much to say and explore about the meanings in those naturalizing processes.

Who would have thought before the mobile phone culture that people would have conducted the most private of conversations in the most public of places? Now it is commonplace. But what does that mean about the way public and private places/spaces and our relationships to them are changing, and how do we become aware of and analyse such changes? The answers lie, as The Matrix trilogy and Metropolis indicate, in examining the linkages between technological and social developments. The former is firmly set in an imagined information age and the latter in an imagined mechanical age, but part of their purchase on reality is an enduring and long-term historical and critical concern with the human-machine complex. These creative works foreground technological questions in ways much of social science is still struggling to do meaningfully. The taken-for-granted approach to technology, already referred to, has often been reflected in the mainstream of social science. Apart from analysis on specific technologies, the majority of work has tended to treat technology as 'an exogenous and given factor' and 'as instrumental - as a tool or as an object of policy' (Talalay et al. 1997: 2).

Analysis that regards technology as exogenous (external to social processes or dynamics) tends to reduce it to its material form as objects to be used and applied. Instrumental approaches follow a similar pattern looking at means and ends, including in policy terms. What is generally missing in both perspectives is social context: the recognition that technologies are introduced into existing sets of social relations and processes, and will impact on them and evolve as part of them in anticipated and unanticipated, constructed and serendipitous ways. In treating technology as indogenous (internal to social processes or dynamics), integrated insights can be gained into its relevance to our understanding of core areas such as power and inequality, change, and questions of empowerment and disempowerment related to it.

\section{Technology and change: continuities and discontinuities}

One of the major reasons for adopting an indogenous approach to technology in the study of global political economy (GPE) is the multidimensional role technology plays in creating and enabling change: whether we are thinking of inventions and new forms of applied knowledge, what is bought and sold in markets, how wealth is generated and exchanged, or how institutional structures evolve to manage and facilitate all these processes. Technology is one of the key ways in which we can study how power is possessed and maintained in GPE, and how inequalities are distributed and persist - whether on broad socio-economic or gender grounds, for example. 


\section{Introduction}

The work of the late scholar Susan Strange ${ }^{1}$ stands out in drawing attention to the former area: how power is possessed and maintained. Her attention to technology was one of the main bases on which she pursued her arguments about the persistence of US hegemony in the late twentieth century: arguments that continue to have relevance in the early part of the twenty-first century. One of Strange's distinctive qualities was her ability to link a firm interest in micro policy orientations to macro (global) shifts in GPE. This hybridity very much characterizes her micro-macro purchase on questions of technology. She develops a fairly traditional recognition of the importance of technology to policy into a sophisticated and multidimensional understanding of its roles in the functioning of GPE and structures of power within it.

It is useful to view this capacity in the context of her broader understanding of how economic issues in general came to be increasingly important on political policy agenda in the latter part of the twentieth century. 'The boom in international political economy [IPE - the forerunner of GPE] as an area of specialization has reflected not ideas but events' (Strange 1995: 154). Nixon's abandonment of the gold standard for the dollar, the oil crises of the 1970s and associated calls from developing countries for better terms on trade and aid were among these (155).

All this was only the beginning of a period in which headlines in the newspapers and the agendas of politicians came, more and more, to be dominated by issues that were superficially economic - but also fundamentally political in the sense that outcomes were the product of changing policies as well as of changing markets'.

(Strange 1995: 155)

Technology is one of the 'superficially economic' areas that Strange recognized as 'fundamentally political', and her pursuit of these political-economic linkages follows the micro-macro pattern of probing the interactions between changing policies and markets.

For these reasons Strange's central attention to power in the context of her investigation of 'states and markets' (Strange 1994), and the increasing shift of authority from the former to the latter in the 1980s and 1990s (Strange 1996), located her in the mainstream of IPE concerns. But her work distinguished itself in many ways from the dominant mainstream neorealist and neoliberal institutionalist varieties, ${ }^{2}$ not least in its particular emphasis on the market and market actors such as firms. This pitted her, in some ways, against these more state-centric theories, and aligned her more closely with the developing work on GPE and globalization, considering change across state/market boundaries and 'at the sub-state as well as the state level' (Strange 1999: 354). ${ }^{3}$

Strange's theoretical orientation contained integrated perspectives on state and market, and this is one of the major reasons that her work offers influential frameworks for understanding change across state/market boun- 
daries. Along these lines, it could be argued that Strange was working on one of the central problems of globalization studies ${ }^{4}$ well before they became the order of the day. She was concentrating on how changing markets were changing states, and vice versa. She developed theory that maintained that equal attention to state and market, staying true to a dynamic study of political economy, in other words, one that recognizes interacting political and economic forces as motors of change.

While keeping state power to the fore, especially the power of the most powerful state, the hegemon, the USA, she sought to offer theoretical enlightenment about how such hegemonic power worked, through state and market, and through state and market actors. Her main mechanism for doing this was her identification of four structures of power - security, production, finance and knowledge (Strange 1994). The knowledge structure placed technological developments at the forefront of interpretations of power. The discussions that follow will touch on all four structures, but the knowledge structure more than the other three, because of how it presaged much later work on the information age in the fields of political science and communications.

It is clear to me that Strange's preoccupation was with the hegemon, the USA, ${ }^{5}$ when she worked on her four-sided model of power, explored in detail in the first edition of her book, States and Markets, published in 1988 and widely used as a main text book. She was seeking an integrated state/ market understanding of the persistence and expansion of US power, and, at the time hers was not a generally accepted argument.

While the mainstream (US) scholars had been preoccupied with possible shifts away from state-centred US power, the classic work being Robert Keohane's (1984) After Hegemony, Strange was wanting to draw attention to how US hegemony was enduring, and to explore detailed (state/market) understandings of why this was the case. Her mechanism was the four structures of power, with security being the traditional (political) state-oriented structure, production the traditional (economic) market-oriented structure, and finance and knowledge being two structures that reflected how hegemonic state/market power was being articulated in the globalizing and high technology era of the late twentieth century. Strange's identification of the finance and knowledge structures as equal to, and interacting with, security and production, is notable.

She was trying to get inside, to explain, how state and market, and their inter-relationships, were changing (and indeed had been for most of the twentieth century and even further back). I would argue that a historical reading of the four structures is possible. To put it simply, security and production are the long-term past, the ideas of state and market most familiar to us, and finance and knowledge are the more recent and future ideas of state and market, and their interrelationships, that are unfolding and yet to become fully familiar to us. One clue that such a reading may be relevant is the fact that Strange emphasized equality and consolidation among the 


\section{Introduction}

four structures. 'No one facet is always or necessarily more important than the other three. Each is supported, joined to and held up by the other three' (Strange 1994: 26).

At the time she was writing security, production, and to some extent finance, would be obvious aspects of understanding state and market power. Finance was understood as having grown in importance in this context and knowledge also, but to a lesser degree. Why does Strange give them equal weight? She is direct and understated about it, describing it rather dismissively, in my view, as follows:

This breakdown of the components of structural power is only common sense. But it is often obscured by theoretical discussions about the nature of the state or of power that are either far too abstract or far too narrow. Structural power has four aspects, each reinforcing or detracting from the other three. In the international political economy, all four are important, and the state which is dominant in most aspects of structural power is the most powerful.

(Cited in Tooze and May 2002b: 132)

Why common sense? At the time her framework of four equal structures of power was certainly not common sense, in the way the term is usually understood as a generally shared assumption. Far from it. So there are grounds for arguing that it is worth thinking through more deeply the meanings behind the framework, whether historically, as I suggest above, or, among other things, theoretically, as Strange indicates in this quote. She points to the problems of abstraction and narrow perspectives in theoretical discussions about the state and power.

So she is trying to theorize them in less abstract and less narrow ways. As I have said, security, production and finance were not new concepts in that regard. But finance and knowledge appear to be the structures through which Strange wanted to concretize and expand understanding of changes in state/market and power. Now, as Strange stresses, all the structures interact with one another, so part of the implication of her framework is the new importance of finance and knowledge in the security and production structures, as well as in their own right and in relation to one another. ${ }^{6}$

I have already indicated that knowledge is the least obvious of Strange's four structures. It has always been, for that reason among others, the most interesting to me. Knowledge is such a general area that impacts on all domains of human activity. Why single it out as an individual structure rather than just recognizing its pervasive influence? I think a major reason lies in Strange's preoccupation with explaining US hegemony, and the specific status of the US as a complex knowledge society with strong formal and informal linkages between state and market functions, e.g. government funding of research in the university sector, and links between that research and research 
and development in commercial sectors in military-related and other forms of production. Strange (1994: 125) articulates this as the triumph of the 'scientific state'.

\section{Knowledge and power: production and consumption}

It is especially interesting for the purposes of this book to note how Strange's account of the knowledge structure echoes analysis in international communications (IC) work more than that of GPE. This is at least in part because her understanding of the relationship of power and knowledge emphasizes issues of control and dissemination as well as what we now tend to term connectivity. She maps the move from the centralized system of medieval Christendom's power over the word, to the era of modern state control over knowledge (education, patents, etc.) where technology has been 'made to serve the interests of the state and to reinforce its power' (Strange 1994: 125).

In this era state and market took over from Church as masters and science served them both (126). Strange's framing has affinities with Ronald Deibert's (1997) later IC-oriented study Parchment, Printing and Hypermedia, which tracks the role of changing communications in social transformations through from the era of Church domination to the digital age. Strange (1988) identified the knowledge structure as something all encompassing, a structure that expressed, extended and maintained power, a structure of both state and market, and one that offered insights into their interactions and interdependencies. She saw technology in such broad (state/market) terms and assessed computers and electronic satellite communication as 'key technical innovations' (131).

These were instrumental in the rising significance and globalization of the financial sector (also dependent on diverse forms of expert knowledge and assessment exchanged instantaneously) and the growth of the knowledge economy and service work in the world of production (131-2). Technological competition not only operated in the market context but also among states, thereby impacting on the security structure, where the USA led the way in development of 'high-powered computers for use in space and for military intelligence and battlefield communication' (134).

Here is an illustration of the way in which Strange saw her four structures - knowledge, finance, production, security - engaging with one another to reinforce and extend power. But, as I have said earlier, her framework is skewed towards understanding the enduring nature of US hegemony, so it can be argued to have limitations as a general structural theory. Still it could be argued that in the unilateral world of the post-Cold War period of the 1990s and the beginning of the twenty-first century, where the USA reigns supreme as the leading global political, economic and military power, the specific US orientation of Strange's work has as much relevance today as ever. There is definitely something to be said for this point of view. It is grounds for revisiting her work, as this study does in relation to hegemony. 


\section{Introduction}

However, what other areas do we need to explore in relation to knowledge/technology to understand the current information age? I take up two major related themes in answer to this question:

1 The role of information and communications technologies (ICTs) in changing production and consumption patterns in the context of globalization, bringing new imperatives for understanding time/space issues within as well as outside of traditional state/market concepts.

2 Deepening complex inequality within and across states signalling the threat that information age developments may further embed the inequities of the industrial age, particularly those related to socioeconomic and gender differences.

These two areas touch on a number of associated issues. Let's start with the importance of consumption as well as production. Major theories of GPE including Strange's have been devoted primarily to the latter and have tended to neglect the whole area of consumption. ${ }^{7}$ This has become increasingly problematic in the era of globalization - characterized by the internationalization of production and production chains across individual national settings, and increasingly from the richer to developing economies (see, for example, Agnew and Corbridge 1995 and Dicken 2003), and the concentration of consumption within the richer economies (UNDP 1998). Since its introduction in the mid 1990s, the United Nations Development Programme's annual Human Development Report has made clear in diverse ways that not only who produces what but who gets and consumes what, matters for our understanding of globalization.

These reports have documented the growing inequality gaps within and across countries as fundamental to twentieth-century processes of globalization, and highlighted the enduring plight of those whose consumption does not even support their own survival. As the twenty-first century dawned (UNDP 2002: 19) the world's richest 1 per cent of people received as much income as the poorest 57 per cent and the richest 10 per cent of the US population had an income equal to that of the poorest 43 per cent of the world. The income of the richest 25 million Americans equalled that of almost 2 billion people and the income of the world's richest 5 per cent was 114 times that of the poorest 5 per cent. In the globalized world of finance and trade in goods and services, the poorest, concentrated especially in Sub-Saharan Africa, are the outsiders. Thanks largely to the staggering 9 per cent a year growth in China (UNDP 2003: 41), East Asia was the only region where the number of people in extreme poverty declined significantly in the 1990s. South Asia with almost 500 million poor people saw little change and in all other regions there was a rise, notably in Sub-Saharan Africa where 74 million additional people entered extreme poverty. In Eastern Europe and the Commonwealth of Independent States (CIS) the number of poor people more than tripled from 31 million to almost 100 million. 
Even in the case of China's high-speed development new outsiders were being created. At the close of the twentieth century economic growth was highly concentrated in China's coastal areas as opposed to its inland regions reflecting also a strong urban/rural divide, with average annual growth of 13 per cent in coastal areas in the 1990s, fives times that in the slowestgrowing north-western regions (UNDP 2003: 62). The rapid growth of China's economy, particularly in manufacturing, and the high levels at which it was sucking in core resources such as oil, was beginning to place attention in mainstream GPE policy and analysis on macro issues of consumption. China's total energy demand was reported to have increased by nearly 14 per cent in 2003, accounting on its own for 41 per cent of the growth in total world oil demand and overtaking Japan as the world's second largest consumer of oil behind the USA (Lorenzetti 2004). While the rich economies have been preoccupied with China for some years as a potential honey pot in terms of its huge market, few were ready for the breakneck rate of its economic growth, the diverse challenges this would represent to the strongest economies and the pressure it would also place on sustainable development debates.

The speed of growth of economies such as China and India emphasizes their dual importance as consumers and producers. This growth is happening at a time when globalization has intensified the linkages between economies across the world. This fact places technology and communications networks as an integral part of our understanding of the changing dynamics of GPE, including the relationships between the established drivers of globalization and the new drivers.

The global economy is undergoing dramatic change, brought about by rapid technological change and falling costs of communication; by the increasing ease with which goods and services can be subdivided and traded between countries and continents; and by the market reforms in large emerging economies such as China and India, enabling them to seize the opportunities that come from closer integration into the global economy.

(HM Treasury 2005: 21)

Technological factors are argued to be at the heart of the diverse challenges faced by established drivers of globalization such as the USA and the EU, in confronting the rapid success of the new drivers such as China and India, as the power axis of GPE looks likely to shift increasingly to Asia. 'Within a decade, [China] might overtake Japan to be the world's second largest economy. The EU and the US will account for a steadily diminishing share of world output' (HM Treasury 2005: 22). Understanding the differences that technological developments make is part of navigating what is different for the new drivers of globalization at the beginning of the twenty-first century in comparison to the old drivers of globalization in the latter part of the twentieth century. 
The role of ICTs and transport are given prominence as part of this picture in policy realms. These are seen as fundamental to 'increasing dramatically the speed and volume of flows of information, goods and services, thus breaking down geographical boundaries to economic activity and driving the integration of world markets' (HM Treasury 2005: 23).

\section{From geospatial to sociospatial GPE: within and beyond the states/markets framework}

This kind of emphasis on ICTs indicates how GPE has shifted in the era of globalization from being just a story of competing national economies of varying scales and wealth to one of a networked global economy where production and consumption chains can be flexibly and speedily disaggregated and extended across physical space. One way of capturing this is to think of a shift from purely geospatial definitions of GPE to incorporate sociospatial ones. Traditionally GPE is framed on the basis of the physical and territorially defined national economies and how they relate to one another through trade deficits and surpluses, for example. This can be captured as the states/markets framework that has been characteristic of the study of political economy both historically and contemporaneously. ${ }^{8}$ This geopolitical framing continues to dominate academic and political debates about globalization, articulated most frequently as the struggle between the power of states versus markets with the latter increasingly winning out. However, as the following comment indicates, these are debates that have repeatedly brought us back to questions of the mutually constituting nature of states and markets as shapers of each other's character and wealth over time.

[T] he experience of globalisation does not ... confirm the victory of markets over politics. The countries that have fared best - America and China - have done so by using their immense political leverage to shape globalisation to their advantage; the former through the global reserve status of the dollar, the latter by regulating access to its vast market.

(Clark 2005)

However, these points are made in the context of an argument for the potential of the political power of the EU, in newly structured forms, to 'bring markets back into balance with society' (Clark 2005). This argument itself has contradictory traces, because the influence of the EU has been substantially through the scale of its increasingly integrated market as a regional bloc, helping individual member economies prosper as well as positioning the EU as a major regional player in GPE. The comment was made mid 2005, a time of uncertainty about the future of the EU's political structures, and of 
fears within the EU and the USA about the scale of exports such as textiles from the new hothouse economy of China and its effects within their own sectors. Such developments highlight that in the twenty-first century GPE is set to be as much a story of states and markets and geopolitical concerns as in the twentieth century.

However, the technological infrastructures that have facilitated globalization, particularly the role of ICTs in the latter part of the twentieth century, have added to the traditional geopolitical notions of states and markets. ICT networks are operating at different levels within and across states and markets, connecting public and private spaces, people within institutions and corporations and across them, individuals to one another and to organizations large and small, businesses to other businesses (B2B), and businesses to customers (B2C). The global financial sector graphically illustrates this ICT shift in GPE, with the demise of the frenetic activities of traders shouting their prices on stock exchange floors and the rise of computer-bound transactions, and financial markets and businesses, networked for instantaneous deals across the world.

It could be argued that the growth of financial globalization was the strongest indicator in the late twentieth century of how individual economies were becoming increasingly integrated with one another, especially among the developed economies, but also across developed and developing ones. Not surprisingly, the leading industrial economies have dominated this picture with International Monetary Fund (IMF) (2005: 110) figures noting a tripling of their average external assets and liabilities between 1990 and 2003. The IMF draws attention to the pivotal role of ICTs in enabling this growth in the new climate of financial liberalization since the 1970s.

The recent bout of financial globalization is partly associated with the decline in information processing and dissemination costs that have fostered cross-border trade in an expanding variety of financial instruments through decreasing transaction costs. ... Domestic and external financial liberalization have played a major role since the early 1970 s when the current era of financial globalization began after a long period of financial disintegration.... Finally, real and financial globalization tend to stimulate each other. Increased trade flows, for example, tend to lead to larger gross capital flows, reflecting trade finance, among other factors.

(IMF 2005:11; see also Cerny 1997)

The 'real' globalization of trade growth is firmly linked to traditional geospatial framings of the global economy and the growing linkages among national economies within it, as increasing amounts and numbers of raw, processed and manufactured products (concrete items) pass between them, including through intra-firm processes. 


\section{Introduction}

Financial globalization (including that directly linked to trade) with its overt dependence on ICTs presents a different 'virtual' framing of the global economy, ${ }^{9}$ one that can be usefully considered as sociospatial. Here the emphasis is on technologically mediated linkages. These are now part of the fabric of globalization in a whole host of complex ways, as the ICT driven internal infrastructures of the global financial sector and its and other transnational corporations (TNCs) show. In addition to the physical aspects of these infrastructures - the electronic cabling, communications satellites and masts, computing and mobile communications devices and the various forms of software they are dependent on - there are the communications they enable that are equally important.

Communications are about both technologies and social process. ICTs, as the operations of the financial sector and global corporations in general indicate, are as much about organizational issues as they are about concrete products and services. Communications infrastructures, most significantly the Internet and its world wide web, provide social spaces that are virtual rather than physical. And the stories of both the Internet and world wide web illustrate Strange's interconnected (state/market) structures of power: the importance of state-funded (often military/defence-related) pure research for scientific and technological developments that when disseminated can have large-scale implications for market innovations and changing patterns of production and consumption.

As is well known by now, the Internet actually began as a US military experiment in the 1970s to design a computer network called ARPANET that would withstand a nuclear attack. The fundamental principal of the network was a distributed form of communications without central control, underpinned by a routing system called 'packet switching'. Through packet switching technologies, messages would be split up and sent along dispersed routes so that if parts of the network were lost in a military conflagration, they would still arrive at their destination. The ARPANET eventually evolved into a communications tool for public research organizations and universities in the USA, to be followed by other similar systems elsewhere (Deibert 1997: 131).

The world wide web, a series of technological developments taking the computer connections of the Internet truly into the network information age, was developed by Tim Berners-Lee at Europe's state-funded joint venture particle physics centre, CERN, in 1990.

The fundamental principle behind the web was that once someone somewhere made available a document, database, graphic, sound, video or screen at some stage in an interactive dialogue it should be accessible (subject to authorization, of course) by anyone, with any type of computer, in any country. And it should be possible to make a reference - a link - to that thing, so that others could find it (Berners-Lee 1999: 40).

While the Internet and the world wide web have to be accessed from physical spaces using different forms of hardware and software, these tech- 
nologically mediated spaces exist beyond such physical spaces and frequently merge or efface local and global territorial boundaries rather than necessarily being defined by them.

They are simulated social spaces (Shields 2003: 4) if we think of contrasting them to the more familiar physical spaces, e.g. online government services versus government offices or online shops versus actual supermarkets. They are symbolic spaces in which real activities, transactions and experiences can take place. Growing numbers of people around the world are accessing these spaces and operating in them for reasons as diverse as setting up businesses, buying goods and services, making friends, and launching global political campaigns. These virtual connections are increasingly integral to defining GPE and are taking us beyond the traditional geospatial conceptualizations of it.

The so-called information technology (IT) revolution of the second half of the twentieth century heralded the need for such shifts of perspective. The move from mainframes to personal computers and the development of intranets (networked computers within firms and organizations) all signalled digital transformations in the ways organizations and people operated and worked. The incorporation of larger communications systems within the digital revolution and the arrival of mass access to the Internet from the last decade or so of the twentieth century would inevitably extend these transformations into wider society.

One way of grasping conceptually such developments is to think of the singular influence of 'generic technology'. IT (and ICT) is usefully considered in this way. 'Generic technology can be taken to refer to a technological innovation or set of innovations with a shared genus, observed to affect large portions of the economy' (Russell 1997: 44). ${ }^{10}$ Its key quality is 'pervasiveness', its contribution to 'changes in technology systems, which not only affect many parts of the economy but also create totally new industries'. It has 'enabling characteristics' leading to 'widespread industrial impact' (44). IT and subsequently ICT represent two stages in the transition to what is frequently called the knowledge (or information) society. ${ }^{11}$ Analysis in political economy and business studies led the way in the first stage looking at areas (in addition to finance) such as: the changing nature of firms and work (see, in particular, Drucker 1993); the role of IT in transnational corporations and global structures (intra-firm as well as inter-firm) of organization and production (see, in particular, Dunning 1993 and 2000); the influence of IT in the development of the service sector and products (e.g. in business consultancy, accounting, insurance and communications) (see, for example, Dicken 2003).

Analysis of the second stage has been led equally by communications and media scholars who have been tracking the growth in significance of communications and media, not only as a major sector of products and services in the economy, but also in the rise of multimedia conglomerates as a characteristic of globalization (see, for example, Herman and McChesney 


\section{Introduction}

1997; McChesney 2002; McChesney and Nichols 2002). One of the distinctions of this area of scholarship is its multifaceted attention to the medium itself, including as technology with different forms of social and cultural, as well as political and economic implications. Prominent and controversial in this respect is Marshall McLuhan (1911-80), who famously coined the idea of the global village and assessed at length the impact of electronic communications on how information is shaped, received and experienced, and how the world is becoming increasingly interconnected (McLuhan 1962, 1964, 1967; McLuhan et al.1997). ${ }^{12}$

One of the benefits of this kind of approach is its sense of these communications as part of the fabric of social existence, a means through which activities, but also senses of being and identity (of organizations, individuals and groups) are mediated. It helps to draw our attention to the growing influence of technologically mediated social spaces (the sociospatial) as added dimensions of the more familiar physical settings (the geospatial).

McLuhan's analysis is an extreme version of the approach, interpreting electronics as extensions of human capacities, activities and presence. As such it is open to criticism that technology is being identified as too determining of human processes, but its integrated notions of woman (man)/machine dynamics are powerful in prompting us to consider how machine-manifested digital competencies are being interwoven into activities and being in continually intensifying electronically mediated lives.

A contrasting, explicitly postmodern feminist take on such developments, Donna Haraway's exploration of the idea of the cyborg, looks at how politics (and thus possibilities for transformation as well as oppression) are inherent in the places where we interface with scientific and technological knowledge processes(see Haraway 1991, 1997a and 1997b).

\section{Industrial and electronic utopias and ghettos: power and inequality in the information age}

So are we living in the world and imaginings of The Matrix or Metropolis? The simple answer is both in some regards. This is a useful way of capturing how difficult and complex it is to think about change in the contemporary period, and how much has definitely changed but how much has stayed the same. The impact of the industrial revolution is far from over as the continuing spread of production processes across the globe attests. The globalization of the late twentieth century has been substantially about the shift of production from the rich economies to developing countries, with China being the most significant beneficiary in the context of the latter (see, for example, OECD 2003).

The hierarchical structure of the global economy demonstrates the enduring importance of industrialization. At the top are the richest economies with high economic and technological innovation and concentration of patent ownership. Second are the developing country exporters of manufactured 
goods, notably China. Then come the fuel-exporting economies, the transition economies of the former Soviet Union, and last the commodity exporting developing countries (UNDP 2003: 83). Between 1980 and 1998 economic growth was concentrated in the first two groups with the other three tending to suffer economic decline.

Sub-Saharan Africa suffered most with two thirds of its countries and three quarters of its population experiencing economic decline (83). Shifts of population from rural regions to urban settings, which has been a defining characteristic of the industrial era, continue to be a dominant trend, with cities and conurbations both hubs of power and the sites of sweatshops and urban ghettos (Lash and Urry 1994). Nearly half the people in the world (48 per cent) were estimated to be living in urban settings by 2003 and this figure of 3 billion was expected to rise to 5 billion (61 per cent) by 2030 (UN Department of Economic and Social Affairs Population Division 2004: 1).

The rate of urbanization has been staggering. The urban population reached 1 billion in 1960 and 2 billion in 1985 and the historic point of more than half the world living in urban areas was expected by 2007 (1). Almost all the world's population growth through to 2030 is expected to be absorbed by the urban areas of less developed regions, with Asia and Africa by that time each having more urban dwellers than any other major area, and Asia alone accounting for more than half the world's urban population (1-2). The so-called mega-cities of 10 million people or more account for only a small percentage of the world's urban population -4 per cent in 2003 compared to over 50 per cent living in settlements with fewer than 500,000 inhabitants (2).

The metropolis of vastly different scales will continue to be as dominant in the information age of the future as it has been in the industrial past, remaining a key site for the study of the haves and have nots and their differentiated relations to technologies as owners and manipulators of it, actual and would-be users and consumers.

The financial globalization and service sector expansion of the late twentieth century brought a particular concentration on global cities such as New York, London and Tokyo, as densely connected networks of state and market power and influence, as well as concentrated sites of wealth and conspicuous consumption (see, e.g., Lash and Urry 1994; Harvey 1990; Sassen 2001, 2002a and 2002b). ICTs are an essential part of the communicative infrastructure that has made these cities what they are, multidimensional and connected strategic global hubs. 'The world's great cities are crucial nodes in the global political economy. They are the geographic basing points in terms of not only production and consumption, but also of political-economic control and social reproduction' (Smith and Timberlake 2002: 117).

Global cities are distinctive sites of power - and inequality - (see Lash and Urry 1994) operating on both the traditional geospatial basis and the newer 


\section{Introduction}

ICT-driven sociospatial basis. They are concrete geographically located settings, which from the late stages of the twentieth century have been increasingly networked through ICTs, and characterized as both locations of concentrations of different forms of expert knowledge and information (financial, commercial, cultural, policy-related etc.), and flows of them between one another and more widely. ${ }^{13}$

Cities as key sites of power are symbolic of the continuities and discontinuities of the industrial and information ages. They signal the dual importance of geospatial and sociospatial perspectives. They represent, to some degree, the fusion of the worlds of Metropolis and The Matrix, while in the information age for many workers the so-called dirty machinery of Metropolis is substituted by the so-called clean technology of ICTs and the virtual connections of cyberspace. Questions about power and the relationship of people to machines endure, albeit that this now includes software as much as hardware.

Questions about control, autonomy, and the monotonous or repetitive nature of work, are as relevant in the information as the industrial age. In the networked world, where intelligent software and increasing dependence on ICTs makes the tracking of people, their movements and activities easier, surveillance is even more of an issue than ever before (see, for example, Lyon 1998 and 2002; Green 1999).

The flexibilities of the information age, its virtual connections and the ways in which they can overcome the limitations of geography are increasingly prominent in considerations of how GPE is operating. This is as true whether we are thinking of the continuing globalization of production processes, or the move of call centres and other service-related work from rich economies (e.g. the UK) to developing economies (e.g. India) in recent years.

So how should we be approaching GPE in the hybrid conditions of the geospatial and the sociospatial? The traditional state/market territorialized model is primarily geospatial in orientation so it is insufficient in the information age, where networks and flows associated with ICTs cannot be simply mapped onto it. We need to consider how such communications structures and processes mirror and align with, challenge and disrupt the territorial boundaries familiar in (national/international) perspectives on states and markets.

As ICTs are as much part of the infrastructure of GPE as they are products to be bought and sold (concrete and symbolic), and different means of consumption and experience, we need to explore in detail the nature of the sociospatial. The first section of the book therefore begins by looking at time and space in geospatial terms, exploring how the state/market model has historically constructed such phenomenon through factors such as national history and territorial citizenship, time measurement in industrial processes, and rationalization of work (productive) and leisure (consumption) time. This section considers how sociospatial shifts have occurred with the 
development and spread of applications of ICTs, the virtual nature of the digital economy and its 24/7 ( 24 hours a day, 7 days a week) characteristics, and the growing importance of horizontal (cross-border and interhierarchical) alongside the traditional vertical (bounded and hierarchical) communication and networks.

This section also examines how we are moving into an era where time/space contingencies play influential parts in defining the nature of social existence, opportunities and constraints. ICTs mean that experience of linkages between time and space is diverse and multi-layered in the information environment. Presence and access become part of analysis in GPE relating as much to the sociospatial as to the geospatial. These concepts relate to the technologically mediated environments of ICTs as well as to the more familiar material environments of state and market.

Access covers infrastructural communications networks as well as hardware and software, and all the associated knowledge structures of their production, application and use. Debates about the digital divide relate to all these areas, raising local and global issues of inequality, including those related to gender. The World Summit on Information Society (WSIS) ${ }^{14}$ has been a major global institutional process pressing for action in these areas for the developing world.

The next section of the book looks at borders and inequality, arguing that we need to consider borders in traditional territorial fashion but also in relation to the virtual and cross-boundary qualities of ICTs. The discussion recognizes how ICTs are a means by which states and major market actors, such as corporations, reassert their hierarchical power and identity, and extend their reach into the lives of citizens and consumers. In such ways, it could be argued that ICTs are enhancing the traditional geospatial power of such actors, hence the importance of the hybridity of the geospatial and sociospatial.

States can be argued to be attempting to reassert their territorial boundaries in the light of virtual reality to ensure their security, for example in combating online terrorist or criminal activity, and pressing their online political (and cultural and/or religious) control (e.g. China, Saudi Arabia), while also wanting to benefit as fully as possible from the economic advantages of the information age. The multi-sector nature of the Internet covering literally all spheres of human activity and featuring pervasive connectivity at home and work, and in transit, thanks to diverse mobile devices, problematizes established notions of the separation and distinctiveness of political, economic, cultural, and public and private spheres.

The capacities of state and market actors, as well as other major institutional entities, to assert their vertical (top-down) power over horizontal (bottom-up) influence are challenged in a range of ways by uses of ICTs by new market players, lobby and action groups and individuals.

This section looks in detail at the multiple structures of inequality dominating the material conditions of the information age. It considers the 


\section{Introduction}

expansion and restructuring of global markets, production and consumption, and the continuing importance of the concentration of control and ownership of key technologies in the rich economies. It discusses broad material, digital and gender divides, their interconnections and reinforcements. It looks at the problem of uneven development across the global economy and within individual economies, including the major growth economies of the developing world, China and India.

I argue that mainstream liberal/neoliberal discourses have persisted in emphasizing the goal of equality, while diverse statistics reveal that development has led to growing extremes of inequality that need to be understood in multifaceted ways. I pose the question of whether the liberal ideology of equality is under intolerable strain in these circumstances. We should consider how this situation has inhibited deep and meaningful understanding of the actual material conditions separating peoples and countries.

Issues of differentiated access to communications infrastructures and technologies are addressed. This section draws on the statistical gender analysis of the UNDP's Human Development Reports, in discussing gender inequality as a global issue, and explores how development has had differentiated benefits for men and women in developed as well as developing economies.

Key areas such as education, political representation and wage gaps are covered. I argue that the information age threatens to embed patriarchy further, especially through historically established patterns of male dominance of science and technology, and the traditional predominant gender identification of high technology and its innovations and applications with men, and low (domestic, service or support) technology with women. Gender divides in the digital economy are a major area of concern in the global women's movement, and NGOs are active in this area, both in practical and policy spheres. Diverse aspects of gender and technology are explored, including in relation to gendered concepts of time, and the issue of work burdens for women inside and outside the home.

The last section of the book concentrates on long-term questions of technology and power. It begins with the concept of hegemony and argues the prime importance of technology in the current era, assessing the continuing expression of US hegemony in military, economic and political forms. The concentration of ownership and control of technology in the rich economies, and the technological achievements and ambitions of the major growth developing economies of India and China are discussed.

I look at the technological have nots in terms of the least developed economies, and socio-economic and educational inequalities. The speed of economic development and innovation in the information age is considered as a key factor impacting on catch-up possibilities for those on the wrong side of the digital divide. Arguments about the leapfrogging possibilities for less-developed economies to bypass traditional development patterns 
and move straight to the information economy stage, as raised in the WSIS process, are touched on.

The multimedia characteristics of ICTs, the related symbolic intensity of the virtual environment, the importance of the Internet as the first integrated multimedia interactive platform, and the diverse virtual settings it offers, are discussed. The fully interactive nature of the symbolic settings means that they should be regarded as social even though they are virtual. Connections and transactions take place, albeit not with any embodied human being there physically in front of you, but via intelligent computer and instantaneous communications systems. The power to create symbolic settings is closely related to innovation and diverse skill sets related to hardware and software, socio-economic access to all of these, as well as adequate communications infrastructures to successfully operate them.

New models of generating value relate as much to information services and navigating the new virtual/information environment as to being present in it, as the headline success of search engines like Google has made clear. I argue that the information age represents an era of mediated political economy, where familiar material concepts of political economy, and the state/market model, need to be supplemented by an understanding of the transcendent and symbolic, horizontal as well as vertical qualities of ICTs.

The new digital economy increasingly means that more complex perspectives on time and space are required than those offered by the traditional state/market model. These take into account the role of technologically mediated social existence, and its linkages to other material forms of existence. Consideration of inequality is made more complicated by these developments because of the long-standing patterns of global and local inequality, and the multifaceted nature of the digital divide. 



\section{Part I}

\section{Time/space frameworks}





\section{States and markets \\ Understanding geospatial time}

Perhaps the most important single aspect of modernity was the way in which, almost imperceptibly, mankind was transforming itself into a single global community, in which different races and civilizations, now touching at all points, simply had to come to terms with each other.

(P. Johnson 1992: 787)

Today, electronics and automation make mandatory that everybody adjust to the vast global environment as if it were his little home town.

(McLuhan et al. 1997: 11)

These two reflections are related to quite distinct historical times: the first to the early nineteenth century, the press of the British empire in the East and the build-up to the opium wars in China; the second to the middle of the twentieth century, the expansion of global media and electronic connectivity. They both signal, in different ways, the influence of questions of proximity in shaping modernity and postmodernity, and the integral role of technologies to them. ${ }^{1}$

In the nineteenth century advances in marine navigation and steam engines helped expand the global reach of trade, with the shift from mechanical to electric power also bringing telegraphic communications. In the twentieth century the growth of wired networks and the arrival of satellite and increasingly mobile global communications were making more and more contact across the world possible without physical movement. The continuity across the two historical periods of transcending the constraints of physical distance is clear. The discontinuity of primarily direct embodied contact through trading networks of colonial times contrasted with the increasingly technologically mediated communications of the virtual era is also clear.

This section of the book explores the importance of time/space frameworks for the past, present and future of GPE. This chapter discusses the modern state's role in framing our notions and experiences of time, and market constructions of time. The symbolic dimensions of money are explored from historical and contemporary perspectives including in relation to the euro. 


\section{Time/space frameworks}

These aspects help us to understand the time/ space configurations that have given us our geospatial sense of the world as steered by state and market.

The approach taken here recognizes individual and collective experience and identity as integral to our sense of GPE and its time/space linkages. I want to begin by examining how locatedness and particular dominant framings of time (including national histories) have characterized the territorialized nature of state and market in contemporary history. My main argument is that modern citizenship and market participation have been intrinsically founded on geospatial realities expressed predominantly in territorial terms.

\section{The political economy of locatedness: national economies and currencies}

States and markets are foremost national in character, in other words they are bounded, territorial entities with specific identities and histories. Even in these days of an extensively integrated global market, this foundational fact remains important. We may all be global now, or with aspirations to be so, but it is evident that we are not global in the same way. This is first a national issue, a question of national differences, and second a regional issue where, as the European Union (EU) demonstrates, collaboration on the basis of shared principles works to challenge, in some ways, the significance of the national boundary.

The common market of the EU is greater than the sum of its parts (the individual national economies) with regard to its impact as a regional integrated market. However, recent national resistances to the future enhancement of the EU project signal how it remains the sum of its territorial parts, nation states. Even more strikingly, the advent of China as a major global economic player, but with a Communist political system, highlights the enduring tensions, which national distinctions generate. States and markets are bounded expressions of differentiated (and in some cases shared), political and economic principles and values; political and economic systems; ways of life.

The bounded nature of states and markets is central to their character as historical and social entities, the ways in which they shape experience and understanding of the world. They are quite literally the spaces that dominate the majority of people's lives around the world. What is less often recognized is the degree to which they also fashion time as a phenomenon articulated in geospatial (territorially defined) ways through national historical trajectories, including market structures and forms relying on the measurement of time as part of the generation of value (including wealth).

It is interesting to return to one of the founding texts of modern political economy, Adam Smith's The Wealth of Nations (1776) in thinking through the relationships between time and space that have formed contemporary 
geospatial realities. His core concept of labour as fundamental to exchange in a market has embedded within it the social expression of productive time - time spent to produce value.

Labour was the first price, the original purchase-money that was paid for all things. It was not by gold or by silver, but by labour, that all the wealth of the world was originally purchased; and its value, to those who possess it, and who want to exchange it for some new productions, is precisely equal to the quantity of labour which it can enable them to purchase or command.

(Smith 1982: 133)

Smith explains, however, how through commodities and money as the main bases for exchange, labour as 'the real measure of the exchangeable value of all commodities' (1982: 134) becomes hidden. Within money, the symbolic medium of exchange - 'the universal instrument of commerce' (131) - lies a complex story of relative values, of commodities produced and exchanged, and the contrasting amounts of labour involved in bringing them to the market-place, and differentiated values attached to those divisions of labour. ${ }^{2}$

Exchangeable values (prices) are composites deriving, according to Smith, from wages, profit and rent (1982:155) and impacted by supply and demand issues (157-65). The expansion of productive labour is dependent on the accumulation of stock (capital), Smith goes on to explore (371-3), and his categorization of its three different functions has temporal characteristics.

Talking about the 'general stock of any country or society' Smith defines its first function as that of 'immediate consumption' covering 'food, clothes, household furniture, etc.' (1982: 375-6). The second function 'is the fixed capital, of which the characteristic is, that it affords a revenue or profit without circulating or changing masters' and consisting of 'useful machines and instruments of trade', 'profitable buildings which are the means of procuring a revenue', improved land, and 'the acquired and useful abilities of all the inhabitants or members of the society'.

The third function is 'circulating capital; of which the characteristic is, that it affords a revenue only by circulating or changing masters' (Smith 1982: 376-8). Smith divides the third function into four parts as he does the second function. But prime in circulating capital, not surprisingly, is money 'by means of which all the other three are circulated and distributed to their proper consumers' - these three being stock and provisions designed to generate profit, products in process but not yet ready for distribution, and completed products yet to be distributed (378).

The linkages between labour and immediate consumption, fixed and circulating capital, are defined in terms of their relationships to one another over time. 


\section{Time/space frameworks}

Every fixed capital is both originally derived from, and requires to be continually supported by a circulating capital. All useful machines and instruments of trade are originally derived from a circulating capital, which furnishes the materials of which they are made, and the maintenance of the workmen who make them. They require too, a capital of the same kind to keep them in constant repair.

No fixed capital can yield any revenue but by means of a circulating capital. The most useful machines and instruments of trade will produce nothing without the circulating capital which affords the materials they are employed upon, and the maintenance of the workmen who employ them. Land, however improved, will yield no revenue without a circulating capital, which maintains the labourers who cultivate and collect its produce.

To maintain and augment the stock which may be reserved for immediate consumption is the sole end and purpose both of the fixed and circulating capitals. It is this stock which feeds, clothes, and lodges the people. Their riches or poverty depend upon the abundant or sparing supplies which those two capitals can afford to the stock reserved for immediate consumption.

(Smith 1982: 378-9)

Smith's market dynamic foregrounds the self-sustaining nature of labourcapital relations in supporting present needs while working constantly through its diverse processes to meet future ones. This is a market dynamic centrally perceived as being about managing resources and productivity towards both short and longer term ends.

It demonstrates how founding principles of political economy concern the practical management of material processes in an ongoing manner, integrating the logic of providing for immediate and longer-term needs. The relationship between labour and capital is framed in these terms, and notions of 'fixed' and 'circulating' capital form part of the process of navigating between immediate and longer-term needs.

Time/space principles are clearly embedded within this analysis, focusing on managing resources effectively over time, and using various forms of space-based (fixed) and transitionary (circulating) capital to this end. In this way it is clear how time/space relations are fundamental to political economy and traditional geospatial framings of it. Money is pivotal in market dynamics, as Smith stresses, as the main means by which capital circulates, in other words is made mobile across both time and space.

The symbolic as well as material weight of money in geospatial respects is an area of enduring significance (see especially Simmel 1990; see also Cohen 1998). The whole notion of national currencies has bound within it the territorial encapsulation of both state and national market, and the relative wealth of different states and markets in comparison to one another. In GPE whole historic eras are indeed identified on the basis of the dominant 
power of such currencies: the nineteenth century with sterling and the colonial might of Britain, the twentieth/twenty-first centuries with the US dollar and America's global political and military reach, the First World War being a key moment of transition between these two eras with the USA taking over the mantle as international creditor nation from Britain.

The scale of the war had outstripped Britain's resources with dependence on US credit tipping the balance of power towards America. Paul Kennedy (1989: 344) explains that 'British defense expenditures rose from $£ 91$ million in 1913 to $£ 1.956$ billion in 1918 , by which time it represented 80 per cent of total government expenditures and 52 per cent of the GNP [gross national product]'. The escalating expense of the war - '[b]y April 1917 . . inter-Allied war credits had risen to $\$ 4.3$ billion, 88 per cent of which was covered by the British government' (346) - was combined with the heavy dependence on the USA for munitions and food and a growing trade deficit.

Neither the transfer of gold nor the sale of Britain's enormous dollar securities could close this gap; only borrowing on the New York and Chicago money markets, to pay the American munitions suppliers in dollars, would do the trick. This in turn meant the Allies became ever more dependent upon US financial aid to sustain their own war effort.

(Kennedy 1989: 346)

\section{The pre-eminent dollar}

The shift from sterling to the dollar era was one of the most influential transitions, if not the most influential, in contemporary GPE. There are a number of points related to it in time/space terms that are worth considering, especially in the light of contemporary analyses of globalization and its historiography. Remembering the geospatial character of national currencies, their roots in and symbolic expressions of national wealth, is helpful in this. The character of the sterling era included a firm fix on the region of western Europe and the wealth concentrated in the states therein.

Its geospatial framing was concentrated on the power of major western European states. The period of 'total war' (where states' resources (human and otherwise) were mobilized entirely, including at home, to wage war) ${ }^{3}$ that began in the latter part of the First World War, but did not come fully into being until the Second World War, heralded a new international (transatlantic) era. The geospatial frame was expanded and the new international creditor status of the USA at the end of the First World War determined in certain regards the future as much as the present. The function of credit - buy now, pay later - guaranteed this. The Allied effort and the complex role of the USA within it intensified transatlantic links in a number of ways - politically and militarily, particularly with the late, and arguably decisive, 


\section{Time/space frameworks}

entry of the USA into the war in 1917, and economically, in the might it brought with it as a creditor and supplier of arms, merchant shipping and food exports (Kennedy 1989: 349-50).

In this transition the combined strengths of the USA across its political and military influence, and in economic and financial spheres, was evident. Its status as a modern power, wealthy and technologically developed, with a resulting global reach as a national economy, was becoming instrumental in shaping international affairs. The transatlantic structure of power politics was consolidated in the Second World War, which with war in East Asia, marked the truly global era of total war. The relationship between the British and US leaders Churchill and Roosevelt symbolized potently the shared values that influenced the transatlantic bond - a relationship that looked as much towards the future shape of world politics (and economy) as victory in the war.

The Second World War is the historical event that marked the complete transition to US dominance of the world capitalist system and the primacy of the US dollar as the global currency, a position it has held through to the present day. Its military pre-eminence and technological lead were devastatingly demonstrated with the ending of the war through the dropping of the atomic bombs on Japan. But the age of the so-called superpowers was soon to dawn with Russia's military strength and nuclear capability confronting the USA on either side of an ideological divide.

The geospatial character of global politics was quickly shaped by the two bloc (communist versus capitalist) nature of the Cold War, with Russia and the USA leading East and West and their international alliance structures respectively, a situation which persisted in different forms through to the collapse of the Soviet bloc and the fall of the Berlin Wall in 1989. ${ }^{4}$

In the post-Cold War age of globalization, where much is often made of the unilateral power of the USA, it is worthwhile recalling that there was a distinctive historical moment when its rise to such power and the triumph of the almighty dollar occurred. Stephen Ambrose (1971) aptly and presciently, considering the much later focus on the global, captured this as the 'rise to globalism'. This rise to globalism consolidated the economic, industrial and military strength that had been building, but it was also very much a fact of the Second World War in which 'the American contribution in manpower and materials was enormous' (Calvocoressi and Wint 1972: 559).

The powerhouse of the US economy at this time had created internal change as much as external change in its world status.

[T] he war altered the distribution of power in the United States geographically and politically. It accelerated the shift of money and people from the east to the west coast and gave the south the boost which it had never had since the Civil War. Industry invaded the West where it had been relatively inconspicuous and the south where - outside Texas, 
already well supplied with capital from oil - it had hardly been at home at all.

(Calvocoressi and Wint: 1972: 560)

Externally, US power was notable in its comprehensiveness across all key spheres - military, economic and political.

It is possible to argue that the defining nature of this power echoes through the years as strongly today as ever, whatever the challenges, for example, from the growing new economic might of China. It was a power with a firm basis in technological advances in both industrial and military sectors, and its political values, not only with regard to their historical roots, but through the Alliance (particularly Anglo-American) of the Second World War had consolidated its 'global' character, its links and affinity with Europe.

American domination of the Alliance reflected ... a new era in world history. The United States had replaced Great Britain as the dominant world power. By 1945 American production had reached levels that were scarcely believable. The United States was producing 45 percent of the world's arms and nearly 50 percent of the world's goods. Two-thirds of all the ships afloat were American-built.

(Ambrose 1988: 29)

These dramatic statistics are just a part of the complex symbolic global status of the US dollar as the expression of a dominant geopolitical and geoeconomic power. It is not an overstatement to say that a large part of the twentieth century and certainly the second half of it were significantly shaped by this power and that the iconic standing of the US dollar captured this in a pervasive and highly mobile form around the world. In historiographic regards the geographical reach of the power of the dollar is an intrinsic part of the geospatial and geotemporal story of US hegemony. The geopolitical as well as geoeconomic story of the dollar is a powerful example of the multidimensional nature of the symbolism of money as a medium. Not only does it represent value but the achievements and influence that value depends on, the economic and political bases of it, the national culture it represents.

As we entered the twenty-first century the dollar continued to represent a potent global expression of the success of a rational highly technologized, industrialized and militarized USA. This endurance of standing through twentieth to twenty-first centuries captures an all-important story of stability of power too - its reality over a prolonged period of history. When we see, hear of, read about and handle US dollars all these kinds of meanings are in play. They concern both time and space in a range of ways, and they connect them in specific senses, notably through the state, the national economy, the hegemon that is the USA. National currencies are at least in part a communication of differentiated state power and history, of the past as much as the present, and to some degree, the future. 


\section{The euro as historic challenge?}

The arrival of the euro in 2002 and debates around it were interesting in this context, because this new currency and different reactions to it brought to the fore of political and public debate issues about the significance of national currencies for national identity, and sovereignty. They highlighted the continuing symbolic power of currencies as representative of specific territorialized entities, states, and the sovereign identities attached to them. On the one hand the development of the euro could be articulated as another logical step in the post-Second World War history of European integration from the 1957 Treaty of Rome through various stages to the 1992 Treaty of European Union. Will Hutton has stressed how much competition with the USA had been driving further European integration towards 'the establishment of a continental-style market. ... Europe had to move from being a customs area to a genuine single European market, and beyond that to become a more united economic and political force' (2002: 296-7).

Not surprisingly the European Central Bank took this unequivocal line to the eventual introduction of a European currency. 'The successful development of the euro is central to the realisation of a Europe in which people, services, capital and goods can move freely'. ${ }^{5}$ The idea here is continual deepening of what began as the common market into an increasingly integrated EU. The sense of continuum however has been severely disrupted by the question of territorial sovereignty and the symbolic as well as material binding of national currencies to that geospatial identity. This tension with the arrival of the euro was characteristic of prominent elements of debates in the UK resisting and certainly delaying incorporation into it to some uncertain date in the future. Hutton (2002: 1-2) has a particular purchase on the possibilities here relating to the UK, which position the history of the transatlantic alliance as pivotal. He refers to the 'question about what values should underpin the building of Britain's economic and social model. How much are we European - and how much do we have in common with an America increasingly in thrall to a very particular conservatism?' His viewpoint is geopolitical, positioning the EU as a potential counter to the long-standing hegemony of the USA. 'In my view, the quest for European union is one of the great rousing and crucial political projects of our time. It is vital in providing a counterweight to the US and thus offering genuine multilateral leadership in the search for securing global public goods' (Hutton 2002: 2).

Such perspectives help us to unpack the complicated symbolism of the euro and its potential. As the European Central Bank triumphantly stated at the launch of the euro in January 2002: 'This is history in the making. It is the largest monetary changeover the world has ever seen'. ${ }^{6}$ The euro heralds a new post-national (regional) era of currencies, the meanings of which are as much embedded in an as yet unknown future as they are in the concrete developments of European integration in the post-Second World War that 
have brought us to this stage. This situation demonstrates how a currency incorporates political as well as economic symbolism, is representative of political (territorial) as well as economic values. The euro could be seen as landmark evidence of processes of regionalization as an intrinsic part of the story of globalization. It is part of processes of change that configure GPE as dynamic, demonstrating the need for critical attention not only 'to the material spatial practices through which the international political economy is constituted, but also to the ways in which it is represented and contested' (Agnew and Corbridge 1995: 7). ${ }^{7}$

The nationalist versus integrationist tensions that have characterized the euro debate also remind us of the degree to which the material and the symbolic are intrinsically integrated in both the expression of territorial sovereignty, and also its historiography. We could look at the particular historiography of the euro, both current and futuristic, as a way of conceptualizing (materially and symbolically) what is happening in globalization - the shift from national to regional concentrations of power. With the fast rise of China and India as the new growth economic powerhouses, the regional story of globalization is shaping along the focal points of America, Europe and Asia.

The euro may be at the very beginning of a long historical trajectory bound up with these developments, likely in terms of GPE to dominate for at least the next 50 to 100 years. The euro is also part of a dynamic integrationist European picture that is as much about conceptualizing the longer-term geopolitical and geoeconomic future as it is about immediate pressures for, or interests in, monetary integration. In their symbolic roles, currencies tell of continuities and discontinuities, past triumphs and failures, but also, importantly, future possibilities. And the conflicts around the euro remind us of this fact. Sterling's potent long-term history linked to colonial world power and as an enduring dominant player in international finance are among the heavy symbolic losses that would result with the UK's abandonment of its national currency in favour of the euro. There is a great deal at stake in symbolic ways that goes well beyond the straightforward arguments about the relationship between national currencies and national sovereignty.

A national currency is part of a state's self-image. This incorporates in the case of a state such as Britain the security of harking back to a time of greater global influence, as well as the struggles to cope with how to hold on to power and influence in an era of globalization, where the increased volumes (and speed) of capital and trade flows across borders test the capacities of governments to exert monetary and economic control within national boundaries. 'The pound may remain an Elite Currency, but it is certainly not what it used to be' (Cohen 1998: 122).

Attachment to national currency is about attachment to a national past, and the stronger the power of that past, the stronger the attachment is likely to be. The fact that aspects of that power endure in contemporary conditions 


\section{Time/space frameworks}

(e.g. the UK's standing as a leading economy and a major player in the key global financial sector) deepens that attachment all the more. But for a proeuro protagonist like Will Hutton, breaking this attachment for the UK is very much a matter of adjusting to the changed conditions of globalization and confronting US competition. We could see it, as I have suggested above, as a monetary path to reflecting the regionalized rather than nationalized realities of contemporary globalization: a means of moving effectively from the past to the future. Or as Hutton puts it:

The arrival of the euro cements the establishment of a continental-scale economy that will not be fractured by different currency regimes. It allows interest rates to be set for the benefit of the Europe-wide economy rather than to protect a particular national exchange rate.... It is the friend, in short, of production, investment and employment. ... The euro is a means of delivering to Europe's citizens.

(Hutton 2002: 331)

Until the time that the euro is a 'Europe-wide' reality this is more a statement about an imagined future than a current reality. So also the idea about 'delivering to Europe's citizens' has a futuristic dimension to it. For how can these citizens begin to conceive of themselves as partly identified by a regional monetary system (rather than a national one) until their territory is incorporated into the euro zone and their (national) currency substituted by the new regional one. And clearly interwoven with arguments such as Hutton's is the fact that global competition, particularly with the USA, is a major imperative for making this shift, however difficult with regard to questions of symbolic and actual national sovereignty.

It is worthwhile noting how the historiography of the euro represents, in major part, a further stage in the historiography of US hegemony and responses to it. This is an important point for the study of GPE. It reminds us of the extent to which, from the early twentieth century through to the early stages of the twenty-first century, the rise and endurance of US power and the pivotal role of the pre-eminent dollar have impacted on major structural shifts in GPE.

In 2004 as any prospect of future UK membership of the euro remained utterly uncertain, the UK treasury was singling out the UK's growth performance over the past four years compared to economic downturns in many industralized countries, including the USA and much of the euro area (HM Treasury 2004: 8). ${ }^{8}$ Comparative economic success delivered to its citizens was being positioned as one of the best rationales for the UK government's hesitation towards the euro: a triumph for the national territorial approach to economy and money, albeit in the context of globalization. The euro scenario, and the geoeconomic changes it incorporates, indicates how national currencies have been a fundamental part of the material and 
symbolic identities of states, and the territorial ways in which they identify themselves both in relation to each other and their own citizens.

As a dramatic shift to post-national currencies the euro is a stark indication of the dynamism of states, and crucially, their sense of sovereignty and how it should be best expressed and evolve. It tells the lie to the rigid sense of permanence that has tended to underpin mystical notions of national sovereignty, based on the fixity of territorial symbology and securities of state and individual (identity) attached to it. It reveals that such fixity is just that, symbolic rather than actual. In most cases states have determined boundaries which contain them, but they are much more than those boundaries (symbolically and actually), they are fluid, changing entities, individually and in relation to one another. The euro is a manifestation of this dynamism and I would argue that this is part of why it can be so disturbing at a political level. It tests the mystical (state-centric) stasis that is the problem in many dominant conceptualizations of geospatial GPE.

\section{The symbology of fixity: geospatiality}

Intrinsic to coming to grips with geospatiality is the recognition of the complexities of its symbology of fixity. The territorial state and the other territorialities that are characteristic of it are central to this. Importantly, it operates at the collective (community) and individual levels, and is therefore about collective (state and national) and individual identities. I have discussed above how national economies and currencies, and their relative impact and power internationally, are part of this picture. Hence, Benjamin Cohen (1998: 34-46) helpfully talks about 'the political economy of territorial money' (34) and how it expresses the modern (Westphalian) $)^{9}$ state system and its creed of rational political and economic management on a national basis. But state-centric mythology of territorial monetary geography has a larger purchase than its actual manifestation. Cohen argues:

From its beginnings in the nineteenth century, it reached its apogee during the Great Depression and the years following World War II, when exchange and capital controls were widely used to reinforce the exclusive role of each state's currency within its own borders. . . . In more recent years ... as currency barriers have come down and financial markets have expanded across the globe, the array of currency choice has greatly widened; and monetary sovereignty, as a result, has as in earlier times become increasingly diffuse and permeable.

(Cohen 1998: 34-5)

This is partly a description of processes of globalization over the last 20 or so years, the loosening of monetary sovereignty, the growing interdependence of currencies in an age of vastly increased financial flows, and the increased vulnerabilities of national economies to one another. 


\section{Time/space frameworks}

However the fierceness of some reactions against the euro in countries such as the UK, stressing the importance of national currencies to national sovereignty, highlights how the territorialized myth of money lives on despite changed realities. This represents a fixity that is part of the problem of geospatial time/space in terms of collective and individual imagining. As part of the symbology of the territorial state, and its power to exert control (its sovereignty), national currency holds mythological as well as actual status. Myths are about the past and the security of what we know about the past. When it comes to a contest between the euro and a national currency, there are a whole host of deficits with mythological and actual significance.

The euro is brand new, it doesn't have any past (his)story to secure it. It overtly lacks a specific territorial identity in familiar state-related form: in that sense it is a post-national currency. Worse still (with regard to the insecurities represented by unknowns) in an age of an expanding EU, its future territorial identity is completely uncertain. As I have argued above, the euro is about an alternative imagined future, but when we consider the points about its deficits carefully, we can see how it comes hard up against the fixity (security) of the familiar world of state-centred monetary geography which the majority of states and their citizens still occupy.

There are major ways in which joining the euro zone is a leap into the unknown compared to that fixity. And, at a general level, I agree with Benjamin Cohen, that one cannot underestimate the power of the myth and reality of that fixity as it manifests itself in the minds of the collective (governments) and individuals (citizens).

Though today no more than a myth, the idea of One Nation/One Money still promises much to reinforce the power of the sovereign state a political symbol to promote national unity, an alternative source of public revenue, a tool for macroeconomic management, and insulation against foreign coercion. These are hardly boons to be given up lightly.

(Cohen 1998: 46)

However, as discussed above, the picture is highly uneven on this front. In contemporary times it is clear that some currencies - and one in particular, the US dollar - can own an enduring real power in the changed conditions of globalization that further reinforce the myth as well as the reality of state sovereignty. This is in sharp contrast with others in competition with it, for example in Europe, feeling the need to move towards alternative imagining of a post-national currency, with all the inherent challenges this presents to ideas of sovereignty in theory and practice.

National currencies are notable concrete examples of the macro-micro characteristics of geospatial sovereignty. They represent the collective (the state and the national economy) but are also meaningful at the individual level, the everyday experience of the economic and political citizen. National currencies are one of the ways in which the collective is envisaged and 
understood at the individual level. They are an essential part of the symbolic geospatial package of sovereignty - communicating and representing much more than just their stark relative value at any one particular time.

Crucially, they represent continuity as well as change, a fundamental aspect of the time/space qualities of sovereignty and its relationship to questions of security at the macro and micro levels. Currencies feature heavily in the individual's experience of the market dynamic, ${ }^{10}$ his or her sense of status, his or her planning for the short, medium and long term. Many individual hopes of security are defined by or actively pinned on national currencies, and how they fare, or are expected to fare, relative to one another over time. Currencies are part of self-identification not only on a national but an international basis. A dollar identity (economic and political citizenship in the USA) carries with it the status of the dollar internationally as well as nationally. Travellers of different kinds frequently note the instantly recognizable power of the US dollar across the world, even in remote places. To and from wherever you are travelling, the dollar is a valuable currency to carry because of its distinctive global status.

The economy of desire around the dollar is as much about the mythology of US power as it is about its actuality. The dollar communicates the hard realities of American success as well as capturing the more elliptical and open-ended qualities of the American dream of success. The dollar is an excellent illustration of how geospatial realities travel, how through the circulations of the market, local and global, the fixity (both symbolic and actual) of territorially defined entities (states) is disseminated, communicated and asserted.

In an era when one of the biggest debates has been around cultural imperialism and the global dominance of products such as Hollywood film, it may be that the root symbolic power of the US dollar itself is too readily overlooked. Its general symbolic status (linked in part to its exchange value but equally importantly to the enduring and multidimensional power of the economy it represents) gives its field of meaning far more reach than the specificities of individual products such as films and music. This is where the potency of the American dream comes in. The dream is an individual dream, any dream, the dollar merely the means by which to achieve it. It is not a product in itself but the transformative route to a whole realm of products or lifestyles, the fulfilment of specific ambitions, goals or forms of security. ${ }^{11}$ The global reach of the dollar and its symbolic depth in this context is probably one of the most prosaic manifestations of American internationalism: a projection of power well beyond national territorial boundaries but nevertheless communicating their geospatial reality as the foundation of that power. These boundaries refer to the political and cultural as well as the economic. ${ }^{12}$ Thus the American dream has a geospatial specificity embedded within its global mobility.

Geospatial specificity is at the heart of state identity and inherently individual political identity associated with it through the concept of 


\section{Time/space frameworks}

citizenship. The theory and practice of citizenship in modern states is first and foremost about state definitions of and control over time and space. There are many ways in which it is helpful to think about the nature of citizenship in direct relation to the nature of the state: likewise the nature of collective sovereignty (state identity and control) and individual sovereignty (citizen identity and control). Through their definition of, and control over, political identity (citizenship), modern states have had a profound influence over individual senses of being and association.

In plain terms the territorially bounded nature of the state and the individual citizen's containment within it maps from state onto citizen a geospatial mentality and framework of identity. To be is literally to be in a territorial sense. To be is literally to be within the space and time of a particular state. State identity papers including passports are the mundane evidence of this at the individual level. Without them the status of non-person becomes very real. A person's whole legitimate existence is tied to these, such that stateless individuals who lack them are non-persons to the extent that they lack the necessary recognition and protection of a state.

The state/citizen nexus is inherently about power and knowledge as Michel Foucault's extensive work on governmentality has highlighted. Modern states manifest their power largely through bureaucratic rational processes: the collection and control of information about their citizens and territory and the rational management of both in economic, political and cultural respects. The term governmentality places the emphasis on practices and techniques, as does much of Foucault's work, for example on the observational and disciplinary activities of medicine, education, prisons (Foucault 1963 and 1975). As Colin Gordon (1991: 4) has put it: 'The nature of the institution of the state is, Foucault thinks, a function of changes in practices of government, rather than the converse. Political theory attends too much to institutions, and too little to practices'. The Foucaultian turn in the study of the state has represented a shift towards considering it as a set of practices rather than as simply an institution, and I have argued elsewhere (Youngs 1999a) that this is to view it as dynamic rather than static.

One of the problems with institutional approaches to the state is that they can tend to focus too much on what it is (its structures and characteristics) and too little on state-initiated practices and their meanings. In arguing that the former is static and the latter is dynamic, I am arguing, in Foucaultian vein, that it is by considering such practices and meanings, including how they change and endure that we can understand how an institution like the state is transforming incrementally over time. If the fix is more firmly on the institution of the state itself and its key characteristics, these may appear to be the same over time, while in fact the practices related to them may suggest that changes are taking place, slowly but surely.

In other words institutional change is slow by its very nature, and may take a long time to reach a conclusion that can be clearly identified. However, attention to practices can offer insight into how that change may be taking 
place over time. The Foucaultian turn in the study of the state has brought new awareness of it as a political space defined by its bounded nature, and has explored among other things, the meanings of its territorial practices in relationship to the nature of sovereignty (collective and individual). The work of Rob Walker (1993) stands out in this context, not least because of its explicit and detailed attention to the relationship between time and space in the study of politics. This approach has links to wider work on the importance of the state for the collective imaginary, most well known being Benedict Anderson's (1991) exploration of 'imagined communities'. Such perspectives recognize how the state acts as a container for human experience, even beyond the basic aspects of conferring political identity such as formal papers and passport referred to above.

The setting of the state is a spatial and temporal context for understanding not only the meanings of political being and experience 'inside' it but also 'outside' it. Walker (1993) positions this 'inside/outside' binary as pivotal in the divisions that the modern state writes onto national and international realities. The implications of the inside/outside critique are many. At its heart it is saying profound things about the 'limits' of political imaginary (Walker 1993: ix) in the world of modern state territoriality. It brings awareness of how the whole essence of political being (identity) in the modern state system (whether we are thinking at the collective or individual levels) is completely predicated on the distinction between inside and outside.

Simply put, we are (as political citizens) because we are inside (a territorial boundary and imaginary, and national history associated with it), and intrinsically this separates (rather than connects us) with those who are outside. The modern state system is ontologically a bounded geospatial system, a system of divided (rather than connected) identities and associations. And, as J. Adam Tooze (1998) points out, the structure of the national economy reminds as that the material and the representational are very much bound together in this ontology.

In making 'the national economy' part of a cultural history of national identity, we are not merely widening our analysis of 'national identity'. In fact, such an approach to the 'national economy' destabilises the dichotomy in which the sphere of 'representations, symbols and culture' is counterposed to the 'material, non-discursive realm' of 'economic reality'.... 'The economy' is not pre-existing reality, an object which we simply observe and theorise about. Our understanding of 'the economy' as a distinct entity, a distinct social 'sphere' or social 'system', is the product of a dramatic process of imaginative abstraction and representational labour.

(Tooze 1998: 213-14)

The inside/outside framework is both material and representational, whether we are thinking politically, culturally, or economically. The inherently 


\section{Time/space frameworks}

bounded nature of both its geospatial and 'spatiotemporal' (Walker 1993: 6) characteristics ensures that national (state) imaginaries of sovereign (collective and individual) being prevail as dominant definitions of (inside/ outside - national/international) realities: political, cultural and economic.

Furthermore, feminist and postcolonial critiques have stressed that the inside/outside framework has gendered, West-centric and racist qualities that are both restrictive and exclusionary. ${ }^{13}$ Sovereign (independent and active) being and citizenship (and political, economic and cultural agency) have primarily been constructed in white masculinist terms in the state politics of modernity (Peterson 1992a). So the relative power dynamics of gender and race are fully implicated in the inside/outside framework, making the issue of relative insiders and outsiders a key concern. Work on, and debates around, 'intersectionality' 14 have outlined the complexity of considering political subjectivity and agency in full relation to the dynamics of power and marginalization, for example, related to gender, race, class or socioeconomic status, and sexuality.

Feminist analysis in both political theory and international relations has explored the foundational nature of the masculinist construction of political subjectivity (Elshtain 1993; Youngs 1999a; Hooper 2000). This is framed in modernity by a series of binary oppositions constructing male as (active) subject over female as (passive) object. These align the former with rationality, science, heroism and war, the public realms of decision-making, influence and wealth generation, and the latter with irrationality, nature and nurturing, the private realms of love, care and (unpaid) social reproduction.

The political subject has historically been a male subject, and economic value and status have been primarily vested in public male-dominated (market) forms of production rather than private female-dominated forms of social reproduction. ${ }^{15}$ And, while political participation and representation by women has increased in contemporary times, it is far too soon to say that the historically entrenched masculinist values, traditions and cultures of politics and economics have been overturned. ${ }^{16}$

Likewise the increasing role of women in paid labour has yet to make equality of opportunity or pay a reality, with the scarcity of women in boardrooms the most graphic demonstration of enduring male domination. ${ }^{17}$ Similarly, feminist scholars in international relations frequently emphasize that if women's political power is limited at the national level it has been even less in evidence in the so-called realm of 'high politics' at the level of international relations (Enloe 1990). The attention drawn to the notable exceptions such as former UK prime minister Margaret Thatcher and US secretary of state Condaleeza Rice only serve to illustrate the point (Youngs 2006a).

So when we map complex issues of inequality onto the inside/outside framework, it is clear that even insiders have different kinds of relative status politically, economically and culturally, and so their association with the holistic representational script of the state in spatiotemporal fashion is 
differentiated. This includes, crucially, the symbolism of the state as an enduring entity. So particular governments may come and go, especially in democratic scenarios, but the state as such endures.

This recalls the ancient 'the king is dead, long live the king'. Individuals are ephemeral while institutions are permanent. National histories ${ }^{18}$ are an essential component not only in telling the symbolic and actual script of the state as an enduring spatiotemporal entity, but also in championing its mythological unified status. Feminist and postcolonial critiques of history ${ }^{19}$ have challenged that mythological unity by exploring the histories of women and colonial and postcolonial subjects, who have either failed to appear in dominant West-centric masculinist (national and international) histories, or have appeared primarily in subordinate (domesticated) and objectified ways.

These critiques have emphasized the lives, experiences and situations of the subordinated that have literally been written out of national (and international) histories. ${ }^{20}$ They show the high degree of partiality of the mythology of the unitary script of the state, its inherent exclusionary and marginalizing qualities. So there is a multi-layered complexity to probing the full 'inside/ outside' story, if we consider both the 'inside' identities, histories and agencies that dominant (rather than critical or alternative) histories tell about the state itself, alongside the temporally and spatially defined attachment of sovereign identity and articulation to the territorial state as opposed to the 'silence' of the 'otherness' that is 'outside' or 'beyond the authentic political community of the state' (Walker 1993: 164). ${ }^{21}$

The internal unity of the state is largely symbolic, but it is a symbolism that dominant historical scripts have asserted persistently over time. It is also a symbolism that has embedded a territorial definition of political identity and sovereignty in space as well as time, positioning 'presence' (inside) over 'absence' (outside). As Rob Walker has argued 'the character of international relations has been understood as a negation of statist forms of political community, as relations rather than politics, as anarchy rather than community' (1993: 164).

For many, as for Walker, troubling and destabilizing this geospatial fixity and its unitary mythology is foundational to working for political and social change. It is identified as limiting understanding of both existing and potential political (and economic and cultural) processes and alternative possibilities for the future. ${ }^{22}$ In the next chapter I want to move on to a series of questions associated with these points and explore how time/space linkages in the information era challenge and disrupt the geospatial fixity of the traditional territorial state configuration of the world both conceptually and actually. 


\section{Virtual realities \\ Exploring sociospatiality}

In the information era, the advent of diverse new media, particularly the Internet and its virtual characteristics, has produced a multiplicity of time/ space dimensions within which communities, including states and their economies and cultures, and individuals operate.

This section continues to explore this multiplicity by moving from the traditional geospatial focus of the last chapter to the newer sociospatial dimensions in this chapter. It is worth pointing out at this stage that there is no attempt to set up an opposition between these two categories, but rather to consider how they exist and interrelate, how they may be in tension with, and changing one another. The stress on both the symbolic and the concrete of the last chapter continues in the consideration of sociospatiality below. This is particularly important and challenging in the context of considering virtual reality, which is testing understanding of the nature of all realms of social interaction (collective and individual/public and private) in political, economic and cultural spheres.

It would not be an overstatement to say that the meanings of virtual reality are only just beginning to be explored across all these spheres. Suffice it to say that the Internet at one and the same time reflects, interacts with and transcends familiar geospatial realities and contexts, and thus represents major shifts in both what GPE is and how we should think about it. The main argument I want to purse in this chapter is that sociospatial realities are increasing in their importance, and impacting on geospatial realities in different ways.

In concentrating on virtual realities in this chapter and then hyper realities in the next, I will be examining both the meanings of the overall environment of the Internet and mobile communications era of virtual spheres, and its intense (hyper) nature of multilayered and interconnecting mediated, and increasingly mobile, processes. Both these areas are fundamental to understanding the distinctions I am trying to draw about sociospatiality. But to begin with, I need to talk in some detail about approaches to technology more broadly. 


\section{Technology: thinking inside and outside the box}

Why do we need to think about virtual reality? Isn't the Internet just a new technological development that adds to all the others that have been characteristic of ever-advancing modern societies and economies? Isn't it just another medium through which we are communicating, like the telegraph and telephone before it? Isn't it just another 'means' of connecting with people and sharing and achieving things in the world, in politics, the marketplace, socially and culturally? Well, while it is all those things, it isn't 'just' those, and this is a key point for thinking in deep terms about Internet-related and mobile communications developments. If we just think of virtual connections in instrumental ways, as functional technological hardware, then the danger is that we treat them in too much of an 'exogenous' manner. We fail to take account of the 'endogenous' characteristics of them, where, why and how they have developed, how they are impacting on and helping to transform social relations of all kinds, and how they relate to existing and changing social structures, hierarchies and diverse relations and processes of power.

I want to make the case here and further on that virtual communications are best and most usefully understood as internal (endogenous) to wider social processes rather than external to (or simply instrumental) in them. This is a particular challenge in the study of IR/GPE where the predominant theories and concepts, as discussed in the Introduction, have been locked much more into the latter than the former perspective, and, as covered in Chapter 1, where understanding of political economy has in diverse ways been primarily geospatial (territorial and bounded), both in symbolic (as regards the imaginary) and concrete ways.

The study of communications is notable in this context because technology has been more central to its whole endeavour than fields such as IR and GPE. One of the major threads of communications, including the study of mass communications (largely examining national media and processes related to them) and international communications (most recently looking at the development of transnational media and globalization), has been the changing nature of the technologies involved in them.

Simply put, the story of communications is substantially a story of technological innovation and application, and questions of power and social transformation associated with them. For example, Brian Winston (1998: 3) articulates technological developments as 'performances of a scientific competence' in the setting of 'the social sphere'. Not only are scientists and technologists as 'social beings, exponents of and prisoners of the culture that produced them' (5) but their ideas, creations and proposals are also shaped and affected by social imperatives and structures (6-7). Ronald Deibert (1997: 38), along related but more expansive lines, presents a model of 'ecological holism' that aims to build in a relationship to the natural as well as the man-made world, and frames belief and value systems as interacting with institutional, technological and geophysical factors. 


\section{Time/space frameworks}

The specific complexity of this approach is notable for a number of reasons, relating to an 'embedded' (Deibert 1997: 39) sense of technology. First, it identifies technology as implicit in men and women's relationship to their wider environment, and therefore illustrative of their interdependence with it. Second, and perhaps most importantly, it positions technology as partially constitutive of the fundamental nature of human beings. 'In ontological terms, technology should not be seen as merely an appendage to human society, but a deeply intertwined constitutive feature of human society' (39).

Embeddedness is operating at three levels here: essential qualities of both human beings and human society and knowledge about them. In other words, the story of technology is part of understanding the who, what and how of human beings and human society. Far from being an add-on, as exogenous approaches tend to depict it, it is integral to the fundamental qualities of humanity, and social forms resulting from it. This clearly relates to arguments about human evolution and the distinctive role of tools and knowledge application in that process (Deibert 1997: 39-40).

I want to raise several points about the 'holistic' orientation of Deibert's framing and ways that it helps us to think through sociospatiality. The binding together of technology with the nature of humanity and human society, and different social forces, e.g. beliefs and values and institutions, and the wider natural environment, has lots of implications for thinking about technology. For one thing, it draws attention to setting as much as instrument, in other words technology is equally about relationships to social, institutional or physical environments and imperatives as it is about means of doing or knowing.

In these ways technologies are seen as part of the human, institutional and physical environment. They come out of human and natural environments, and are related to the specific histories of them, and, as they are invented and applied, and contribute to reshaping those environments, they become embedded parts of their histories. In this way we can think about the relationship between technologies and these environments, including their institutionalized structures (such as government and other policy processes), as dynamic and ongoing.

This is not by any means to stress that outcomes are totally open: quite the reverse in fact. They are subject to the influences of power and inequality that are already part of those environments, and which, importantly, have as many symbolic as they do concrete impacts. For example, to take an obvious illustration, it would be ridiculous to think about the relationship between Microsoft's powerful and internationally dominant Windows software without taking account of Microsoft's US origins and commercial might.

Context has multiple meanings when we think about technological developments: meanings related to things as diverse as knowledge production, research and development, innovation, application, dissemination, 
marketing, etc. Holistic and embedded approaches to technology encourage us to explore deeply what considering it as endogenous means, and as I hope the discussions in this book show, this seems almost an endless journey, because there are so many avenues and historiographies to follow.

One area of particular interest here is the connection between what we might think of as the macro (general environments and institutional settings) and the micro (specific contexts and individual engagements). Technologies, if assessed with the kind of holistic tendencies outlined, fix our attention on macro and micro linkages. We can look at the how, why and who of the generation of technologies and the different macro/micro connections in play, and follow through their application and dissemination, including unexpected transformations (what are sometimes referred to as unintended consequences) along the way, and the resulting macro/micro changes along the way. For instance, the point is often made that those involved in the early origins of the Internet could never have forseen the variations of uses it has come to be put to, and many often collapse the world wide web and the Internet as one, when they were two distinctly different moments of innovation with complementary but specific trajectories of their own.

Deibert (1997: 120) emphasizes that the US military origins of the Internet were very much related to the Cold War competition of the 1950s and 1960s 'for more efficient, smaller and speedier communication technologies' with a central concern being the space race. With the collapse of the Cold War, Deibert explains, there was a shift from the 'capital-science-governmentmilitary' complex to market orientations. 'A new complex has formed as communications-related industries and corporations from around the world, encouraged by national governments, are now focusing on the largely untapped "home" or private market' (122). ${ }^{1}$

The development of the web in 1989, which was instrumental in the rapid expansion of the Internet as a virtual platform for businesses and organizations to operate in, and thus its mass popularity, is located in this commercial/market stage, rather than in the earlier strategic Internet innovations. However, the home of the web invention was CERN, ${ }^{2}$ Europe's government-funded pure science research hub. The concept of the web can also be viewed as second order in terms of Internet development. What I mean by that is that while the Internet was very much about connectivity and the fast exchange of information, the web was more about what this could mean for all kinds of interactions, including importantly those related to knowledge and a new virtual environment of a kind that would allow extended presence in time and space as well as what we might think of as deep connectivity.

The inventor of the web Tim Berners-Lee has not surprisingly become a legend in his own lifetime, not as well known in a mass sense as head of Microsoft Bill Gates, but perhaps even more influential in a historical and fundamental sense, if we are thinking about virtual developments. BernersLee is depicted very much as a visionary who, as head of the industry World 


\section{Timelspace frameworks}

Wide Web Consortium (W3C) since its foundation in 1994, has continued his commitment to developing 'the full potential' of the web and the 'interoperability' of web technologies. ${ }^{3}$

Berners-Lee's book on his creation Weaving the Web (1999) is one of the best places to start for thinking in holistic (macro-micro) ways about the Internet and the idea of the information society. His way into the latter may be technologically rooted but it is interactive with regard to the wider human environment along lines that are in some way similar to Deibert's holistic perspective. Berners-Lee is certainly a technical visionary oriented towards social transformation in relation to computing power and his expansiveness mirrors in some ways the more specifically business oriented future-talk of Gates (1995 and 1999). ${ }^{4}$ Berners-Lee (1999: 1) frames his vision as both 'encompassing the decentralised, organic growth of ideas, technology and society' and being about 'anything being potentially connected with anything'. If we combine these two aspects of the vision their multidimensionality is among their most interesting facets. In the first instance he is emphasizing that we should think about the web as technology, which is interacting with ideas and social relations and developments.

This is clearly an attempt to view the web as an endogenous technology. But his orientation towards anything being connected to anything is perhaps more illustrative of the techno-social shifts that information society is engendering. The 'anything' encompasses places (countries, cities, villages, homes), people (individuals, groups, organizations, communities, states), information (share prices, advertising, distance learning material, news, etc.). Connectivity of this broad kind is certainly at the heart of his vision and it is, in many ways, a distinctively open and holistic sense of connectivity. All too often the initial image of connectivity in the information age is not surprisingly dominated by the hardware and software components of computing and communications that physically provide the linkages. Crucial as this all is, Berners-Lee is gesturing towards the social and geographical as well as the technical components of connectivity.

In an extreme view, the world can be seen as only connections, nothing else. We think of a dictionary as the repository of meaning, but it defines words only in terms of other words. I liked the idea that a piece of information is really defined only by what it's related to, and how it's related'.

(Berners-Lee 1999: 14)

Hypertext is the linking principle that is basic to the connectivity of the web through, for instance, the Hypertext Transfer Protocol (the http that appears in web addresses) that allows computers to communicate over the Internet (Berners-Lee 1999: 31). Considering the holistic and all-embracing nature of the hypertext idea is useful for understanding the sociospatial transformations at stake in information society transitions. Hypertext explicitly relates to connectivity between computer systems, information on 
those systems, and inevitably the physical (geographically located) and virtual (computer-mediated) spaces related to all of them.

Here we have the multidimensional sense of the Internet that gives us an idea of a wired world - one in which the computer-mediated informational sphere is at one and the same time embedded in traditional geospatial contexts but also released from many of their constraints. Part of this shift was getting the internal logic of connectivity and searchability of traditionally located databases (on specific computer systems, etc.) externalized on the web so that 'a person should be able to link with equal ease to any document wherever it happened to be stored' (Berners-Lee 1999: 36).

Berners-Lee (1999: 38-56) sets out in some detail the coding and universal address system that allowed, at the simple click of a mouse on a highlighted hypertext link, the immediate move from one informational source to another, whether that be on the same web server or one located many thousands of miles away. The hypertext principle remains one of the simplest and most elegant ways of understanding the nature of the information society. Connectivity is a central driver in this context, ${ }^{5}$ but it is a very complex form of connectivity, that integrates the familiar with the new. People and places, information sources and organizations, computing systems and databases, are interconnected, and computer-mediated social relations and spheres become increasingly integrated with more widespread facets of more familiar physical (place-based and face-to-face) social presences, interactions and activities.

\section{Virtual or real: overcoming a crucial binary trap}

The hypertext principle is new in many ways, particularly in the manner that it relates to digital processes and languages, but it is based on familiar ideas about connection, interaction and knowledge-building. It is to some degree at one remove from the human because it is technologically generated, but, as the likes of Berners-Lee's discussions of it signal, it can be understood as much as an extension and enhancement of human capacities and proclivities, as a disjuncture with them purely because of its technical characteristics.

Such a point is at the heart of ongoing tensions associated with so-called technological determinism in approaches to information society. I want to raise a basic question in this regard through this book. Is a focus on technology and its capacities necessarily technologically determinist or is it too often taken to be so? ${ }^{6}$ This touches on deeply philosophical questions about the status of technology in human societies and the ways in which developments such as the Internet, but also others associated, for example, with genetics $^{7}$ and nanotechnology, are impacting dramatically on the human/ technology interface, how it is changing and how it is understood. I will only have space to touch quite briefly on some of these, but will need to do so because they are relevant to perspectives on sociospatiality as, in part, a technologically mediated and shaped reality. 


\section{Timelspace frameworks}

Returning to the discussion in the introduction on Metropolis (Lang 1926) and Matrix Reloaded (Wachowski and Wachowski 2003), it is clear that we can think in very broad ways about technology and its interdependence with human developments. We can think about it as an extension and enhancement of them, and as something that through power structures can be used to enslave humans and drive them to specific ends and purposes. We can think about it as something that brings into reality human imaginings, creativity and invention (for what might be regarded creative as well as destructive purposes), and as something that can in turn inflict such imaginings and inventions on others with varied results (again which can be regarded as either or both creative or destructive).

I want to argue for an open, not a naïve or merely utopian approach to technology in my investigation of the information age. By open I mean one that allows for all such interpretations, and avoids reductionism to either one or the other. I argue that technological developments such as the Internet can have utopian elements as well as dark, sinister and power-driven ones. To take a graphic example, hypertext links are just as easily and actively adopted and used by human rights and anti-poverty campaigners as they are by paedophiles and pornographers. This is not to argue that technology is necessarily and always neutral, because many technologies such as military ones are designed with specific intents, but that humans apply and shape technologies and the environments they create. Such processes will frequently therefore represent the full range of social influences and activities, judged variously as positive and negative, and reflect the full range of human proclivities, productive and destructive, and mixtures of both.

So I would argue that it is useful to think in a continuum when thinking of the human/technology interface rather than in binary or oppositional terms. ${ }^{8}$ Technologies are human inventions and are applied, used and adapted through human and social processes and structures. This may seem obvious but it is important to restate it in the context of debates around the status of different forms of computer-mediated (virtual) communication. In the early years of debates about information society there tended to be automatic assumptions about the inferiority of such communication in relation to more traditional forms of face-to-face communication. I anticipate that the undertow of those in debates about information society will continue for some time. They are related to suspicions that surround the human/ technology interface and tendencies towards oppositional rather than integrated perspectives on wo(man) versus machine.

There is a fix in such oppositional viewpoints on the lack of human qualities in the machine world. Prime among these are advanced forms of thinking, intelligence, decision-making, learning, creativity, emotion, etc. There is also a historically grounded sensitivity to the ways in which, through the imposition of power, humans and human structures have used machines and technologies in general against other humans, for example: to extract their productive energies; encourage them to consume in the work 
and market-place; keep them under surveillance; and most starkly to destroy them in warfare and extermination camps.

The complex messages of the films Metropolis (Lang 1926) and Matrix Reloaded (Wachowski and Wachowski 2003) cover several of such areas. Major themes of Metropolis include the exploitation of workers enslaved to a machine-driven world, and Matrix Reloaded presents a futuristic viewpoint where a war of the machines features a machine world that farms humans to sustain it and threatens to overturn completely the wo(man)/machine hierarchy. Metropolis also talks to my continuum ideas about the human/ technology interface in a central character, Maria, whose likeness is replicated in a robot, which appears sufficiently real to convince the workers for a time. As symbolic texts these two films illustrate some of the intricacies and contradictions of the philosophical and psychological issues and fears that pervade the human/machine interface.

We are still in the early stages of understanding the full implications of the machine (hardware and software)-created virtual spaces of the cyberworld and the growing number and range of activities and forms of relating taking place within it. Part of this is the long history of geospatial contexts, discussed in Chapter 1, that have been the prime contexts for human interaction, relating and identity processes. The most notable among these are the state and community (village, town, etc.). These have been in the human imaginary, in different ways across contrasting geographical national and local settings, as much as they have been in the historiographies of major national and local events and processes.

To be in these familiar settings, not least in the specificities of their locatedness and boundedness, has obvious contrasts with being in computermediated settings. Analyses of the nature of virtual spaces seek to tackle what seem to be the differences and often to explore how they are less than might at first be imagined. In other words, they seek to overcome the virtual versus real binary. The arguments range across the historical, philosophical, perceptual and technosocial. One of the approaches is to point out that the question of the virtual is far from new. For example, Rob Shields (2003: 5-7) explains that it has been debated theologically in terms of Christ's 'virtual presence' in the Eucharist, and more mundanely in terms of the 'virtual image' in the mirror that is not an exact representation because it is reversed.

Closer to the contemporary computer-mediated virtual spaces is the liminal sense of a space in between associated with rituals such as weddings, university graduations or other social rites, where individuals pass from one form of social status to another. 'The liminal state is characterized by ambiguity, openness, and indeterminacy. One's sense of identity dissolves to some extent, bringing about disorientation. Liminality is a period of transition, during which your normal limits to thought, self-understanding, and behavior are relaxed, opening the way to something new' (Wikipedia online). Liminal spaces retain social presence while allowing for transformations 
within it. They are therefore heuristically useful in thinking through the idea of the human/technology interface as a continuum in relation to cyberspace. For entering virtual spaces is both to retain traditional social presence (either as an individual or a group, sitting at a computer for example, in the home or office or on a train) while entering a space within it or connected to it, but somewhat separate from it, and which may be transformative.

This transformative process can operate across a whole realm of more minor or major activities and engagements from creating new identities in virtual worlds or chatrooms, joining political groups or other interest communities and forums, taking part in online campaigns, searching for new jobs or setting up an online business, seeking new friends or partners and so on. People engaging in online activities and relating in these ways may be aiming at transformations of the most diverse kinds: trying out new aspects of their identities; exploring new job or professional possibilities or places to live and work; looking for new friendships, love affairs, or marriage; seeking out communities of people who have similar problems in life as varied as suffering from eating disorders, cancer or depression, sexual or other forms of physical or psychological abuse; joining global political campaigns for women's human rights, to help aids victims, fight global poverty, etc., to name but a few.

What is clear here is the connection between micro (individual) and macro (collective) levels. The transformation sought may be very much on an individual basis, to improve or change one's own life by setting up a new online business or searching for new work, education, training or new life opportunities, and to seek advice or assistance with specific life or health problems, for example. It may also be sought at the collective level in terms of global political campaigning and activism on, for instance, the environment, global trading inequalities, and human rights issues.

Thinking about spheres of virtual communication and activity as spaces in between helps to make the kind of continuum between the wo(man)/ machine interface I refer to above more concrete and to overcome a simplistic and disconnected binary sense of the real versus the virtual. It also helps to clarify the associated and overlapping nature of the traditional geospatial spheres and identities associated with them with the newer sociospatial spheres of the Internet. For we are, at one and the same time, firmly located in those geospatial spheres, with all their elements of bounded citizenship and non-citizenship etc, and extending outside of them, when we enter the newer sociospatial spheres of the Internet. So-called virtual (online) communities, ${ }^{9}$ which vary enormously from very loosely connected groups of largely anonymous individuals to closely knit and long established groups, have tended often to be viewed as less real as communities than traditionally located ones, encountering again the problems of the binary of the real versus virtual worlds.

It is true that their nature as communities is very much shaped by the hardware and software of information and communications technologies 
(ICTs) rather than geospatial categories of place and face-to-face interaction. Virtual communities and interactions are mediated by complex combinations of technologies and occupy the in between world of the Internet but, as my examples above illustrate, they are as often extensions of offline interests and activities, identities and explorations, as they may be disjunctures with them, for example, play, leisure and economic exchange associated with avatars, imaginery characters with whole sets of generated identities, in virtual worlds and economies.

Apart from the very obvious point that the hardware and software of ICTs, and the political and economic structures generating and governing them, embeds cyberspace within the geospatial world, the synergies and interconnections between online and offline activities, organizations and interests, affirm the utility of considering the continuities as well as discontinuities across them.

\section{From cityscapes to cyberscapes: the new world of digital economy}

In very simple ways, the Internet has become a new technologically generated space that increasing numbers of people and organizations around the world exist and operate in for increasing amounts of time. In this way it prompts us to think further about the long-term history of technologies' different roles in shaping and reshaping the human environment to accommodate, enhance and expand human engagements and possibilities.

Through history to contemporary debates on globalization, the city has remained iconic in this context. The city has represented the concentration and expression of political, economic and cultural power. The changing nature of the city represented both the changing nature of that concentration and its expression as well as the evolving ways in which different forms of technology, particularly those related to the built environment and communications, have combined together to bind ever more closely the centres of power both within and across states. Lewis Mumford $(1895-1990)^{10}$ is one of the most prominent scholars whose extensive body of work concentrated on the broad roles of cities, their technological construction as the built environment and their social implications. Mumford interrogated the multidimensionality of cities as geographically located sources of human organization and invention, association and creativity.

The city is a related collection of primary groups and purposive associations: the first, like family and neighborhood, are common to all communities, while the second are especially characteristic of city life. These varied groups support themselves through economic organizations that are likewise of a more or less corporate, or at least publicly regulated, character; and they are all housed in permanent structures, within a relatively limited area. The essential physical means of a city's existence 
are the fixed site, the durable shelter, the permanent facilities for assembly, interchange, and storage; the essential social means are the social division of labor, which serves not merely the economic life but the cultural processes.

The city in its complete sense, then is a geographic plexus, an economic organization, an institutional process, a theater of social action, and an esthetic symbol of collective unity. On one hand it is a physical frame for the commonplace domestic and economic activities; on the other, it is a consciously dramatic setting for the more significant actions and the more sublimated urges of a human culture. The city fosters art and is art; the city creates the theater and is the theater. It is in the city, the city as theater, that man's more purposive activities are formulated and worked out, through conflicting and cooperating personalities, events, groups, into more significant culminations.

(Mumford 1938: 480)

The breadth of such a perspective on the city encourages a sense of it as a deeply social space where different influences of power, production, exchange and creativity interact and are expressed. Despite its date it has strong synergies with the wealth of work on the city that has threaded through globalization studies. ${ }^{11}$

At the end of the twentieth century the global city was the core location in varied ways for understanding key processes of globalization, especially those concerned with the concentration and expression of corporate, political and cultural power. ${ }^{12}$ It is important to note that the city's status in these regards has always been as symbolic as it is concrete, affirming it as a vital space of the imaginary as well as the actual. ${ }^{13}$ This has been a continuous theme through history and is as prominent as ever in the current era of globalization, where global cities such as New York, London, Tokyo, have been pivotal locations of the global story.

This story has been one of global restructuring where the spatial relations of power have been definitive. ${ }^{14}$ Structures of production have been extended geographically, expanding development across the world, but inequalities have deepened between the richest and poorest, with consumption concentrated in the wealthy North and global poverty concentrated in the least developed South at the beginning of the twenty-first century. ${ }^{15}$ In this restructuring the most powerful global cities across the world have been lifted out and above, as it were, other spaces as a network of financial, corporate and cultural centres of control and conspicuous consumption. The growth of the use of ICTs has been integral to the global city phenomenon with stock markets and financial trading as well as other forms of business and service communication and transaction taking place increasingly in the virtual realm. ${ }^{16}$

Global businesses of all kinds have been able to use ICTs to both rationalize and extend control of their own operations, including different 
production processes, across different national settings around the world as well as to operate more effectively and extensively in the general marketplace. ${ }^{17}$

It is always therefore essential to remember in relation to ICTs that they link the internal transformation of organizational practices in entities such as TNCs to the broader macro picture of global restructuring. In this picture it is arguably the phenomenon of global cities as a network of power loci that has most challenged, in both concrete and symbolic ways, statecentred perspectives and imaginaries. As Saskia Sassen points out:

a focus on cities makes it possible to recognize the anchoring of multiple cross-border dynamics in a network of places, prominent among which are cities, particularly global cities or those with global city functions. This in turn anchors various features of globalization in the specific conditions and histories of these cities and in their variable insertions in their national economies and in various world economies across time and place.... This type of conceptualization about globalization contributes to identifying a complex organizational architecture that cuts across borders and is both deterritorialized and concentrated in cities.

(Sassen 2002b: 9)

So it could be argued that there are grounds for thinking in integrated ways about cityscapes and cyberscapes in processes of globalization and, perhaps, more generally.

After all, they are both technologically constructed architectures that we inhabit, albeit that the former are real spaces in the traditional concrete sense, and the latter are virtual spaces in being mediated by ICTs. As I have already touched on above, they can both be thought of on the basis of the networks (corporate, financial, cultural) they facilitate. The network principle has become central in new practices and imaginaries, fusing the roles of concrete and virtual spatial connectivity. This foregrounds the fact of connectivity rather than the means by which it happens.

This may be face to face in specific places, or it may be synchronous or asynchronous over distance, for example in the former via online instant messaging or telephone conversations or video conferencing, or in the latter via email which can be sent and collected at different times convenient to the sender and receiver.

The idea of networks is of course not new in any way. The history of networks is as long as the history of human interaction itself. Activists in the global women's movement have been among those keen to point this out: that networking did not arrive with the Internet, it was done before via faceto-face meetings, all forms of communication including letter, fax and phone, but that the Internet has enhanced and expanded the possibilities of such networking, particularly internationally, and in this regard often relatively more cheaply, faster and more conveniently than in the past. ${ }^{18}$ 


\section{Time/space frameworks}

Manuel Castells (2000: 134) in The Rise of the Network Society applies the network principle to both the 'segmentation' of the global economy and its changing dynamics in what he describes as a 'double movement':

on the one hand, valuable segments of territories and people are linked in the global networks of value making and wealth appropriation. On the other hand, everything, and everyone, which does not have value, according to what is valued in the networks, or ceases to have value, is switched off the networks, and ultimately discarded. Positions in the networks can be transformed over time, by revaluation or devaluation. This places countries, regions, and populations constantly on the move, which is tantamount to structurally induced instability.

(Castells 2000: 134)

This approach to networks helps us to think through more deeply the structural implications of ICTs and the virtual possibilities they enable, for example to enhance the flexibilities for changes in networks, in financial, corporate and market exchanges and communications.

The digital market-place of online business and retail sales represents both in real and symbolic fashion the ultimate expression of this flexibility. The virtual market-place offers instant cross-border access for sales and purchases of services and goods, transcending the traditional geospatial constraints of traditionally place-based markets. Early twenty-first century GPE marked a hybrid era for the digital economy, where purely online businesses were rapidly developing with some success, as well as traditional place-based businesses existing and trading online, and increasingly using standard media (TV and print) advertising to draw customers to their virtual outlets as well as their place-based ones. Here we see again what might be termed a fusing of the geospatial and sociospatial in concrete and symbolic ways. The sister term to networks in this context is flows, once again to signal exchanges which take place in both geospatial and sociospatial realms, and interconnect them.

The idea is that flows, ${ }^{19}$ including importantly symbolic ones, have increased in the contemporary era of globalization. Transnational flows continue to grow across trade and services; intellectual property of different kinds including cultural products such as film, books, computer games; communications of all kinds including the full range of media, business and personal links.

Castells (2000: 406-17) talks about the global economy as a 'space of flows' but emphasizes that there are hierarchies within it. As discussed above, the global cities are at the apex, and the traditional urban over rural and North over South patterns persist. So in this new world of flows, concentration of power and influence is as much a concern as ever, where major cities feature 'information-based, value-production complexes' which constitute: 
networks of production and management, whose flexibility needs not to internalize workers and suppliers, but to be able to access them when it fits, and in the time and quantities that are required in each particular instance. Flexibility and adaptability are better served by this combination between agglomeration of core networks, and global networking of these cores, and of their dispersed ancillary networks, via telecommunications and air transportation.

(Castells 2000: 415; see also Sassen 2001)

\section{Cybercitizens to cyborgs: some micro considerations}

So the world of networks and flows directs our attention to the interconnections between the geospatial and sociospatial contexts. I want to close this chapter by bringing in some micro considerations to the thinking about such interconnections and talk briefly about the concept of the cyborg as an examination at the individual level of the wo(man)/machine interface in relation to ICTs. By way of introduction, however, it will be useful to say a few things about the general shifts evident in the geospatial and sociospatial contexts. In terms of emphasis, the former, as it has historically developed has been, as discussed in Chapter 1, related to state-centred territorial and bounded communities and identities driven by inside/outside and associated divisions and distinctions. While such geospatial circumstances continue, with some shifts in orientation, for example the particular importance of global cities as discussed in this chapter, the rise of the sociospatial and computer-mediated communication represents shifts towards cross-boundary and virtual communities and identities.

I have stressed already the overlapping nature of geospatial and sociospatial contexts and this applies here as well. So it is neither helpful nor appropriate to think of one or the other, but of both, with the sociospatial playing increasing roles in diverse areas of GPE and individuals' interactions with them. The digital economy integrates elements of the geospatial and sociospatial worlds with those participating in it (individuals, businesses, organizations, etc.) occupying both with different priorities and intensities at different times. It is a hybrid form of economy in these spatial regards.

Virtual developments, however, do place new priorities on our analysis of GPE that direct our attention to the micro as well as the macro and micro/ macro interactions. This is in part a matter of technology and specifically the ways in which ICTs are increasingly shaping GPE. In this regard, it is necessary to look to the analysis of communications and media more broadly, for understanding of the transformative implications of media both spatially and socially, hence my use of the term sociospatial.

Let's take the spatial dimension first. Media scholars have long emphasized the diverse ways in which different forms of broadcast media transcend public/private divides, linking through sets and transmissions the public 


\section{Time/space frameworks}

spheres of politics, the market and the culture to private spheres of consumption in the home, the car, etc. There is also stress on the pervasive relevance of media and communications in social research.

The modern communications media have become a major focus for research for the simple reason that they are central to organising every aspect of contemporary life, from the broad patterning of social institutions and cultural systems to intimate everyday encounters and people's personal understandings of the world and their sense of themselves. We cannot fully understand the ways we live now without understanding communications.

(Deacon et al. 1999: 1)

In these regards the research field of communications has a distinctive orientation ${ }^{20}$ among the social sciences that is of increasingly general multidisciplinary relevance in the new multimedia information age. For ICTs very much continue the traditions of familiar broadcast media of radio and television in transcending public/private divides and bringing the macro realms of the market-place, politics and culture to the micro level of the individual consumer, information gatherer and citizen.

Mainstream study of GPE has tended in the main to focus predominantly on the macro sphere of markets and political institutions with very limited attention to, certainly in spatial terms, macro-micro connections, and this is problematic in the information era. ${ }^{21}$ Such connections are fundamental to sociospatial configurations of information society, where digital developments are very much integrated with other mass communication structures, notably broadcast media such as radio and television, but also print media with online presences and communities.

Even if we just consider the personal computer (PC), ${ }^{22}$ there is almost a seamless connection for increasing numbers of people between the PC on the desk at work and at home, collapsing somewhat the distinctions between these as spaces of production, consumption and leisure. Macromicro connections are spatially central to our thinking about GPE in the information age, which is all about multimedia, and the convergence ${ }^{23}$ of different forms of media technologies and outputs in digital formats. If we take this point sufficiently seriously then many of the insights of communications and media studies, as discussions above have already begun to indicate, need to be integrated into other disciplines such as political economy, politics, geography, etc.

With regard to this shift, feminist critiques have something particular to offer, because they have continually highlighted how masculinist viewpoints tend to abstract the public (macro and masculinized) sphere from the private (micro and feminized) sphere, neglecting attention to the latter and especially public/private interconnections and dynamics. ${ }^{24}$ Feminist theory in fields such as international relations, international political econ- 
omy, politics, geography and sociology, has included substantial interest in the interrelationships between public and private processes and their implications for our understanding of the nature of these spheres. ${ }^{25}$

A major motivator for this concern is the historically gendered nature of public/private divides and values associated with them: a prime concern being that societies historically have been constructed on the basis that paid production of material wealth and the diverse types of status associated with it have been located in predominantly masculinized public realms of activity (political, economic, cultural) and that unpaid social reproduction (nurturing, love, affective relations) has been located predominantly in the feminized private realm of home and relationships.

Work of varied kinds clearly takes place in the public and private realms, but the paid/unpaid hierarchy impacts directly on their relative status, and the masculine and feminine identities associated with them. Even though increasing numbers of women have also been undertaking paid work, the historic weight of these gendered perspectives and divides continue to affect women's identities. This is the case for both women's own subjectivities and the attitudes of others to them, especially as these have become institutionalized, for example in professions and settings that have been maledominated, from corporate boardrooms to army barracks. ${ }^{26}$

There are logical grounds for arguing that the increasing significance of sociospatial factors in the information era, and the extent to which these include deeper integration (of working, political engagement, consuming, etc.) across public and private spheres, should result in greater mainstream curiosity about, and interest in, arguments that feminists have been making about public/private interconnections for the longest time, largely for deaf ears as far as masculinist scholarship has been concerned.

In the world of networks and flows the actualities and meanings of assumed public/private divides are shifting, and the integrated public and private approach of feminist analysis obviously has much to offer our general thinking in this context. The largely abstract (public without private) orientations of malestream approaches have less to offer, I would argue. So to summarize, we need to recognize how ICTs cross, blur and, to some degree, transcend public/private divides, and, as feminist studies have been stressing, the ways in which public and private settings should be understood as interdependent in GPE. ${ }^{27}$

One particular strand of feminist thought is also notable when we are thinking at the micro level in relation to ICTs. This is the argument that abstracting social reproduction from analysis of GPE and concentrating purely on production as the realm of value leads to a substantially disembodied sense of political economy. This disembodied stance is driven by attention to statistics, summing up the value that characterizes the public sphere and different forms of economic and political insitutionalized power associated with it. Abstracting the public sphere from the private sphere avoids the complexities of the actual embodied experience of people that 


\section{Time/space frameworks}

takes place across both spheres, and relies as much on the value of forms of (unpaid) social reproduction as (paid) production. These complexities are quite simply left out of the picture in the main in disembodied analysis. It is feminist analysis that has waged the largest battle to bring them in, to argue for embodied approaches that incorporate public and private interactions and dynamics. ${ }^{28}$ It is perhaps not surprising then that feminists have been among the leading thinkers in relation to the concept of the cyborg, that posits ever-closer fusions between humans and machines.

The cyborg is sometimes regarded as an extreme idea, but if we think about the extent to which many lives depend on different kinds of medical applications, for example, pacemakers, transplants, drugs, and see these as technological interventions and adaptations, we can begin to see that we have already travelled some way along the road towards the cyborg phenomenon. Donna Haraway (1991: 149) posits the cyborg, a 'hybrid of machine and organism', as pervasive in the contemporary scene across medical, military and economic settings.

By the late twentieth century, our time, a mythic time, we are all chimeras, theorized and fabricated hybrids of machine and organism; in short, we are cyborgs. The cyborg is our ontology; it gives us our politics. The cyborg is a condensed image of both imagination and material reality, the two joined centres structuring any possibility of historical transformation. In the traditions of 'Western' science and politics - the tradition of racist, male-dominant capitalism; the tradition of progress; the tradition of the appropriation of nature as resource for the productions of culture; the tradition of reproduction of the self from the reflections of the other - the relation between organism and machine has been a border war.

(Haraway 1991: 150)

Haraway's is a somewhat utopian and certainly radical postmodern vision of the human/machine interface, perceiving it as a border open for contestation, struggle and change, as a site of the collapsing of boundaries such as the natural and artificial (151-2). As she argues: 'So my cyborg myth is about transgressed boundaries, potent fusions, and dangerous possibilities which progressive people might explore as one part of needed political work' (154). In common with many commentators she recognizes the concentrations of technological power and the threat of 'the final imposition of a grid of control on the planet' (154), but her stress is more optimistic on counter possibilities for working against the 'unity-through-domination or unity-through-incorporation' of, for example, patriarchy and colonialism (157; see also Haraway 1997a). Her dark vision of information society is 'the infomatics of domination' Haraway 1991, 161) but she urges the possibilities for feminist transformations to challenge such developments, for feminists to harness the power of technologies. ${ }^{29}$ 
One does not have to accept as a whole Haraway's rather extreme position to recognize that the cyborg framework is far from the realms of fiction in the contemporary world, and that it may, as the likes of Haraway argue, be at the very heart of political economy, and our understanding of the new wo(man)/machine interface as a key boundary for examining the operation of power, influence, resistance and identity-making. I would argue that in the information era this is part of the story of sociospatiality, where wo(man)/ ICT interactions grow in both number and significance, and where increasing numbers of daily activities and social structures and operations become dependent on them and function through them. 


\title{
3 The political economy of time
}

\author{
Historical time, speed and \\ mobility
}

Time is probably the concept that has received least attention in the social sciences. The most likely reason for this is that there is a specific discipline - history - that addresses the passage of time and events and periods considered significant. The historical perspective may be applied to any area of study, including the economy of course, but it tends to carry with it the traditions of history as a discipline focusing on epochs, civilizations, empires, major events such as war, political and economic power and changes related to them.

History is one of the most influential ways in which geospatial realties have been mapped, explored and analysed: explaining how geopolitical and geoeconomic power have been located and shifted and why and how this has happened, and the diverse impacts of such processes. As the word suggests history is about a story of the past that we use to inform our understanding of the present and the future. Importantly, it is a story essential to states and their sense of individual and distinctive histories and identities. It is commonplace that histories of the same event told from different national perspectives will often have quite different emphases and conclusions. One well-known example is the ongoing tension between China and Japan over the depiction of the Sino-Japanese conflict (1931-45) in Japanese school textbooks, with the Chinese government accusing the Japanese government of minimizing atrocities committed by their military. ${ }^{1}$

The sub-field of history, international history, often analyses events across a number of national settings and trajectories, and probably the largest bodies of contemporary historical work in this regard remain analyses of the First and Second World War. ${ }^{2}$ Other sub-fields of history related, for example, to feminism, and postcolonial studies, have included critiques of mainstream historical approaches themselves and their tendency to tell the (his)stories from the standpoint of the powerful (in the main men and white Westerners). So as well as writing alternative histories, these critical branches of historical work have also attempted to disrupt established thinking about the whole nature of historical discourse and the universalism of the power-laden male and Western-centred picture it has tended to present. Such alternative his- 
tories have stressed that we should critically investigate the history of history, and how it has left out the stories of the less powerful and, for example, their diverse acts of resistance. Such omissions amount to a writing out of history of the stories, experiences and influences of those less powerful, whether oppressed women or colonized individuals or states. ${ }^{3}$

Foucaultian scholars, by paying attention to the linkages between the operations and enduring structures of power (including international and global power) have worked to open up debates about history, interrogating who has told the prime stories of the past, why they have been told in the ways they have, and the kinds of impacts they have had on their audiences. Foucaultian scholarship has, through its varied challenges, encouraged many to locate discourses and their institutionalized forms at the centre of the making of social (including intellectual, political, economic and cultural) realities. It has refused to see discourses (notably historical ones) as objective outside commentaries on realities - that is as somehow separate and outside of them - but has insisted that we live, understand and negotiate realities in and through discourses.

Through diverse interests in texts, such scholarship has brought into much closer connection than ever before the academic concerns of literary, cultural and social science scholars, and blurred the distinctions between their concerns as well as their methods of study. ${ }^{4}$ Similar questions about history have been posed across these disciplines and these have contributed to greater awareness of not only what is put into the narratives of history and how this occurs, but also, equally importantly, what is left out and how this occurs. A simple yet potent result is the sense that history's monopoly over the telling of time has resulted in too much knowledge building that has been taken for granted or limited at best and/or highly partial or power driven at worst. '[W] e must, we are often told, get back to history. But where is this history that is so confidently invoked?' (Young 1990: vi).

The latter part of the twentieth century marked an era where confidence in history as it had previously prevailed was significantly undermined by much critical research - history came very much to be something that was not just about understanding the past, but also understanding how perceptions that reigned in the present were rooted, often problematically, in discourses of the past. To put it more succinctly, history was as much our present as our past, whether we were always aware of this or not.

In what might be called a post-Marxist period, ${ }^{5}$ inequalities or oppressions were no longer predominantly understood along just class or socio-economic lines, although these remain central. Increasingly, multiple influences including race or ethnicity and gender were brought into play. More critical attention was paid to dominant historical discourses and knowledge structures. Understanding of contemporary patterns of power come now as much from critical considerations of these discourses and structures, and the ways in which they have continued and been accepted, as from more straightforward assessments of where power actually lies. 


\section{0}

Time/space frameworks

Awareness of historical time has through such developments become increasingly complex, with growing acceptance that what has been left out of historical accounts may be as important as what has been included. Postmodernity as a broad shift in social science and the arts has been in large part about a growing reflexivity about the history of modernity and the major discourses and knowledge structures associated with it.

Postcolonial perspectives have stood out in this regard because they have weaved together concerns with major international historical trajectories that are essentially political (and economic and cultural) and intrinsically bound up with the institutionalized knowledge processes in these spheres. Such approaches have demonstrated, in particular, how political, economic and cultural processes help to explain one another. They have been especially influential in raising the critical stakes with regard to questions surrounding modernization and development, and thus a vital strand of critical globalization studies. They have highlighted how these two concepts are rooted not only in a particular colonial history, but also the major discourses and knowledges, notably around science and technology, and their material and organizational rationalities, that expressed and sustained colonial power and control over international political, economic and cultural processes.

David Slater (2003: 48), for example, talks in terms of interrelated silences representing 'a crucial historical and geopolitical amnesia', including the link between contemporary global power divisions and the history of West and non-West or North/South relations. The economic expansion of colonialism cannot be understood simply in those ways: 'the economic is nothing other than one dimension of Western culture. Moreover, in the West the economic is tending to become the substitute for culture, by absorbing all expressions of culture into itself' (55). Neoliberalism, as expressed in the ideologies of the West and the international institutions it dominates such as the World Bank and IMF, not only binds together economic and political imperatives, but is 'a key reflection' of 'the North's will to gain geopolitical power over the South' (55). This kind of critical analysis is pointing heavily towards the continuities of historical patterns of dominance, albeit ones that have been insufficiently explored, and stands at a distance from many views of globalization as a new phenomenon. 'Neoliberal development doctrine ... is reflective of "globalization from above" (55).

Philip Darby (1997: 3) likewise emphasizes what is missing from history in discussing 'worlding' as 'a strategic move to ensure the visibility of the problems and perspectives of people too often overlooked or marginalized in dominant discourses - which means, of course, discourses of the dominant'. Darby (42) points to the problem of a restricted and West-centric notion of modernity (and consequently late modernity and postmodernity) embedded in notions of the global in contemporary times. The problem includes assumptions that 'what is observable from a Western vantage point is necessarily a global phenomenon; that is a common, homogeneous experience' (43). 
In effect this problem represents assumptions of Westernization, assumptions about the inevitable imprinting of developments in the North onto the South. While these may have some purchase, the need is rather to recognize differentiated forms of modernity, etc. 'What is required is a critical spatialized account of modernity which takes into consideration uneven development' (44). What is implicit here is a dramatic shift in the historiography of modernity - a move away from an internalized and taken for granted linearity of modernity.

As part of Westernization, this assumed linear movement from one stage of development to the next, mirroring Western political economic history, has been mapped, spatially, and equally importantly, conceptually and symbolically onto the geography of the South. Part of this process is the power of binary interpretations working on the basis of structures of presence and absence. So while the North is seen to be rich in development (framed along Western lines) the South is seen to be poor or lacking in development. Critical thought quickly reveals the limited, narrowing and distorting picture that results.

As Jane Parpart and Marianne Marchand (1995) have highlighted, the complexities of unequal gender relations within and across North/South lie within this constricted picture. They have framed their arguments by linking feminism, postmodernism and development. These linkages remain powerful in considering how shifts in theoretical thinking, in complex ways, map onto shifts in material patterns of change, including those related to globalization. To illustrate this point we can look, for example, to the issue of feminization of labour, which has occurred across North/South contexts but with differentiated formations and impacts on varied groups of women.

The growth of the service sector in rich economies has included the incorporation of increasing numbers of women across a range of high and low paid occupations. The geographical spread of manufacturing work, as varied as textiles and electronics, has at the same time led to feminization of labour in developing economies. The terms of employment for women across North-South continue to follow the dominant patterns of inequality between North and South. But the concentration of women in informal, casual, contract and part-time working conditions continues to highlight commonalities as well across North and South contexts.

The global picture is that women's earnings account for about three quarters of men's earnings. ${ }^{6}$ Women's work is something that both connects and differentiates them. Parpart and Marchand's emphasis is noteworthy: on the parallel interests of postmodernism and the recent stage of feminist debates on 'difference', and the relevance of this theme to subtle considerations of women's diverse forms of inequality across North/South settings. It strikes to not only material developments, changes, for example, in geographical distribution of production, but also to women's diverse experiences of globalization, and the recognition or lack of recognition of this diversity. It also points to the need for new forms of reflexivity within feminist 


\section{2}

Time/space frameworks

scholarship and activism about (dominant) worldviews (North over South), and challenges to them.

Increasing prioritization of 'difference' within feminism, in theory and practice, has been as much about the diversity of women within, as across national and North/South settings. Feminist scholars in North and South alike have attacked the tendency for hegemonic 'othering' within dominant feminist discourses: identification, for example, of poor, disadvantaged, black and Southern women as 'powerless and vulnerable' (Parpart and Marchand 1995: 7) and thus inherently passive rather than active. The kind of powerful alignment that Parpart and Marchand make of postmodernism, feminism and development, reminds us that this hegemonic problem is indeed a characteristic of the larger linear and colonial and postcolonial partialities of modernity. These have impacted on our understanding of history, which in turn has impacted on our understanding of the present. Part of postmodernism's theoretical turn is to highlight how these hegemonic forms of historical understanding have minimized the importance of 'difference' as a conceptual starting point. One of the most influential thinkers in this regard, bell hooks (2000), captures it perfectly in the title of her work Feminist Theory: From Margin to Center. 'Nowadays it has become so commonplace for individuals doing feminist work to evoke gender, race, and class, it is often forgotten that initially most feminist thinkers, many of whom were white and from privileged class backgrounds, were hostile to adopting this perspective' (xii).

Women, and men, can be disadvantaged or advantaged by a whole range of factors, including gender, class or socio-economic status, race or ethnicity, cultural and geographical locations and influences, including those related to rural and urban divides. These factors intersect to make up the complex conditions of inequality that characterize the era of globalization and postmodernity, and the uneven development and wealth gaps that characterize them both within and across societies, rich and poor.

'Intersectionality ${ }^{7}$ is a feminist theory, a methodology for research, and a springboard for a social justice action agenda. It starts from the premise that people live multiple, layered identities derived from social relations, history and the operation of structures of power' (AWID 2004: 1-2). This feminist perspective tells us a number of interrelated things about research and contemporary GPE. It emphasizes the theory-practice relationship, and, less usually noted, the linkages between methodology and ethical questions related to social justice. Such linkages have been especially prominent in a significant amount of feminist analysis of recent times, whether selfdefined as postmodernist or not. They signal an anti-essentialist ${ }^{8}$ tendency, a fix on lived and multiple realities, and new kinds of open inquiry into the chosen sites for understanding the dynamics of changing forms of power and inequality in GPE. ${ }^{9}$

Cynthia Enloe stands out as an influential figure in this regard. Not only has her on the ground research taken her to factories and activist locations 
across the world and to the daily realities of different women around military bases, but her methodologies and analysis have led her to stress what might be regarded as an avant-garde and disarmingly simple concept of feminist curiosity. ${ }^{10}$

Curiosity, as Enloe employs it, is a heavily loaded term in theoretical, methodological and ethical respects. It connects these areas by reminding us that the way we choose to think (theorize) the world is both a reflection of our own relation or approach to it, as well often of our own position in it. It reminds us that international research is about learning from others and taking that learning so far into ourselves that we can reflect on and dislodge what might be deeply held assumptions, assumptions that might be due to ignorance or just sheer laziness. She reminds us that the 'ungendered' labels we use, 'rape survivors', 'sweatshop workers', 'child soldiers', 'military spouses', etc. are part of the problem, serving to 'hide the political workings of masculinity and feminity' (Enloe 2004: 4).

Enloe is one of the few scholars who has devoted substantial intellectual and analytical energies to helping others to understand just how challenging it is to try to overturn the dominant historical discourses that have become embedded in our approaches to power and inequality in GPE, discourses that have led to too many assumptions about North and South and the diverse linkages that explain power and inequality (including their gendered manifestations) across them, and the lives of those who live within them. '[A] feminist curiosity finds all women [and men] worth thinking about, paying close attention to, because in this way we will be able to throw into sharp relief the blatant and subtle political workings of both femininity and masculinity' (my emphasis and insertion) (Enloe 2004: 4).

Feminist analysis of GPE, and the history of capitalism and major discourses associated with it, is oriented among other things towards a revisioning of its categorization of economy as a whole: its restriction of notions of productive value to the public sphere, excluding the private sphere of social reproduction, childrearing, family and personal relations. With the historical emphasis of male activities and identities primarily in the public sphere and female activities and identities in the private sphere, the overall construction of economic value is thus highly gendered. This is a matter of both material realities and gendered patterns of experience linked to them, but also of identities. The public/private (male over female) hierarchy is deeply historically embedded across the global economy, such that despite the fact that more and more women are generating value (earned income) in the public sphere, they are still often doing so on an unequal basis.

Women around the world also continue to deal with the lack of value, and thus a serious 'invisibility' in economic terms, of the substantial socially reproductive and caring work they undertake on a daily basis, frequently in addition to other paid and, in some contexts, subsistence agricultural work. The double and triple burdens in this regard are alive and well for increasing numbers of women, and therefore it still counts that mainstream economic 
value and data excludes much of their productive activity. Julie Graham and Katherine Gibson have been among those to explore in most detail the hegemonic meanings behind this construction of capitalism as the touchstone for interpreting productive contributions and value. Such commentators highlight how capitalism has been a defining system, equally important for how it has steered (gendered) understandings in the world as for how it actually operates in its own terms. 'Thus despite their ostensible variety, noncapitalist forms of economy often present themselves as a homogeneous insufficiency rather than as positive and differentiated others' (GibsonGraham 1996: 7).

So in capitalism's terms the socially reproductive work that women in particular have undertaken historically and contemporaneously is not just 'different' work. It is work that is not counted in economic statistics of national economic productivity and wealth, it is not recognized or paid, therefore in capitalism's framework it is not really work at all. It is something altogether different, that is in the value framework of capitalism, not valued at all. As indicated already, this is as important for questions of identity as it is for material existence. To the extent that what we do and how it is viewed (and valued or not valued socially) is part of our sense of identity, then the fact that socially reproductive work is actively devalued by the value framework of capitalism impacts directly on the identities of the people who have and largely continue to do the bulk of that work, namely women.

The public/private hierarchy that feminists have interrogated is thus foundational to the structure of capitalist designations of value and nonvalue. As Isabella Bakker (2003: 67) describes the contemporary picture: 'the macroeconomic framework of neoliberalism and its attendant governance structures expose fundamental contradictions between the formal gender neutrality of market citizenship and its unspoken reliance on women's unpaid work in social reproduction'. It is useful to recognize explicitly that current feminist critiques of this kind are working as much to change our vision of history as they are to achieve contemporary change. Both are influential, because of how mainstream (malestream) history has, for example, in relation to capitalism as explained here, written women's active participation and contributions, identities and realities out. The exclusions of the past are an essential part of what help us to understand the exclusions of the present and the grounds for their persistence. These critiques are urging us to ask as many new questions about the past as the present and to ponder as much on what previous histories have left out as what they have written in.

There is much to be said along these lines about the history of science and technology and its relationship to postcolonial and feminist critiques. These seek to displace established debates about science and technology from their white Western male-centred constraints. These constraints are part of the explanation of the enduring linear historical notion of 'development' placing the high-tech economies of the North inevitably at the top of a development hierarchy and allocating other lesser developed economies in (inferior) catch 
up roles. As Sandra Harding (1998: 14) has argued 'Central among the presuppositions of eurocentric discourses are that peoples of European descent, their institutions, practices, and favored conceptual schemes, express the unique heights of human development'.

This linear hierarchical perspective on science and technology underpins both developments in modernity and postmodernity. It is therefore an aspect we need to consider in relation to the continuities and discontinuities of information society developments, material and discursive. If anything, the control over science and technology, ownership of intellectual property and the means to exploit natural and human resources has become even more concentrated in the (corporate) North (and the hands of men) in the era of globalization.

Firms in developed countries account for 96 per cent of royalties from patents, or $\$ 71$ billion a year (UNDP 2005: 135). The information age in part means the colonization of the world through code and the expanded forms of control and production that result. Genetic engineering of natural products and processes such as food and seeds, for example, illustrate how knowledge processes and the intellectual property that generates value from them are becoming embedded deep in traditional practices as well as helping to generate many new ones.

Many are warning that the new information era threatens to deepen existing gaps between the information rich and information poor whether along North-South or gender lines. The current global governance regime on Trade-Related Intellectual Property Rights (TRIPS) is bound to work in favour of the haves rather than the have nots, incorporating a 20 -year patent protection period.

Reduced to its essentials, the new regime will increase the price of patented technologies, creating gains for patent holders and raising the cost of technology transfer. ... The TRIPS agreement threatens to widen the technological divide between technology-rich and technology-poor countries.... With technology increasingly important to international trade competitiveness, the rising cost of technology imports could further marginalize many developing countries.

(UNDP 2005: 135)

TRIPS impact across all areas of the economy, agriculture, manufacturing, drugs, hardware and software in ICTs, film, books and other creative products, etc. TRIPS are a major mechanism of global governance through the World Trade Organization (WTO) expressing how knowledge, and importantly, ownership of it, are increasingly driving profit-making in GPE.

Feminist critiques focus broadly on how the generation of knowledges related to power, including the scientific and technological, have featured characteristics defined as masculine. Indeed science and technology are iconic in this regard, elevating the qualities of objectivity and rationality, which in 
gendered structures of identity are generally placed in opposition to feminine characteristics of emotionality and irrationality. 'It was not just that conventional theories of rationality and objectivity inadvertently neglected to talk about women, too, as rational and objective humans. Worse, these concepts were often formulated precisely in opposition to the feminine' (Harding 1998: 82).

The general implication of feminist critiques of science and technology is a recognition of the gendered nature of material and epistemological aspects of their development. The gendered divides that have resulted and continue to, can be considered to be even more important in an information age where technological innovations and applications are increasingly driving different areas of economic (and political and cultural life).

In most studies of the information era and time, not much space would necessarily be allocated to discussing history and grand senses of time embedded within it, as has been done here. It will be useful to say a few more words about why I have chosen to do so. The challenge that has been presented to dominant discourses of history by diverse postcolonial and feminist critiques in particular is important for a range of reasons. Included among them are two central concerns of this book with continuities as well as discontinuities, and with questions of inequality and power. Critiques that pay attention to long-term issues that dominant historical discourses have either overlooked or explicitly written out or excluded, are, in an age of expanding knowledge, helping to develop a greater understanding of power and how it has operated both across and within societies. They are also helping to increase awareness of diverse forms of inequality and their interrelationships. In this and other ways they are an intrinsic part of the story of globalization. That such critiques make us think differently about the history that has been written, and perhaps more curious about alternative histories, is among the opportunities that the current era presents. It may indeed lead to new conclusions about historical time and what is worthy of our attention in relation to it. ${ }^{11}$

\section{From clock time to digital time: speed as the new imperative}

The shift to an emphasis on speed and the new intensities of exchange that have resulted - financial, communicative, etc. - is perhaps the most commonplace and generally understood feature of the information age in relation to time. Broadly, this shift can be summed up as a move from the clock time of modernity to the digital time of postmodernity. This shift concerns not only the way we measure time, and the implications of that for work patterns, but the diverse symbolic functions of time in our daily realities, for example, the most simple and graphic switch from the 12-hour face of the mechanical clock to the 24-hour number representation of digital clocks. Little did we know in the early stages of this change how much the idea of the 24-hour cycle would come to dominate contemporary life in theory and practice. 
The arrival of the web at the end of the twentieth century concretized this 24-hour reality, by providing a virtual space within which trading, advertising, networking, information provision, online banking etc, could literally go on non-stop around the clock. Automated software systems enabling all these varied forms of transaction also indicated the degree to which the human factor could be removed from such processes, a fact that could both enhance their speed and intensity. The spatial reach of the web, and ICTs more broadly, also gave new reality to the idea of freedom from geographical constraints. ICTs, and the reduced costs of communication at speed they heralded, facilitated the search for global business strategies in the area of services, for example, as the boom in call centres in India illustrated. Such developments show how time has become a core factor in the ICT era. The speed of exchange and association that is characteristic of the digital economy, and the new kinds of organizational, business and trading networks it enables, are also at the heart of the transformation of spatial relations, including between developed and developing economies.

These changes are making our considerations of geospatial dimensions of power and inequality far more complex than in the past. They are foregrounding time and speed as key economic concepts, not just in terms of intensity of production and exchange, for instance, but also as a cross-border facet of who can produce or service what, where and when. The political economy of time is hybrid in contemporary times, and our understanding of power and inequality needs to incorporate that hybridity. The temporal conditions of modernity and postmodernity overlap across North and South, but with sharp distinctions relating to the richest and poorest.

The majority of the world's poorest, who are not part of the digital economy, are still living largely in the no-time of starvation economies where the need for sustenance that is just not available is the over-riding concern, or in pre-industrial, agricultural seasonal time, and/or in industrial era clock time. ${ }^{12}$ They are producing crops and other primary products according to seasonal changes and increasing numbers are working in processing related to them, or manufacturing. The hybrid political economy of time is part of what explains the gaps between the richest and poorest, and is an aspect of the extreme unevenness of globalization that increasingly needs to be taken into account, in order to understand the nuances of change in GPE. The speed and intensity of the digital era, for example, drives us to look more and more to the future, but the poorest sections of the global economy are actually being forced backwards by the uneven patterns of globalization.

The UNDP (2005: 34) explains that global poverty reduction has been driven largely by the extraordinary success of East Asia, particularly China. At the other extreme, Sub-Saharan Africa had almost 100 million more people living on less than $\$ 1$ a day in 2001 than in 1990. South Asia reduced the incidence of poverty, but not the absolute number of poor people. Latin America and the Middle East showed no progress, while Central and Eastern 
Europe and the Commonwealth of Independent States (CIS) experienced a major rise in poverty. 'In a military metaphor, the war against poverty has witnessed advances on the eastern front, massive reversals in Sub-Saharan Africa and stagnation across a broad front between these poles. The worrying trend for the future is that overall progress is slowing' (34).

Overall in the world, the share of people living on less than $\$ 1$ a day nearly halved between 1981 and 2001 from 40.4 per cent to 20.7 per cent, which is clearly a positive picture. But if we contrast the dramatic fall in East Asia and the Pacific (from 56.7 per cent to 14.3 per cent) with the reverse increase in Sub-Saharan Africa (from 41.6 per cent to 46.4 per cent), we can see the extent of unevenness (34). The complexities of the global poverty and development picture remind us that exclusion is both an established fact but also, perhaps more importantly, one that is renewed constantly by contemporary globalization. So while the most privileged and developed areas of the global economy are the most intensely locked into the experience and benefits of the new factors of speed that are characteristic of digital developments, others at the opposite end of the wealth and development spectrum are forced into a quite different temporal political economy. This is one of the often futile daily struggle for survival, where time is primarily about the effort and search for sustenance and access or lack of it to medical and healthcare facilities, services and products.

If we look at the basic level of life expectancy at birth this contrasted in 2003 at 78 for the high human development countries and 46 for the low human development countries (UNDP 2005: 222). Infant mortality rates per 1,000 live births were 9 and 108 respectively for the two groups of countries (253). Inequalities within even the rich economies are noteworthy. For example, a baby boy in a family in the top 5 per cent of the US income band enjoys a life span 25 per cent longer than a boy born in the bottom 5 per cent (58).

Such contrasts are stark and help to give us a conceptual grip on the growing gaps that characterize the information age. Basic survival, life expectancy and child mortality rates impact at the most fundamental levels on people in different societies' experience of time and its potential. Extreme inequalities exist across the global economy, including within rich economies. There are very different ways in which the political economy of time helps us to think about power and inequality in this context. Speed in the familiar high-tech networked mode of information society is a key part of this picture. It is something that helps us to understand how patterns of power and inequality, inclusion and exclusion, are operating and expressed in contemporary times. It is something that relates and differentiates those participating in the global economy, or excluded from it, and the range of grounds for their exclusion.

At one end of the scale it is clearly the richest economies and their corporations that are driving the speed agenda through infrastructural and technological developments, innovations in products and services, new 
working practices and forms of intensified consumption. The infrastructural issue reminds us of the continuities across modernity and postmodernity and that the economic developments of the current period are built upon the achievements of the past. This is starkly evident in the area of ICTs where the advanced communications infrastructures of the richest economies have been the foundations on which their digital economies have been built. ${ }^{13}$ Not surprisingly then the UN Millennium Development Goals (MDGs) include the availability of ICTs as a major priority. While mobile telephony has eased the dependence on fixed line communications, the dramatic gaps in relation to the latter as well as the former across North-South indicate that the historic headway of the rich North in communications infrastructures continues to count.

For example, if we compare the USA (which is the 10th highest ranking country in terms of human development) to Ethiopia (which ranks near the bottom at 170th) the USA in 2003 had 624 telephone mainlines per 1,000 population compared to 6 per 1,000 in Ethiopia. Similarly the number of cellular subscribers per 1,000 in the USA was 546 compared to 1 in Ethiopia, and Internet users per 1,000 were 556 in the USA again compared to 1 in Ethiopia (UNDP 2005: 263-5). The speed at which ICT developments are transforming rich economies such as the USA is also signalled in the contrast with figures for 1990 in cellular phone and Internet usage, 21 per 1,000 and 8 per 1,000 respectively. Over the same period (1990-2003) telephone mainlines, cellular phone and Internet usage figures per 1,000 for the growth economies of India and China rose from 6 to 46,0 to 25 and 0 to17 in each case for India, and 6 to 209, less than half to 215, and 0 to 63 in each case for China (263-4).

\section{The new global political economy of access: neoliberal ideology and universal aims}

The extent to which different societies across North-South are networked through fixed line, mobile and Internet connectivity, influences not only how they as individual economies can reap the economic benefits of ICTs internally but also externally in the global economy. One of the features of the new networked economy is the even greater synergy between national development and integration into the global economy. ICTs, in the infrastructural role they play, simultaneously contribute to the internal developments of economies, and show how that development can be facilitated and enhanced by trading connections, etc. with the wider global economy. The concept of access has taken on whole new meanings in the information age, when the promise of ICTs and the connectivity they offer, with all the benefits this can bring to individuals and economies, becomes one of the definers of haves and have nots, between and within countries.

This was a clear driver of the World Summit on Information Society (WSIS) process (Geneva 2003 - Tunis 2005). ${ }^{14}$ This process highlighted in 
many ways the increasing importance of sociospatial developments in global political economy: the integral role of ICTs and virtual interconnections via them to economic development and innovation. The international focus of the summit obviously placed in the foreground the main digital divide between the richer and poorer parts of the world. This positioned ICTs within the wider framework of the UN MDGs. ${ }^{15}$ As the WSIS 'Declaration of Principles' states:

Our challenge is to harness the potential of information and communication technology to promote the development goals of the Millennium Declaration, namely the eradication of extreme poverty and hunger; achievement of universal primary education; promotion of gender equality and empowerment of women; reduction of child mortality; improvement of maternal health; to combat HIV/AIDS, malaria and other diseases; ensuring environmental sustainability; and development of global partnerships for development for the attainment of a more peaceful, just and prosperous world.

(WSIS 2003)

While the scope of this statement may seem ambitious and extreme in specific relation to ICTs, it serves a multidimensional political purpose, including identification of ICTs as fundamental to development aims. This counters, in some ways, traditional linear notions of development, and allows for leapfrogging notions of developing societies moving straight to the information revolution, without, for example, necessarily passing through the same kinds of industrial revolution and economic development that have marked the stages of progress of the richest economies of today. It signals that the information society brings new models of development based on ICTs, communications infrastructures and knowledge economies, rather than just the traditional technologies and skills of industrialized economies of the past.

WSIS has also emphasized the 'universal' importance of ICTs by drawing links between information society and the Universal Declaration of Human Rights:

We reaffirm, as an essential foundation of the Information Society, and as outlined in Article 19 of the Universal Declaration of Human Rights, that everyone has the right to freedom of opinion and expression; that this right includes freedom to hold opinions without interference and to seek, receive and impart information and ideas through any media and regardless of frontiers. Communication is a fundamental social process, a basic human need and the foundation of all social organization. It is central to the Information Society. Everyone, everywhere should have the opportunity to participate and no one should be excluded from the benefits the Information Society offers. 
Access to ICTs and the benefits of the information society, for individuals as well as economies, via such means, is being politically articulated as foundational to contemporary understandings of global equality. The sociospatial orientation I have outlined is being foregrounded as inherent to new patterns of development in the twenty-first century. Human development is assessed as occurring not only in the familiar physical geospatial settings of the past, but also in the less familiar virtual settings of the present and future.

Women, and minorities, are also being explicitly recognized as requiring particular attention in this shift:

We affirm that development of ICTs provides enormous opportunities for women, who should be an integral part of, and key actors, in the Information Society. We are committed to ensuring that the Information Society enables women's empowerment and their full participation on the basis o[f] equality in all spheres of society and in all decisionmaking processes. To this end, we should mainstream a gender equality perspective and use ICTs as a tool to that end.

In building the Information Society, we shall pay particular attention to the special needs of marginalized and vulnerable groups of society, including migrants, internally displaced persons and refugees, unemployed and underprivileged people, minorities and nomadic people. We shall also recognize the special needs of older persons and persons with disabilities.

(WSIS 2003)

From these standpoints, access to ICTs is argued as a new facet of broader liberal/neoliberal approaches to 'women's empowerment' and 'gender equality', and to the needs of other disadvantaged and minority groups.

The WSIS approach to access to ICTs has clear macro and micro trajectories, but in the main these reinscribe traditional notions of aspirations to 'universal equality' embedded in liberal ideology and its more economically steered neoliberal manifestations in processes of globalization. One way of thinking critically about the WSIS process is to recognize its role in bringing the ideology of liberal/neoliberal perspectives into the information age in relation to development. There are obvious tensions when we recognize that, just as other global inequalities are partly a result of the dominant neoliberal order, so are those related to ICTs and information society developments.

The extent of the digital divide within and between countries across the world bears witness to the material problematics of this ideology. Liberalism's and neoliberalism's rhetoric of 'universal equality' persists in a global system, where while development is spreading, albeit very unevenly, the gaps between those who have most and those who have least within and across countries has grown substantially. The average income of the top 20 per cent of the world's population is about 50 times the average income of the bottom 20 per cent, with the former holding three-quarters of world 


\section{Time/space frameworks}

income, the poorest 40 per cent (roughly corresponding to the two billion people living on less than two dollars a day) holding 5 per cent and the poorest 20 per cent just 1.5 per cent (UNDP 2005: 36). It is clear that there are profound tensions between the liberal vision, captured in major discourses such as the WSIS declaration of principles, and the facts of global existence where the neoliberal order in political economy dominates.

What we can note here is that digital developments and all the potential and possibilities they offer only serve to complicate further the pressing problems of global and local inequalities. They have added yet further layers to the complex realities of GPE that threaten to embed existing and historically created inequalities even more deeply. Whether we are thinking of countries, business or financial entities, or individuals, global statistics currently present a highly uneven picture where, among other developments, the richest get richer and the poorest get poorer. The share of Sub-Saharan Africa in the poorest 20 per cent of world income distribution has more than doubled since 1980 from 15 per cent to 36 per cent and continues to rise. One in every two people in the region is in the poorest 20 per cent of world income distribution, and this compares with one in every five people in East Asia and one in every four in South Asia (UNDP 2005: 36).

Digital infrastructures, and the access to different forms of knowledge and economic opportunity which they offer, complicate even further the challenges the world faces in combating the enormous problems of inequality that are growing by the day. For just as they present multiple opportunities for all, and the WSIS process aimed to emphasize and harness such possibilities, they are yet another set of developments that allow the richest to further embed their advantages at all levels. The WSIS process, involving stakeholders across government, business and civil society, highlighted the potential of the digital brave new world for rich and poor. It presented a 'universal' vision of a digital future, and as such, has to be regarded as an agenda of hope as much as reality. In any event it is an agenda with a context, and that context is the unequal world of contemporary globalization.

Different kinds of inclusion and exclusion dominate in this world, and they are in tension with the 'universal' visions of neoliberalism in the contradictory conditions of vast inequalities of wealth and opportunity. Digital divides add yet another reason to challenge the contradictions of liberal ideology: the gaps between its pretensions and the actual material results of the global neoliberal order. Access to the new world of digital economy and opportunity is dependent on relative wealth, but it is also increasingly essential to the means and possibilities for generating that wealth in the competitive global economy.

The examples of the growth economies of India and China signal this, where their advances incorporate varied digital developments, including in global servicing and software work. The International Telecommunication Union (ITU) (2006) reported that China's telecommunications investment totalled 27 billion US dollars in 2004, almost 15 per cent of the world's total. 
Europe and the Americas made up 33 and 23 per cent respectively, while only four per cent was invested in Africa. The ITU commented that this figure while low compared to Africa's population size, was an encouraging level in the light of the continent's current share of ICT/telecommunications.

The digital world remains an elite one with regard to the full global picture and reflects the different kinds of unevenness that are evident globally and regionally. The ITU (2006) reported that via all platforms there were an estimated 840 million Internet users across the globe, representing just 13.2 per cent of the total population by the end of 2004 . Almost a third of the population was online in Europe and the Americas, the highest penetration rates. The Asia-Pacific region showed wide variations: over 60 per cent in countries such as South Korea, Australia, and New Zealand, to less than five per cent in others, including Bangladesh and Cambodia. Highlighting the extreme contrasts, the ITU pointed out that although in several countries more than 50 per cent of the population was online, the average figure for Africans was only 2.6 per cent.

\section{Moving through time and space: the new economics of mobility}

The new political economy of time in the digital era is increasingly about mobility, signalling the importance of seamless connectivity and access on the move as integral to developing forms of flexibility. This mobility, including in technological regards is part of the terms of competition in GPE. And there are interesting contrasts to note in this regard, including in geographic distribution. Mobile telephony is more of a mass technology than the Internet at this stage with the ITU (2006) reporting roughly 28 per cent of the world's population subscribing to mobile telephony services by the end of 2004, however with the majority, 74 per cent, in Europe and Asia. The mass appeal and accessibility of the medium is also indicated by the flexibility in its marketing and service structures.

The main reasons for growth in mobile telephony have been the introduction of prepaid services, rapid network deployment, and a highly competitive environment. Across the world, the sector is marked by more competition than any other. Prepaid services allow operators to reduce risks and serve clients who might not qualify for a monthly subscription. They account for almost half of mobile subscriptions worldwide, and they are the norm in developing countries - in Africa, prepaid services make up almost 90 per cent of the entire mobile market.

(ITU 2006)

But the concentration of access to the high end technological developments in relation to mobile telephony, the so-called Third Generation or 3G, delivering wider informational and multimedia services, shows a specific 


\section{Time/space frameworks}

geography of world leaders, a small elite of hi-tech economies, the USA, South Korea and Japan. At the end of 2004, the USA, with 49.5 million subscribers to 3G, South Korea (27.5 million) and Japan (25.7 million) together accounted for more than two-thirds of the world total (ITU 2006).

In terms of speed and access, the switch from dial-up Internet access to broadband, bringing increased speed and capacity, is another qualitative shift that differentiates digital developments across the world. To date the broadband elite, while set to grow, is tiny too in relation to the global population. By 2004 only 2.5 per cent of the world's population (38 per cent of Internet users worldwide) had broadband Internet access. Countries in Europe, Asia and North America dominated the list of the top 20 economies in relation to broadband penetration for 2004, with South Korea leading the way (ITU 2006).

The diverse technological developments associated with the sociospatial shifts of the virtual realm show clearly the growing importance of speed and different facets of access. This includes access to mobile technologies, and broadband facilities, which increase the speeds and volumes of multimedia transmissions. We can note that digital developments map onto some of the major characteristics of inequality in the familiar geospatial settings of globalization. In this sense, it is appropriate and politically important to recognize that such developments threaten to embed existing inequalities even further, while the digital elite of economies speed ahead in this area.

It is also clear that even in geospatial terms there are specific and distinct geographical groupings to be considered when we look at digital elites operating at the cutting edge of technological progress, for example 3G and broadband. Countries in Asia feature strongly in this regard, including in leading positions, alongside those in Europe and North America. The spread of the digital economy is global in its reach from Asia to North America, but is highly uneven across the world, and still excludes the majority of the world's population, if we are thinking about the numbers of people online and with access to mobile telephony. Mobile telephony can be considered a more democratic or accessible technology than the Internet on the basis of the numbers of users, but again with its own geography of subscribers, substantially concentrated in Europe and Asia. 


\section{Part II}

\section{Borders and inequality}





\section{Transcendence and communication}

In this section of the book I unfold a range of considerations about borders and inequality in the new conditions of sociospatiality and geospatiality. Exploring different aspects of digital divide and their relationship to familiar and established patterns and structures of GPE is a core focus. I examine the implications of the time/space complexities discussed in Part I for our thinking about GPE and different modes of being, activities, associations and interests within it.

In this chapter I discuss the broad area of transcendence and communication, exploring different ways in which sociospatial and geospatial realities interact to produce new multidimensional frameworks for being and engagement. I explore the contrasting natures of vertical communication and horizontal communication and diverse developments related to them in the information age. The stretching of the public sphere and transitions from the mass media to the new media environment are part of this picture, as are tensions resulting from the overlaps and interconnections between sociospatial and geospatial settings.

\section{Vertical communication, globalization and new public sphere issues}

We can think of communication in two general ways: vertical and horizontal. In broad terms the familiar geospatial world of GPE has historically been interpreted mainly through vertical (top down) structures of communication of state and market. Such structures reflect the power matrix of states and markets, colonial and hegemonic patterns of political economy at international levels, governmental forms of control at national levels, and the interactions of major financial and market players and interests across national-international contexts. When we look at the history of modern communications, it has been primarily about the increasing democratization of information, a process in part about decentralization of church and state control, and in part about the combination of technological and market influences.

The print revolution following the invention of the printing press is the pivotal development in this story, leading to a literal explosion in the 


\section{Borders and inequality}

production and dissemination of printed materials. 'About 20 million books were printed before 1500 in Europe among a population at the time of about 100 million. This number of books, produced in the first fifty years of printing, eclipsed the entire estimated product of the previous thousand years' (Deibert 1997: 65). It is obviously useful to revisit the print revolution when thinking about changes and drivers characterizing the contemporary information society.

We can consider the age of print as the roots of the current age of information. We are immediately reminded that there is a historiography to the information age and that its complexities are part of our understanding of the development of modern (democratic) states and markets. Transformations associated with print are linked directly to the relationship between power and knowledge, and the influences of technological invention and market forces in contributing to a more democratic and decentralized world. As Ronald Deibert (1997: 65) points out: 'Before 1500 the majority of printed works - about 70 per cent - were in Latin, with about 45 percent of them being religious in content'. Most of us take the secular realm of print almost entirely for granted these days, but revisiting the history of communications offers reminders of how control of information was once primarily about who could read and write and limit and structure access to documents, and that in pre-printing press times this was an intrinsic element of church power.

It is also important to think in spatial terms about the print revolution, and to recognize how it made knowledge mobile and transmissible. The printed document disseminated through the market is literally a means by which knowledge travels, and is made accessible to increasing numbers of people. There are diverse ways in which we can consider such changes in the context of knowledge and power. As knowledge travels more, it is less constrained and fixed, including in geospatial regards. Not only control over knowledge itself is decentralized, but, equally vitally, how that knowledge is interpreted, engaged with, debated, and criticized. Once knowledge is spread rather than contained, its influence goes far beyond its own content. From existing ideas, new ones are generated and so on and so on. Knowledge is not static but constantly in process and the more people included in that process, the more opportunity there is for diversity of viewpoint, counter-argument and contestation.

The current information society is firmly based on the kinds of dissemination the print revolution helped to facilitate, and a print culture is at the heart of the development of modern democratic states, their successful operation and their geospatial characteristics. The relationship of a democratic state with its citizens is textually mediated, whether we are thinking of legal instruments and their application, for example, or democratic political processes including elections through ballots. As the legitimacy of democracies is inherently derived from the active participation of their citizens, democratic states are duty bound to guarantee as far as they can that 
their citizens are equipped with the basic skills to participate. ${ }^{1}$ Mass literacy (and thus state education systems that are aimed to ensure it) is part of what gives democracies their legitimacy. National education systems, in transmitting the culture and history of states to citizens contribute substantially to shaping identities along geospatial (bounded state territorial lines). These systems prepare citizens to participate in the public (communicative) sphere ${ }^{2}$ of democratic states that is shaped by vertical top down structures of state and market, including those of traditional mass media, public (e.g. BBC) and commercial.

Changing state/market dynamics, particularly in the era of globalization, are challenging the geospatial (state-centred) frameworks for thinking about democracy and legitimacy. ${ }^{3}$ Globalization can be argued to represent a paradigm shift in the ways in which the international sphere, and the relational matrices it consists of, are understood, negotiated and critiqued. It moves us beyond a predominant sense of the 'inter-national', which has historically framed (and constrained) worldviews, into an era of multiple spatial framings. ${ }^{4}$ These take into account the ways in which local, national, regional, and global linkages cannot be considered in simplistic hierarchies or layers. The world may still be dominated by the rich economies, but an understanding of how their wealth is generated and configured cannot be understood within a state-centred spatial framework.

Political, economic and cultural patterns of power have become increasingly internationalized and institutionalized, with concentrations of wealth relating as much to the role of TNCs as to states. The dominant political and economic (neoliberal) interests across state and market invariably come together in the deliberations and decisions of major international groupings and institutions such as the G8, ${ }^{5}$ the World Economic Forum (WEF) ${ }^{6}$ and the WTO. Such entities, and the neoliberal ideologies they work within, are influential in what might be considered a global public sphere in the making. It may not be a public sphere of the ideal kind, or of a kind which directly imitates that of national democractic public spheres, but that is all the more reason that critical investigation of its actual characteristics should be part of democratic debate.

Debates in this global public sphere in the making are, among other things, directed towards the democratic deficits, which are resulting from contemporary state/market dynamics and patterns of governance operating across as much as within state boundaries. These deficits result from the multiple spatial framings (national, regional (e.g. EU) and global) within which interacting sets of political and economic strategies, decisions and policies are debated and formulated. The deficits relate to a lack of direct accountability, participation and transparency. Clearly all three qualities are inter-linked. They are principles familiarly associated with the practices of democratic political systems and part of their bases for legitimacy. They have been learned and understood in the main in national democracies, which citizens engage in, and through various levels of representation. 


\section{Borders and inequality}

Legitimacy in these contexts rests partly on the opportunities for citizens to engage actively in debates related to decision-making processes, and this is dependent on sufficient transparency for citizens to be informed of the diverse issues, viewpoints and policy possibilities involved. Such informed public debate contributes directly to the potential for satisfactory senses of levels of accountability. The stretching ${ }^{7}$ of the public sphere through globalization is resulting in varied tensions in these areas. As key aspects of decision-making have become to some extent disembedded from the national and local contexts of direct political representation, citizens have become increasingly left out of the active realm of democratic engagement.

Increasing numbers of people around the world have what might be considered globalized lives ${ }^{8}$ because as producers and/or consumers they are actively engaged in the world market. However, the degree to which they can understand and critique their place in that market - its diverse impacts on them, their daily lives, and futures - is affected by their political identities. These have been primarily (and vertically) state-defined and thus bounded in national territorial terms, so they no longer reflect the complex political-economic realities of a globalizing world. Explanations of how we are differentially situated, politically and economically, must be derived increasingly from transnational conditions. Importantly, this applies to richer as much as to poorer states, because the changes in production and consumption patterns impact on both, as notably illustrated by the shift of major areas of production to so-called developing economies, a contributory factor in China's major economic growth in recent years.

We are living in a time of great tension between the established national limits to our political thinking and the transnational characteristics of globalization.

Many decisions are made on behalf of citizens by governments or their representatives in various international forums, without priorities given either to the dissemination of information relating to the generation of a rich public debate about the issues involved, or transparency in the decisionmaking processes themselves. The stretching of the public sphere represents a double tension related to the changing circumstances of democratic practices and perspectives on their relative legitimacy. The spatial arena of decision-making, associated directly and indirectly with the diverse political, commercial and institutional processes of globalization, is being extended geographically. This leads to problems for governments, in particular in maintaining effective and democratically oriented informational linkages with their citizens across the full geographical reach of decision-making in which they are engaged.

Media are an integral part of public sphere functioning and traditional media of the broadcast and print variety have been predominantly mapped along national lines, whether we are thinking of public service or commercial entities. There are strong political, cultural and linguistic reasons why such a situation largely persists, despite significant internationalization of owner- 
ship of media and the growth of conglomerates with diverse interests as well as expanded markets for media products. ${ }^{9}$ Furthermore, media of national and international varieties may report decision-making processes of global institutions and forums, but the ways in which they fall victim to the generally limited nature of the transparency of those settings locates them as only marginally more informed than the citizens of the governments involved. There are ways in which whole issues of accountability transform once you move beyond the national political boundary, where governments are understood, in the main, to represent their citizens. There are distinctions from the national political space itself where, in democratic systems, greater day-to-day informational flows and levels of transparency are taken-forgranted elements of legitimation.

\section{Horizontal communication: sociospatial versus geospatial contexts}

Globalization is to some degree a story of political practices that have got away: practices that have become 'disembedded' (Giddens 1991) from their traditional local and national (geospatial) settings and reconfigured and relocated in political economic sites of regional and global institutional and capitalistic structures. The manner in which ICTs cut across and transcend traditional geospatial boundaries has proved powerful in this context for those frustrated at the sense of political disempowerment resulting from the democratic deficits. The Internet has become a kind of global (sociospatial) forum, or more precisely multiplicity of virtual spaces, through which diverse forms of horizontal communication: activism, community building and lobbying can take place and have visible presence. The 24/7 (24 hours a day seven days a week) and interactive nature of the Internet gives some concrete sense to its potential as a global public sphere in the making. So what are the contrasts between vertical and horizontal communication that help us to understand this potential?

Two helpful themes are anarchy and lack of mediation. ${ }^{10}$ The combination of the two as a way of thinking about horizontal communication is an indication of the cross-disciplinary demands of studying ICTs and their effects. The first, anarchy, is a familiar theme in the study of IR, and the second, mediation, is central to the field of communications. They both relate to borders and questions of power related to them, and they both impact on knowledge in contrasting ways: knowledge about the world, about political community and individual identities related to it. Attention to both signals how bounded political communities (states) are knowledge communities, linking collective and individual senses of identity (history and culture), and the integral part of mass media in the day-to-day maintenance of the public sphere of modern states. ${ }^{11}$

The boundaries of mass media have traditionally, and still largely remain mapped onto national boundaries, and play a substantial part in 


\section{Borders and inequality}

communicating both inside states and to the wider world, the particularistic identities of individual national public spheres. The growth of importance of transnational media, including broadcast news services such as CNN News, Sky News, BBC 24 and Aljazeera add to this picture but do not substantially transform it. ${ }^{12}$ Their locations remain part of their broadcast identities, while they are transmitting to, and also catering for, an international audience. As such, these stations remain embedded in the vertical structures of state and market, structures that articulate specific boundaries (of the states and commercial entities to which they belong) as much as crossing them through their transnational communications networks.

The above points signal one of the most interesting aspects of thinking about horizontal communication: how it forces us to reflect in more depth on the nature of vertical communication (through organs of state and market), and the implications of its boundaries as well as the inherent takenfor-granted nature of them. The concept of anarchy in international relations positions the state boundary as pivotal, the divide between (internal) order and (external) chaos, based as it is on the system of international relations and law where states are the supreme legal entities with no other power reigning over them. ${ }^{13}$

States are the core vertical power structures and mass media (whether explicitly state-controlled or part of what we usually term the free press of democratic systems) are a vital part of the communicative/political glue between state and citizen. Most of the vital information people have traditionally received in these contexts has come via national and local governments, agencies and media systems. These informational and media linkages are taken-for-granted elements of everyday processes of communication related to the maintenance of political community and myriad individual associations with it. ${ }^{14}$ The $\mathrm{BBC}$ remains an icon of this mass media era. As a public service broadcaster it has demonstrated the high level of national political importance attached to media services in one of the leading democratic systems.

The BBC is also an excellent example of how vertical communication has been enhanced and expanded by virtual communications. Governments and traditional media organizations are among the most complex and prominent presences on the Internet, as are other major international institutions, notably the EU, the UN family of organizations, the OECD and so on: another reminder that the information age is very much about interconnections and overlaps between geospatial and sociospatial developments.

These interconnections and overlaps indicate a number of things. Established processes of mediation (through national print and broadcast and transnational media) endure, in addition to expanding their roles and characters sociospatially in the virtual realm. These expansions transcend their traditional time/space constraints by making their products available in the transnational setting of the 24/7 Internet and harnessing its interactive capacities to allow individual audience-specific choice and use (e.g. through searching an archive such as that offered online by the British newspaper The 
Guardian, downloading a podcast from BBC Radio 4, or listening online to a live BBC Radio 3 concert at the time of broadcast or later through a listen again function). So now in the virtual era, traditional mass media have online as well as offline identities and functions, some of them the same or similar, and some of them completely distinct.

It is also important to note that the presence of diverse forms of vertical communication of state and market online contributes to the new horizontal world of communications. This presence is part of the anarchic informational sphere, where no overarching (national) order rules but where many can be observed and engaged with. Here it is useful to think in audience terms, whether we are considering one government as an audience of another, for example, or individual citizens. Citizens with access to the Internet can easily and quickly, and both are very important, move well beyond their national mediated channels of information. They can gain access to a whole host of informational sources that extend outside of their own national boundaries. These sources can be diverse in nature and both mediated and unmediated. They can include different kinds of official and social movement outlets, and varied national and international news media.

Thanks to online sources, one government's actions and decisions could be viewed by a citizen through varied informational lenses, for example, the pronouncements of a range of other governments and international institutions, views of media across different national and political settings, comments by NGOs or commercial entities involved in or concerned with the events. Relevant websites may be hosted by the bodies themselves, or others commenting on their activities, and interactive possibilities could include joining e-petitions or e-mailing inquiries or protests. Such circumstances are in sharp contrast with the pre-Internet age when national (and international) media would have been the prime accessible sources of information. It is important to stress that the global public sphere of the Internet, such as it is, has as many impacts on those involved in old fashioned vertical communications as it does for the many new actors who are keen to harness its horizontal potential.

This is why the idea of an anarchic informational sphere is particularly valuable. It reminds us that the distinction between inside and outside ${ }^{15}$ (the state) no longer holds true in the way it did. The Internet represents an informational space that, in many ways, transcends the inside/outside divide, and those in the traditional vertical structures of communication (whether they are government ministers or journalists) need to be aware of this as much as those wishing to criticize their decisions or assessments. Governments still have to gain and maintain their legitimacy primarily within their own political communities (boundaries), but the realm of critique and available information relevant to such critique extends well beyond those boundaries, more dramatically than ever before thanks to the nature and content of the Internet. This is where we return to the political economy of access touched on in Chapter 3. 


\section{Borders and inequality}

The question of accessibility is not only technical and economic, although both are important. When we are thinking about a horizontal communications environment, as opposed to vertical communications, we are addressing issues of who has access to information, and to the variety of information sources mediated (by traditional media organizations) or unmediated (direct from governments, local, national and international NGOs, and international institutions of varying kinds). In a vertical, mainly mediated system, there are information gatherers with professional status linked to that role, journalists being among the most familiar. These professionals have privileged access to information and part of their professionalism is their function in disseminating it, as it were, on behalf of a larger public. The Internet enhances this informational environment by its transcendence of traditional geospatial boundaries, but it also represents a more complex multi-level (sociospatial) realm where the few-to-many model of information provision is accompanied by a many-to-many multi-source model of communication.

We need to think about horizontal communications and the Internet in diverse ways in order to deepen our understanding of the political economy of access in the information age. One aspect relates to the ordering of information, or more accurately its disordering in the new anarchic informational environment. In the traditional (vertical) setting of, for example, mass mediated information there is a hierarchy or ordering of legitimacy in information delivery. This is demonstrated in the high status allocated to the BBC, for example, with its public service mission, but it is also signalled in the distinctions drawn between quality and tabloid publications, the former regarded as focused more firmly on the delivery of serious (factual) information, including background and commentary. In such structures the professional hierarchies take care of, as it were on behalf of the audience, the categorization of authority allocated to different informational sources. Trust and legitimacy become substantially located in the structures of mediation themselves. This is a key characteristic of media systems in developed democracies and an intrinsic part of the way they operate.

This makes it clear that in the processes of mediation, the transfer of trust from the audience to the system itself, and the articulation of legitimacy are inherent in how mediation is perceived both directly and indirectly. These characteristics are part of the politics of access and the freedoms those participating in the public sphere have to designate their identities as both producers and consumers. This whole picture becomes much more complex in the sociospatial informational environment, where as well as the traditional mass media information deliverers, there is a whole host of alternative information suppliers. We have an entirely new sphere which is as dominated by unmediated information delivery as it is by mediated delivery. Those established actors in the vertical system (governments, international institutions, etc.) can communicate directly with their audiences, and in much more detail, via their websites and documents stored on them, 
as well as indirectly through the mediated communications systems of newspapers and broadcasters. Equally importantly other information suppliers, who usually had much less access to audiences through traditional mediated channels, such as NGOs and individual citizens, have direct access to their own audiences via the Internet.

This is the new world of many-to-many communication, but it is a world where the technical and political economy dimensions of interactivity are brought into relationship with one another in challenging ways. In order to explore this further, it is helpful to recognize how much vertical communications systems tend to be supply-side dominant. This is a core facet of their verticality in which the few (e.g. broadcasters and newspapers) make informational choices, decisions and selections on behalf of the many (their listeners, viewers and readers). This system is relatively passive to the extent that it requires only limited choice on behalf of the audience, for example which newspaper, or selection of newspapers, to read. The choices in a horizontal communications environment are far more complex and challenging. The technical interactivity of the Internet means that audiences can choose from a comparatively vast menu and an endless choice spectrum among both mediated and unmediated information suppliers, across rather than within traditional geospatial boundaries. There is a clear political economy to such possibilities, as I began to discuss in some detail in Chapter 3, because there is vastly different access to them across the world for varied political and economic reasons.

However, if we just stay for now in the broad zone of possibilities, it is important to recognize that this is far from just a technical question of interactivity. It is indeed evident that audiences need to be aware of what the Internet offers as a horizontal communications environment in order to take advantage of it. But, perhaps even more importantly, they require a deep critical consciousness of the relative passivity in relation to information consumption that the established few-to-many models of vertical communications have engendered in them. This relative passivity is characterized by an informational environment (and culture), where in the main the few make informational decisions and choices on behalf of the many. Transcending those passive informational times remains one of the challenges for audiences ${ }^{16}$ in making the most of the contemporary horizontal communications sphere, and the empowerment potential it offers them in their own decisionmaking and political and economic life choices. This transcendence is not something that can be taken for granted in the information age, because it represents a shift across all vertical informational cultures. It represents a new kind of informational individualism where the vast expansion of (sociospatial) informational boundaries leaves the fate of how information rich or poor individuals are much more up to them in the present and future than it was in the past.

What we can emphasize here is the tension between vertical and horizontal communications systems, and the work of states to resist the informational 
anarchy of contemporary times. ${ }^{17}$ This is most starkly evidenced by states such as China and Saudi Arabia, which heavily control access to the Internet and censor its contents from within their national boundaries in an effort to maintain the integrity of their political and cultural systems. But it is also evidenced in other respects by the EU and home legislative instruments in states such as the UK to combat access to online child pornography, in an effort to maintain the integrity of its geospatial legal control of this area, and to take a leading role in international criminal investigations to crack down on paedophile rings and bring to court those involved. ${ }^{18}$ In the 'war on terror' post-9/11 2001 increasing attention has also been given to the work of national security services in tracking and monitoring networking in the sociospatial as much as geospatial settings, as part of their overall efforts to combat terrorist threats and activities.

Across all such areas we can see new kinds of macro/micro tensions developing on two major fronts: one between the international bordercrossing (sociospatial) nature of online information sphere and the traditional nationally bounded (geospatial) state information sphere; and the second between the individual citizen's access to the former and the state's efforts to maintain the (political, cultural, legal) integrity of the latter. Both fronts raise many issues of complexity in the information age. They offer insights into new kinds of thinking about globalization in relation to overlapping geospatial and sociospatial influences.

Let's take the tensions between the international and national informational spheres first. There are many ways in which elements of these can be viewed through the lens of globalization, where technologically and Western-centred development of the Internet has spread across the world from the USA, testing the capacities of states to resist it. This is evident in the efforts, for example, of a communist state such as China, which is aiming to replicate as far as possible the anti-democratic political and cultural censorship it has maintained in its geospatial boundaries in the sociospatial setting of the Internet, by government control of access to it and censorship. This includes through commercial operators such as major search engines Google, Yahoo and Microsoft, which China has allowed to operate within its boundaries on the basis of agreements to adhere to its culture of censorship. ${ }^{19}$ States such as China and Saudi Arabia want to be part of the information age but on their own geospatial terms. They want to reinforce their vertical communication structures, in not full but limited and specified opposition to the new horizontal communication patterns. In this sense they are resisting the heterogeneity of the new anarchical information environment as far as they perceive it threatens the homogeneity of their own political and cultural systems.

This tension is arguably demonstrating a number of things, which are far from new but are perhaps being given new significance in the information age. One is the importance of recognizing the geospatial setting of the state as an informational/communications sphere. Another is the ways in which 
this has been a matter of technology and its reach. This has been profoundly changed by the specific nature of the Internet, and its anarchical tendencies to transcend geospatial boundaries. Another is the way in which considering the importance of communications draws our attention to the importance of political economy in understanding macro changes and different forms of resistance to them. For, clearly, the neoliberal synergy of democratic politics and economics that the horizontal communications sphere of the Internet offers, is being resisted by states who want to exert their own specific control of it. While the free flows may be welcome economically for the benefits they bring, including vitally for overall development, they are resisted politically (and culturally) for the threat they represent to internal homogeneity and legitimacy.

There are clear contradictions here and they are overtly ideological. The neoliberal principle works on the basis of the inherent interdependence (not separation) of liberal democratic and liberal political principles of individual freedom and free flows of information and association. ${ }^{20}$ The Internet, originated and developed in the USA and Europe, has its own firm geospatial roots in this neoliberal framework of tendencies towards free flows. ${ }^{21}$ As a technological sphere it therefore has its own ideological characteristics. The technologies that shape it have been generated from particular (neoliberal) historical and material contexts. ${ }^{22}$

It could be argued that the network ${ }^{23}$ (sociospatial) power of the Internet as an informational and communications sphere, in its diverse capacities to transcend the national (geospatial) limits of the state, represents a new global materiality, perhaps even a new global paradigm. This paradigm posits connectivity as a new form of (political and economic) productivity, and this connectivity is anti geospatial limits in theory and to some degree already in practice. There are two questions that remain unanswered about this connectivity. How much and how long can it be resisted in geospatial terms? And, how much and how long can its (neoliberal) ideology of the synergy (rather than separation) of liberal political and economic principles of individual freedom and free flows be resisted? ${ }^{24}$

It is worth stopping here to remind ourselves of the symbolic significance of the Internet as a new global paradigm. In my estimation this cannot be underestimated and it operates along a whole host of lines, material and imagined, actual and posited. The Internet in all its sociospatial characteristics, and the promise as well as the actuality of the multiple freedoms from geospatial constraints uses of it offer, has transformed the idea of globalization as much as many of its material practices and structures. In the variety of means the Internet provides to transcend traditional time and space limitations, it literally encapsulates a reality of globalization as a world in which the global is as close and meaningful as the local or national, as near and intimate ${ }^{25}$ as what and who is physically close at hand.

In these ways, the Internet is a new touchstone for thinking about the world, the way it works, and our places in it as individuals or members of 
organizations. This is a potent development symbolically with regard to GPE, for this is traditionally a macro sphere, a world of structures and institutions, major power brokers of politics and economics. As a complex of technologies providing different forms of connectivity and access at the individual (micro) level, the Internet points to new and more intimate grounds for thinking about GPE.

The technological environment of the Internet points us towards new ways of approaching the individual (citizen or organization) in relation to GPE both materially and symbolically, and with regard to what is actually or potentially possible. This is already evident, in the tensions for states trying to reassert geospatial realities over geosocial ones, as discussed above. The Internet potentially offers their individual citizens and organizations direct access to global sources. The nature of the Internet, and its transcendence of geospatial (including national) boundaries, provides a direct, sociospatial connectivity for individuals with the international/global realm (partial as this currently is due to the limits on who is actually online across the world). Sweeping (political and cultural) online control and censorship by certain states is clearly a double-edged sword. While it maintains to some degree the political and cultural homogeneity of geospatial national boundaries, it also, by its very existence, highlights the freedoms, which the Internet offers in transcending those boundaries. While it takes away freedoms from its citizens and organizations within its boundaries, it is simultaneously highlighting the extent to which those freedoms exist, symbolically if not actually.

The same is true but in very different ways even in democratic states, which in principle are harnessing all the (neoliberal) opportunities of the Internet. But they are also endeavouring to maintain legal protections of geospatial contexts, for example, in combating the abuse of children through the online activities of paedophiles, as well as, even more fundamentally, safeguarding the security of the state and its citizens against terrorist threats. It could be argued that the use of the Internet, and the ways in which it offers connectivity across as well as within state boundaries, has highlighted more than ever before the surveillance function of state over citizen. It has given this surveillance function a new transparency, not least because of the horizontal forms of online communication, which enable multiplication of debates about it. Part of this new surveillance culture, however, is the role of self-surveillance by users of the Internet. Here we see the ways in which legal change has to take account of technological change.

The concept of anarchy and the problems of control that it generates are central to these developments. Once the anarchical (sociospatial) informational sphere intrudes on the geospatial sphere, we have a situation of disorder within order. As the anarchical sphere is clearly beyond the control of the geospatial (state) sphere, the obvious way to regain control is through the means of access to that anarchical sphere at the individual (citizen) level. So, for example, in the UK, a legal structure is introduced making the downloading of child pornography onto an individual's computer a breach 
of the law, ${ }^{26}$ and a regime where Internet Service Providers (ISPs) once notified of illegal websites are expected to take action to remove them. ${ }^{27}$ Here we see the emphasis on self-regulation at the individual level, concerning both citizen and organization. ${ }^{28}$

We can see here how sociospatial developments have complicated the inside/outside structure, inserting a technological layer in the form of the Internet between citizens and states, bringing the outside inside. This situation suggests that we should increasingly be thinking about the overlaps and linkages between geospatial and sociospatial settings, when thinking about state/citizen relations and identifications. The technological layer of the Internet as a sphere of communications is as relevant to reflective processes in this regard, as it is to activities and networks. In other words, for those citizens actively engaged online as well as offline, their reflective (political and economic) spaces are as evident online as well as offline. ${ }^{29}$ Cybercitizenship can be as much about outside as inside, as much about reflecting on and critiquing inside through debates outside as well as inside, as much about identifications beyond traditional state citizenship as they are related to it. The boundaries of cybercitizenship are sociospatial as well as geospatial. They can be self-selecting and draw quite new geographies of identification and reflection, especially in contrast to traditional geospatial notions of states as communications communities.

New online surveillance cultures (which operate as much for market as for state purposes) point to the increasingly technologically mediated lives of citizens through sociospatial as much as geospatial settings. In different ways, these lives reduce individuals to data, which can be gathered, for example by companies wanting to know how we are using websites for purchases and services, tracking our consumer identities and using the information to target and profit from our preferences, ${ }^{30}$ or by government agencies including secret services monitoring online communications for key words, indicating evidence of anti-government or potential terrorist activities or threats. ${ }^{31}$ The continuing expansion of online lives is itself a material change in GPE, and the technological fabric of the Internet, the ways in which it stores data that can be easily tracked and identified, is essential to our understanding of the nature of that material change. I often think about this as being literally caught in the machine, as a way of encapsulating what it means to have activities travelling through and in evidence on the virtual pathways of the Internet. The more lives are online, the more identities are evident in the online sphere. The interactivity of the online world is now an aspect of understanding of the workings of state and market power in GPE. The transformation of material identities into virtual data identities, to the extent that this is happening online, makes such identities accessible, including for surveillance purposes, and more readily available as a resource that can be manipulated, including for profit. ${ }^{32}$ 


\section{The political economy of interactivity: state and market in the virtual sphere}

The hybrid sociospatial and geospatial world is a matter of political economy, and shifts related to it impact on both how we think about politics and economics and the relationship between them, and how we think about the workings of power within and across them. This is the case whether we are considering collective (state) or individual (citizen) contexts. Both state and market are operating through sociospatial and geospatial settings, and individuals are operating across them both. The predominantly vertical communications of the historically established geospatial environments are being reasserted and in some ways expanded and transformed in the new virtual sociospatial environments. These sociospatial environments are also characterized by the multiplication of horizontal forms of communication, which cut across familiar (state-centred) geospatial boundaries, and offer new critical and reflective spaces, new means of association and identification beyond as much as within state boundaries. Indicating the contemporary speed of change, the phenomenon of the blog went from small beginnings to a veritable explosion during the time of my writing this book.

Blogs have become popular examples of horizontal patterns of communications. They have been adopted increasingly within vertical communication systems, such as the mass media, as part of their transformation in the new media era, and as new ways of reaching out to, and involving their audiences. They have been developed extensively by individual bloggers, such as the notable Iraqi woman blogger (Riverbend) on the Iraq War. ${ }^{33}$ The blogosphere, as it soon became known, was one of the most dramatic illustrations of the appeal of the horizontal communications facilitated by the Internet, and the revolution in individual interactivity it offered. Weblogs - online diaries - in the variety of voices they brought online, gave substance to notions of an expanding online public sphere. The take up by mainstream media was definitely part of this substance. Following The Guardian's launch of a 'Comment is Free' collective comment blog in March 2006, the paper reported:

The editor of the Guardian has been directing the steps of his journalists towards this new world for some time. A few days before the launch of Comment is Free, he gave a contextual talk to the paper's senior staff, saying in effect that the Guardian had to be where the debate was taking place. He pointed out how some blogs in the US already had more followers than well-established newspapers or news magazines - and were establishing a growing authority too. ${ }^{34}$

The blogosphere proved graphically what Dale Spender (1995) had recognized in the early days of the Internet that where the print era had brought a dramatic expansion in readership, the Internet era promised 
to do so in authorship. But the blogosphere's growth of democratization on the Internet, as it were, also brought into sharp focus the embedded and historically entrenched inequalities of the print era, including crucially those related to literacy. One of the most fundamental aspects of the digital divide globally remained the extent to which millions had not yet benefited from the print revolution, a factor which decidedly excluded them benefiting from the Internet, either as readers or authors.

As UNESCO has pointed out:

While societies enter into the information and knowledge society, and modern technologies develop and spread at rapid speed, 860 million adults are illiterate, over 100 million children have no access to school, and countless children, youth and adults who attend school or other education programmes fall short of the required level to be considered literate in today's complex world. ${ }^{35}$

With women accounting for two out of three illiterate adults, inequalities in this area were also part of the gendered facets of the digital divide. ${ }^{36}$

The illiteracy barriers to interactivity are among the most fundamental elements of the digital divide worldwide. They are certainly to be taken into account alongside the infrastructural, economic, and political barriers to interactivity discussed in this and the Chapter 3. The provision of basic education is a core state function and clearly a prerequisite of online participation. The role of education as part of the development of states, economically and politically, is of growing importance in the digital age, and so long-standing inequalities and North/South divides in this area count more than they ever have.

I have considered in this chapter how state and market influences are shaping the new sociospatial environment, and differentiated access to it and interactivity on it across the world. States are actively engaged in vastly varied forms of control, censorship and regulation of the Internet, and thus the distinctions across geospatial contexts remain central to our considerations of GPE in the information age. However, the history of the Internet and its origins in the USA ${ }^{37}$ and Europe are intrinsic to its neoliberal characteristics in promoting flows of goods and information, and encouraging ease of access to them. The Internet is enabling horizontal communication as well as vertical communication, and transformations in the latter related to the former. New kinds of interactivity, including across as well as within geospatial (state) boundaries are features of transcendence in the information age, but they also draw our attention to basic questions of exclusion and inclusion. 


\section{Inequality as driver}

It is one of the barest facts of the new information age that it has dawned in a world that is defined by inequality. Bearing in mind the promise and potential of ICT developments, and much of the genuine excitement (and hype) that has been generated about them, this is a deeply depressing scenario. Neither is it something particularly new, as the technological developments of the twentieth century and the growth of mass production and consumption associated with them, together with the internationalization of markets post-1945, have produced a highly contradictory legacy. There has undoubtedly been major economic growth and an expansion of wealth, markets and development, as well as a geographic spread of production, particularly through globalization, bringing employment and other benefits to the less developed world. This fits in with the neoliberal promise of benefits for all through the spread of capitalism, and its competitive structure.

However, what has become evident, and what I will look at in some detail in this chapter, is that these benefits are so unevenly divided both between and within the richer and poorer countries, that the overarching driver in the system could be argued to be inequality itself. This inequality is related to a number of factors: the embedding of historically established inequalities; the reappearance of old patterns of inequality in new forms; and the creation of entirely new structures of inequality. These different factors are part of the complexity of the information age, and in the main they present major challenges for the future, in both theory and practice. They also suggest the need for new critical thought about the ideology of neoliberalism as the dominant institutional discourse.

I argue that the beginning of the twenty-first century is the moment to recognize that liberalism and its more economically driven form, neoliberalism, have reached a watershed with regard to their utopian visions of equality and equal rights. I attempt a subtle approach to this situation that foregrounds contradictory issues and argue this as paramount for the continuing legitimacy of such visions. I do not seek to reject their positive aspects, and the diverse roles these have played in the international arena, for example through the UN and its varied agencies. But I maintain that the burden of practice (increased inequality despite greater economic develop- 
ment) is now threatening to overwhelm the theoretical pretension to the goal of equality. In other words, it is impossible to keep holding up the mirror of practice to theory without seeing the extreme mismatch between the two. Theoretical and policy discourses need to take more active account of this mismatch, and engage with its problematics, if they are to hold on to a legitimate claim of enduring relevance.

Information society developments and the more rapid and expanded flow of commentaries across the virtual spaces of the world only add to this imperative. The sociospatial environment of online news, weblogs, NGO statements, discussion forums and activist networks have expanded both knowledge about what is happening around the globe as well as the diversity of critiques about it. No ideologies are safe from this expanded world of exchange and reflection, least of all the dominant one that drives the major institutional structures in GPE. In many senses it is exposed to criticism in ways it has never been before, especially from those angry at its deficits and determined to seek redress.

The loosely formed anti-globalization movement has been a high profile nexus of such sentiments, ${ }^{1}$ and has harnessed ICTs, mobile telephony as much as the Internet, to network and build its activities, share information, and stage its protests at strategic institutional sites such as meetings of the WTO and WEF. The World Social Forum (WSF), developed as a parallel and counter to the WEF meetings, is a broad civil society gathering, and has become a key focus since the first one in Porto Alegre, Brazil in January 2001. The negative impacts of neoliberalism in practice are core to the concerns of participants and in many senses the main cohesive force for this experimental and fluid collective form of activism.

The World Social Forum is an open meeting place for reflective thinking, democratic debate of ideas, formulation of proposals, free exchange of experiences and interlinking for effective action, by groups and movements of civil society that are opposed to neoliberalism and to domination of the world by capital and any form of imperialism, and are committed to building a planetary society directed towards fruitful relationships among Humankind and between it and the Earth. ${ }^{2}$

This section from the WSF Charter of Principles shows signs of its own brand of utopian vision, and this is at least partly vested in the whole experiment of the forum itself. As Marlies Glasius and Jill Timms (2006: 190) have commented: 'what is most ground-breaking in social forums, and what most attracts people to them, is the experimentation with form itself. It becomes part of the substantive message that "Another World is Possible", and it creates a new kind of space for global civil society'.

ICTs have been bound up with both the development and mobilization (the methodology) of such new social movements, as well as their virtual presence on the web, giving them an enduring identity in sociospatial terms 


\section{Borders and inequality}

well beyond the times and places of the forums themselves. WSF activists have been champions of the new horizontal communication and its expanded and cross-boundary sphere of reflection and critique. These processes highlight how much the information age is about exposure and greater transparency of neoliberal values, and criticisms of them, especially in relation to inequality.

\section{Inequality as long-term trend: exclusion over inclusion}

Many would see it as radical to claim that inequality is the driver of the contemporary world. But I want to do just that here, and to illustrate the weight of evidence that can lead to such a conclusion. I am not deterministic about it, and am open to the fact that much could change it in the future, including through ICT developments in the poorer as well as richer parts of the world. But for now, I regard the extent of issues of inequality across the world and within individual societies, the length of time that such problems have endured, and the fact that some are getting worse not better, as the prime concern. There are three main areas to cover. The first is the most optimistic, which I frame as the new regionalization, where the high growth economies, particularly China, but also India, demonstrate the 'economic miracle' side of the globalization story. However, I point out that a major price has been paid for such miracles: vast imbalances in investment patterns in relation to the developing world. The economic distortions that China, as the major destination of globalizing investment, has produced have widespread impact and are far from new. Global inequalities are not just about the gaps between North and South, but the result of heavily concentrated country-specific investment choices made in the North in relation to the South for many years past.

The second area I want to cover is the poorest parts of the world, including Sub-Saharan African, where problems of poverty, in some instances, have actually beome worse rather than better, and the crises of disease including HIV and AIDS are overwhelming. This shifts us from perhaps the proudest stories of globalization, related to economic success, to the most shameful. In the face of liberal goals of equality, it might be argued that a scenario where those who have least and suffer most get even less and suffer even more is the deepest indictment. Third, I consider inequality as a problem that has grown in the North as well as the South. I draw on a combination of evidence from across these three areas to outline the complexity and depth of inequality in the information age.

China leads the field among developing economies in the context of globalization. The explosion in both its growth rates and the extent to which it was consuming world commodities, notably oil, was the headline news of the global economy as the twenty-first century dawned. This followed China's attraction of the lion's share of inward investment into developing economies worldwide in the latter part of the twentieth century. China's 
contribution to global economic growth was already calculated at 16.3 per cent in 2000 and had grown to 20.6 per cent by 2004, and China and India's combined contribution to global output growth was put at around 30 per cent each year from 2001 (Reisen 2006). As Anne Krueger (2006) of the International Monetary Fund (IMF) pointed out, this economic expansion needed to be considered not just in terms of the individual countries concerned, but the global economy writ large: 'whereas in 1950 the United States was THE economic power, and by the mid 1970s Europe and Japan were clearly established as major global players, by 2000, emerging Asia - especially China and India, but also a number of other countries - had become a significant economic force in the international economy'.

The dramatic and rapid growth of China, and to a lesser degree India, among developing economies has increasingly been identified as evidence of not only the success of globalization but also of historic shifts in the global economy. One aspect of this has been the impact of growing production on commodities imports and consumption. It was argued that China had contributed all of world growth in demand for woods and cotton in the years around the turn of the century, and a third of the global growth for oil and metals (Reisen 2006).

China's rise to fourth largest economy in the world behind the USA, Japan and Germany, was headline news in early 2006, fuelling further debates about China as a new superpower. ${ }^{3}$ Its economic expansion and trading links with the USA and the EU, as well as its dominance of the share of foreign direct investment (FDI) to developing countries, certainly signalled its multidimensional role as an integrated hub of contemporary processes of globalization. This role suggests at the very least a new regionalization, where Asia (especially if India is included) is evidently playing a far greater and more influential role in shaping global economic futures. The nature of the integration of China, and to a lesser degree India, is as much a story of transnational corporate as well as trade and financial linkages.

China's lead in attracting FDI among the developing countries had been one of the most notable characteristics of globalization in the latter part of the twentieth century and this trend continued into the opening of the twenty-first century. In 2004 flows of FDI into China continued to grow to reach $\$ 61$ billion. 'Strong economic growth, an improved policy environment and further opening up to FDI in certain industries - such as banking and other financial services - contributed to the increase' (UNCTAD 2005: 52). Hong Kong (China), an integral part of the overall China picture, ranked second in 2004 with regard to inward FDI showing an increase of more than 150 per cent over the previous year to $\$ 34$ billion led by flows to the services sector. Hong Kong continued to play a leading role in FDI outflows in Asia, including to China, with a huge jump in its total FDI outflows from $\$ 5$ billion in 2003 to $\$ 40$ billion in 2004 (57).

FDI outflows also showed growth in 2004 from China and India in part connected to their commodity needs. 'Latin America became the largest 


\section{Borders and inequality}

destination for Chinese investment, accounting for half of the total outflows from China due to massive investments in natural resources. The largest FDI transactions by Indian companies were also in the natural resources sector in other regions' (57-8).

Information economy developments, including ICTs, offshoring and outsourcing are an intrinsic aspect of the anticipated continued growth of trade and investment for China and India. For example, the OECD (2005) reported that China became the biggest exporter of ICT goods in 2004 ( $\$ 180$ billion), surpassing Japan and the European Union in 2003 and taking the lead over the USA in 2004 ( $\$ 149$ billion). The main destination for China's ICT goods was the USA ( 24 per cent) with Europe taking 20 per cent. China had a trade deficit in ICT goods with OECD countries in 2000 ( $\$ 2$ billion) but a significant trade surplus in 2004 (\$46 billion).

China's growth rate in Gross Domestic Product (GDP) terms - averaging almost eight per cent in the 20 years to 2003 - was described as 'spectacular', equally so the growth in its share of world trade from less than one per cent in 1979 to around six per cent by 2003 (Prasad and Rumbaugh 2004: 1). Its integration as a leading growth economy globally was equally noteworthy, with it following the USA and the UK as the third largest recipient of FDI by 2004 (UNCTAD 2005: ix), and by 2003 being the third largest importer of developing countries' exports after the USA and European Union. The rapid development and diversification of China's economy has been part of this picture, with the shift in its exports towards higher end electronics and other goods from textiles and light manufacturing, a feature between the early 1990s and early 2000s (Rumbaugh and Blancher 2004: 7). China's role was becoming crucial in the Asian region as well as the wider economy, with the growth in its final assembly and production of Asian products destined for Western markets and its share of industrial economies' imports growing and diversifying (Prasad and Rumbaugh 2004: 1; Rumbaugh and Blancher 2004: 5).

UNCTAD (2005: 60-1) anticipated that East Asia would continue to receive the largest share of FDI inflows in Asia, with more growth in flows to China, for instance in the area of services including banking. It expected flows in FDI to India to continue growing, particularly in steel, telecommunications, infrastructure and finance, pointing out that the Indian government aimed to attract $\$ 150$ billion over the next decade by setting up special economic zones, science parks and free-trade and warehousing zones.

In 2004 China and India together accounted for around half of all new registered greenfield and expansion projects in developing countries (UNCTAD 2005: xx). Another sign of the significance of these two economies in global developments is the rise of Asian investment in developed countries with 2004 seeing some large acquisitions of US and EU firms by Chinese and Indian TNCs - notable among them being the acquisition by Lenovo (China) of the personal computers division of IBM (USA) (xxi). The deal was heralded as a great leap forward for China, being the largest 
overseas acquisition by a Chinese company at that point with Lenovo becoming the third largest maker of personal computers in the world (Youngs 2005: 75).

In the case of Indian economic growth, the importance of the continuing move away from labour-intensive to skill-intensive sectors, and substantial growth in services, including telecommunications, and software and business outsourcing, have been among the noteworthy features (Kochhar et al. 2006: 4). Commentators on the information economy orientation of a significant element of the Indian success story point to complexities of context, including education, training, etc., as well as opportunity (26-7) This reminds us of the importance of considering the possibilities for digital economic developments against the longer historical and particular developmental aspects of political economy in relation to specific states. The context, including the technological and knowledge base and capacities, matter as much as the opportunities.

In the case of India, one key capability was institutions: democracy, rule of law, free press, universities, and technocratic bureaucracy that recent research shows are crucial to economic development. Another key capability that has been extensively remarked upon in the context of the IT boom is the pool of skilled human capital, built through the technology, management, and research institutes, as well as through the public sector.

(Kochhar et al. 2006: 27)

The indicative statistics and points covered here are sufficient to support the excitement that generally surrounds the rapid rise of China and India as major growth economies, including in relation to information economy developments. In stark contrast to these high points of globalization is the story of the least developed economies, struggling to be any part of global economic success, let alone its latest hi-tech boom. The overall picture of global economic progress is one of stark contrasts in this regard, where the glitz and promise of ICT and wider scientific and technological advances of the richest and fastest growing economies compare with the struggle against hunger, poverty, and death from often preventable diseases of the poorest.

Sub-Saharan Africa stands out as the prominent example of regions at the bottom end of the development scale, and one that has much that is negative to tell us about the workings of contemporary GPE. The UNDP's Human Development Index (HDI) provides us with a reasonably complex view of economic well-being by taking into account education and health as well as income. The UNDP (2005: 21) reported in 2005 that over the last decade HDI had been rising across all developing regions at varying rates, with the exception of Sub-Saharan Africa. This region featured prominently in the list of countries that had actually suffered 'unprecedented reversals', amidst this overall progress. So an intrinsic part of our understanding of GPE in 
the information age is the following recognition: that it features far from a positive forward trajectory in terms of development, let alone technology driven development, in any fully inclusive sense. Furthermore, not only are the poorest who have traditionally been excluded remaining so, but it could be argued that they are becoming more so, against a picture where more and more wealth is being generated for those who are included in the positive sides of the story of globalization.

So GPE is moving backwards as well as forwards in development terms and the negative impact of the former is highly evenly borne, including notably by countries in Sub-Saharan Africa.

Eighteen countries with a combined population of 460 million people registered lower scores on the HDI in 2003 than in 1990. (Only six countries suffered such reversals in the 1980s.) The reversals have been heavily concentrated in two regions. Twelve of the countries with reversals are in Sub-Saharan Africa. Just over one-third of SubSaharan Africa's population - 240 million people - live in countries that have suffered an HDI reversal. The former Soviet Union accounts for the other six countries in which HDI slid backwards.

(UNDP 2005: 21)

These hard facts about contemporary GPE indicate that there is much that is political about economic knowledge in the information era. To comprehend the full realities of global economic dynamics, we need to be equally aware of the depths of human suffering and struggle at one end of the scale, as much as of all the potentialities of ICT and other technological developments and all their promise, especially for those at the other end of the scale, in the rich economies and other economies managing to develop at a fast pace. It seems that the breadth of economic information that we need to take in and digest, and the stark contrasts it presents across those who have least and most, those who are most disadvantaged and those who are most advantaged, is one of the major conceptual and theoretical, as well as substantive challenges of the current era.

The complexities of development and the extent to which new problems can interact with others with long-standing historical precedents is part of this picture. For example, the UNDP (2005: 22) explains that Sub-Saharan Africa's problem is 'the lethal interaction of economic stagnation, slow progress in education and the spread of HIV/AIDS'. The Joint United Nations Programme on HIV/AIDS (UNAIDS) reported in 2004 that with just over 10 per cent of the world's population Sub-Saharan Africa had close to two-thirds of all people living with HIV - some 25 million. In 2003 alone an estimated three million people in the region became newly infected, while 2.2 million died of AIDS. Among young people aged 15-24, nearly seven per cent of women and around two per cent of men were living with HIV by the end of 2003 (UNAIDS 2004). 
Such figures and the global inequalities of suffering, as well as the overall damage to populations indicated by them, are hard to come to grips with, and it is also stressed that within them lie other elements of inequality, including those related to gender.

Nowhere is the epidemic's 'feminization' more apparent than in subSaharan Africa, where $57 \%$ of adults infected are women, and $75 \%$ of young people infected are women and girls. Several social factors are driving this trend. Young African women tend to have male partners much older than themselves - partners who are more likely than young men to be HIV-infected. Gender inequalities in the region make it much more difficult for African women to negotiate condom use. Furthermore, sexual violence, which damages tissues and increases the risk of HIV transmission, is widespread, particularly in the context of violent conflict.

(UNAIDS 2004)

The AIDS epidemic is also a strong indicator of how development issues are interrelated and mutually reinforcing, impacting on overall economic development at the household and national economy levels. The result is not only an explosion in multiple vulnerabilities and societal loss, but daily situations where life-threatening and impossible choices have to be made. For example, in Namibia and Uganda studies have found households resorting to selling food and livestock to meet medical costs, and Zambia loses two thirds of trained teachers to HIV/AIDS (UNDP 2005: 22). The dramatic burden of HIV/AIDS for Sub-Saharan Africa comes on top of the already heavy number of preventable deaths in the region, including those among children. While the region has 20 per cent of births it also has 44 per cent of child deaths, most of which are preventable, notably from malaria (24).

Education has always been an important area of development and in the information era we could argue that it is even more so. This could lead us to conclude that those still disadvantaged in this sphere are doubly disadvantaged, both as individuals and whole economies, when it comes to benefiting from information society developments. This includes ICTs, where basic literacy of reading and writing are in many senses a prerequisite to the new layer of the less and more sophisticated technical forms of literacy that are required. Inequalities in global educational opportunities are extreme with around 115 million children estimated as missing even basic primary education, and the majority of children not enrolled in school in Sub-Saharan Africa and South Asia (UNDP 2005: 24).

Education is also an area that highlights the future consequences of current inequalities, concerning as it does the preparation of future participants in economic and political development, or where it is lacking, the sacrificing of much of their potential for doing so, especially in the information era. Where the demands for education are growing in information societies, and the stress in rich and growing economies is increasingly laid on it, the 
enduring effects of the global education gaps are part of the future as much as the present. And gender gaps come into play here too with primary school completion rates in the developing world at 75 per cent for girls versus 85 per cent for boys, and even wider gender disparities in secondary levels and beyond (UNDP 2005: 25).

The overall poverty picture globally shows improvements but with extreme variations, with poverty reduction heavily driven by the East Asian, notably Chinese success, and with most of the world's poorest countries falling even further behind rich countries (UNDP 2005: 34-6). 'Measured at the extremes, the gap between the average citizen in the richest and in the poorest countries is wide and getting wider. In 1990 the average American was 38 times richer than the average Tanzanian. Today the average American is 61 times richer' (36-7). The problem of inequality has many layers across North and South, including in the success stories of globalization in the developing world, so this is the third area for us to consider. Initially let us return to the examples of China and India, where despite their growth and progress, continuing limitations in human development are evident.

The UNDP (2005: 28-31) points out that despite increased growth, annual progress in cutting child deaths slowed in both countries from 1990, with India accounting for 2.5 million child deaths annually (one in five of the world total) and China for a further 730,000. Gender differences are evident here too, with, for example, girls between one and five in India 50 per cent more likely to die than boys. Geographical contrasts are part of the uneven picture of development with extreme poverty concentrated in the rural parts of the 'northern poverty-belt' states in India. 'Some of India's southern cities may be in the midst of a technology boom, but 1 in every 11 Indian children dies in the first five years of life for lack of low-technology, low-cost interventions. Malnutrition, which has barely improved over the past decade, affects half the country's children' (30).

Such comments and statistics put some of the hype and hope of the digital economy in sobering perspective. The fact is that it is as much a part of the picture of growing inequality gaps (within and between countries), as it is economic growth and regeneration, including in the developing world. This suggests that information economy developments should not be looked at as a quick fix, even in those developing contexts where they seem to be having the most profound impact and benefit. This is at least partly because they are overlaid on existing and deep human development deficits. This is a reminder that considerations of the information economy need to be contextualized in terms of economies as a whole, and, importantly questions of human development, that involve infrastructures such as health and education, which have substantial timeframes in relation to investment.

World Bank (2006) figures showed that while more than 400 million people were lifted above the $\$ 1$ dollar a day poverty level in the last 20 years in China, it was still home to 18 per cent of the world's poor with 150 million 
people still living on less than $\$ 1$ a day. Here we have stark evidence of how even the success stories of the developing world are an intrinsic part of the global inequality patterns. At the same time as bringing dramatic news of economic growth, they are also adding to the stock of the world's problems of inequality. The strains of hyper development are also evident in areas such as environmental impacts, with China having 20 of the world's 30 most polluted cities. The WHO (2006) points out how this adds to China's health burden as the world's second largest greenhouse gas emitter. 'The state of the environment in China is of major health concern that requires urgent systematic multi-agency, multi-sector and multinational response'.

China's progress on basic provision of fresh water and sanitation is significant but imbalances reflect its uneven geographical development, with 75 per cent of the population having access to safe drinking water, and sanitation improving from a low eight per cent coverage in 1993 to half of the population by 2005 , but with ' a huge urban rural divide' and only 10 per cent reached in some of the underdeveloped western regions (WHO 2006). Overall income inequality in China rose substantially from 28 per cent in 1981 to 41 per cent in 2006, working on the basis of 0 representing total equality and 100 total inequality (Gini index).

It is clear that even the developing economies that are the major success stories in information economy progress are suffering from the pervasive problems of inequality that characterize contemporary GPE. The UNDP Human Development Reports, published since 1990, have stood out as a resource tracking, documenting and commenting on this inequality, including its evidence in countries of the North and South, thus highlighting the degree to which this is, or should be, a common global concern. It can be regarded as a unifying factor across North or South, a phenomenon that could promise a politics that could connect interests amidst the overall inequalities between North and South that so deeply divide them.

The UNDP (2005: 38 and 272) reports that the majority of global income inequality - about two thirds - lies between countries, with inequality within countries accounting for the balance. The overall pattern of inequality for the world is 67 on the Gini yardstick with only one country, Namibia, showing higher inequality at 70.7. If we look across the Gini income inequality rankings, we can get a sense of some of the commonalities of problems of inequality across the vast divides of the global economy. For instance, the USA, one of the richest economies and highest ranking (10) in terms of human development, is 40.8 on the Gini index. This is much higher than Norway at 25.8, the highest ranking country for human development, and is the same as Ghana, classified as a medium ranking human development country, and far down the HDI rankings at 138 (270-2).

Not only is the problem of inequality pervasive and evident in rich as well as poor countries, so is the problem of rising inequality. Here we see the embedded nature of inequality in the dynamics of GPE. Regionally, Sub-Saharan Africa is at the top of the Gini table (72.2). Below are Latin 


\section{Borders and inequality}

America and the Caribbean (57.1), East Asia and the Pacific (52.0), Central and Eastern Europe and the Commonwealth of Independent States (CIS) (42.8), the high income Organization for Economic Co-operation and Development (OECD) countries (36.8) and South Asia (33.4). The UNDP cites a clear trend: 73 countries for which data is available, 53 (with more than 80 per cent of the world's population) have seen inequality rise, and only nine (with four per cent of the population) had seen it reduce. 'This holds true in both high- and low-growth situations (such as China in the first case and Bolivia in the second) and across all regions' (UNDP 2005: 55).

One of the major features of long-term inequality relates to gender, and, in addition to areas such as infant mortality, impacts on educational opportunities, access to nutrition and healthcare, as well as overall status. 'Gender disparities are among the deepest and most pervasive of inequalities' (UNDP 2005: 61; see also Youngs 2004b). Increasing attention is also being focused in recent times on the importance of intersections of disadvantage, as related, for example, to gender, ethnicity, poverty, social status, etc., including in the context of major threats such as HIV/AIDS, where it has been stressed:

low socio-economic status, lack of access to and control over empowering and emancipating resources such as land and property increases women's and girls' exposure to many dehumanising cultural norms, beliefs and practices that undermine women's and girls' emotional, spiritual and psychological well being, choices and agency, bodily integrity and self esteem and increase their vulnerability to HIV infection. ${ }^{4}$

Assessments of complex inequalities also draw growing attention to difficult issues of agency, and the diverse effects of different forms of inequality that inhibit the capacities of groups and individuals in societies to address their problems, access opportunities, envision alternative futures or act towards them. The gender empowerment measure (GEM) introduced in the UNDP's 1995 Human Development Report is one of the most important annual statistical means attempting to address some of this complexity. It recognizes broad participatory influences impacting differently on opportunity and voice in society between men and women. 'Worse outcomes for women in many aspects of human development result from the fact that their voices have less impact than men's in the decisions that shape their lives' (UNDP 2002: 23 - my emphasis). The GEM takes into account seats in parliament held by women, percentages of legislators, senior officials and managers, and professional and technical workers who are women, and ratio of estimated female to male earned income (UNDP 2005: 303-6).

It may surprise some that the GEM is not necessarily in any close ranking correlation to the HDI for each country. Japan, while ranked 11th highest in the HDI, is much lower in GEM terms at 43. Cyprus, while ranked much lower in the HDI at 29 is close to Japan in the GEM at 39. Italy is ranked 
18 in HDI but 37 in the GEM. Of 80 countries assessed for the GEM, Yemen, which is ranked among the low human development countries, comes lowest close behind Bangladesh and Saudi Arabia, which are ranked in the medium human development countries (UNDP 2005: 304-6). Such indicators disrupt deeply the simplistic traditional framing of successful development, predominantly based on rather crude factors such as gross domestic product. They highlight the need for more complex models of measuring human development that take seriously the relative opportunities that exist for different members of society, including on the basis of gender. They provide useful material for assessing how well or comparatively poorly even wealthy societies are doing in terms such as the GEM (Youngs 2004b).

Information society developments represent, as it were, other levels of complexity in considerations of inequality, but in many ways they also mirror, continue and further embed other existing inequalities. Globally, possibly the most stark continuation is the technological lead that the richest societies have over the poorest. This represents exponential gains in ownership and control of varied forms of expert knowledge, scientific and technical, as well as applications of it, with firms in developed countries accounting for virtually all of the royalties from patents -96 per cent amounting to $\$ 71$ billion a year (UNDP 2005: 135). Innovation and development related to the information sector is far from restricted to the richest economies, as the notable examples of China and India discussed here demonstrate. But the historical technological imbalance between North and South is continuing to have ongoing and significant impact.

Taking into account the role of FDI flows in development, not only is Africa's low figure of three per cent of world inflows notable, but also the dominance of its links to petroleum in major countries such as Nigeria and Angola, and to a lesser extent Egypt, accounting for 90 per cent, 93 per cent and 64 per cent respectively in 2004 (UNCTAD 2005: 42). Added to the importance of mining in Africa, the picture is one where the historical role of the region in providing vital commodities fuelling the global economy endures. While the rise in commodity prices linked to economic expansion elsewhere is a positive factor, the broader development prospects are less so: 'attracting FDI into the manufacturing sector in Africa is becoming difficult as competition grows from the other developing countries, particularly in Asia. Factors such as good physical infrastructure and appropriate human skill levels have become increasingly important in attracting FDI projects' (47).

This comment in 2005 is one example of how long-term development challenges are as alive as ever in GPE, and also how imbalances in development in the South, and the recent and rapid concentration of this development in the high growth economies like China add to the competitive stakes. The issue of skill levels, and education and training associated with them, have become all the more influential in the high technology orientation of the information economy. Beyond the stark and extreme inequalities across 


\section{Borders and inequality}

the global economy in this area, there are also concerns about the imbalances in even the most developed economies. Here again we come to the theme of inequalities within as well as between countries.

Participation in the information society, even as users of computers and the Internet, for example, reflects socio-economic and educational gaps. In the USA, for example, the number of households with computers has grown from 8.2 per cent of the population in 1984 to 61.8 per cent in 2003 , and those with Internet access from 18 per cent in 1997 to 54.7 per cent in 2003 (US Census Bureau 2005: 1). But the figures for different groups in society differ. In 2003 for households with computers, the estimate for families with annual income of less than $\$ 25,000$ was 41 per cent, compared to 83.7 per cent for those with an income between $\$ 50,000$ and $\$ 74,999$, and 94.7 per cent for those with an income of $\$ 100,000$ or more. For Internet access at home in the same groups the figures were 30.7 per cent, 77.9 per cent and 92.2 per cent respectively.

In education levels, of those with less than high school graduation 27.9 per cent were estimated to have computers at home, compared to 51.1 per cent for high school graduates and 81.9 per cent for those with a bachelor's degree. Internet access at home was put at 20.2 per cent, 43.1 per cent and 76.8 per cent respectively (US Census Bureau 2005: 2). Inequalities in computer ownership across age and ethnic groups have also been noted, with only 35 per cent of householders aged 65 and over, and around 45 per cent of Black or Hispanic householders having computers in the home (3).

A UK government report (DTI 2005: 1-13) was triumphant about rapidly expanded broadband use and access, and expansion of e-business, with UK businesses assessed as being amongst the most sophisticated users of ICT in the world, competing with the other leading economies, and Australia, Ireland, South Korea and Sweden. But the report also highlighted the need to address a digital divide where the richest in society were three times more likely than the poorest to have access to the Internet in the home (24). Increases in take-up of home Internet had been concentrated in the mid- to high-income groups, with the rate of connection among the lower groups remaining around 20 per cent since 2001 (24). Around 40 per cent of children were estimated to have no home access to the Internet and single parent households were significantly less likely to have this access than homes with two adults (25).

The digital divide, according to the report, was heavily linked to knowledge about the technologies and what they could offer, with more than half of adults who were non-users of the Internet stating that they did not want or need to access it or did not have an interest in doing so. 'Research evidence shows that improving access can help to some extent in bridging the digital divide. By far the biggest barrier to accessing ICT is interest and motivation, followed by a lack of perceived need' (DTI 2005: 24). A total of 35 per cent of the non-users said they lacked the knowledge or confidence to use the Internet, and operating costs and the complexity of computer packages were 
other negative factors cited (24). The conclusions were that education, information, support and easy access to ICTs were essential to achieve inclusion of low-income groups in the digital world (25).

\section{The realities of inequalities: beyond neoliberalism?}

The illustrative points raised here indicate the breadth and depth of inequalities that dominate in the global economy, most dramatically between the richest and the poorest countries, and sectors of society within individual countries. With regard to the overall pattern and problems of inequality, the information age is yet another unfolding of the old as well as the new. Digital divides are yet another layer of the existing and historically influenced range of divides (socio-economic, gender, etc.) that have characterized GPE. As things stand the digital future is a highly unequal one, as is the broader economic picture at the beginning of the new century. Deepening aspects of inequality are definitely one of the darkest characteristics of contemporary globalization, and it could be argued, its most problematic and daunting.

If the information age is about a greater focus on knowledge, then it seems that part of that focus should be on the problems of complex inequality both across and within North and South, and within individual societies. Information developments also indicate that there can be different kinds of winners and losers and contrasting elements of progress. The extraordinary leap in China's economic growth, and India's to a lesser extent, as well as their participation in the information economy, have been covered as major examples in this context. The concentration of flows of FDI globally may have contributed strongly to such success stories, but they have also contributed to the deficits that have occurred elsewhere.

The evidence about growing trends in global inequality has been gathering since the latter part of the twentieth century. I would argue that it is now sufficiently accumulated and weighty to destabilize the ideological fix of dominant neoliberalism on the goal of equality in specific ways. There is unbearable tension between the hard material facts of multiple forms of inequality, and the blindness to them, which the perpetual focus on equality as ideal appears to generate. Few if any of us would object to the goal of equality for all, and it is fair to assume that it is a fundamental part of the success and appeal of liberal and neoliberal ideology. ${ }^{5}$ However, inequality is so much a result of neoliberal policy and development (as well as other factors) at global and local levels, in North and South, that any focus on equality has to sit more squarely alongside attention to inequalities.

The information age is likely to be about confronting the contradictions of neoliberal aims and results, and it is possible that if the problems of inequality are foregrounded more, a far more sophisticated and complex approach to the goal of equality may result. There should probably be much more political and economic debate about the means of neoliberalism, and its byproducts globally and locally, as well as its ends. Development may 
have spread, and with staggering speed in certain areas, and the information economy may have expanded the potential for new products, services and connections. But the positives are also accompanied by many negatives, and, equally importantly, age-old problems such as extreme poverty, avoidable disease and death, malnutrition, and lack of access to education, often with unequal impacts on women and girls as compared to men and boys.

The wealth of problems of inequality, their interconnections and their often as yet little understood complexities, clearly need to be a central concern. And, I think, we have to ask whether contemporary proponents of neoliberalism, as it manifests itself especially in international and national policy realms, are either unwilling or reluctant to do this sufficiently, and if so, why? It is uncomfortable to focus on how unequal the world has become, it is perhaps depressing and overwhelming. But we should think about how necessary this may be, including with regard to the digital divide, which is yet the latest layer of inequality in technological development of the economy.

Would such a focus take us beyond neoliberalism or to a different kind of neoliberalism perhaps? This is a core question in contemporary GPE. Commentators like Ronaldo Munck address it in terms of social exclusion, including as it applies to the long-term exploitation of the poorest economies in the world.

The concept of social exclusion allows us to break definitively with the economistic and individualistic parameters of traditional conceptions and definitions of poverty. It does not focus on individuals but rather on the social relations that create and reproduce the complex processes of exclusion/inclusion that lie at the core of contemporary capitalist society ... social exclusion in the era of globalization must necessarily focus on the international relations of production, trade, migration, technology, and so on that structure the uneven development of capitalism on a global scale.

(Munck 2005: 30-1)

Such an approach has many distinctive qualities, not least among them a deep sense of history, and historical injustices and their implications for the times we live in. The information age, with its stress on technological advance and imagining, is perhaps a more future oriented stage than any which has come before in GPE. The risk that we may lose sight of history could therefore be more pressing than ever. However, the complex of global inequalities steers us towards not doing so. In fact, it may encourage us towards a reversal of that, towards actually placing more attention on history, rediscovering it and rethinking it.

In a way, we could look at aspects of the global social movements attacking the shortfalls and negative sides of capitalist development, as in part prioritizing our sense of the past as much as the present, and the extent 
to which the past has made our present. One perspective on this is that in pressing the transnational and global in their modalities, they are pushing us beyond 'methodological nationalism', ${ }^{6}$ to a new sense of causal connections and social justice across rather than within boundaries. These movements, and the formal and informal organizations associated with them, have in some senses found a natural home in the cross-border transnational virtual realm of ICTs.

The technological networks and infrastructures, and their material manifestations, have mapped well onto the political and connective processes of such movements. It is possible to view the development of the latter as being intimately connected with and interwoven with the development of the former. The use of ICTs as an intrinsic part of the politics and strategies of social movements and organizations has contributed to the whole understanding of what (critical) globalization is. Included in this are ideas linked to horizontal as opposed to vertical forms of political activity and communication, to bottom-up rather than top-down processes. As one framing of the WSF argues:

The Forum opens up from time to time in different parts of the world with one key objective: to allow as many people, organisations and movements as possible that oppose neo-liberalism to get together freely, to listen to each other, to learn from the experiences and struggles of others, to discuss proposals for action and to become linked to new networks and organisations that aim to challenge the present process of globalisation dominated by large international corporations and financial interests.

(Whitaker 2006: 68)

This kind of activity in opposition to neoliberalism can be read as follows. A starting point for working to get beyond its current crisis of inequality and exclusion may be to find ways to actively listen to and consider alternative voices, and transnational political participatory practices: to expand the horizontal influences on its vertical (political and economic) structures and processes. While these voices and practices do not have the formal status of national political settings, they do mirror in some vague ways the transnational linkages and workings of GPE. Their informalities and fluidities are part of their political experimentation, and it may be that they are an important signal of the need for increasing horizontal (rather than just vertical) perspectives on the current conditions of global inequalities. 


\section{Embedded patriarchy \\ Feminism and inequality in the Internet era}

Gender inequalities are a dominant feature of contemporary globalization and the information age demands that we revisit them in some fresh ways. While taking account of historical structures and patterns of oppression, these should recognize that new orientations may also be necessary. This chapter considers embedded patriarchy in the information age. The notion of embedded is used here in the spirit of this book's focus on continuities as well as discontinuities, as is the contested concept of patriarchy. When we think of aspects being embedded we recognize that there may be layers upon layers of effects over long periods of time. The first straightforward point to make is that the information age has dawned in a setting of widespread and historically entrenched and differentiated forms of inequality encountered by women and girls. I want to begin this chapter by developing further the consideration of these traditional forms of inequality.

Then I continue on to look at feminist perspectives on the political economy of time ${ }^{1}$ as illustrative of how gender inequalities are being perpetuated in complex and under-explored ways, and how these can only be understood through a lens that takes into account historical patterns of gender relations to technology. The use of the term embedded is also intended to keep to the fore the interaction of different forms of inequality (economic, political, etc.) in understanding not only structures and processes of gender inequality but also how they impact on dominant patterns of gendered identities.

Patriarchy is a useful concept because it maintains a historical sense of gender inequalities, and how they have operated in and incorporated both public and private spheres. It also indicates a system of oppression, which is institutionalized in social and cultural norms and practices that contribute to the formation of differentiated male/female identities and roles. Such norms and practices structure and represent gendered power, predominantly with the man or masculine roles in the subject position and the woman or feminine roles in the object position. The concept of patriarchy has been a theoretical, political and consciousness-raising tool for feminists to explore, understand and campaign against the injustices and disempowerment that frequently result for women from this subject/object positioning. 
The specificities of patriarchal forms differ across time and social and cultural contexts. Also colonial settings indicate ways in which patriarchal influences from different contexts can be mutually reinforcing, or operate alongside one another in a colony. ${ }^{2}$ So patriarchy is not one monolithic idea, but the controversies around it do include consideration of whether it is too simplistic and unifying to fully explain gender power dynamics.

This kind of criticism of patriarchy is justified in my view. It cannot be the beginning and end of feminist analysis, but its relevance endures as a broad-brush concept that takes account of the enduring and multifaceted expression of institutionalized masculinist power in societies across the world. As Ara Wilson points out:

Whereas the widespread use of patriarchy in feminist analysis has declined, the insights that the space of patriarchy allowed continue as key understandings of feminism: the idea that certain seemingly private and individual interactions, events and emotions - rape, sexual harassment, psychiatric diagnoses, and self-sacrifice - are in fact stratagems of a larger system predicated on male-female difference and inequality.

(Wilson 2000: 1496) ${ }^{3}$

\section{Global gender inequalities}

Global statistics indicate that gender inequalities remain pervasive in GPE, especially if equality of participation and opportunity are taken into account. The UNDP measures gender-related development according to life expectancy at birth, adult literacy rate and combined enrolment ratio for primary, secondary and tertiary education, as well as estimated earned income. Many countries across the world rank lower on the Gender Development Index (GDI) than they do on the HDI. Those where the difference is greatest in this respect include Saudi Arabia, Peru, Lebanon, Pakistan (UNDP 2005: 300-2).

The GEM, which measures participation and influence of women in societies, shows that even in those with the most equality for women, there remain significant shortfalls. For example, Norway, which is at the top of the HDI, GDI and GEM rankings, has only 38.2 per cent of parliamentary seats held by women and 30 per cent female legislators, senior officials and managers. In Israel, which ranks 24 on the GEM, the figures are 15 per cent and 29 per cent respectively; in Hungary, which ranks 44, 9.1 per cent and 34 per cent; in Turkey, which ranks 76, 4.4 per cent and 6 per cent (303-4).

The GDI and the GEM have dramatically changed the terms of consideration of the whole issue of gender inequality in GPE, by beginning to gather and present detailed comparative statistics, where available, about the different roles, status and opportunities for women as compared to men in societies around the world. These are only indicative of overall gender inequality, but they are changing the grounds for debate by concretizing how 
inequality manifests itself. The limited voice of women, for instance in political processes (where national parliaments are key), and in senior legislative, official and managerial roles, indicate not only the current state of affairs, but the likely pattern of the short and possibly medium-term future, bearing in mind how slow change might be to come about.

Earned income inequality is another area covered by the GEM. This has been a major area of inequality for women, not least because of their unpaid nurturing and socially reproductive roles as mothers and carers, in addition to their frequently differentiated lesser job functions and pay in the workplace. The ratios of female to male income are a graphic and clear demonstration of embedded inequalities even in the most gender empowered societies. For example in Norway the estimate is 0.75 per cent, in the USA which is ranked 10 and 12 respectively on the HDI and GDI, 0.62 per cent, the same as both the UK, which is ranked 15 and 18 respectively on the HDI and GDI, and Hungary. The ratio in Israel is estimated at 0.55 per cent and in Turkey 0.46 per cent.

The GDI and GEM provide some evidence of general inequalities between men and women. These impact not only on their economic and political conditions of existence, but also their life chances and opportunities. Dominant structures in GPE across countries can therefore be mapped in patriarchal terms, even if we accept that these are highly generalized. They will differ and be contradicted dramatically for certain individuals and groups in particular circumstances and locations. Gendered relations with technology represent another layer of inequalities, which have general relevance. These also need to be treated with the same provisos about variations across different groups and individuals in societies.

The broad technological inequalities across North and South discussed in earlier chapters provide the backdrop to considerations about gender and technology. I concentrate below, in addition to some general points about historical patterns, on the political economy of time, for two major reasons. As well as representing one of the most abstract areas of experience, and thus among the most difficult to address, it is also one of the most underinvestigated generally, as well as in relation to gender questions. It is an obvious statement that time is an intangible aspect of existence, but this does not mean that it is outside politics and economics. Indeed, as I have already examined, it is at the heart of GPE in the information age. As such, I now want to consider how it is integral to thinking about gender inequalities. Let us begin by thinking a bit more about the pervasive importance of time and speed across different facets of life in the information era.

\section{Time and the experience of it}

James Gleick (2000) subtitles his book Faster, 'the acceleration of just about everything' capturing neatly how technologically driven existence is leading to a speeding up across the board, lives lived at break-neck speeds, measured 
in ever smaller and smaller fragments, and as a result with intensities of experience previously unknown. ICTs have heightened instantaneity and intimacy over distance as factors of everyday life, whether we are talking about stock market exchanges, access to information or professional and affective networks. ${ }^{4}$ The old idea of 'time is money' rarely gets mentioned these days as time becomes everything, a pervasive aspect of how people think about what they do, as multimedia and mobile ICT environments allow them to live as much in virtual spaces as well as actual places, and in diverse forms of synchronous and asynchronous social connections, near and far.

This pervasiveness, especially in richer economies, relates to leisure (including consuming) time as much as work (producing) time and ICTs diverse roles across both increasingly blur many of the boundaries between them. The Internet era has fast become the broadband era, with the emphasis upon more and more information, particularly multimedia material, being delivered faster and faster, including to mobile devices. Time as a core concept of high-tech contemporary societies is directed towards how to keep everything moving (e.g. data, money, goods, ideas) and connected in a dynamic situation, where people need to be constantly on the move too. Real time ${ }^{5}$ is here and now but it also incorporates the virtual networks that link as instantly to other sites of the here and now, and offer the means by which decisions, etc. can be effective and enacted across them. In the information age, the value of time cannot be underestimated. Not only as an intrinsic dimension of understanding how ICTs are contributing to change in GPE, but also identities (work, leisure and otherwise), including gendered identities.

In investigating the premise that social time is gendered, I argue for thinking of the gender matrix of time, and how it is mystified via the dominant patriarchally informed frameworks of social science. A central question under consideration is: Why and how is it important to consider time as gendered? A second is: What does such analysis tell us about the world? This assessment addresses both questions in direct relation to technology and globalization. Understanding the gender matrix of time contributes to detailed explanations of the linkages between technology and processes of globalization.

While ICTs and their expanding roles in the organization of societies and business have intensified analytical attention to the interrelated phenomena of time and space (Giddens 1991; Lash and Urry 1994; Deibert 1997), the predominant fix has been on time and space in public sphere fashion. The capacity of ICTs to restructure relations of time and space is at the heart of the story of globalization. The utilization of ICTs by companies has contributed directly to the development of a global market, in which the rationale of organization can be maintained over increasingly dispersed sites of production, exchange, distribution and consumption. The global financial market is the icon of the ICT era: a round-the-clock realm of virtual exchange linking a chain of 'core' cities - New York, London, Frankfurt, Paris, Tokyo, Hong Kong etc. (Agnew and Corbridge 1995: 206; Cerny 


\section{Borders and inequality}

1995; Diebert 1997: 147-55). But this is very much the public patriarchal face of ICTs and globalization. What about 'everyday life' (Cockburn 1997: 362) and ICTs? How do we access that story, and how can it deepen our understanding of processes of globalization? What does the hidden political economy of time tell us about the nature of inequality with regard to these processes? In what ways is it gendered and why and how can these be identified?

One strategy for beginning to answer such questions is to connect insights from feminist work on the separate areas of technology and globalization. In both areas the detail of masculinist logics underpinning and legitimating patriarchal paradigms, structuring science and technology and political economy respectively are revealed and criticized. By drawing on these forms of analysis, it is possible to link the theories of science, technology and political economy to the practices, which apply them and help to perpetuate them as given and sufficient explanations of social reality. These explanations, while being partial (particular), masquerade as complete (universal) because of their dominant status. Feminist critiques challenge these depictions, effectively revealing the hidden gendered social dynamics veiled by these masculinist truth claims. These dynamics concern two major temporal contexts: long-term historical developments; and present senses of time use, where time is understood as a resource in social life.

\section{The gender matrix of time and embodied political economy}

The term matrix suggests a number of elements, which make up a whole. It is useful in relation to the conceptualization of time because it reminds us that there are different forms of social time, but that they fuse together as a whole in life experience. The two major forms of time - historical ${ }^{6}$ and present - are both shaped by technology and political economy, and can both be interpreted as gendered. Historical and present time are themselves general categories, each composed of different forms: ancient and contemporary history, for example, and the present time of clock, calendar and lifespan. Examination of the links between technology and political economy could reach back into the farthest depths of historical time, and touch on all the aspects of present time referred to. I concentrate here on the contemporary history of modern industrial and post-industrial capitalism, and the rationalized and embodied present time experiences of it.

Investigations of temporality automatically provide us with an embodied approach to technology and political economy, if we are thinking about human experience. Time may be abstract, but it is concretized in the memories and bodily experiences of it (Lash and Urry 1994: 238-9), as well as in the social articulations of it in historically established forms such as institutions, discourses and relations. Embodied political economy is gendered political economy (Youngs 2000d). To recognize political economy 
as embodied is to challenge the abstract rational-actor model that characterizes traditional masculinist perspectives (Hooper 2000). This model offers a particular interpretation of the social reality of political economy as a universal encapsulation of it. The particularities and abstractions of the model are closely connected, and present a reductive picture of political economy. It bounds consideration of social dynamics within the so-called public realm of political and economic institutions and decision-making. The linkages between that realm and the so-called private sphere of domestic/ home life, social reproduction and care, are left out of the picture, omitted as if they have no relevance to explaining the workings of political economy (Youngs 2000b).

The analytical vacuum left by such restricted framings has been stressed by a wealth of feminist work (see, in particular, Harding 1995; GibsonGraham 1996; Kofman and Youngs 2003). I have argued and illustrated (Youngs 1999a and 2000a) how this work is gaining new purchase in an era of globalization, where the boundaries of political and economic spaces are a pivotal category of investigation. The loose and generic concepts of state and market are coming under scrutiny, as part of efforts to gain understanding of processes of globalization, and how they are affecting political-economic interactions (Agnew and Corbridge 1995; Sassen 1996; World Bank 1997; Youngs 1997b). Social space, rather than being ignored or taken as given, is recognized as integral to understanding power relations and practices. ICTs, as explored in Section 1 of this book, have emphasized the sociospatial as much as geospatial sites of these.

John Agnew and Stuart Corbridge (1995: 14) have argued: 'To understand the world ... requires that we understand its changing geography'. We need to recognize that 'the human world is open and changing and the precise relationship between objects and the spatial fields that contain them is dynamic'. The problem is that dominant masculinist sensitivities to space maintain the mythology of public social space abstracted from private social space. Their notion of the dynamics of spatiality is reductive and particular. Feminist perspectives offer a deeper sense of social and spatial dynamics, that aim to incorporate public/private linkages and, importantly, their changing characteristics. These issues are identified as central to understanding processes of globalization (Youngs 1999a; Marchand and Runyan 2000).

The embodied nature of political economy is illustrated in various ways by such forms of analysis. In a mode far distant from the abstract rationalactor model, they negotiate gendered lived experiences across public/private boundaries. In effacing the relationships between public and private, the rational-actor model takes patriarchal power as given, via a number of mutually reinforcing moves. The concept of actor is inherently the male actor of the public world. The attachment of the category of rationality to this actor reinforces this identification through the dualistic association of man with rationality and woman with irrationality common to Western traditions of thought (Peterson 1992b). Neither the actors nor their sphere of action, 


\section{Borders and inequality}

and both are important, are gender-neutral in the rational-actor model. They are infused with male gender and categories associated with it, and as such actively contribute to an understanding of the world where patriarchal power, its purposes and its effects, are in place. The gender distinctions of that power are veiled by the model. It does not account for them, and indeed presents itself and the world as if there is no need to. Questioning patriarchal power is simply not on the agenda. Its place is an embedded and assumed aspect of social reality.

Feminist analysis looks at the gendered underpinnings of the rational-actor view of the world. It exposes its coherence as a myth, and focuses on the gender inequalities that make the appearance of such coherence possible. From this discussion it is clear that I would build consideration of power/ knowledge issues into assessments of the gender matrix of time. It is the historical power of masculinist interpretations of political economy that is being contested by feminist interrogations. The contest is as unequal as the gender relations at issue, and the weight of influence of dominant perspectives over historical time, as well as in the present, contributes to their ability to hold firm. Feminist social critique is working to loosen the patriarchal grip on time. The spatial and embodied revelations of feminist political economy lay important groundwork for this difficult endeavour. They indicate the multiple fronts on which attacks on the abstractions of the rational-actor model can be launched. They also establish firmly the bases for a detailed critique of the partial sense of temporality that the model utilizes. These include public/private linkages that bring into relation the worlds of public production and social reproduction.

In the rational-actor model the world of public production is abstracted and designated as quite distinct from the world of social reproduction. The former is captured through political and economic categories associated with the institutions of state and market. It is granted status through the definition of work as paid work in the public sphere as opposed to unpaid work in the private (domestic) sphere. Nancy Folbre (1991) has explored how the classification of women's work in the home as a historical process is associated with capitalist developments. Through the study of population censuses in England and the USA, she has traced how women who were considered productive workers in 1800 came to be viewed by 1900 as dependants, along with children and the elderly (Folbre 1991: 464). This was linked to 'men's demands for a family wage'.

Ironically, the moral elevation of the home was accompanied by the economic devaluation of the work performed there. The growth of wage labor, which separated individuals from traditional family-based productive units, almost inevitably wrought new concepts of productive labor. Goods that could be bought and sold, quantities that could be expressed in dollar terms, became the new arbiters of value. Indeed, the growing enthusiasm for social statistics, reflected in new census-taking 
efforts, deflected attention from activities that could not easily be reduced to a money metric.

Over the course of the nineteenth century, work once performed within patriarchal households under the authority of fathers and husbands was gradually, but only partially, supplanted by the growth of an impersonal market-place in which the labor power of individuals was bought and sold like any other commodity. Single women entered the labor force in large numbers, but most left upon marriage.

(Folbre 1991: 465)

\section{The rationalizing of time and patriarchal constructions of time}

Folbre's form of analysis locates the interrelated transformations of public/ private spheres as intrinsic to the historical development of capitalism. It links the process of valuation of forms of work outside the home to the process of devaluation of work inside the home, and clarifies that the distinction lies between paid and unpaid work, in capitalist terms. Government informationgathering, and the experts associated with it, are implicated in legitimizing and naturalizing changes as 'objective' that in actuality relate to 'socially constructed concepts ... laden with cultural and political values' (Folbre 1991: 463). The commodification of work under the capitalist system has instituted highly complex mechanisms associating time directly with financial reward. These include configurations of hourly, weekly, annual pay levels and measurements. The rationality of capitalism is configured in substantial part through the rationalizing of time. The major division of time has been between work and leisure - between production and consumption (Lash and Urry 1994; Ritzer 1998). Monetary articulations of time are captured by all four terms. Work is time spent earning money by producing goods that are sold for money; leisure is time spent consuming products that cost money. Both production and consumption are 'depersonalized' activities.

It is under wage labor that the separation of work and nonwork takes a particularly stark and clear form, where payment marks a strict distinction between work and leisure time. Second, the production of commodities for exchange has allowed the most complex and detailed division of labor in history to be carried out. Finally, because manufactured commodities are produced for the market, rather than for any particular consumer, and bought from the market, rather than from any particular producer, their origin becomes intrinsically irrelevant; everything relevant to their consumption must be embodied in their characteristics as a product. In this way, the activity by which a commodity is produced is depersonalized, that is, made separable from the person who performs it, mirroring the depersonalized exchange that forms the wage-labor relation. It is thus under the relations of capitalist 


\section{Borders and inequality}

wage labor in manufacturing that these three characteristics of 'work' take their quintessential form.

(Himmelweit 1995: 4-5)

The divisions between work and leisure, production and consumption obscure the continuities across them. It is more accurate to view the workleisure, production-consumption, relationships as continuums, where capitalistic forms of rationality (organization) have increasingly constructed all types of social experience.

Technologies, including ICTs, have both enabled and been symbolic of the rationalizing tendencies of capitalism, and the globalizing processes that have characterized its geographic spread (Youngs 1997a and 2000c; see also J. Webster 1999). Dominant social (including academic) attitudes to technology, have reflected the public over private hierarchy of rational-actor models of state and market. Technology is generally taken to refer to the applications of scientific and engineering knowledge to the pursuit of state and market goals of defence, production and consumption. This can lead to discourses of globalization, which basically celebrate 'the transnational triumph of the technological imperative' (Youngs 1997a: 31; see also Youngs 1996). A notable example is the Francis Fukuyama (1992: 126) 'end of history' thesis that posits a 'global culture' based on 'a technologically driven liberal political economy' (see also Youngs 1997a: 31).

The Fukuyama thesis makes the historical significance of technology explicit. It is identified as a central and continuous social force in modern times, expanding the reach of capitalism in the context of a liberal political economy, which, in Fukuyama's idealized senses, offers to meet human needs, material and non-material. Such mainstream approaches to technology define it as part of an ideology of progress (Youngs 1997a: 34-6). Time is measured principally on an evolutionary basis with regard to technological progress. Interest in socio-historical circumstances is reduced to those which relate directly to the perceived existence or lack of such progress (36). This grand sense of historical time in relation to technology, is intimately connected with the more immediate sense of time that the applications and uses of specific technologies bring into play. Scott Lash and John Urry (1994: 241-51) refer aptly to the first as 'evolutionary or glacial time' and the second as 'instantaneous'. While the first, concerning the incremental and centurieslong mastery of nature, has been an 'imperceptibly changing process', the second is 'based upon time-frames that lie beyond conscious human experience' in the electronic realm of nanoseconds (241-2).

The problem is that both forms of time, evolutionary and instantaneous, are mutually reinforcing in their patriarchal partiality. Through complex social structures, patriarchal control over evolutionary and instantaneous temporalities has been maintained. The scientific knowledge base, from which advanced technologies develop is part of the explanation. Patriarchal institutions of state and market steer scientific and technological developments. 
Dominant attitudes recognize only what Hilary Rose (1983: 73) has termed 'the distinction between the manual and mental labor associated with production'. They exclude 'the sexual division of labor in which caring labor is primarily allocated to women in both paid and unpaid work'. Rose argues for 'transcendance of this division of labor set up among hand, brain, and heart'. She also discusses the social processes constructing 'the family wage' which 'emerged during the nineteenth century in the most unionized and better-paid sectors of the economy [and] served to improve the conditions of an entire class fraction - but at the price of enforcing women's and children's dependence on men' (84). And, she stresses, despite the contemporary increase in single-parent families 'the family wage retains its ideological grip' - my emphasis (85).

One of the interesting things about this kind of approach is the way in which it encourages us to integrate perspectives on science and technology, capitalism (the labour market and divisions of labour) and wage/time/ value questions. The ideological linkages across these areas and issues help to explain the detailed nature of the gender matrix of time. An important common theme is 'systems of production - the production of things and the production of people' (84). Rose maintains that there is a 'dialectical relationship', for example, between the limited participation of women in science ${ }^{7}$ and the 'abstract and depersonalized' forms of knowledge it produces.

From a feminist perspective, the approach to evolutionary time should cover scientific and technological developments and capitalist transitions, which have asserted, celebrated, and socially instituted particular patriarchal notions of production. These locate production and, vitally, its associated values, in the public and formalized worlds of knowledge-generation and work, which are abstracted from the so-called private worlds of social reproduction and care. A major path to our understanding of gendered time is the dimension of 'value': the patriarchal social value attached to these public forms of production. This value is expressed in multiple ways: financial reward, status, recognition, institutional priorities, to name a few.

This value is part of the social construction of the public-over-private hierarchy, representing a continuous restatement and reapplication of the patriarchal ideology that maintains it, through the diverse areas of social life over time. The whole expression of evolutionary time, with its emphasis on the value of public forms of production, is a key transmitter of that ideology and its historical continuities. In very concrete ways, social reproduction and domestic care, their value and the value of the time spent on them, stand outside this dominant strand of historical understanding. Such are the processes by which the history of women and their direct social contribution (in the private sphere) to the public forms of production that are validated become effaced.

The sense of time as a resource is defined in particularistic fashion by the public-over-private patriarchal hierarchy. There is a real hierarchy of public time over private time, the latter, in the form of social reproduction, 


\section{Borders and inequality}

is in the service of the former. Its temporal relevance is directly bound to, and subsumed within, the value contained in public forms of production.

This is partly why women can feel they do not 'own' their time, that they are not in control of it, or that it should first and foremost be used in the service of others, and that it is most legitimately, in society's terms, used in this way. Women are thus, through the historically produced patriarchal conditions of their existence, alienated from their own time. Susan Drew and Ruth Paradice in their research on how women felt about their time found that:

In women's accounts time was talked about as if it were a scarce commodity which they did not own. Women's time appeared to belong not to themselves but to all the other people in their lives who were dependent on them and was discussed as if it were a kind of currency which could be 'given' to tending the needs of others and could be 'spent' on activities such as work, housework and childcare. These ways of using time were considered legitimate and appropriate. However women did not feel the same about 'spending' time on themselves, even though they frequently reported feeling desperate to have the opportunity to become involved in activities that were purely for themselves.

(Drew and Paradice: 1996: 563-4)

Women's time then is primarily socially defined as relational in two main ways. First, it is relational by being directed to the care of others, first and foremost the family. Second, it is relational in that this role of social reproduction is directed to the service and maintenance of the public world of production. In this dual manner women are socially separated from their own time. It is placed at the service of others (the family) and, more widely, of patriarchal society as a whole.

Autumn Stanley's (1992: 194-6) arguments about the relation of women to invention and technology are interesting in this respect. She locates the public/private divide again as central to understanding why invention tends to be associated primarily with men. She points out that 'professionalization' and 'commercialization' were developments characterized by men taking over technological invention in areas where women had held sway, such as horticulture, pottery and herbal medicine. She emphasizes the importance of both reclaiming a history of women's invention and encouraging its expansion in contemporary times.

Stanley considers the argument that women are oriented more towards the invention of immediate and practical applications, while men are oriented more towards the visionary. While recognizing the problem of the stereotyping involved here, she raises the issue of the availability of time to men 'and more licence from society and more freedom within families - for play than ... women. This includes intellectual play' (Stanley 1992: 198). Stanley makes a straightforward but powerful point: 'Freedom from distraction is 
as important as time itself. If a man wants to go fishing or retreat into his study to work out an idea, his wife will keep the children occupied while he does so, but the reverse would still be surprising'(198).

Of course such a point relies on fairly firm boundaries around stereotyped roles, and these have undoubtedly been subject to some change in certain circumstances, especially with the involvement of increasing numbers of men in childcare, for example. There are also for both genders questions of class or socio-economic circumstances to be borne in mind too, with regard to the amount of available time. Nevertheless, the overall emphasis applies in relation to my points above about the alienation of women from their own time. If women do not feel they own their time, because of the patriarchal conditions of their existence, if they do not feel that time as a resource is primarily theirs to use for themselves, but rather for others, then it is a logical result that their predisposition towards a feeling of time to think creatively, playfully, intellectually, is likely to be highly restricted if not non-existent.

As Stanley's explanation and other aspects of the arguments presented here indicate, freedom from distraction is a socially constructed phenomenon: often for men at the expense of women's time (see also Stanley 1993). The service functions that are predominantly performed by women in the home, and in various jobs (such as secretary and clerk) at work, represent the expenditure of women's time to allow predominantly men particular kinds of temporal freedom, including to act and to think playfully and creatively.

\section{Time in the service of others and gendered technologies}

It is worth addressing the question of immediacy that has come up directly and indirectly at various stages in this discussion. The focus of women on the legitimate use of their time in the service of others provides them with an immediate practical preoccupation outside of themselves. Creative, playful, intellectual thought requires, in important respects, an internal focus on the legitimate use of time for one's own purposes, and some perception, at times, that this freedom from external distraction is within one's control and can be extended, at least to some degree, at one's desire. These are generalized statements, of course, and thus have mainly indicative purchase. They are useful, however, for helping us to think about the contrasting conceptual timeframes that form part of the gender matrix of time. There are patriarchal grounds for arguing that the external pressures on women's time not only work to intensify their focus on the present, but are also instrumental in providing the social space which permits men's time to be spent on creative, intellectual thinking towards the future.

These aspects can be pursued further in terms of women's relationship to technology. Work on gender and technology has highlighted the mutually constitutive relationship between technology and gendered roles and identities. 'Gender ideologies play a central role in human interactions with technology, and technology in Western culture is crucial to the ways male 


\section{Borders and inequality}

and female identities are formed, gender structures defined, and gender ideologies constructed' (Lerman et al. 1997: 1; see also Youngs 2004a). The hardware of technology, its applications and uses, and the knowledges that originate and support them, are infused with gender, as indeed is the history of technology itself. This history has been largely written in ways that express the exclusions of women and their experiences described above.

Attention to gender not only exposes the bases of those exclusions, but also how they are constructed and maintained over time. In very fundamental ways, technologies are gendered and their relative status as technologies is affected by this gendering. ${ }^{8}$ Thus, the technologies associated with the private realm of domestic work and social reproduction, have not been granted the social status of technologies associated with the public realm of science, defence, and industrial and post-industrial capitalism. Recalling my emphasis on the private serving the public, technologies associated with the former are given inferior status, to the extent that in any general sense of the word they are often disregarded as technologies at all. Their role is to service the demands of the technologically driven sphere of the public world.

It therefore tends to be viewed as unproblematic within patriarchal structures that domestic and reproductive technologies, which primarily involve the lives of women, should be substantially controlled by men, both with regard to their development, and, in the case of reproductive technologies (Haraway 1997b and Zalewski 2000), their application. Cynthia Cockburn (1997: 361) has articulated clearly how public/private dichotomizing has contributed to the home (household) being viewed as 'nontechnological', in turn rendering 'its particular [domestic] technologies relatively invisible'. ${ }^{9}$ Thus for Cockburn the public/private (male/female) dualism historically has been matched by a 'technology/nontechnology' one.

Joint research in which she was involved (Cockburn and Fürst-Dilić 1994) examined the developmental and commercial processes, contributing to the social construction of such oppositions. While engineers found 'brown goods' (televisual, audio and camera equipment) 'state of the art' and 'challenging', 'white goods' (cookers, fridges, washing machines etc.) were regarded as 'simple' and 'uninteresting' (Cockburn 1997: 363). 'White goods are equated with family consumption and hence a female user, and this is what in part confers low value' (363). But despite this situation the research still found the design of white goods to be a male domain where 'real women' were 'elusive' (366).

The gendering of the development of domestic technologies also reaffirms the time hierarchy discussed above, where male access to creative futureoriented thinking time is privileged over and facilitated at the expense of female time. Domestic applications are, as it were, an afterthought. They tend to be an offshoot of major technological discoveries. 'Microwave cooking for instance was a serendipitous byproduct of radar. ... The technological potential comes first, applications second.... Often the market the technologists see as ripe for exploitation is the household' (Cockburn 
1997: 366). Domestic technologies have always been identified in part as time-saving, but we can begin to understand the complex political economy of that term only through the public/private social hierarchy.

Whether or not we would want to argue that women's relationship to technology is primarily defined by the service role of (nontechnologically defined) domestic appliances, it is evident that this relationship is mirrored in their association with technology in their service roles in the public realm of work (Runyan 2003). The typewriter and more recently word-processor and computer are technological motifs in this respect. But so are the nimble fingers that make women such a major part of the electronics production industry, particularly in the developing world (J. Webster 1995; Harcourt 1997). The point I want to stress here is that the gendering of technology, while strongly reflecting public/private (male/female) distinctions in society, also reflects how patriarchal power is, via particular processes, mutually constituted across public/private boundaries.

In industrialized countries, time-saving domestic appliances have, at the same time as making household work easier in many respects, also facilitated the feminization of the workforce, which has intensified in the ICT-driven service era. ${ }^{10}$ The issue is therefore not of time being saved, but time being saved for what? One important consideration when answering such a question will be the gendered nature of conceptualizations of time as a resource. I have argued that women are predisposed to see their time as a resource to serve others, and that this is mirrored in working roles inside and outside the home. The relationship of women to time is partly mediated by technology at home and at work, and the mainly inferior or service status of that time is mutually reinforced across the private/public divide.

The double burden of women working in and outside the home has, for the majority of women, increased the pressure on both their time, and their capacity to view their time as their own. Thus, if anything, it could be argued that the historically entrenched elements of the gender matrix of time are of increasing, rather than diminishing, interest. They are part of a deep consideration of what the terms of gender equality might be, and the multiple challenges to working towards such possibilities.

I want to return in this context to the area of instantaneous time in the Internet era. The existence and growing availability of Internet facilities are highlighting the potential uses of instantaneous time via ICTs for all kinds of purposes: political, commercial, personal, emotional. Access to these uses of time can be considered part of the digital divide debate. Those in the poorest areas of the South confronting the toughest struggle for daily existence lie at the very bottom of that particular strand of the digital divide as well as many others, including access to ICTs and the necessary infrastructure to support them. As the World Bank (1998/9: iii) has commented: 'In our enthusiasm for the information superhighway, we must not forget the villages and slums without telephones, electricity or safe water, or the primary schools without pencils, paper, or books'. 


\section{Borders and inequality}

Women's socially constructed knowledge about, access to and facility with technology are all factors of the digital divide. ${ }^{11}$ But so, as this discussion maintains, is the patriarchal identification of their time as most legitimately geared towards the 'nontechnological' service of others rather than themselves. However, the use of ICTs can breach public/private divides in their conventional forms, and the Internet and the kinds of communications it facilitates are helping to generate a wider and less rigidly hierarchical debate about knowledge.

The virtual communities of the Internet allow such debate to take place across boundaries of nation, culture and gender (Harcourt 1999). They should be understood in relation to the kinds of factors assessed here, because they involve, among other things, women's relation to technology, and the diverse roles of technology in facilitating and mediating relations between women. They concern the use of women's time both professionally, socially and personally, and, importantly, the relevance of that use of time as a resource in social processes with transformative potential, including networking, campaigning, pressure group work, policy interventions and lobbying.

\section{Women on the Net (WoN) and women's online empowerment}

These are the kinds of issues I became aware of in formal and many informal ways in my involvement in the UNESCO/Society for International Development (SID) Women on the Net (WoN) project several years ago. This experimental project involved an international group of scholars and activists (women and men) interested in gendered relationships to the cyberworld. All of the participants were involved, mostly across the boundaries of theory and practice, in the use of ICTs for the pursuit of practical political and economic goals of women and communities (Harcourt 1997 and 1999). One interesting aspect of the $\mathrm{WoN}$ project was its open agenda, focusing on 'the right mix of imagination and technology' (Arizpe 1999: xiii), exploring how cyberspace was being used by women and for women, and communities and global movements, and the diversity of its creative political and social applications.

There were a number of meanings behind the 'international' nature of WoN, which if examined carefully help us to understand part of the story of how ICTs are reshaping the international sphere in concrete and historically meaningful ways. International connections between women in contemporary times are built on a history of missed opportunities due to the patriarchal hierarchies of politics. These have severely limited the possibilities for women to link up effectively in international contexts. As I have argued elsewhere, the meanings of the domestic locations of women extend beyond the general notion of their prime identification with the domestic setting of home and family. They extend to a confinement primarily within the domestic, that is state, setting of politics, and still with unequal influence 
there. The international or global sphere has been, and in many senses remains, dominated politically and economically by masculinist principles and influence, and the sphere most resistant to feminist interrogation and female influence (Youngs 2000e).

WoN has been among the projects to demonstrate both the role of ICTs in helping to challenge such an entrenched picture of global politics, and the many ways in which women and communities are using ICTs to connect local and global processes more closely. ${ }^{12}$

The group demonstrated how the Internet offered potential for radical improvements in women's capacity to take control of their own instantaneous time and utilize male-driven ICTs to their and their communities' ends. The group illustrated this on two main levels. First, it collected together the individual and geographically and socially diverse uses of the Internet by its members for local and global aims. Second, in its formation of a group, which operated mainly on the basis of its listserve and website, it asserted the collective importance of this work and contributed to opening up possibilities for exploring its transnational significance. There were periods of extensive listserve discussions, two face-to-face meetings, and participation in a Gender and Globalization conference at Berkeley, California, in March 1998.

The project began in 1997 and in autumn 1999 its second phase included workshops in member locations in Nairobi, Kenya, and Zanzibar, Tanzania, with local women and organizations. These workshops were devoted to Internet training, combining conceptual and practical dimensions. I helped to lead them and one of the issues highlighted was the importance of much more than just economic and technical factors. These were clearly among the considerations and priorities; questions of access to ICTs, relevant training, etc.

However, the focus was equally on the social and political reasons for ICT use, emphasis on how the technology was relevant to local problems and goals, some of which obviously have global purpose. For instance, one point that was raised was the growing amount of information about Africa on the Net. But it was stressed that there was an urgent need for more information about Africa by Africans. It could definitely be argued that the workshops became framed by those involved as very much about 'the right mix of imagination and technology'.

I sensed that the open nature of WoN's agenda was relevant here: the project's collective interest in the potential of ICT associated endeavours in local and global contexts, and their further potential and relevance to others (Harcourt 1999).

It is often stated that the Internet is a radical medium that offers possibilities for contestation of structural norms. One thing that an early small project like WoN highlighted was the diversity and expansion of international and local activity undertaken by women for women, utilizing the Net. Hubs such as the Association for Progressive Communications Women's Networking Support Programme (APCWNSP), ISIS International 


\section{Borders and inequality}

Manila and DAWN, show and provide information about how many such projects are underway across the world. ${ }^{13}$ The wide range of activities undertaken demonstrates the real potential of ICT use to contribute to disrupting the established gender matrix of time.

In connection with points raised earlier, I would argue that it is important to make these developments visible. The political and social effects of work on the Net are yet to become fully evident and understood. Women's online activism and policy-related work in areas as diverse as development, women's rights as human rights, ICT advocacy and training, and digital entrepreneurship are contributing to both contesting the patriarchal patterns of GPE and expanding women's overall presence in the global sphere. There has been substantial and growing evidence online of the significance of the sociospatial context for women in this expansion of their international presence and action. In many ways, it has enabled women to overcome the geospatial constraints that limited the possibilities for them to be present to one another in international contexts, to build linkages together, and to work for political, economic and social goals.

ICTs arrived amid growing international women's movements, in which the meetings and processes surrounding the UN World Conferences on Women, for example, played a significant part. Networking and collective political activity were already expanding and ICTs have helped to deepen those processes (Gittler 1999). There is much to be positive about in the prospects ahead for women's use of ICTs, and its potential to add to challenges to historical patterns of gender relations to technology. But part of the intention of the assessment undertaken here, is to suggest that it is best to approach those prospects with a strong sense of the masculinist history of technological development, and the parts it continues to play in shaping political economy and society.

One aim of feminist work is to counter actual and possible scenarios of women as outsiders in the new online world, and to interrogate and address the nature of any relative insider status they may have or gain. The Internet combines ever-growing sets of expert systems. Involvement in them generates new knowledge and applications with every day that passes. We can think of this in terms of corporations, individual Internet entrepreneurs and users, and the policymakers who set the conditions for their operations. The historical weight of male influence and control over the spheres of science and technology and the gendered identities this has generated cannot be ignored when we think seriously about empowerment of women as full participants in the virtual arena. ${ }^{14}$ 


\section{Part III}

\section{Technofutures and power}





\section{Complex hegemony in the twenty-first century \\ Power and inequality}

How do we think about hegemony in the twenty-first century? This is the broad question I address in this chapter. My main aim is to reflect on patterns for thinking about power in the global setting in this opening stage of the new century. My arguments develop from the major themes that have threaded through the earlier chapters, perhaps most importantly that questions of continuity are equally important as questions of discontinuity. In other words, theories and facts of the recent past should feed into our thinking about the future as much as new perspectives and developments.

I consider three main areas, beginning with US hegemony in the information age. Here I revisit Susan Strange's arguments of the 1980s and beyond related to the persistence of US hegemony, and the earlier debates about the risks of the demise of it, and institutional considerations related to it. Here I argue that globalization is one of the key redefiners of US hegemony, including the rise of new growth economies, especially China. I argue that the scientific knowledge base, and its extension through technological application, including in the influential area of military and defence capabilities, remains a major consideration in recognizing continuing US hegemony. I discuss the sociospatial sphere of the Internet as a medium through which a number of processes are underway related to US (and Western) hegemony. These can be considered both an extension of the geospatial assertion of this hegemony, as well as the site of many contestations of it, ranging from the political and economic might of countries like China, to the less easily interpreted impact of social movements related to critiques of globalization. The embedding of and challenges to US hegemony are articulated as part of the complexity of hegemony in the twenty-first century.

Next, I consider the far-reaching problems of inequality and possibilities for leapfrogging in the knowledge economy that are also intrinsic to this complexity. These prioritize considerations of the haves and have nots in the new knowledge economy, and press on us two major contradictory factors relating to the past. The first is the compounding of earlier historical inequalities, and their endurance through technologically driven aspects of economic growth in contemporary times. Illiteracy is a graphic example in this regard. It is put in a whole new context in the information age, where 


\section{Technofutures and power}

what has been a basic skill related to development for hundreds of years, is a fundamental part of any leapfrogging potential individuals and societies might have, for joining and being empowered in the digital economy, without the long development of previous processes of industrialization.

I stress here how widening debate, political campaigning and awareness in the Internet era are bringing history back in as much as moving us forward. This is particularly important in the case of inequalities, which are intimately bound to the possession and expression of power in the GPE over the longterm. The potential that the information economy offers for leapfrogging only serves to highlight the extent to which many of the poorest and most disadvantaged individuals in the world are least able to take advantage of such opportunities. The possibility of these, we become increasingly aware, is inevitably tied to historically entrenched factors.

Next, I consider how the relationship between geospatial and sociospatial framings is inherent in consideration of hegemony in the twenty-first century, both how it is being asserted and contested. This means that analysis of GPE incorporates what could be called mediated political economy. The digital economy extends the manufacturing and service eras into a realm of mixed spatialities, geographical and symbolic. While goods and services still have to be accessed, produced and distributed, the means by which these processes take place are increasingly dependent on different kinds of virtual networks and spaces.

These are both internal (organizational) factors and (external) market ones. In other words, the sociospatial realm is a formative aspect of how economic activity is generated and organized, how production and consumption are envisaged, initiated and enacted. We have now to think in virtual as well as traditional concrete or physical ways about GPE and how innovation occurs within it. The age of big corporate power is far from over, and the information economy has proved yet again how conglomerates such as Microsoft can corner innovation and the global market-place to make distinctive economic gains. But new entrepreneurial business models and virtual enterprises are being generated across a vast range of scales, including the one-person business. The digital economy incorporates new kinds of flexibility in this and other ways, for experimentation, success and failure. ${ }^{1}$ We also need to note that the virtual environment is fundamentally symbolic, thus enhancing the integral role of multimedia in GPE, and the associated importance of the communicative power of language and image, especially through marketing.

\section{US hegemony in the information age}

If anything, the material covered in Sections 1 and 2 about the dawning of the information age, has proved the prescience of Susan Strange's (1994) early arguments about the endurance of US hegemony. She identified the significance of considering hegemony in a disaggregated fashion - in other 
words looking at the different facets of hegemonic power, in order to understand in some detail its bases. Her framework and interpretations retain many lasting heuristic utilities, not only related to her identification of the role of four main structures of power - security, production, finance and knowledge - but also for the nature of her attention to knowledge (science and technology) for its underpinning role in the other areas. This approach holds as much significance now as it did when she initially developed it, and it definitely helps us to make enduring sense of what is happening in GPE, including in the context of globalization, a concept about which Strange was sceptical. In a characteristically sharp dismissal she described it as 'a term which can refer to anything from the Internet to a hamburger' (Strange 1996: xiii).

As a researcher who has concentrated a great deal on globalization, ${ }^{2}$ I, along with many other scholars and policymakers, do not share Strange's dismissal of it. But perhaps in some ways her reaction was related to her being ahead of her times in her analysis of GPE. As someone influenced heavily by her analysis, I would argue that it set the tone and many of the conceptual bases for globalization studies in the field, and that, especially in her last major work Retreat of the State (Strange 1996) she was actually working in similar or associated substantive terrains to globalization scholars. I would single out her focus on the four structures of power and the pervasive role of knowledge across them. Throughout her work Strange held firm to the importance and central role of the state in GPE while exploring the internationalization of GPE. It is interesting that she notes in Retreat of the State that it represents continuity of her work back even beyond States and Markets (the first edition appearing in 1988 followed by the second in 1994) in which she developed her four structures of power arguments (Strange 1996: $\mathrm{x}$ ).

The persistence of her position concerning US hegemony or structural power has increasingly become part of its potency, for it signals two highly useful sensitivities. The first to how such power over the long-term contributes to shaping the political and economic environment in its own interests, and second to how specific aspects of that power may over time become more influential than others. It is partly on the basis of such sensitivities that Strange (1996: xi) can confidently claim that 'the authority of the state - with the notable exception of the United States of America - has declined in recent years'. The exceptionalism ${ }^{3}$ of the USA in GPE is the core area of Strange's work that I want to assess here rather than her wider points about corporate and other multilateral institutional aspects of global governance. It would seem that this exceptionalism is just as influential if not more so in the current war on terror (unlilateral) phase of US hegemony, a decade after Strange made this statement.

The war on terror expresses US hegemony in two dramatic and mutually reinforcing ways. The first relates to Strange's security structure. The overwhelming world dominance of the USA in military and associated 
technological terms has been one of the main characteristics highlighted. The Stockholm International Peace Research Institute (SIPRI) (2006) comments on the rapid expansion of US military expenditure in the war on terror, primarily for operations in Afghanistan and Iraq. With the USA accounting for around half of the total world military expenditure (estimated at $\$ 1,035$ billion in current dollars in 2004), its might is unquestioned, especially when added to its coalition partners, including the UK (ranked second among the countries with highest military spending but with only five per cent share of world military expenditure). ${ }^{4}$

The military power of the USA is a foremost feature of continuity in the post-1945 GPE through the Cold War, post-Cold War and current war on terror phases. Its links to technological dominance make it a vital part of considerations of US hegemony in the information age. As Eric Hobsbawm (2005) has argued: 'Only the enormous military-technological power of the US is well beyond challenge. It makes the US today the only power capable of effective military intervention at short notice in any part on the world. ... And yet, as the Iraq war shows, even this unparalleled capacity to destroy is not enough to impose effective control on a resistant country, and even less on the globe. Nevertheless, US dominance is real and the disintegration of the USSR has made it global' (see also Kaldor 2001).

The global nature of this dominance is worthy of consideration. It undoubtedly is now a major element of the exceptionalism of the USA, and as I indicate, the continuity of that exceptionalism in GPE. As such it has significance not only as a main aspect of the explanation of US hegemony, but also for its influence in prioritizing the role of this form of (military) power in global relations writ large. Thus it serves, not only as a form of security (and threat) in its own right, but also as an example to other countries. SIPRI director Alyson Bailes spoke to this issue on a visit to China in May 2005, as problems of terrorism and violence continued to confront US and coalition forces in post-Saddam Iraq, and the civilian and military death and injury toll to grow.

Perhaps it is just one further proof of the USA's unique strength today that it can keep on going down the same path even when loaded with so many costs and burdens (including costs and burdens of a political and moral kind), just as a tiger hunted by dogs may be able to survive and to keep on running for a while even with several dogs hanging on to it, and even if their teeth are in its throat. I want to stress this last point because, so long as the US does manage to keep on going with its present policy line based directly on military power and on freedom to use that power, other nations may at any time still be tempted to copy its approach. I would say to anyone who is thinking that way that they need to ask themselves, not just if they might also succeed in the way that the USA succeeded, but also whether they would be able to survive and keep going after the degree of failure that the US has 
experienced - and this is even leaving aside the question of how much longer the USA will keep going!

(Bailes 2005)

There is no doubt that hegemonic power says as much about the nature of power in any given set of circumstances, as it does about the hegemon itself. $^{5}$ Thus the extreme level of US military-technological power can be regarded as not only a reflection of a highly militarized hegemon, but also of a world defined substantially in military terms. We can note on questions of continuity, that increasing technological capacity has been a historically enduring facet of hegemonic and global militarization, from the Second World War through the Cold War, post-Cold War, and war on terror phases, including the development, use and expansion of nuclear weaponry; the more recent so-called 'network wars' ${ }^{6}$ where ICTs are in full use across military, terrorist and media operations; and so-called 'star wars' efforts by the USA to take defence into outer space. ${ }^{7}$

If it is accepted that building consensus is part of what defines hegemony, ${ }^{8}$ then militarization and the technological culture that supports it, can be treated as a prominent characteristic of US political (and ideological) global power. Here we come to the second way in which the war on terror expresses US hegemony: through the consensus built with its allies supporting its policies in this area. Harsh critics of the tactics underpinning US hegemony like Noam Chomsky (2004: 6-7) stress the battle to steer hearts and minds at home as much as overseas. "Neoliberal initiatives of the past thirty years have been designed to restrict [the public arena], leaving basic decisionmaking within largely unaccountable private tyrannies, linked closely to one another and to a few powerful states. Democracy can then survive, but in sharply reduced form' (6).

The war on terror reflects not only the US's technological might, but broader (political and ideological) adherence to and acceptance of its role (or legitimacy) in the wider world. Earlier debates about the militaryindustrial complex ${ }^{9}$ played a major part in foregrounding the extent to which military technological developments were linked to the wider technological framework of industrial and economic growth. Strange's (1994 and 1996) emphasis on technology and change identified the importance of the link between them in state (notably US) and market (corporate) power. Strange (1996: 7-10) identified technology and finance as 'neglected' factors in the analysis of GPE (see also Talalay et al. 1997), and included attention to the increasing need for finance of continuing and growing rates of technological innovation.

There are complex grounds for including Strange's work on technology in a consideration of GPE in the information age, on the basis of sociospatial and geospatial factors that have been discussed in this study. It informs in direct and indirect ways the importance of considering how the new sociospatial (virtual) spheres are contributing to change in GPE both in state 


\section{Technofutures and power}

and market terms. And the distinctive recognition that Strange's composite of work gave to the knowledge structure in interpretation of US hegemony is particularly useful in this context. It reminds us firmly that we should focus on both state and market in considerations of hegemony.

The Internet's origins within the military-industrial complex of the USA are themselves an expression of US technological hegemony. So, to a significant degree, has been the Internet's expansion across the world, and the major role of American innovation and corporate power in defining its platforms and dominant software environments (notably by Bill Gates' Microsoft). ${ }^{10}$ As an informational sphere, however, the sociospatial context has to be considered as fully politically and economically, as the geospatial one. In other words, we need to think about how much the sociospatial sphere is contributing to US hegemony politically and economically. This point keenly reminds us that technology is not neutral, but as much an expression of how it is used and moulded by different institutionalized forces (political, economic and cultural).

In these senses, the sociospatial sphere in its boundary-crossing, flexible, and hi-tech characteristics has built into it many features of the neoliberal ideology championed by the USA - in both state and market framings. Therefore, as a technological medium (channel, pathway, highway), the Internet articulates, in many ways, in its very operation, the ideals of the free-ranging, exchange-orientated and expanding neoliberal agenda. This infrastructural ideological identity, which is substantially a matter of material history related to the founding and early development of the Internet in the USA, is more fundamental than even institutional structures that govern the Internet, and the companies and other entities that shape and operate on it.

The Internet is distinctive as a new technology or complex of technologies in GPE. It is a whole new sociospatial setting that is expanding daily in use around the world, by governments as much as companies and individuals. It is pervasive in its use at home and work, for production and consumption, for private as much as public purposes. It is both an environment and the means by which new forms of political, economic and cultural productivity and exchange can be created, established and profited from in different fashions. And in these relatively early days of its operation, the Internet is as much an object of myth making ${ }^{11}$ as it has been of substantive and enduring change. Much is as yet unknown about the ultimate relationship between the sociospatial and geospatial contexts, and just how much the former will ultimately challenge and change (transcend) the latter. What I have set down in this study are the kinds of areas we should consider in these processes as they begin to unfold.

One thing that has quickly come to the fore has been related to the fundamental neoliberal characteristics of the Internet as a medium, and its challenge to the political boundaries of states such as China, which along with other regimes opposed to (Western) democratic traditions of free speech 
such as Saudi Arabia, have done most to pit the geospatial against the sociospatial. We should recognize this battle in hegemonic as well as other regards. The Internet now represents a powerful arena on which the neoliberal principles of free exchange (politically (and culturally) as much as economically) are being played out. The very essence of neoliberalism in binding economic to political freedoms is being contested in this regard. The desire among some states for the economic benefits of the new sociospatial sphere is strong and already progressing, especially fast in the case of China, but so is the will to disaggregate these from the expansion of political exchange that come along with it.

This is a global issue gaining more and more prominence as evidenced by the launch in May 2006 of a campaign by one of the most prominent human rights organizations, Amnesty International (AI), on Internet freedom of speech as a human rights issue. The campaign entitled 'irrepressible.info' urged members of the public to sign a pledge to urge the release of the growing number of 'cyber dissidents' to be presented to the UN in November 2006. 'China is perhaps the clearest example. Its Internet censorship and clampdown on dissent online is sophisticated and widespread. But AI has documented internet repression in countries as diverse as Iran, Turkmenistan, Tunisia, Israel, the Maldives and Vietnam' (Allen 2006: 8; see also Human Rights Watch 2005). AI pointed out that its target was also companies implicated in such government censorship, whether in the provision of monitoring and filtering software or the involvement in censoring, pointing out that the 'results of searches using China-based search engines run by Yahoo, Microsoft, Google and local firms are censored.... We do not accept these firms' arguments that it is better to have a censored Google, Yahoo or Microsoft in China than none at all' (8). ${ }^{12}$

The linking of the Internet to the human rights terrain in such ways makes it clear that the sociospatial sphere is pressing particularly strongly the neoliberal political as much as economic agenda. The economic rise of China is the hot topic as this study is being completed, but it needs to be stressed that in GPE terms the sociospatial context is growing in signficance in relation to geospatial constraints. The boundary-crossing and information-flow orientation of the Internet is doing much to test political geospatial boundaries. As such it is part of whatever hegemonic contestations are developing in GPE, and its neoliberal characteristics are part of the continuing assertion of US (Western) hegemony in technological guise.

\section{Inequality and leapfrogging in the knowledge economy}

Concentrations of technological power and economic development and the strong hold of the West on innovations, and therefore much of the dynamics of growth, related to them, is at the heart of inequalities in the information age. Clearly countries like China and India are proving that leapfrogging is a reality. Developing economies are harnessing the possibilities of ICTs to 


\section{Technofutures and power}

speed up their growth and benefit from the global economy. But the picture of inequality is an embedded and deeply entrenched one in GPE, especially where it is most evident, in the poorest parts of the world, and in women's partial participation in the major political, economic and technological processes that control it, including in the richest economies.

China's economic miracle has been substantially fuelled through the latter part of the twentieth century and the beginning of the twenty-first century by the direction to it of the bulk of FDI from rich economies. It is significantly a miracle of globalization as much as internal economic transformation (see, for example, Youngs 1997c). Both are clearly important and interrelated. But they indicate that the story of China's success should be told as much on a GPE basis as an individual country one. And we could think about the GPE aspect in part as a transformation of Western hegemony in the era of globalization into a story of markets as much as states. We can read the kind of analysis Susan Strange offers as directing us along such lines even if she held on to the states and markets framing rather than opting for that of globalization.

It is easier to talk about China's success in traditional state terms but it is a highly partial reflection of the economic dynamics that have brought it about. The tendency to do so results from, as Strange suggests, the problems of considering the 'enhanced power' of markets, a situation likely to make social scientists 'uncomfortable'. 'They are accustomed to think of power as pertaining to someone, or some social or economic institution. But markets do not fit this conception. They are impersonal, intangible, not even necessarily to be found in any one place' (Strange 1996: 29-30). The digital economy is making such insights all the more pertinent when markets, and networks, exchanges and innovations related to them, operate across sociospatial and geospatial spheres, in virtual as much as actual (traditional) arenas. The spatial complexities of GPE have grown because of ICTs and this now has to be built into considerations of power and inequality within it.

The role that outsourcing has played in contributing to India's digital growth is an example of how ICT infrastructures have impacted on economic linkages across markets. This again is a story of globalization as much as it is of internal economic transformations within India. ICTs have increased the accessibility of different national markets (and economies as a whole) to one another, opening up new possibilities for those who are able (states, firms, entrepreneurs and innovators) to take advantage of potential new flows of production and exchange. Economic connectivity has expanded substantially through the virtual sphere, and the wider potential of this development for poorer societies around the world is key to recent processes such as WSIS.

There are contrasting early results from the information age, with extremes of inequality being a core feature in the success of countries such as India and China, as much as across the world more generally. This signals an 
influential feature of the information age, which is a continuing theme in the account of globalization. Development, including digital development, is spreading and contributing to economic growth, in the developing as well as the developed world. But patterns of inequality are persisting and include depressing and devastating extremes, notably in the poorest parts of the world such as Sub-Saharan Africa, where people are struggling against combined and growing problems of disease and economic deprivation.

The varied and deep inequalities can be taken as signs of how divided the world, and many individual societies, developed and less developed, are. It can be taken as a negative indication of the vast gulf between human destinies across the world, between, for instance those who do not even survive childhood and those who can look forward to longer and longer life expectancy in the comfort and luxury of expensive healthcare and continually growing consumption. The digital economy adds yet another layer to what can divide people within and across societies, the haves and have nots. In this sense, it has made the already complex problem of inequality even more complex.

I have stressed that we need to keep a strong long-term focus on all the layers of inequality, including those related to gender, as we navigate all the positive developments and possibilities digital progress is opening up. Illiteracy, concentrated in the poorest parts of the world and frequently more prevalent among women than men, is a basic and graphic example of why we need to do this. It illustrates that the failures to address the inequalities of the past, far from being less significant in the information age are even more so. Basic competencies such as reading and writing have always been prerequisites for human and economic development in modern societies. The digital economy offers a whole new set of opportunities that those without such competencies, let alone the additional educational and technical skills that are a prerequisite for success, are shut off from. Writing now means writing software in computer code, which can create whole new spaces, environments and protocols for virtual interaction, as much as writing the traditional text of the pre-IT age. Digital literacy incorporates a whole host of technical skills in addition to basic reading and writing capacities, but the virtual informational sphere, also enhances the relevance and potency of those basic capacities.

The speed at which the digital economy develops and changes also adds to this picture. Those who are already behind, or outside of it, may get left increasingly behind as it moves forward in different directions. It is too early for us to know the full implications of digital economy and transformations associated with it. And that is an intrinsic part of the problem. Clearly sociospatial presence is growing in its importance alongside geospatial presence, whether we are thinking economically, or perhaps to a lesser extent at this stage, politically and culturally. Opportunities and possibilities, and the diverse forms of information and organizations (political, economic, and cultural), reside increasingly in sociospatial as much as geospatial locations. 


\section{Technofutures and power}

This hybrid spatial scenario is contributing directly to changing the nature of global and local inequalities, defining different kinds of insiders and outsiders, and relative forms of status in either category.

We are still navigating the range of inequalities related to the digital economy. For example, it is clear now that having online access, important and unequal as this is, is just part of the story. There is a vast difference in economic empowerment between simply using the Internet to buy goods and services, for example, and setting up an online business that ultimately provides substantial income, or innovating software to generate new intellectual property. Even different levels of familiarity with what is possible online can be considered a fundamental element of inequality, whether we are thinking about whole economies, organizations and companies or individual citizens within them.

Reading or surfing is not as powerful as creating, interacting and adding content to the Internet. A merger of reader/writer roles is necessary to empower users as producers, selectors and commentators of information and not just consumers of information.... An 'information society' implies new social structures and information dependencies.

(Conley and Patterson 2000; see also Spender 1995: 221)

Dependent on whether you are an insider or outsider (state, company, individual) in the digital economy, your considerations and priorities across such areas are bound to differ vastly, and with digital inequality a relatively new issue, debate about it is still limited, including on the economic front. While those most inside are racing ahead to benefit as fully as possible from the digital economy, those most outside do not even have the elemental knowledge about what it actually represents and the possibilities it might offer. In between there are a whole host of inequalities among people and organizations relating to cost, technical and other forms of know-how, motivation etc. This is all terrain that is only beginning to be charted and it is clear that much needs to be discovered.

What is evident from the outset is that digital inequalities have links to other forms of inequality (socio-economic/cultural, gender, educational and so on), and therefore they should be considered in connection with wider questions of inequality globally and locally. We live in a highly unequal world, in geospatial and sociospatial contexts, and the fact that we now have to consider both, means that issues of power and inequality have become a whole lot more complicated. We do not have to turn away from the more utopian and dramatic achievements and possibilities of the information age, many of which are already being celebrated by rich and developing economies on the digital trail. These are real and clearly a vital part of contemporary economic dynamism.

But alongside them sit a whole range of factors related to inequality and challenges facing economies, as well as millions of individuals across the 
world for whom the leapfrogging potential of the digital economy is not even a distant dream right now. Digital transformations have expanded the problem of inequality, as well as making the gulfs between the haves and have nots even more multifaceted than they were before.

\section{Mediated political economy: geospatial and sociospatial contexts}

The implications of taking the geospatial and sociospatial settings seriously, when thinking about GPE, include recognition of the symbolic significance of the Internet. We are living in an age of mediated political economy, where participation in the market, whether as producers or consumers, can take place in part or whole through virtual spaces and connectivity. Across all these spaces and forms of connectivity (Internet access, mobile phone services, etc.) ICTs themselves become a new complex of production and consumption. Critical commentators stress the intensification of commodification that results, including of 'information and entertainment content' (Mosco 2004: 156). Thus digitization and the deepening of commodification are intrinsically bound up together. 'Digitization takes place along with the process of commodification or the transformation of use to exchange or market value. The expansion of the commodity form provides what amounts to the material embodiment for digitization' (156).

Speed is a core value in this intensification. The extent to which ICTs enable the transcendence of time and place-based constraints, fuels both supply and demand sides of the developing digital cultures. In this new world of mediated political economy, suppliers and consumers meet in a virtual market-place of expanding opportunities. But it is also a symbolic environment, where the possibilities for advertising those opportunities is itself also expanded. We have moved on from the days when accessing a specific media product entailed enduring the advertising that went along with it, whether we are talking about a newspaper, television or radio programme. In the new media age, we have online accessibility, where virtual spaces can be infused with symbolic communications, and informational boundaries continually blurred between what is actually being sought and accidentally encountered, what is information and what is infomercial. And in mediated political economy we not only see but are seen, in a digital way of course.

Digital systems which measure and monitor precisely each information transaction can be used to refine the process of delivering audiences of viewers, listeners, readers, movie fans, telephone and computer users, to advertisers. Companies can package and repackage customers in forms that specifically reflect both their actual purchases and their demographic characteristics.

(Mosco 2004: 157-8) 


\section{Technofutures and power}

The information age includes the digitization of the whole exchange process, including the linkages between producers and consumers, and promotional aspects. Exchange wears an informational cloak that makes the consumption process far more visible and precise. Digital access allows for interactivity based on data, whether it is gathered and detected behind the scenes, as it were, by automated software, and/or revealed on screen in part or full.

Mediated political economy represents a new commercial culture of availability on behalf of producers and consumers. To be present in the virtual sphere is to accept the symbolic nature of its construction, existence and operation. You do not have to opt to inhabit the self-declared softwareconstructed virtual worlds that operate online, to be immersed in the symbolic. You are in any event online. These are just specific and designated virtual worlds within the virtual sphere. This sphere also has a particular form of incorporation when it comes to different aspects of the lifeworld. ${ }^{13}$ For the first time, it represents a communications environment where all aspects of private and public activity take place. In itself this represents a new form of penetration of the market and the rationalizing effects of technology, including into the home environment.

We can bring together here two associated considerations relating to new media, as a continuation of impacts already resulting from traditional mass broadcast media. The latter represented the further penetration of the market, notably through advertising, into both daily life in general, and the private sphere of the home as well as the public sphere. New media take this penetration onto quite new levels along similar trajectories. And the comparative sophistication of the technologies involved, especially the new forms of interactivity they facilitate, emphasize that this is a combined penetration across areas of supply and demand. As well as listening to, or receiving messages from the market, it is possible to enter the market, operate in it both as a producer, supplying goods, services or information, as well as seeking, selecting, purchasing and consuming them.

Thanks to the digital economy the market has penetrated the private sphere in ways never imagined before, to the extent that sociospatial connectivity is continually eroding traditional geospatial boundaries between home and work and different kinds of leisure and other activities. The fact that the sociospatial environment has pervasive seamless qualities across its differently oriented spaces, is a main facet of its technological rationalization of social existence. In simple regards, the world is at one's fingertips, and it is possible to move from one distinct location to another in split seconds, from one form of activity to another similarly, all without moving, or on the move if that is most convenient. Flexibility and 24/7 accessibility are paramount. The convergence of multimedia, including traditional areas such as television, and including on mobile devices, signals the degree to which sociospatial contexts frame experience in powerful new ways. 
We are always located even if we are on the move but sociospatial settings deliver the world to us rather than us having to move to it. This applies whether we are thinking about shopping, booking travel, checking on official information, joining an NGO or signing up to one of its campaigns, looking at a planning application and making an objection against it, checking on cinema times, writing and sending a document to work, answering a query from a friend, and so on. It is fair to assume that our conceptions of the commonplace boundaries of the past, public/private, home/work etc are breaking down through sociospatial experience and activity. We might also consider this to be the case between the market and other spheres of life, politics and culture. Such distinctions played major parts in modernity, including the formation of the study of it through politics, sociology, economics, etc. Could it be that, due in major part to sociospatial developments, such distinctions will be much less influential in postmodern futures?

The virtual space wherein we seamlessly, as it were, move across these spheres at whim, and almost instantaneously, is intricate in the multiplicity of boundaries it transcends. Mediated political economy is intensifying in a mutually reinforcing fashion the power and functioning of technology ${ }^{14}$ and the market in daily life. The forms of rationality associated with this intensification are highly involved. They include the technological, institutional, governmental and commercial operations that drive and manage ICT infrastructures as well as services and content. And, if we take the increasing amounts of time spent in sociospatial settings seriously, we have to recognize that our consciousness of space and place will be influenced increasingly by them. For growing numbers of people around the world, time spent is time spent virtually as much as in geospatial settings. Where exactly are we if engaged in online activities linked to or located in far distant places, while we are sitting on a train, or in our living room at home or the office? Do we need to think now about multiple levels of simultaneous concurrent experience (and presence) online and offline?

Also, we can think about the continuities of lives lived in front of screens across the mass media, new media eras. In the mass media age of the twentieth century the television is the iconic piece of technology. In the new media age of the late twentieth century and twenty-first century we are talking about the computer screen. Is it less or more sinister that the market could access us as comparatively more passive consumers in the mass media era, and that now through ICTs we have expanded interactive access to it? This is a complicated question, which takes my thoughts back to the connections I drew across the films Metropolis and Matrix Reloaded at the beginning of this book. Is the monotony of typing and mouse clicks so different from the exaggerated automated movements of workers at their machines in the opening scenes of Metropolis? Is the technological sophistication of the software-driven environments of the virtual world not a far deeper experience of control than factory production lines? Are many of us trapped (and 
controlled by) ICTs now, in ways that have some similarities to those who are, and were in the past, trapped at factory production lines?

Are our lifeworlds being transformed in ways we are far from yet aware of? I think there is much reason to answer yes to this question. We are so comparatively new to virtual experiences and their influences in our sense of ourselves, our world around us, and our places in it, that it is hard to tell yet what the full implications will be. Suffice it to say that we should probably keep a firm conceptual grip on the continuities of technological developments in modernity and postmodernity. ICTs are enabling more and more activity and connection at a distance, even from those we are geospatially close to, for example in our offices and communities. Will this lead in the long term to new forms of alienation as well as intimacy in our associative lives and identities, work-wise and otherwise?

Herbert Marcuse offered some characteristically dark reflections on modernity, which bear revisiting in the information age.

Individuals are stripped of their individuality, not by external compulsion, but by the very rationality under which they live. ... The system of life created by modern industry is one of the highest expediency, convenience and efficiency. Reason, once defined in these terms, becomes equivalent to an activity which perpetuates this world. Rational behaviour becomes identical with a matter-of-factness which teaches reasonable submissiveness and thus guarantees getting along in the prevailing order.

(Marcuse 1998: 48)

We do not need to be technologically determinist, or necessarily over pessimistic to take on board some of the implications of such perspectives. These include the distance from instrumental or neutral approaches to technology, that we need to maintain if we are to encourage as much critical reflection and analysis as possible. Also that technology is about process and organization, power and inequality, and cultural orientations, as much as it is about machines and techniques. Technological developments come out of social systems and historically created structures, and by their applications and uses, many of which may not have been foreseen originally, contribute to how those systems and structures continue, evolve and change.

Technology, as a mode of production, as the totality of instruments, devices and contrivances which characterize the machine age is ... at the same time a mode of organizing and perpetuating (or changing) social relationships, a manifestation of prevalent thought and behavior patterns, an instrument for control and domination.

(Marcuse 1998: 41)

In the case of ICTs it is not surprising then that much of the positive comment on their potential has related to horizontal rather than vertical 
processes - political, economic and cultural. The explosion of NGO and social movement activities online, including those related to women's rights, and major areas such as ecological and anti-globalization/capitalist issues, signal that the interactive and horizontal nature of the Internet allows for resistant or alternative engagements and associations. Much of this activity, in the North as well as the South, is directed towards challenging the dominant trends in GPE, including those related to inequalities. So it is worth emphasizing that the expansion of the neoliberal culture encouraging free exchange involves the growth of political (and ideological) critique. While this expansion entrenches neoliberal culture further, it cannot exclude counter-debate against aspects of it. This includes anti-hegemonic, anti-war, anti-globalization and anti-capitalist lobbying. The Internet is part of the changing context for hegemony, in vertical (state and market) and horizontal networks, and contrasting forms of (political and economic) expression, production and consumption.

Mark Nunes (1997) has discussed it as an 'electronic geography' highlighting how it demands fresh thought about what political and economic developments may result from its diverse uses. It is a social sphere in the making, its varied shapes and impacts being fashioned in the mix of technological, social and communicative innovations that relate to it, and result from one another. Alongside commercial efforts to harness mulitmedia to build communities of affiliation and identification with brands and products, there are extensive online efforts to bring together global and local communities of concern with the widest range of social issues. These virtual communities may be temporary around a short-lived campaign or targeted policy action, or more long-term around a shared political or cultural interest.

Mediated political economy can be seen, from such standpoints, as a jumping off point for new thinking, experimentation and association, for fresh kinds of actions. This reminds us to maintain a purchase on the linkages between online and offline (sociospatial and geospatial), so that we recognize influences across them as well as within them.

[T] he Internet might offer a virtuality which resists our attempts to totalize it as a world, presenting instead loci for playing with the assumptions that we have taken for granted in modernity: community, information, liberation, self. Virtual communities could pose questions about how individuals construct connections rather than attempting to achieve a determined end (electronic democracy, egalitarian utopia).

(Nunes 1997: 176)

Such approaches direct our attention towards the role of online empowerment at the level of individuals as much as wider societies. It also signals that ICTs have complex implications for deepening individualization as well as new forms of association and action (political, economic and cultural). The free for all and open possibilities of the new sociospatial world cannot 


\section{Technofutures and power}

be just assumed as an obvious good. And I am not thinking here of all the negative sides of online community building from terrorism to paedophilia and cyberstalking, which clearly remind us, if we needed reminding, that negative motivations can be just as powerful in society as positive ones.

My focus is much more on the everyday and ideas around where different groups of people do, or might draw inspiration and motivation from, to achieve new things in the online world. If we are all pretty much individual nodes in the new environment of connectivity, then our existing social (educational, cultural, personal) resources probably lie at the heart of what might be possible for us online, at least initially. We have to start somewhere as it were, and the resources connected to the lives we are leading, and networks and knowledge within it, our financial means and access to knowhow, are likely to represent a major part of this. Mediated political economy expands macro-micro connections and possibilities, but it also puts new forms of pressure on individuals to navigate their way meaningfully through the virtual maze of information and opportunities, to make it work for them individually, to choose between different risks and openings, and to resist damaging temptations or dangers that might present themselves. The information age is not just about accessing information, it is also about the challenge of making that positive, relevant, productive and useful on a day-to-day and often individual basis. 


\section{Conclusion \\ Contradictions between \\ connectivity and inequality}

There is a profound contradiction in the information age. Gulfs of inequality in the world are growing deeper as electronic and other forms of connectivity are drawing people and communications ever closer to one another. This is the general terrain this book has discussed and it is at the heart of much of the critical politics of the future. What I mean here is threefold. First, it is a contradiction that needs to be better seen before it can be better understood. It needs to find its way onto increasing numbers of political and economic agendas at all levels to be brought sharply into view across the board. Much more political time, thought and commitment need to be invested in it.

Second, it needs to be analysed much more for what it says about the world and the place of different groups and individuals in it. It needs to be interrogated from multiple perspectives and locations, geographical and social. In this way complex understanding may result in new and positive steps forward. Third, it needs to be something, which policymakers as much as activists and campaigners need to be comfortable addressing, at the very least as a possible problem, if not always an actual one in all places at all times. Comfort is used here in a political mode. I intend to signal by the application of it a mode that actively embraces the challenges thrown up by the contradictions between connectivity and inequality. Evidence presented here would indicate this is insufficiently the case to date.

This mode would recognize these challenges as opportunity as much as cost, as possibility as much as barrier. I have argued that liberal and neoliberal emphasis on equality is intrinsic to the problems countering such developments. The ideology of equality sits so tensely in a world that has a counter dynamic towards inequality. This situation can be seen as counterproductive. It appears to be inhibiting, rather than facilitating recognition of and action against the dire problems of inequality. I recognize this may be a controversial position, but it is addressed to the effectiveness of a focus on equality and the hard facts working against it.

I am by no means suggesting we abandon the principle of equality and realize its status as an ideal category. In other words, its main role in practice includes its function as an operating principle aimed at reducing inequalities. 


\section{Conclusion}

This is different from the ideal status envisaging a utopia where all are equal. This might be possible, but even if it is not, working towards greater equality can be regarded as a good in its own right, and is not necessarily dependent on the achievement of the ideal end point.

My arguments have been directed towards the problem with the functioning (and non-functioning) of the equality principle. This recognizes that there is most pressure on it in this regard. If in practice the world has actually veered towards huge inequalities, then the equality principle is obviously severely undermined.

The role of this operating principle in legitimizing liberal and neoliberal ideology, places it centre stage and severely tested by the actuality of a world, where massive inequalities have endured and grown. Also, and just as important, the ideology of equality (ideal and operating principle) acts as a kind of comforting discursive blanket that contributes to political blindness, to the harsh dimensions of the bare truth. This is manifest in pervasive forms, because liberal and neoliberal discourses about equality, including those related to human rights, run thick and fast across national and global contexts. Dominant institutional (Western) frameworks of GPE are shaped by and through such discourses, which are, at the very least a poor reflection of the world we actually inhabit, North and South.

This world has horrifying levels of inequality within and between states, which if looked at closely cannot help but sicken societies and individuals truly concerned with equality. I have illustrated a number of aspects of this inequality and there is no need to repeat them here. The major sources I cite, notably the UNDP Human Development Reports, offer a wealth of further detail for those who want to know more. Suffice it to say, there is overwhelming evidence of grave inequalities, including in the new growth economies such as China.

At this point I want to ask four hard but I think pertinent questions. First, if our recent past has been so heavily defined by this steer towards widespread and deep inequalities, what evidence is there that the future may be any different? Also, how ideologically sound is it to continue chanting equality when all around inequalities have been growing? Furthermore, how could dominant discourses move beyond the tension between claiming to be working towards equality in the face of mounting inequalities? If, in fact, what is being worked for is more equality for some and less for others, and for some of those so much less that the result is death from starvation, preventable disease and so on, what does this mean?

These are large and highly charged political questions in the contemporary global scenario. While I will not attempt to answer them fully here, I want to offer some reflections related to the material I have presented earlier. With regard to the first question about the possibility of change in the future, there is no point in indulging in too much crystal-ball gazing, because ultimately the future will unfold in expected and unexpected ways. The rate, spread and global impact of China's economic growth is probably the most recent 
example of both of these dimensions. So, while recognizing that much is unknown, I would suggest a few things.

The information age seems to be contributing to the spread of economic growth, including in the developing world, with the concept of leapfrogging clearly worth keeping in play. The connectivity of ICTs has been especially powerful in the major growth of China, as well as India, including in ICT hardware and software as well as outsourcing. Major inequalities persist even in those countries, and it can be assumed that these are unlikely to be addressed quickly, although they may be in the medium or long-term future. These are positive prospects, which are encouraging, but the overall picture is far from rosy. The imbalance of flows of FDI heavily weighted towards China in particular, is one of the major characteristics of the period of globalization through from the late twentieth century.

This has been one of the strongest influences in the fate of the developing world, certainly as far as the rich economies and their outflows of FDI are concerned. Such flows have been very far from equal. They have chased the golden egg of China's vast consumer market and profitable production conditions, leaving the majority of the developing world substantially out of the picture, Sub-Saharan Africa a notable case. In geospatial terms, the connectivity achieved has been transnational, with corporate, financial, trading and associated communications networks, welding the richer economies closely to one another and the developing economies along highly specified and partial lines. This, together with the heavy concentration of patent ownerships and wealth in the rich economies, offers the most pessimistic view of how the future might be different from the recent past. This is especially the case if we focus on broad global imbalances of wealth and technological concentrations related to innovations, and economic benefits that can be generated from them.

Overall, economic and human development has been spreading geographically, and we can be as sure as possible that this is likely to continue. Many, particularly in Sub-Saharan Africa, have however gone backwards in these terms, a situation which surely should be intolerable according to the operating principle of equality. Others have stagnated, and in this world of extremes gaps between those with most and those with least are vast. Also, within North as well as South, inequality gaps within individual societies have grown, including through new digital divides. These are significant tendencies, not least because of the ways in which inequalities at local and global levels can be seen as overlapping and mutually reinforcing.

For example, the more that rich and poor societies come to accept or accommodate such inequality gaps within their own national communities, the easier it is likely to be to see such developments as inevitable or unavoidable at the wider global level. The ways in which the inequality web of insiders and outsiders weaves across and through individual societies in North and South only serves to contribute to this problem. I see this as one of the most challenging areas of politicization for the future. It poses the 


\section{Conclusion}

following question. Has deep inequality already become so embedded that it is hard to mobilize polities, individuals and multilateral institutions, to muster the political will to address it? Naturally here, in view of my earlier points, I am talking about much more than recourse to the tired discourses of equality.

This brings us to the second question about the tensions between such discourses and the levels of inequality that have been building. I have argued that the result of such tensions is an untenable strain on the neoliberal ideology of equality, as it is generally currently framed. The only way that this strain can be addressed is a greater foregrounding of the problem and reality of inequality across the whole range of local and global manifestations, especially on socio-economic and gendered bases. This involves a lot more discussion of and focus on inequality at all policy levels (local, national, global) than is at present happening. Overall, a much higher profile on questions of inequality, the bases for them and the ways we might address them, are needed.

Clearly there are settings in which inequalities are being highlighted, as illustrated in the different kinds of evidence presented, but this clearly needs to go much further and deeper in political and economic policy environments. What I am suggesting is that inequality needs to begin rising up policy agendas to close the gap with the current proportion of emphasis on equality. If this does not start to happen soon then claims of hypocrisy against them will have a huge and growing basis in evidence. This would be clearly most negative for those highly committed to working for equality, and with a deep belief in liberal and neoliberal ideology, and less so for those who are far more sceptical or critical about its purpose and outcomes, and want to attack and destablize it.

In my discussion of time, I have touched on the role that critical historical analysis plays, for example in postcolonial and feminist studies, in asking us to look backwards as well as forwards in considering these problems. The sweeping message is that the history of colonial, postcolonial and patriarchal power offers varied explanations of different forms of inequality in contemporary times. NGOs and social movements are contributing in major ways to taking these agendas forward through activism, policy advocacy, campaigning and networking. Much of this work takes place in socialspatial (virtual) spheres as much as geospatial ones, and also does much to connect the two, for example linking online campaigns and information exchange to institutional processes such as UN conferences. I have discussed the women's movements as one example, touched on how the WSF harnesses sociospatial connections to bring people together in experimental ways in geospatial settings.

My own practice and policy-related work leads me to believe that NGOs, and social movements attached to them, have generally been among the most active and successful actors in utilizing sociospatial opportunities to full effect to work for change in traditional geospatial contexts. There are many reasons 
for this, some of which relate to areas I have covered on borders and inequalities and political identities. Those working on global issues have to some degree a vested interest in disrupting traditional geospatial boundaries mapping political associations and identities. They are frequently emphasizing human interdependence across rather than just within these boundaries, and attempting to mobilize people and policymakers on the basis of it. Sociospatial transcendence maps onto such interests in its boundarycrossing and networking capacities. Political interest and boundaries are not necessarily already set in the sociospatial world.

I use 'not necessarily' carefully here because, as I have discussed, state and market interests occupy the sociospatial environment in ways that enhance and expand them. Governments, TNCs, mass media and new media operators are among the most powerful and accessed online presences. Countries like China are also working hard to manipulate sociospatial openness, in an effort to harness its economic benefits, but limit its political free flow of information. But such efforts are also exposed in a world of offline and online flows, including through NGO campaigns and activism against such restrictions of what are now being regarded as digital human rights.

I have argued that this exposure should be seen as part of information age developments. The existence of virtual space and connectivity, with its actual and potential transcendence of national boundaries, has created a whole new political and economic context. This is one defined by general principles of increasing free flow of communication, information and exchange of goods and services. There are always controls and limits on such flows, including regulation aimed at combating criminality and security threats such as terrorism, and ensuring appropriate taxes are charged on goods. But the trend is towards increasing flows, and it can be argued that these sociospatial developments have taken neoliberal principles further in material ways.

I have argued that this is an ideological issue too. The logic of free flow is a technological, as well as communications and exchange, characteristic of the connectivity of sociospatial networks. It is also an expression of symbolic as well as actual effects of the hi-tech mode of economic progress. Its Western roots still count in this regard, even though global players in the digital economy are rapidly expanding. The time/space reconfigurations of the online world, its power to connect across the globe and to operate as an information-rich synchronous or asynchronous means of communication is enabling the building of temporary or longer-standing virtual communities, e-business of all kinds and social action across as well as within boundaries. Full access to this transcendent sphere of communication and action is now being incorporated into the framework of human rights. It is another dimension of what it means to be free as a society or individual, and to be able to participate fully in liberal and neoliberal terms.

The nature of the information age is also that as well as the means for such new rights, the virtual sphere is also the site where they are explored, 


\section{Conclusion}

championed and contested, and, where those who resist them are noticeable by their absence or partial presence. The implications of the new online freedoms in this neoliberal world are that the more you have access to the sociospatial arena, the more you are able to benefit from it, politically, economically, and culturally, and the more free you are or are likely to be. Of course we also need to take into account the structures of state and market power, control and influence that exist online, whether the more overt or subtle. Across these areas, connections between the geospatial and sociospatial are key.

Critical perspectives on sociospatial phenomena maintain a firm fix on these connections to temper the utopian overtones of online freedoms, but also to maintain in play the understanding that technologies and their applications are far from neutral in relation to power. I have argued that taking a long view of technology across its modern and postmodern manifestations, back over the past century, is helpful to the latter. This assists our understanding of the complexities of dependencies on technologies, and also of the generation of these out of social conditions structured by certain forms of power. Such technologies and dependencies then become woven into our existence by their uses and familiarity, and become part of the social fabric from which future decisions and choices are made within societies and across them. The destructive as well as productive purposes of technologies also reminds us of the extent to which their innovation and use covers the full range of human proclivities. The overarching power of the USA at this time, notably through technologically driven military might, is part of this picture.

On a wider note about control, we can observe how technological complexes such as the Internet become pervasive in daily existence, and part of automated realities (tapping the keyboard and clicking the mouse) in ways that have analogies with the repetitive functioning at factory machines and conveyor belts. I have suggested that it is worth giving thought to the pervasive presence and roles of the Internet across home and work settings, and the growing hours that are spent trapped in front of computer screens or mobile devices of various kinds. The Internet is fusing the spheres of production and consumption ever more closely, blurring boundaries between them, and between work and leisure. The Internet is clearly just as invasive as it is liberational.

The symbolic qualities of the sociospatial sphere are especially noteworthy here. This invasiveness relates to the market, which, thanks to 24/7 communications, can reach us anywhere, any time, even when we are on the move. The market is more present than ever thanks to the Internet, and we can stumble across its messages relentlessly online, whether we want them or not. Of course we can access the market more easily and conveniently, but we should also take into account that this accessibility fuels consumption too. And the interactivity of the Internet has enhanced the sophisticated data that marketers can gather on us as we enter virtual spaces and make choices within them. The Internet makes it much harder for us to escape the market, 
and with its penetration in the home, it is blurring distinctions between public and private spaces. I have discussed how feminist purchase on public/private dynamics offers a major contribution to understanding such developments.

This blurring of public and private is only deepening what was already well underway with traditional mass media, which has given the market access to people in their homes, through print and, much more powerfully, broadcast media. The role of television in particular at the core of mass communications has delivered and guaranteed audiences on a daily, now round the clock basis. There are synergies between the images of people glued to television screens, now computer screens, or a combination of both. The digitization of television is bringing extra potential to its market functions through interactivity, to, for example, find out more about a product being advertised on screen. The information-rich, online environment allows many more details about products and services to be provided to customers, and to gather data profiles on them, that, for instance, allow recommendations to be made to them.

The symbolic capacities of the online world are a paradise for marketers and the more work, shopping and other leisure activities move online, the greater and more captive audiences are for them. Critical perspectives on the drivers and influences, positive and negative, are just as important with new media as they have been with traditional mass media. And the latter have much to teach us about the former. Continuities as well as discontinuities are all around us when it comes to technologies. The world of Matrix Reloaded is not that far apart from Metropolis, despite their distance from one another in time. Contrasting capacities, productive and destructive, are among core factors dividing the world in the information age. So when we come to our third question of how inequalities might be tackled, one of my messages is that we should bear in mind what has gone before, as much as what is happening now.

Debates about global warming focus on the long-term unanticipated or ignored results of industrially fuelled economic growth and consumption associated with it. Iconic items in this context remain the car and the jet aircraft. The mobility they permit within and across societies, and the sense of freedom associated with them, are embedded in contemporary capitalistic culture. If expansion of consumption of cars and air travel continues in the interests of equal opportunity for developing as well as developed societies, then the pollution problems associated with them will also continue to grow. It appears that both developed and developing countries need to consider these problems, among many others, but there is scarce evidence yet that this is going to happen with sufficient urgency.

Sociospatial connectivity offers possibilities for new forms of virtual mobility, lessening dramatically many of the reasons to physically travel in order to produce and consume: teleworking, videoconferencing, webcam chatting being among the examples. There are clearly many more possibilities for working on how sociospatial and geospatial contexts could be differently 
related in people's navigation of work and play as part of sustainable development strategies. But mind shifts and policy shifts need to be steered in new directions along such lines. It is probably not sufficient to just leave it to the market if wholesale forms of change are desired and in relatively short timeframes. Political will as well as imagination and effort are likely to be needed.

On the more negative side sociospatial freedoms are facilitating the extension of working hours through the flexibility to continue tasks and access email at home as well as in the office, and move across the two fairly seamlessly. This is a small example of the extent to which sociospatial developments are enhancing the operation of capitalism, through its established tendencies of further rationalization, and specific concepts of efficiency related to it. This is part of the problem in generating imaginative uses for the sociospatial towards sustainability. Not surprisingly this sphere predominantly reflects, and is structured by, dominant state and market framings. These are based on growth-oriented approaches to industrially fuelled capitalism of traditional varieties, and reflect its values. The growth in online travel and flight business are simple illustrations.

The new sociospatial sphere does not necessarily mean a new way of thinking about sustainable development, or the application of it to such purposes. This would take a whole set of deliberate shifts in political and economic agendas and will. Commentators are arguing that such shifts are desperately needed to begin working towards sustainable livelihoods and lifestyles.

When we come to my fourth question I would have to argue that this statement is an accurate representation of the recent past and contemporary picture. The world does seem to be moving towards more equality for some and less for others, and for some of those so much less that the result is death and struggle from economic deprivation. The meanings of this complex situation are varied, but I am highlighting tensions between declared equality aims versus inequality reality as part of the problem.

One of the questions on my mind as I close this book is the extent to which the sociospatial sphere will be a focus of two main ways of raising awareness. First, about the deep inequalities in the information age, and possible ways of overcoming them, and second, about the challenges of sustainable development and how sociospatial connections could actively and more creatively be used towards it. In my reference to Adam Smith I touched on the time/space dimensions of his analysis of the organization of different elements of economic activity and their relationship to one another in providing for the future.

Perhaps we need to return to some fundamentals about the organization of the economy, building in the sociospatial as well as geospatial frameworks, and consider how they should and could be interrelated more effectively towards sustainable development goals. This is after all the new overall context for GPE, and fresh thinking is bound to be needed. States and 
markets are operating increasingly in sociospatial as well as geospatial settings. Symbolic factors are far from new in GPE, money and the status as well as functions of cities being among factors I have discussed. Symbolic environments of the sociospatial kind are new, and as they become increasingly integral to all aspects of GPE, the demands on us to fully interrogate them will expand. 


\section{Notes}

\section{Introduction: twentieth to twenty-first century imaginings and realities - a long view of information society}

1 Susan Strange played a significant founding role in shaping the whole field of international/global political economy (IPE/GPE). She completed a large body of scholarly work including on theory of international/global political economy, state/market relations, multinational firms, and finance. See the range of essays on her contributions and bibliographical material on her publications in Lawton et al. (2000) and Tooze and May (2002b). IPE/GPE developed as a subfield of International Relations (IR). See, for example, Gilpin (1987), Strange (1995) and Gill (2003: Ch. 2). IR is itself is a sub-field of politics. See the useful overview and introductory material in Booth and Smith (1995) and Williams et al. (1993).

2 Kenneth Waltz (1979) is generally seen as the founder of neorealist theory in IR. Robert Keohane $(1984,1989,2002)$ is the most prominent neoliberal institutionalist. See also Keohane and Nye (1977) and important debates across neorealism and its critics and between neorealism and neoliberalism in Keohane (1986) and Baldwin (1993) respectively. On the problem of state-centrism in these mainstream approaches see Youngs (1999a).

3 See the comprehensive and subtle assessment of Strange's work by Tooze and May (2002a).

4 James Rosenau, whose work straddles IR/IPE concerns, can also be seen as another scholar whose work heralded the arrival of globalization studies. See Rosenau (1990). On globalization see, for example, Mittelman (1996), Kofman and Youngs (2003; see also 1st edn 1996), Scholte (2005).

5 This view is also expressed by Tooze and May (2002a: 13).

6 Strange (1994: 26-7) goes to a lot of trouble to visualize and represent the four structures as in relation to each other through a diagram of 'a tetrahedron' - 'a figure made up of four planes or triangular faces'.

7 There are rare and notable exceptions. See, in particular, Rupert (1995). See also my discussion of globalization, technology and consumption in Youngs (2000c).

8 This states/markets framework crosses classical and critical approaches to political economy, in various guises, including if we think back to founding texts in these areas that continue to have influence, such as Adam Smith's Wealth of Nations (1776) and Marx's Capital (Vols I, II, III, 1867, 1885 and 1894 respectively). A definitive thread in debates in GPE in the late twentieth century pitched state against market, and as globalization was seen to be increasingly driving change, the problem was framed more and more as state power losing out to market power. This shift in power was seen to be evidenced in a whole complex of 
processes including the demise of the welfare state, particularly in Western Europe, the transfer of production processes in transnational company networks from developed to other developed and to less developed economies, and the growing wealth concentrated in major financial and other global corporate giants to levels dwarfing the scale of some national economies. At issue in broad terms in such debates was the consideration of collective (public) state interests versus (private) market ones. One of the most accessible and authoritative discussions of related issues with a policy orientation is Stiglitz (2002). Discussing the damage done to fragile developing economies through the triumph of market ideology in International Monetary Fund (IMF) policies, Stiglitz's combined academic and practice-based experience gives him a distinctively even-handed approach to the roles of state and market.

I had studied the failures of both markets and governments, and was not so naïve as to think that government could remedy every market failure. Neither was I so foolish as to believe that markets by themselves solved every societal problem. Inequality, unemployment, pollution: these were all issues in which government had to take an important role.

(Stiglitz 2002: xii)

Phil Cerny has been one of the most lucid academic commentators on public/ private shifts in globalization. See, for example, Cerny (2003). See also Hutton (2002) on the distinctions between Europe and America in the context of globalization.

9 See Peterson's (2003) discussion of 'the virtual economy'. On finance see also Cerny (1997).

10 Alan Russell (1997) refers to Peter Dicken's work on other generic technologies. See Dicken (2003).

11 Different areas of the growing literature on knowledge/information society issues will be discussed in this study. Contrasting approaches in political economy include May (2002). From communications and media studies see, for example, Webster, F. (2002 and 2003). Castells (2000) is probably the best known related work. See also the range of related articles in the journal Information, Communication and Society.

12 See the official Marshall McLuhan website <http://www.marshallmcluhan.com>.

13 See Castells (2000) on networks and flows related to ICTs. Recent work on global cities has focused in more detail on the exact nature of the flows between them in different areas, such as accountancy and banking/finance. See, for example, on London Beaverstock et al. (2003).

14 See <http://www.itu.int/wsis>.

\section{States and markets: understanding geospatial time}

1 For a detailed discussion of proximity in relation to the information age see Tomlinson (1999).

2 Smith begins his thesis with a discussion of 'the division of labour' in Ch. 1 of The Wealth of Nations.

3 On the concept of 'total war' see, in particular Calvocoressi and Wint (1972). For a broad discussion of points relating to western Europe raised in this section see Joll (1990). On Britain, empire and the world economy see, for example, Hobsbawm (1990).

4 For detail on the US in world war two and the beginning of the Cold War see, for example, Calvocoressi and Wint (1972). See also Ambrose (1988), Ch. 2.

5 Quoted from the European Central Bank website 21 September 2005: $<$ http://www.euro.ecb.int/en/what/history.html>. 
6 Quoted from the European Central Bank website 21 September 2005: <http:// www.euro.ecb.int/en/what/history.html>.

7 I have been among those who have pointed to the problematic and static nature of state-centrism in mainstream study of international relations, and the role of GPE approaches in contesting it. Globalization studies have emphasized the importance of spatial perspectives, which go beyond the idea of territorial national units and consider political economic interactions within and across localities and global spheres. 'The globalized world economy is based on the transnational movement of the mobile factors of production: capital, labour and technology. As this movement has occurred at an increasing pace localities and regions within states have become increasingly vulnerable to economic restructuring' (Agnew and Corbridge 1995: 98). See also Youngs (1999a) and Kofman and Youngs (1996 and 2003).

8 Hutton (2002: 331-8) explores at length 'why Britain's sceptics on the euro are wrong'. 'Once the ECB's [European Central Bank's] credibility is won, it will have the same power and potential autonomy as the US Federal Reserve Board' (338).

9 See, for example, Taylor (1996).

10 See also, for example, Marcia Pointon's (1998) essay on money and nationalism focusing on the significance of the imagery of banknotes. 'Most European currencies are portrait galleries in little: a rich array of transcendent imagery that speaks of national achievement and a collective identity'(229).

11 One of the best collections related to these points is Slater and Taylor (1999).

12 Interesting in this context is Jeremy Rifkin's (2004) recent arguments about the European Dream versus the American Dream. Among the contrasts between them he notes that the European dream is a multicultural one and premised more on interdependence than autonomy (13-14). He posits also a historical distinction: that the American dream is more of the past, and the European dream more of the future. The points I raise here indicate that the homogeneity of the American dream may be an essential ingredient of its translatability globally. This would seem a more complex issue in the case of the heterogeneity of the European Dream but only time will tell of course.

13 For discussion of a range of relevant theoretical and substantive points on these areas see, for example, Darby (1997), Ling (2002) and Mohanty (2003).

14 See, for example, Stasiulis and Yuval-Davis (1995), Yuval-Davis (1997) and K. Williams (1994).

15 Notable in this context is V. Spike Peterson's (2003) integration of the 'reproductive, productive and virtual economies'.

16 The picture on women's parliamentary representation in the UK is interesting in terms of how recent change is:

Until 1997 women constituted fewer than 10 per cent of MPs - and fewer than 5 per cent between 1918 and 1983. This under representation persisted despite women's growing achievements in education, work and other areas of public life and despite increasing numbers of qualified women seeking office. In response women began to mobilise to achieve political equality, culminating in the introduction, by the Labour Party, of all-women shortlists in 1997. The number of female Labour MPs almost doubled from 62 to 121 - the ubiquitous 'Blair's Babes'. This, in part, helped to push so-called women's issues higher up the political agenda than ever before - with childcare, flexible working, maternity and paternity issues and even domestic violence much more prominent.

The use of all women shortlists for most of its retirement seats in the 2005 election meant that although Labour significantly lost seats overall, it was still able to increase its number of women MPs by four. Women now 
represent 28 per cent of the Labour Party in Parliament. The Liberal Democrats, whose share of the vote increased from 19 to 23 per cent, also increased the number of women MPs by four, totalling 16 per cent of the party. The Conservatives, in spite of making large gains, only increased their proportion of women MPs by one percentage point to nine per cent. The total number of women MPs now stands at 128 , around 20 per cent. At the current rate of change, the Fawcett Society predicts that it will take Labour around 20 years to achieve equal representation, the Liberal Democrats around 40 years and the Conservatives more than 400 years to gain equal numbers of women and men MPs.

(Wild 2005)

The title of research on UK women MPs' experience of sexism at Westminster Whose Secretary Are You, Minister? carried out by Joni Lovenduski, Margaret Moran and Boni Sones (2005) indicates how slow masculinist political environments are to change. See also Lovenduski (2005).

17 A recent report on women in London's economy (Greater London Authority 2005: 2) pointed out that the average gender pay gap is 25 per cent for women working full-time, but that this hides the real extremes of women's concentration in less senior posts and lower paid industries. The most common male pay was $£ 17.30$ an hour compared to the most common female pay of $£ 5.38$ an hour. Women made up less than 10 per cent of directors and less than 5 per cent of exective directors of FTSE 100 companies based in London. On global gender equality issues see also Youngs (2004b).

18 Nicholas Stargardt points out:

Assumptions about the inherently national character of, especially, modern history as practiced in western Europe and the English-reading world have remained safely ensconced in their dominance well into the post-1945 era. Even today, as real border controls are being removed, at least within the European Community, national boundaries discreetly impede traffic across its narrative landscape. Separate histories and tacitly national methodologies survive.

(Stargardt 1998: 22-3)

See also Ken Dark's (1998) discussion of 'long-term change and international relations'.

19 There are vast bodies of literature in these areas. On feminist history see, for example, Scott (1996). In postcolonial analysis the work of Edward Said is the best known, particularly in relation to his critique of imperialism and 'orientalism' (Said 2003. See also Said 1994). See also Young (1990) including for his discussion on Said. Postcolonial critiques have focused heavily on literature as part of the national script. See, for example, Ashcroft, et al. (2002).

20 In feminist international relations the body of work of Cynthia Enloe stands out in this context for the different ways she has explored the roles and experiences of women across the world. See, for example, Enloe (1990, 1993 and 2004). See also Mohanty (2003).

21 I have undertaken a detailed feminist critique of the 'inside/outside' issue related to broad questions of political economy and globalization. See Youngs (1999a).

22 Paul Hirst's (1997) arguments about 'associative democracy' are interesting in this context. 


\section{Notes}

\section{Virtual realities: exploring sociospatiality}

1 One of the best analyses of the development of the commercial communications business in this regard is Schiller (2000), which maps well the role of neoliberal privatization and liberalization facilitated by new legislation in the USA.

2 CERN's website (<http://public.web.cern.ch/Public/Welcome.html>) offers information about its role and history.

3 See the extensive information on the W3C website (<http://www.w3.org >), including about the 'semantic web', the next stage of development focused on data rather than just document interconnectivity.

4 Information on Gates, his publications and speeches can be found on his homepage <http://www.microsoft.com/billgates/default.asp $>$.

5 Castells (2000) undertook probably the most well-known early work on this area, but his focus tends to place less emphasis on the technological developments than I do. See also Castells (2001).

6 Deibert's (1997: 26-31) discussion of medium theory is interesting in this regard, particularly in relation to accusations of technological determinism which have tended to be fired most notably at Marshall McLuhan's body of work. Deibert emphasizes the need to avoid reductionism in this area, especially in relation to monocausal orientations, or tendencies to see social developments as necessarily tied to specific technological developments.

7 Alvin Toffler's (1971) Future Shock remains an iconic text in this area. Many of the points Toffler raises remain prescient more than thirty years on. For example, in his discussion of the wide potentials of genetic engineering, he makes an observation directly relevant to debates of the present day: 'Ultimately, the problems are not scientific or technical, but ethical and political. Choice - and the criteria for choice - will be critical' (Toffler 1971: 187).

8 McLuhan et al. (1997) stream of consciousness type thoughts about the human/technology interface offer some rather extreme, and sometimes outlandish, yet heuristically interesting perspectives along these lines. For example:

The computer is by all odds the most extraordinary of all the technological clothing ever devised by man, since it is the extension of our central nervous system. ... Since the new information environments are direct extensions of our own nervous system, they have a much more profound relation to our human condition than the old 'natural' environment. They are a form of clothing that can be programmed at will to produce any effect desired. Quite naturally, they take over the evolutionary work that Darwin had seen in the spontaneities of biology.

(McLuhan et al. 1997: 35-7)

9 Howard Rheingold remains the earliest and most well-known commentator on the whole area of virtual community. See especially Rheingold (1993 and 2002). See also the range of material and links on his website <http://www.rheingold. com> accessed 25 November 2005.

10 See in particular Mumford (1938 and 1961). His wide body of work ranges across related areas of interest. See, for example, on the machine and technology Mumford (1963). Also see information on Mumford, resources and links at the University at Albany, New York, Lewis Mumford Center for Comparative Urban and Regional Research (<http://www.albany.edu/mumford $>$ ) accessed 27 November 2005. Mumford's interdisciplinarity is stressed as informing the breadth of his insight. As the Mumford Center puts it:

Urban planner, historian, sociologist, local advocate, and architectural critic Lewis Mumford is recognized as one of the greatest urbanists of the 20th 
Century. A lifelong opponent of large-scale public works, much of his writings concern the effect of buildings on the human condition and the environment.

(<http://www.albany.edu/mumford/about/about1.html> accessed 27 November 2005)

See also the arguments by May (2000: 262) about the ongoing relevance of Mumford's work to information society and the 'interaction and conflict between democratic and authoritarian technics'.

11 Saskia Sassen has produced some of the most ground-breaking work on the global city phenomenon. See especially Sassen (2001 and 2002a).

12 See Sassen $(2002 a)$ for a range of essays on related areas.

13 See Bird et al. (1993) for a collection of discussions in this area.

The city, the contemporary metropolis, is for many the chosen metaphor for the experience of the modern world. In its everyday details, its mixed histories, languages and cultures, its elaborate evidence of global tendencies and local distinctions, the figure of the city, as both a real and an imaginary place, apparently provides a ready map for reading interpretation and comprehension.

(Chambers 1993: 188)

14 Harvey (1990) and Agnew and Corbridge (1995) offer comprehensive discussions on this. For wider theoretical discussions on spatiality see, for example, Lash and Urry (1994), Thrift (1996) and Soja (1996).

15 The annual UNDP Human Development Reports have been the most consistent and detailed in tracking these developments, particularly in relation to the widening inequality gaps as a long-term trend. UNDP (1998) focused explicitly on consumption. Dicken (2003) addresses different areas of global restructuring and offers case studies of globalized industries including automobiles and financial services.

16 See Sassen (2002a). Strange (1996) includes discussion of the distinctive role of the major accountancy firms in the world economy.

17 Dicken (2003) looks in detail at the similarities and differences in the 'complex organizational-geographical networks' of TNCs. Sassen (2002a) includes varied assessments of the role of ICTs.

18 See the range of discussions on related matters in Harcourt (1999). This book focuses on a small UNESCO-Society for International Development international policy and practice related research project in the late 1990s called Women on the Net (WON) involving academics, development practitioners and researchers. WON focused on the potential of the Internet for women. I took part in the project and was particularly interested in the ways it revealed the difficulties of communicating effectively across different kinds of boundaries of culture, expertise, professional interest, etc. One of the major lessons I learned from the project was the extent to which greater communication across such boundaries in cyberspace actually revealed the hurdles that we have to overcome to do so meaningfully, effectively and respectfully. The experiences emphasized that ICTs provide the channels of communication but the appropriateness and success of the communication itself was very much a human issue, and one involving translating across different kinds of languages and forms of expertise and knowledge. Harcourt (1999) remains one of the richest sources exploring such issues, not least because this was a very mixed group in terms of the work, interests, backgrounds and geographical experiences of those involved. Another area that the project highlighted was that the worth of ICT links was often interdependent 


\section{Notes}

with other forms of linkages such as face-to-face meetings. See also Youngs (1999b, 2001b and c and 2002a).

19 Arjun Appadurai's work has been amongst the most well known in this area in its embrace of very different kinds of flows including of people through migration and diasporas and of cultural products and imaginaries. He focuses on flows and varied 'scapes' such as mediascapes. See Appadurai (1996) and also information on his work, publications, etc. on his website <http://www.appadurai.com> accessed 30 November 2005.

20 Media and communications scholarship considers diverse elements of mediation: technological, social, cultural, emphasizing in the study of mass communication the role of public sphere institutions and their disseminated messages, and active audiences' reception of them. Linkages between public and private spheres are often implicit as well as explicit.

21 This same problematic has also been argued in relation to the study of globalization, where spatial restructuring as discussed already in this chapter is one driver of change. See Harvey (1990), Agnew and Corbridge (1995), and Youngs (1999a).

22 See Winston (1998) on the development of the PC and networking across PCs.

23 Communications convergence is a key area in terms of economic development. The OECD held a roundtable on it involving regulators and public and commercial media operators in June 2005. Topics for discussion included the role of public broadcasting in the context of convergence, questions of targeted regulation, and the balance between liberalization and property rights. See OECD (2005).

24 There is a wealth of feminist scholarship on this point. See, for example, Youngs (1999a and 2000c) and Peterson (2003).

25 Kramarae and Spender (2000) is a good source for multidisciplinary material in this regard. See also Code (2000).

26 I have discussed this area in Youngs (2000a).

27 Interdependencies across public and private in GPE are explored in detail and breadth, including diverse case study material, in Marchand and Runyan (2000) and Youngs (2000d).

28 I discuss this in some depth in Youngs (2000a).

29 Other feminists have urged women to be active in engaging with all aspects of ICT transformations. See, especially, Spender (1995) and Harcourt (1999). On cyborg-related themes see also Thomas (2004).

\section{The political economy of time: historical time, speed and mobility}

1 See, for example, 'Japanese PM Apologizes Over War' a BBC online news report 22 April 2005, accessed online 5 December 2005 at <http://news.bbc.co.uk/ 2/hi/asia-pacific/4471495.stm>.

2 See, for example, Calvocoressi and Wint (1972), Thorne (1972) and Joll (1990).

3 The work of postcolonial scholars such as Edward Said $(1994,2003)$ has raised awareness of how this writing out of history contributes to perceptions of the less powerful as less active and empowered. It has also included attention to narratives, including fictional ones, as relevant to our understanding of the colonial imaginary and its geospatial power dynamics as well as resistances to them.

As one critic has suggested, nations themselves are narrations. The power to narrate, or to block other narratives from forming and emerging, is very important to culture and imperialism, and constitutes one of the 
main connections between them. Most important, the grand narratives of emancipation and enlightenment mobilized people in the colonial world to rise up and throw off imperial subjection; in the process, many Europeans and Americans were also stirred by these stories and their protagonists, and they too fought for new narratives of equality and human community.

(Said 1994: xiii)

4 These developments have been part of the whole poststructural turn in theoretical and academic work, that has been the subject of fierce and ongoing debate, with concerns that textual orientations are surface forms of analysis and stray too far from the concrete operations of power in politics and economics, political and economic institutions and social relations. In this sense read post-Marxist for poststructural, the idea being that somehow the material was being left behind in exchange for the textual. But it is clear that much poststructural analysis is influenced by Marxist theory and critiques, and is post in the sense that it is taking them in another direction. My reading of much of Foucault's theory is in this direction. I see his extensive work on discourse and governmentality as a pursuit of understanding discourses as embedded aspects of material reality and experience. His insights are oriented towards the significance of discourses at the individual as well as the institutional levels. His particular contributions include a sharp focus on interaction between institutional and individual restrictions and perceptions through diverse discourses of power in modern society, for example, of disciplinary systems (education, the military), and post-enlightenment knowledge building (academic and governmental). See Foucault (1969 and 1971). See also Burchell, Gordon and Miller (1991) including material by Foucault. His work on the history of sexuality considers how aspects of individual identity are formed in and through social practices and constraints. See Foucault (1976). For an accessible discussion of key issues in poststructuralism and postmodernity see Best and Kellner (1991).

5 Post-Marxist is clearly a problematic term. I am using it here to indicate that while the influence of Marx's critique of capitalism persisted, other critical trajectories, for example associated with poststructuralism, adopted contrasting or expanded social critiques, assessing different aspects of culture, including discursive and representative modes.

6 See, for example, Youngs (2004b), for a general discussion of these areas. Refer also to the annual UNDP Human Development Report for broad discussions of economic and associated gender inequalities across North-South. Pettman (1996) remains one of the clearest and most comprehensive perspectives on women's inequalities and political economy in relation to globalization, and Kofman and Youngs (2003) includes a number of chapters on this theme.

7 See K. Williams (1994) on intersectionality, and Pettman (1996) and Mohanty (2003) for related analysis.

8 On the problem of essentialism in feminist theory see, for example, Abbott (2000).

9 See the range of debates and research on this area in Marchand and Runyan (2000), and my early discussion of 'globalized lives, bounded identities' (Youngs 1997b).

10 Enloe has actually called her recent collection of essays The Curious Feminist (2004). The introduction to this collection is an excellent reflective discussion on how and why she has come to place such emphasis on the whole issue of curiosity in her analysis and research. See also Enloe (1990, 1993).

11 Martin Davies' philosophical approach to history as a dominant idea is also notable in this context, especially as he argues it as being distinct from postmodernist critiques. His exploration of 'historics' positions history (whether in modernist or postmodernist forms) as a fundamental fabric of social orientation: 
'history, the socially dominant idea of an already historicized world, is the intellectual instrument of dominant socio-economic interests' (2006: 5).

12 Anthony Giddens' influential sociological approach to globalization features an emphasis on the 'separation of time and space' as intrinsic to the 'dynamism of modernity' (when compared to 'traditional cultures') and the various measurements of time through calendars and clocks, which facilitate the 'ordering of time and space' into divisions such as work and leisure (1991: 16-18).

13 Brian Winston's (1998: 243-260) historical analysis of media technology from the telegraph to the Internet demonstrates the early beginnings of today's network era in the mid-nineteenth-century spread of telegraphy and the building of the transoceanic telegraphy network.

14 I undertook an earlier version of this discussion about WSIS in Youngs (2005).

15 The Milllennium Development Goals (MDGs) are ambitious development targets set for 2015, but trend analysis related to them already signals some pessimism. For example, that 50 countries with a combined population of almost 900 million are going backwards on at least one of the goals and 24 of these are in SubSaharan Africa. A further 65 countries with a combined population of 1.2 billion will fail to meet at least one MDG until after 2040, missing the target by an entire generation (UNDP 2005: 41). For further details on the goals see the UN MDG website <http://www.un.org/millenniumgoals>.

\section{Transcendence and communication}

1 I was stimulated to think about these points in broad philosophical senses by discussions in the classical text De L'Esprit des Lois (The Spirit of the Laws) by Montesquieu (1748).

2 The most prominent critical thinker in relation to the development and changes in the public sphere is Jürgen Habermas.

3 I first developed the points in this section in Youngs (2001a).

4 I explore a range of theoretical arguments related to this spatial multiplicity in Youngs (1999a).

5 The G8 (G7 until Russia joined in 1998) is a grouping of the major economies (USA, UK, Canada, France, Germany, Italy, Japan, Russia), whose heads of state/government meet at an annual summit. See for example University of Toronto G8 Information Centre website <http://www.g7.utoronto.ca>, Canadian government's G8 website <http://www.g8.gc.ca>, and UK government's Gleneagles G8 2005 website <http://www.g8.gov.uk/servlet/Front?pagename= OpenMarket/Xcelerate/ShowPage\&c=Page\&cid=1078995902703> (all accessed 6 April 2006).

6 The World Economic Forum representing leading world business interests meets annually at Davos in Switzerland. For background on the Forum and resources related to its meetings see its website $<$ http://www.weforum.org $>$ (last accessed 6 April 2006).

7 See Giddens (1990) for discussion of the concept of stretching of relations and globalization.

8 I first touched on related issues in Youngs (1997b).

9 On globalization and the media, see, in particular Herman and McChesney (1997), Mohammadi (1997). See also Mosco (1996) on political economy and communication. Mosco highlights 'the state's constitutive role' in '[c]ommercialization, liberalization, privatization, and internationalization', as well as regulation (204). He points out: 'historical practice leads a political economic analysis to conclude that both the industry and the state are primary forces in the development of communication, that their relationship is mutually constitutive 
and variable' (204). He also discusses the 'interstate coordination' that has facilitated 'transnationalization of communication networks' (203-4).

10 I first touched on these two themes in this context in Youngs (2002b).

11 See also Tehranian and Tehranian (1997) for discussion of a range of related issues.

12 See the websites of these stations: <http://www.cnn.com>; <http://www.sky. com/skynews/home>; <http://www.tvhome.co.uk/bbcnews24>; <http://english. aljazeera.net/HomePage $>$ (all last accessed 10 April 2006).

13 The concept of anarchy is at the heart of traditional realist approaches to international relations. In this context Hedley Bull's (1977) modified idea of 'anarchical society' continues to hold purchase in stressing influences of order as well as disorder in international relations.

14 One of the foundational texts on 'mass society' remains Biddis (1977) where he comments: 'In the classic model mass society is differentiated from what precedes it by an enlargement in the scale of activities, institutions, and loyalties' (15).

15 I have discussed in Chapter 1 the importance of Rob Walker's (1993) work regarding 'inside/outside'.

16 I have learned most about this situation from teaching my undergraduate and postgraduate students about critical use of online information sources and the need for independent assessment of them. I am grateful to them for the insights they have helped me to develop about the new political economy of interactivity. For discussion of relevant issues see also Dijk (2005).

17 Everard (2000) was one of the earliest discussions of the following points and remains one of the most lucid. On the governance of cyberspace see also Loader (1997).

18 As part of 'Operation Ore', for example, the Federal Bureau of Investigation in the USA passed to UK police details on users of a US paedophile website, leading to hundreds of convictions. See BBC report 'Child Porn Crackdown Nets Results' accessed 15 April 2006 at <http://news.bbc.co.uk/1/hi/uk/3514950.stm>.

19 On critical debates about related issues see, for example, Goldenberg (2006).

20 One of the most detailed contemporary theoretical justifications of this interdependence between liberal politics and economics can be found in Fukuyama (1992).

21 See Castells (2000) on flows.

22 Schiller (2000) remains one of the best analyses of history of the Internet and the political economy of communications related to it. See also Nye (2004).

23 See, for example, Castells (2000) on 'the rise of the network society'.

24 Joseph Nye's (2004) discussion of the influence of American 'soft power', vested basically in dominant neoliberal pluralist principles, is of interest in this regard. Nye stresses however that the USA treads a fine line between the positive effects of liberal policies at home and abroad ('consistent with democracy, human rights, openness, and respect for the opinions of others') and the 'danger' that it 'may obscure the deeper message of its values through arrogance and unilateralism'. He sums up succinctly: 'The trends of the information age are in America's favor, but only if it avoids stepping on its own message' (93).

25 John Tomlinson's (1999) discussion of proximity is particularly useful in thinking through such questions.

26 See the Sex Offences Act 2003. Extracts posted on the website of the Internet Watch Foundation accessed 15 April 2006 at <http://www.iwf.org.uk/police/ page.22.13.htm>.

27 See the Liability of Intermediary Service Providers Directive 2000/21/EC which came into UK Law in 2002 as part of EU E-Commerce regulations. Extracts posted on the website of the Internet Watch Foundation accessed 15 April 2006 at <http://www.iwf.org.uk/police/page.22.40.htm>. 


\section{Notes}

28 The watchdog and information functions of the Internet industry-funded Internet Watch Foundation (IWF) demonstrates the multi-stakeholder and developmental character of the new regulation environment for the Internet in democratic settings. As explained on its website:

The IWF is the only authorised organisation in the UK operating an internet 'hotline' for the public and IT professionals to report their exposure to potentially illegal content online. Our aim is to minimise the availability of potentially illegal internet content, specifically:

child abuse images hosted anywhere in the world

criminally obscene content hosted in the UK

criminally racist content hosted in the UK

We work in partnership with UK Government Departments such as the Home Office and the Department of Trade and Industry to influence initiatives and programmes developed to combat online abuse. This dialogue goes beyond the UK and Europe, to ensure greater awareness of global issues and responsibilities.

(accessed 16 April 2006 at <http://www.iwf.org.uk/media/ page.70.214.htm>

29 See, for example, the discussion of the new media environment after 9/112001 by B. Williams (2003).

30 Commentators such as Bloor (2000) provide accessible and clear discussions of how the Internet has changed the marketplace dramatically, including making it an information sphere where customers and businesses can easily contrast and compare details on competitors. This is an element of the transparency of the new virtual marketplace and its orientation towards data.

31 The EU Directive on Data Retention impacting on Internet Service Providers (ISPs) was being debated in the UK as this book was being written. The government was reported to be stressing the importance of working with industry on this legislation aimed at requiring the storing of data for set periods for availability to law enforcement agencies pursuing serious criminal investigations. See Internet Service Providers' Association (2006). Developments related to data tracking for anti-terror/crime purposes showed the hybrid state/market nature of Internet surveillance functions, hence the focus on cooperation between state and market actors referred to here.

32 Activism related to internet privacy issues is extensive. See, for example, the Electronic Privacy Information Center <http://www.epic.org>.

33 See, for example, the Riverbend blog at $<$ http://riverbendblog.blogspot.com $>$. See also <http://www.huffingtonpost.com>.

34 See report entitled Open Door accessed online 16 April 2006 at <http://media. guardian.co.uk/newmedia/story/0,,1745659,00.html>.

35 See United Nations Literacy Decade 2003-2012 accessed online 16 April 2006 at <http://portal.unesco.org/education/en/ev.php-URL_ID=5000\&URL_DO= DO_TOPIC\&URL_SECTION=201.html>.

36 See United Nations Literacy Decade 2003-2012. World Literacy in Brief - A Statistical Overview accessed online 16 April 2006 at <http://portal.unesco. org/education/en/ev.php-URL_ID=12874\&URL_DO=DO_TOPIC\&URL_ SECTION=201.html $>$.

37 ICANN the Internet Corporation for the Assignment of Names and Numbers, based in the USA (<http://www.icann.org >) has taken over the previous US government overarching management of the Internet including address allocation and top-level domain name management of the Internet. See also ICANN Watch (<http://www.icannwatch.org $>$ ) and Mueller (2002). 


\section{Inequality as driver}

1 For a range of interesting theoretical and substantive essays see, for example, Eschle and Maiguashca (2005).

2 Accessed online 18 April 2006 at the World Social Forum website <http:// www.forumsocialmundial.org.br/main.php?id_menu $=4 \& c d$ language $=2>$.

3 For a fairly wide-ranging critical discussion of the 'China as new superpower' question, see, for example, C. Johnson (2005).

4 Included in a statement from African Women's Regional Consultation on Women's and Rights and HIV/AIDS in Africa, in Johannesburg, South Africa, April 6-7, 2006 accessed online via UNIFEM's Gender and HIV/AIDS Web Portal 20 May 2006 at <http://server1.stupidcensorship.com/cgi-bin/nph-surf.cgi/010 $100 \mathrm{~A} /$ uggc/jjj.fneca.bet.mn/qbphzragf/q0002000/vaqrk.cuc>.

5 It is interesting to read the theoretical parts of Fukuyama (1992) on this point. Whether one agrees with his thesis or not, and I have been severely critical of it among many others (see Youngs 1997a), he explores detailed arguments about the basis for the positive appeal of political and economic liberalism.

6 See Anheier and Katz (2006: 289). They cite Beck (2003) and Shaw (2003).

\section{Embedded patriarchy: feminism and inequality in the Internet era}

1 I first developed these points in Youngs (2001c).

2 This was clear to me in research I undertook in Hong Kong. See Youngs (2000a).

3 Ara Wilson's essay provides an excellent overview of the background to, and debates surrounding, the concept of patriarchy in feminist analysis. See also Walby (1990).

4 Tomlinson (1999) offers one of the best analyses of such areas. Gleick (2000) 5 also covers a lot of relevant ground. See also Gates (1999).

[R]eal time began with the birth of computers. But computers did not create real time. Computers created fake time - simulated time in simulated realities. ... The computer is defined by speed; it depends on speed, more than any of the fast machines that came before - more than the steam engine, more than the automobile, more than the airplane.

(Gleick 2000: 66)

6 For a range of broad points concerning time and historical change see, for example, Dark (1998). See also on beliefs related to time Raju (2003).

7 For a useful brief overview of science and feminist perspectives see, for example, Star (2000).

8 For a range of discussions related to these points in North and South see, for example, Mitter and Rowbotham (1995), Harcourt (1999) and Green and Adam (2001).

9 See also Cockburn (1985), Cockburn and Ormrod (1993) and Cockburn and Fürst-Dilić (1994).

10 See, for example, Perry and Greber (1990), J. Webster (1995) and Green and Adam (2001).

11 The Association for Progressive Communication's Women's Networking Support Program (APCWNSP) is one of the best sources on these issues in general and in relation to the South in particular. See <http://www.apcwomen.org/eng index.shtml>.

12 APCWNSP (<http://www.apcwomen.org/eng_index.shtml>) is one of the best sources on projects in this area. 


\section{Notes}

13 See notes 11 and 12. See also ISIS International <http://www.isiswomen.org>, DAWN (Development Alternatives with Women for a New Era) <http://www. dawnorg.org>. WoN had links to all these organizations.

14 See my further arguments about these areas in Youngs (2006b). See also Youngs (2002a and 2004a).

\section{Complex hegemony in the twenty-first century: power and inequality}

1 For material related to early online business ventures, including rise and fall scenarios, see, for example, Cellan-Jones (2001) and Cassidy (2002).

2 See especially Youngs (1999a) and Kofman and Youngs (1996 and 2003).

3 The issue of US exceptionalism is a wide area of study related to the distinctive political history of the country as well as its role in the world. See, for example, Lipset (1996). On associated areas see, for example, Slater and Taylor (1999).

4 In these rankings France is third also with five per cent of world military expenditure, Japan fourth with four per cent, and China fifth with an estimated four per cent. These are based on market exchange rates (MER). On purchasing power parity (PPP) China is ranked second, India third, Russia fourth and France fifth. See SPIRI (2006).

5 See Chomsky (2004) for critical assessment of related issues. On feminist perspectives on the war on terror see, for example, International Feminist Journal of Politics (2006) and Youngs (2006a).

6 On network wars and related issues, for example, Kaldor (2001) and Der Derian (2002). On the media, see also Thussu and Freedman (2003) and Tumber and Palmer (2004).

7 For a critical discussion see, for example, Kaldor (2001) and Caldicott (2004). See also Caldicott and Eisendrath (forthcoming 2007). See also the US Department of Defense website on 'The Ballistic Missile Defense Organization' at <http://www.defenselink.mil/specials/missiledefense/history.html>.

8 Critical Gramscian analyses focus most on this area. See, for example, Cox (1981).

9 Mary Kaldor has been a prominent thinker and commentator in this area. See, for example, Kaldor (2001).

10 Schiller (2000) is one of the best references for digital developments in the USA in GPE terms. See also Deibert (1997).

11 Vincent Mosco (2004) talks directly to this issue.

12 See also on the Internet and human rights Hick et al. (2000).

$13 \mathrm{I}$ am using this term in an indicative manner here to focus on overall lived experience and different influences on it including mediated activities. For discussion of the concept see, for example, Habermas (1984 and 1987).

14 In my student days my thinking about technology in shaping the nature of modern life was heavily influenced by Herbert Marcuse's (1964) One Dimensional Man. His arguments would seem to me worth rereading with the advent of the information age. 


\section{Bibliography}

Abbott, Pamela (2000) 'Essentialism', in Routledge International Encyclopedia of Women: Global Issues and Women's Knowledge, vol. 2, ed. Cheris Kramarae and Dale Spender, London: Routledge, pp. 615-16.

Agnew, John and Stuart Corbridge (1995) Mastering Space: Hegemony, Territory and International Political Economy, London: Routledge.

Allen, Kate (2006) 'Today Our Chance to Fight a New Hi-Tech Tyranny', The Observer, 28 May, pp. 8-9.

Ambrose, Stephen E. (1971) Rise to Globalism: American Foreign Policy, 1938-1970, London: Penguin.

Ambrose, Stephen E. (1988) Rise to Globalism: American Foreign Policy Since 1938 5th edn, London: Penguin; 8th edn, 1997.

Anderson, Benedict (1991) Imagined Communities: Reflections on the Origin and Spread of Nationalism, London: Verso.

Anheier, Helmut and Hagai Katz (2006) 'Learning from History? Comparative Historical Methods and Researching Global Civil Society', in Global Civil Society 2005/6, ed. Marlies Glasius, Mary Kaldor, Helmut Anheier, London: Sage, pp. 288-302.

Appadurai, Arjun (1996) Modernity at Large: Cultural Dimensions of Globalization, Minnesota, MN: Minnesota University Press.

Arizpe, Lourdes (1999) 'Freedom to Create: Women's Agenda for Cyberspace', in Women@Internet, ed. Wendy Harcourt, London: Zed, pp. xii-xvi.

Ashcroft, Bill, Gareth Griffiths and Helen Tiffin (eds) (2002) The Empire Writes Back, 2nd edn, London: Routledge.

Association for Women's Rights in Development (AWID) (2004) 'Intersectionality: A Tool for Gender and Economic Justice. Women's Rights and Economic Change', No. 9 August. Accessed online 19 Feburary 2006 at <http://www.awid.org/ publications/primers/intersectionality_en.pdf $>$.

Bailes, Alyson J. K. (2005) 'Lessons of Iraq', Speaking Notes Beijing 9 May 2005. Accessed online 28 May 2006 at <http://www.sipri.org/contents/director/ 20050509.html/view? searchterm=China's\%20military\%20spending $>$.

Bakker, Isabella (2003) 'Neoliberal Governance and the Reprivatization of Social Reproduction: Social Provisioning and Shifting Gender Orders', in Power, Production and Social Reproduction, ed. Isabella Bakker and Stephen Gill, London: Palgrave Macmillan, pp. 66-82.

Baldwin, David A. (ed.) (1993) Neorealism and Neoliberalism: The Contemporary Debate, New York: Columbia University Press. 


\section{Bibliography}

Beaverstock, Jonathan, Richard Smith and Peter Taylor (2003) 'The Global Capacity of a World City: A Relational Study of London', in Globalization: Theory and Practice, 2nd edn, ed. Eleonore Kofman and Gillian Youngs, London: Continuum, pp. 223-6.

Beck, Ulrich (2003) 'The Analysis of Global Inequality: From National to Cosmopolitan Perspective', in Global Civil Society 2003, ed. Mary Kaldor, Helmut Anheier and Marlies Glasius, Oxford: Oxford University Press.

Berners-Lee, Tim (with Mark Fischetti) (1999) Weaving the Web: The Past, Present and Future of the World Wide Web by its Inventor, London: Orion.

Best, Steven and Douglas Kellner (1991) Postmodern Theory: Critical Interrogations, London: Macmillan.

Biddis, Michael D. (1977) The Age of the Masses, Harmondsworth: Penguin.

Bird, Jon, Barry Curtis, Tim Putnam, George Robertson and Lisa Tickner (eds) (1993) Mapping the Futures: Local Cultures, Global Change, London: Routledge.

Bloor, Robin (2000) The Electronic B@zaar. From the Silk Road to the eRoad, London: Nicholas Brealey.

Booth, Ken and Steve Smith (eds) (1995) International Relations Theory Today, Cambridge: Polity.

Bull, Hedley (1977) Anarchical Society: A Study of Order in World Politics, London: Macmillan.

Burchell, Graham, Colin Gordon and Peter Miller (eds) (1991) The Foucault Effect. Studies in Governmentality, London: Harvester Wheatsheaf.

Caldicott, Helen (2004) The New Nuclear Danger: George W. Bush's MilitaryIndustrial Complex, 2nd edn, New York: New Press.

Caldicott, Helen and Craig Eisendrath (Forthcoming 2007) War in Heaven: the Militarization of Outer Space, New York: New Press.

Calvocoressi, Peter and Guy Wint (1972) Total War: Causes and Courses of the Second World War, Harmondsworth: Penguin.

Cassidy, John (2002) Dot.Con: The Greatest Story Ever Sold, London: Allen Lane.

Castells, Manuel (2000 [1996]) The Rise of the Network Society, 2nd edn, Oxford: Blackwell.

Castells, Manuel (2001) Internet Galaxy: Reflections on the Internet, Business and Society, Oxford: Oxford University Press.

Cellan-Jones, Rory (2001) Dot.bomb: The Rise and Fall of Dot.Com Britain, London: Aurum.

Cerny, P. G. (1995) 'Globalization and the Changing Logic of Collective Action', International Organization 49, 4: 595-625.

Cerny, Phil (1997) 'The Search for a Paperless World: Technology, Globalization and Policy Response', in Technology, Culture and Competitiveness: Change and the World Political Economy, ed. Michael Talalay, Chris Farrands and Roger Tooze, London: Routledge, pp. 153-66.

Cerny, Phil (2003) 'What Next for the State?', in Globalization: Theory and Practice, ed. Eleonore Kofman and Gillian Youngs, London: Continuum, pp. 207-21.

Chambers, Iain (1993) 'Cities Without Maps', in Mapping the Futures: Local Cultures, Global Change, ed. Jon Bird, Barry Curtis, Tim Putnam, George Robertson and Lisa Tickner, London: Routledge, pp. 188-98.

Chomsky, Noam (2004) Hegemony or Survival: America's Quest for Global Dominance, London: Penguin.

Clark, David (2005) 'Politics Over Markets', The Guardian, 8 June, p. 23. 
Cockburn, Cynthia (1985) Machinery of Dominance: Women, Men and Technical Know-How, London: Pluto Press.

Cockburn, Cynthia (1997) 'Domestic Technologies: Cinderella and the Engineers', Women's Studies International Forum 20, 3: 361-71.

Cockburn, Cynthia and Ruza Fürst-Dilić, (eds) (1994) Bringing Technology Home: Gender and Technology in a Changing Europe, Buckingham: Open University Press.

Cockburn, Cynthia and Susan Ormrod (1993) Gender and Technology in the Making, London: Sage.

Code, Lorraine (2000) Encyclopedia of Feminist Theories, London: Routledge.

Cohen, Benjamin (1998) The Geography of Money, Ithaca, NY: Cornell University Press.

Conley, Marshall and Christina Patterson (2000) 'Communication, Human Rights and Cyberspace', in Human Rights and the Internet, ed. Steven Hick, Edward F. Halpin and Eric Hoskins, London: Macmillan, pp. 211-24.

Cox, Robert W. (1981) 'Social Forces, States and World Orders: Beyond International Relations Theory', Millennium: Journal of International Relations 10: 127-55.

Darby, Philip (1997) 'Introduction', in At the Edge of International Relations: Postcolonialism, Gender and Dependency, London: Pinter, pp. 1-32.

Dark, Ken. R (1998) The Waves of Time: Long-Term Change and International Relations, London: Pinter.

Davies, Martin L. (2006) Historics: Why History Dominates Contemporary Society, London: Routledge.

Deacon, David, Michael Pickering, Peter Golding and Graham Murdock (1999) Researching Communications: A Practical Guide to Methods in Media and Cultural Analysis, London: Arnold.

Deibert, Ronald J. (1997) Parchment, Printing and Hypermedia: Communication in World Order Transformation, New York: Columbia University Press.

Department of Trade and Industry (DTI) (2005) Joint report with Cabinet Office, Prime Minister's Strategy Unit, Connecting the UK: the Digital Strategy, March. Accessed online 20 May 2006 at <http://www.strategy.gov.uk/downloads/ work_areas/digital_strategy/digital_strategy.pdf $>$.

Der Derian, J. (2002) 'In Terrorem: Before and After 9/11', in Ken Booth and Tim Dunne (eds), Worlds in Collision: Terror and the Future of Global Order, Basingstoke: Palgrave Macmillan, pp. 101-117

Dicken, Peter (2003) Global Shift: Reshaping the Global Economic Map in the 21 Century, 4th edn, London: Sage.

Dijk, Jan van (2005) The Deepening Divide: Inequality in the Information Society, London: Sage.

Drew, Susan and Ruth Paradice (1996) 'Time, Women and Well-being', Feminism and Psychology 6, 4: 563-8.

Drucker, Peter F. (1993) Post-Capitalist Society, New York: HarperCollins.

Dunning, John H. (1993) The Globalization of Business, London: Routledge.

Dunning, John H. (ed.) (2000) Regions, Globalization, and the Knowledge Economy, New York: Oxford University Press.

Enloe, Cynthia (1990) Bananas, Beaches and Bases: Making Feminist Sense of International Politics, Berkeley, CA: University of California Press.

Enloe, Cynthia (1993) The Morning After: Sexual Politics at the End of the Cold War, Berkeley, CA: California University Press. 


\section{Bibliography}

Enloe, Cynthia (2004) The Curious Feminist: Searching for Women in a New Age of Empire, Berkeley, CA: California University Press.

Eschle, Catherine and Bice Maiguashca (2005) Critical Theories, International Relations, and 'the Anti-Globalisation Movement': The Politics of Global Resistance, London: Routledge.

Elshtain, Jean Bethke (1993) Public Man/Private Woman: Women in Social and Political Thought, 2nd edn, Princeton, NJ: Princeton University Press.

Everard, Jerry (2000) Virtual States: The Internet and the Boundaries of the NationState, London: Routledge.

Folbre, Nancy (1991) 'The Unproductive Housewife: Her Evolution in NineteenthCentury Economic Thought', Signs: Journal of Women in Culture and Society 16, 3: 463-84.

Foucault, Michel (1963) Naissance de la Clinique: Une Archéologie du Regard Médical, Paris: Presses Universitaires de France (rev. edn 1972) ; trans. Alan Sheridan Smith as Birth of the Clinic: An Archaeology of Medical Perception, New York: Pantheon, 1973.

Foucault, Michel (1969) L'Archéologie du savoir, Paris: Gallimard; trans. A. Sheridan Smith as The Archaeology of Knowledge, London: Tavistock Publications, 1970.

Foucault, Michel (1971) L'ordre du discours, Paris: Gallimard ; trans. I. McLeod as 'The Order of Discourse', in Language and Politics, ed. M. Shapiro, Oxford: Blackwell, 1984, pp. 108-38.

Foucault, Michel (1975) Surveiller et Punir: Naissance de la Prison, Paris: Gallimard; trans. Alan Sheridan as Discipline and Punish: The Birth of the Prison, New York: Pantheon, 1977.

Foucault, Michel (1976) Histoire de la sexualité 1: La volonté de savoir, trans. as The History of Sexuality: An Introduction, Harmondsworth: Penguin, 1981.

Fukuyama, Francis (1992) The End of History and the Last Man, London: Penguin. Gates, Bill (1995) The Road Abead, London: Longman.

Gates, Bill (1999) Business @ the Speed of Thought: Succeeding in the Digital Economy, London: Penguin.

Gibson-Graham, Julie Katherine (1996) The End of Capitalism (As We Knew It): A Feminist Critique of Political Economy, Oxford: Blackwell.

Giddens, Anthony (1990) The Consequences of Modernity, Cambridge: Polity.

Gilpin, Robert (1987) The Political Economy of International Relations, Princeton, NJ: Princeton University Press.

Gill, Stephen (2003) Power and Resistance in the New World Order, New York: Palgrave Macmillan.

Gittler, A. (1999) 'Mapping Women's Global Communications and Networking', in Women@Internet, ed. Wendy Harcourt, London: Zed, pp. 91-101.

Glasius, Marlies and Jill Timms (2006) 'The Role of Social Forums in Global Civil Society: Radical Beacon or Strategic Infrastructure', in Global Civil Society 2005/6, ed. Marlies Glasius, Mary Kaldor, Helmut Anheier, London: Sage, pp. 190-5.

Gleick, James (2000) Faster: The Acceleration of Just About Everything, London: Abacus.

Goldenberg, Suzanne (2006) 'A Moral Minefield for Corporate America', The Guardian, 20 February. Accessed online 17 April 2006 at <http://www.guardian. co.uk/china/story/0,1713295,00.html>. 
Gordon, Colin (1991) 'Governmental Rationality: An Introduction', in The Foucault Effect. Studies in Governmentality, ed. Graham Burchell, Colin Gordon and Peter Miller, London: Harvester Wheatsheaf, pp. 1-51.

Greater London Authority (2005) Women in London's Economy, London: Greater London Authority. Accessed online 2 November 2005 at $<$ http://www.london. gov.uk/mayor/economic_unit/docs/womenlondoneconomy.pdf $>$.

Green, Eileen and Alison Adam (eds) (2001) Virtual Gender: Technology, Consumption and Identity, London: Routledge.

Green, Stephen (1999) 'A Plague on the Panopticon: Surveillance and Power in the Global Information Economy', Information, Communication and Society 2, 1: 26-44.

Habermas, Jürgen (1984 and 1987) Theory of Communicative Action, vols 1 and 2, Boston: Beacon.

Haraway, Donna J (1991) Simians, Cyborgs and Women: The Reinvention of Nature, New York: Routledge.

Haraway, Donna J. (1997a) Modest_Witness@Second_Millennium. FemaleMan ${ }^{\odot}$ Meets_OncoMouse ${ }^{\circledR}:$ Feminism and Technoscience, London: Routledge.

Haraway, Donna J (1997b) 'The Virtual Speculum in the New World Order', Feminist Review 55: 22-72.

Harcourt, Wendy (1997) An International Annotated Guide to Women Working on the Net, rev. edn, UNESCO/Society for International Development.

Harcourt, Wendy (ed.) (1999) Women@Internet, London: Zed.

Harding, S. (1995) 'Can Feminist Thought Make Economics More Objective', Feminist Economics 1, 1: 7-32.

Harding, Sandra (1998) Is Science Multicultural? Postcolonialisms, Feminisms, and Epistemologies, Bloomington, IN: Indiana University Press.

Harvey, David (1990) The Condition of Postmodernity: An Enquiry into the Origins of Cultural Change, Oxford: Blackwell.

Herman, Edward S. and Robert W. McChesney (1997) The Global Media: The New Missionaries of Corporate Capitalism, London: Cassell.

HM Treasury, UK (2004) Opportunity For All: The Strength to Take the LongTerm Decisions for Britain. Pre-Budget Report December 2004, Norwich: Her Majesty's Stationery Office. Accessed online 6 January 2006 at <http://www.hmtreasury.gov.uk/pre_budget_report/prebud_pbr04/report/prebud_pbr04_repindex. cfm>.

HM Treasury, UK (2005) Long-Term Global Economic Challenges and Opportunities for Europe, Norwich: Her Majesty's Stationery Office. Accessed online 6 January 2006 at <http://www.hm-treasury.gov.uk/media/A1D/6B/global_ final_140305.pdf>.

Hick, Steven, Edward F. Halperin and Eric Hoskins (eds) (2000) Human Rights and the Internet, London: Macmillan.

Himmelweit, Susan (1995) 'The Discovery of "Unpaid Work": The Social Consequences of the Expansion of "Work", Feminist Economics 1, 2: 1-19.

Hirst, Paul (1997) From Statism to Pluralism, London: UCL Press.

Hobsbawm, E. J. (1990) Industry and Empire: From 1750 to the Present Day, London: Penguin.

Hobsbawm, E. (2005) 'America's Neo-Conservative World Supremacists Will Fail', The Guardian, 25 June. Accessed online 15 September 2005 at <http://books. guardian.co.uk/departments/history/story/0,1514403,00.html>. 


\section{Bibliography}

hooks, bell (2000) Feminist Theory: From Margin to Center, 2nd edn, London: Pluto Press.

Hooper, Charlotte (2000) Manly States: Masculinities, International Relations, and Gender Politics, New York: Columbia University Press.

Human Rights Watch (2005) 'False Freedom: Online Censorship in the Middle East and North Africa' 17, 10(E). Accessed online 25 November 2005 at <http:// hrw.org/reports/2005/mena1105/mena1105webwcover.pdf>.

Hutton, Will (2002) The World We're In, London: Little, Brown.

International Feminist Journal of Politics (2006) Theme issue: Feminist International Relations in the Age of the War on Terror: Ideologies, Religions and Conflict, 8,1 .

International Monetary Fund (IMF) (2005) World Economic Outlook, Washington: IMF. Accessed online 10 August 2006 at <http://www.imf.org/external/pubs/ $\mathrm{ft} / \mathrm{weo} / 2005 / 01 /$ index.htm $>$.

International Telecommunication Union (ITU) (2006) 'World Telecommunication/ ICT Development Report Overview’. Accessed online 8 April 2006 at <http:// www.itu.int $/$ itunews/manager/display.asp?lang=en\&year=2006\&issue=02\&ipage =big_picture\&ext=html>.

Internet Service Providers' Association (UK) (2006) 'Home Secretary Commits to Consult with Internet Service Providers', ISPA UK Press Release. Accessed online 16 April 2006 at <http://www.ispa.org.uk/html/index3. html? frame=http $\% 3 \mathrm{~A}$ //www.ispa.org.uk/html/media/press_releases.html>.

Joll, James (1990) Europe Since 1870: An International History, 4th edn, London: Penguin.

Johnson, Chalmers (2005) 'No Longer the "Lone" Superpower: Coming to Terms with China', Japan Policy Research Institute Working Paper No. 105 (March 2005). Accessed online 8 May 2006 at <http://www.jpri.org/publications/ workingpapers/wp105.html>.

Johnson, Paul (1992) The Birth of the Modern: World Society 1815-1830, London: Orion Books.

Kaldor, Mary (2001) 'Beyond Militarism, Arms Races and Arms Control'. Accessed online at the Social Science Research Council, 29 May $2006<$ http://www.ssrc. org/sept11/essays/kaldor.htm>.

Kennedy, Paul (1989) The Rise and Fall of the Great Powers: Economic Change and Military Conflict From 1500-2000, London: Fontana.

Keohane, Robert O. (1984) After Hegemony: Cooperation and Discord in the World Political Economy, Princeton, NJ: Princeton University Press.

Keohane, Robert O. (ed.) (1986) Neorealism and its Critics, New York: Columbia University Press.

Keohane, Robert O. (1989) International Institutions and State Power, Boulder, CO: Westview.

Keohane, Robert O. (2002) Power and Governance in a Partially Globalized World, London: Routledge.

Keohane, Robert O. and Joseph S. Nye (1977) Power and Interdepedence, Boston: Little, Brown and Co.

Kochhar, Kalpana, Utsav Kumar, Raghuram Rajan, Arvind Subramanian and Ioannis Tokatlidis (2006) India's Pattern of Development: What Happened, What Follows?, IMF Working Paper WP/06/22. Accessed online 8 May 2006 at $<$ http://www.imf.org/external/pubs/ft/wp/2006/wp0622.pdf >. 
Kofman, Eleonore and Gillian Youngs, (eds) (2003 [1996]) Globalization: Theory and Practice, London: Continuum.

Kramarae, Cheris and Dale Spender (eds) (2000) Routledge International Encyclopedia of Women: Global Women's Issues and Knowledge, London: Routledge.

Krueger, Anne O. (First Deputy Managing Director, IMF) (2006) 'The World Economy at the Start of the $21^{\text {st }}$ Century', Remarks by Anne O. Krueger at the Annual Gilbert Lecture, Rochester University, New York, 6 April. Accessed online 8 May 2006 <http://www.imf.org/external/np/speeches/2006/040606.htm>.

Lang, Fritz (1926) Metropolis, A Simitar Entertainment Release, Jet Films, 1992.

Lash, Christopher and John Urry (1994) Economies of Signs and Space, London: Sage.

Lawton, Thomas C., James N. Rosenau and Amy C. Verdun (eds) (2000) Strange Power: Shaping the Parameters of International Relations and International Political Economy. Aldershot, UK: Ashgate.

Lerman, N. E., A. P. Mohun and R. Oldenziel (1997) 'Versatile Tools: Gender Analysis and the History of Technology', Technology and Culture 38, 1: 1-30.

Ling, L. H. M (2002) Postcolonial International Relations: Conquest and Desire Between Asia and the West, New York: Palgrave.

Lipset, Martin Seymour (1996) American Exceptionalism: A Double Edged Sword, New York: Norton and Company.

Loader, Brian (ed.) (1997) The Governance of Cyberspace, London: Routledge.

Lorenzetti, Maureen (2004) 'BP. World Oil and Gas Reserves Still Growing at Healthy Pace', Oil and Gas Journal, 21 June. Accessed online 18 May 2005 at Energy Bulletin <http://www.energybulletin.net/761.html>.

Lovenduski, Joni (2005) Feminizing Politics, Cambridge: Polity.

Lovenduski, Joni, Margaret Moran and Boni Sones (2005) Whose Secretary Are You, Minister? London: British Library.

Lyon, David (1998) The World Wide Web of Surveillance: the Internet and Off-World Power-Flows', Information, Communication and Society 1, 1: 91-105.

Lyon, David (2002) 'Everyday Surveillance: Personal Data and Social Classifications', Information, Communication and Society 5, 2: 242-57.

McChesney, Robert W. (2000) Rich Media, Poor Democracy, Champaign, IL: Illinois University Press.

McChesney, Robert W. and John Nichols (2002) Our Media Not Theirs, New York: Seven Stories Press.

McLuhan, Marshall (1962) The Gutenberg Galaxy: The Making of Typographic Man, London: Routledge and Kegan Paul.

McLuhan, Marshall (1964) Understanding Media: The Extensions of Man, London: Routledge and Kegan Paul.

McLuhan, Marshall (1967) The Medium is the Massage, London: Penguin.

McLuhan, Marshall, Quentin Fiore and Jerome Agel (1997 [1968]) War and Peace in the Global Village, San Fransisco, CA: HardWired.

Marchand, Marianne H. and Anne Sisson Runyan (eds) (2000) Gender and Global Restructuring: Sightings, Sites and Resistances, London: Routledge.

Marchand, Marianne H. and Jane L. Parpart (eds) (1995) Feminism/Development/ Postmodernism, London: Routledge.

Marcuse, Herbert (1964) One Dimensional Man: Studies in the Ideology of Advanced Industrial Society, Boston: Beacon. 


\section{Bibliography}

Marcuse, Herbert (1998) Technology, War and Fascism, Collected Papers of Herbert Marcuse vol 1, ed. Douglas Kellner, London: Routledge.

McQuail, Dennis (2005) Mass Communication Theory, 5th edn, London: Sage.

Marx, Karl $(1867,1885,1894)$ Capital, vols I, II and III. Accessible online at the Marxists.org Internet Archive: <http://www.marxists.org.uk>.

May, Christopher (2000) The Information Society as Mega-Machine: The Continuing Relevance of Lewis Mumford', Information, Communication and Society 3, 2: 241-65.

May, Christopher (2002) The Global Information Society: A Sceptical View, Cambridge: Polity.

Mittelman, James (ed.) (1996) Globalization: Critical Reflections, Boulder, CO: Lynne Rienner.

Mitter, Swasti and Sheila Rowbotham (1995) Women Encounter Technology: Changing Patterns of Employment in the Third World, London: Routledge.

Mohammadi, Ali (ed.) (1997) International Communication and Globalization, London: Sage.

Mohanty, Chandra Talpade (2003) Feminism Without Borders: Decolonizing Theory, Practicing Solidarity, Durham and London: Duke University Press.

Montesquieu, Charles de Secondat Baron de (1748) L'Esprit des Lois, trans. Thomas Nugent, The Spirit of the Laws, 1952; Ontario: Batoche Books, 2001. Accessed online 8 April 2006 at <http://www.ecn.bris.ac.uk/het/montesquieu/spiritoflaws. $\mathrm{pdf}>$.

Mosco, Vincent (1996) The Political Economy of Communication, London: Sage.

Mosco, Vincent (2004) The Digital Sublime: Myth, Power and Cyberspace, Cambridge, MA: MIT Press.

Mueller, Milton L. (2002) Ruling the Root: Internet Governance and the Taming of Cyberspace, Massachusetts: MIT Press.

Mumford, Lewis (1938) The Culture of Cities, London: Secker and Warburg.

Mumford, Lewis (1961) The City in History: Its Origins, Its Transformations, and Its Prospects, New York: Harcourt Brace.

Mumford, Lewis (1963 [1934]) Technics and Civilization, New York: Harcourt Brace, 2nd edn.

Munck, Ronaldo (2005) Globalization and Social Exclusion: A Transformationalist Perspective, Blookfield, CT: Kumarian.

Nunes, Mark (1997) 'What is Cyberspace? The Internet and Virtual Reality', in Virtual Politics: Identity and Community in Cyberspace, ed. David Holmes, London: Sage, pp. 163-78.

Nye, Joseph S. (2004) Power in the Global Information Age, London: Routledge.

Organization for Economic Co-operation and Development (OECD) (2003) (September) Policy Brief: Attracting Investment to China, Paris: OECD. Accessed online 10 August 2006 at <http://www.oecd.org/dataoecd/14/30/11724736.pdf>.

Organisation for Economic Co-operation and Development (OECD) (2005) (July) 'Working Party on Telecommunication and Information Services Policies', Summary of the OECD Roundtable on Communications Convergence Held in London 2-3 June 2005, Paris: OECD. Accessed online 2 December 2005 at <http://www.oecd.org/dataoecd/15/62/35119906.pdf>.

Perry, R. and L. Greber (1990) 'Women and Computers: An Introduction', Signs: Journal of Women in Culture and Society 16, 1: 74-101. 
Peterson, V. Spike (1992a) Gendered States: (Re)Visions of International Relations Theory, Boulder, CO: Lynne Rienner.

Peterson, V. Spike (1992b) 'Transgressing Boundaries: Theories of Knowledge, Gender, International Relations', Millennium: Journal of International Relations 21, 2: 183-206.

Peterson, V. Spike (2003) A Critical Rewriting of Global Political Economy: Integrating Reproductive, Productive and Virtual Economies, London: Routledge.

Pettman, Jan Jindy (1996) Worlding Women: A Feminist International Politics, London: Routledge.

Pointon, Marcia (1998) 'Money and Nationalism', in Imagining Nations, ed. Geoffrey Cubitt, Manchester: Manchester University Press, pp. 229-54.

Prasad, Eswar and Thomas Rumbaugh (2004) 'Overview', in China's Growth and Integration into the World Economy: Prospects and Challenges, ed. Eswar Prasad, Washington: International Monetary Fund, pp. 1-4. Accessed online 8 May 2006 at <http://www.imf.org/external/pubs/ft/op/232/op232.pdf>.

Raju, C. K. (2003) The Eleven Pictures of Time: The Physics, Philosophy and Politics of Time Beliefs, London: Sage.

Reisen, Helmut (2006) China's and India's Implication for the World Economy. Accessed online 10 May 2005 at <http://www.oecd.org/dataoecd/42/33/ 36278574.ppt>.

Rheingold, Howard (1993) The Virtual Community: Homesteading on the Electronic Frontier, New York: HarperPerennial.

Rheingold, Howard (2002) Smart Mobs: The Next Social Revolution, Cambridge, MA: Perseus.

Rifkin, Jeremy (2004) The European Dream: How Europe's Vision of the Future is Quietly Eclipsing the American Dream, New York: Penguin.

Ritzer, George (1998) The McDonaldization Thesis: Explorations and Extensions, London: Sage.

Rose, Hilary (1983) 'Hand, Brain, and Heart: A Feminist Epistemology for the Natural Sciences', Signs: Journal of Women in Culture and Society 9, 1: 73-90.

Rosenau, James N. (1990) Turbulence in World Politics: A Theory of Change and Continuity, Hemel Hempstead, UK: Harvester Wheatsheaf.

Rumbaugh, Thomas and Nicolas Blancher (2004) 'International Trade and the Challenges of WTO Accession', in China's Growth and Integration into the World Economy: Prospects and Challenges, ed. Eswar Prasad, Washington: International Monetary Fund, pp. 5-13. Accessed online 8 May 2006 at <http://www. imf.org/external/pubs/ft/op/232/op232.pdf>.

Runyan, Anne Sisson (2003) 'The Places of Women in Trading Places Revisited: Gendered Global/Regional Regimes and Inter-nationalized Feminist Resistance', in Globalization: Theory and Practice, ed. Eleonore Kofman and Gillian Youngs, London: Continuum, pp. 139-56.

Rupert, Mark (1995) Producing Hegemony: The Politics of Mass Production and American Global Power, Cambridge: Cambridge University Press.

Russell, Alan (1997) 'Technology as Knowledge: Generic Technology and Change in the Global Political Economy', in Technology, Culture and Competitiveness: Change and the World Political Economy, ed. Michael Talalay, Chris Farrands and Roger Tooze, London: Routledge, pp. 41-57.

Said, Edward W. (1994) Culture and Imperialism, London: Vintage. 


\section{Bibliography}

Said, Edward W. (2003) Orientalism: Western Conceptions of the Orient, 2nd edn, London: Penguin.

Sassen, Saskia (1996) Losing Control? Sovereignty in an Age of Globalization, New York: Columbia University Press.

Sassen, Saskia (2001 [1994]) The Global City: New York, London, Tokyo, 2nd edn, Princeton, NJ: Princeton University Press.

Sassen, Saskia (ed.) (2002a) Global Networks, Linked Cities, London: Routledge.

Sassen, Saskia (2002b) 'Introduction. Locating Cities on Global Circuits', in Global Networks, Linked Cities, ed. Saskia Sassen, London: Routledge, pp. 1-36.

Sassen, Saskia (2003) De-Nationalization, Princeton, NJ: Princeton University Press.

Scott, Joan (1996) Feminism and History, Oxford: Oxford University Press.

Shaw, Martin (2003) 'The Global Transformation of the Social Sciences', in Global Civil Society 2003, ed. Mary Kaldor, Helmut Anheier and Marlies Glasius, Oxford: Oxford University Press.

Schiller, Dan (2000) Digital Capitalism: Networking the Global Market System, Cambridge, MA: MIT Press.

Scholte, Jan Aart (2005 [2000]) Globalization: A Critical Introduction, 2nd edn, London: Palgrave Macmillan.

Shields, Rob (2003) The Virtual, London: Routledge.

Simmel, Georg (1990) The Philosphy of Money, 2nd edn, ed. David Frisby and trans. Tom Bottomore and David Frisby, London: Routledge.

Slater, David (2003) 'Rethinking the Geopolitics of the Global: The Case of North-South Relations', in Globalization: Theory and Practice, ed. Eleonore Kofman and Gillian Youngs, London: Continuum, pp. 47-63.

Slater, David and Peter J. Taylor (eds) (1999) The American Century: Consensus and Coercion in the Projectin of American Power, Oxford: Blackwell.

Smith, Adam (1776) The Wealth of Nations. Full text can be accessed online at the Adam Smith Institute website: <http://www.adamsmith.org/smith/won-intro.htm>. Smith, Adam (1982 [1776]) The Wealth of Nations, London: Penguin English Library.

Smith, David and Michael Timberlake (2002) 'Hierachies of Dominance Among World Cities: A Network Approach', in Global Networks, Linked Cities, ed. Saskia Sassen, London: Routledge, pp. 117-41.

Soja, Edward (1996) Thirdspace: Journeys to Los Angeles and Other Real-andImagined Places, Oxford: Blackwell.

Spender, Dale (1995) Nattering on the Net: Women, Power and Cyberspace, North Melbourne, Vic.: Spinifex.

Stanley, Autumn (1992) 'Once and Future Power: Women as Inventors', Women's Studies International Forum 15, 2: 193-203.

Stanley, Autumn (1993) Mothers and Daughters of Invention: Notes for a Revised History of Technology, London: Scarecrow Press.

Star, Susan Leigh (2000) 'Science: Overview', in Routledge International Encyclopedia of Women. Global Issues and Women's Knowledge, vol. 4, ed. Cheris Kramarae and Dale Spender, London: Routledge, pp. 1778-81.

Stargardt, Nicholas (1998) 'Beyond the Liberal Idea of the Nation', in Imagining Nations, ed. Geoffrey Cubitt, Manchester: Manchester University Press, pp. 22-36.

Stasiulis Daiva and Nira Yuval-Davis (eds) (1995) Unsettling Settler Societies: Articulations of Gender, Race, Ethnicity and Class, London: Sage. 
Stiglitz, Joseph E. (2002) Globalization and its Discontents, London: Penguin.

Stockholm International Peace Research Institute (SIPRI) (2006) 'Recent Trends in Military Expenditure and the 15 Major Spenders in 2004'. Accessed online 28 May 2006 at <http://www.sipri.org/contents/milap/milex/mex_trends.html>.

Strange, Susan (1994 [1988]) States and Markets, 2nd edn, London: Pinter.

Strange, Susan (1995) 'Political Economy and International Relations', in International Relations Theory Today, ed. Ken Booth and Steve Smith, Cambridge: Polity, pp. 154-74.

Strange, Susan (1996) The Retreat of the State: The Diffusion of Power in the World Economy, Cambridge: Cambridge University Press.

Strange, Susan (1999) 'The Westfailure System', Review of International Studies 25, 3 (July): 345-54.

Thorne, Christopher (1972) The Limits of Foreign Policy: The West, the League and the Far Eastern Crisis of 1931-1933, London: Macmillan.

Thrift, Nigel (1996) Spatial Formations, London: Sage.

Talalay, Micheal, Roger Tooze and Chris Farrands (1997) 'Technology, Culture and Competitiveness: Change and the World Political Economy', in Technology, Culture and Competitiveness: Change and the World Political Economy, ed. Michael Talalay, Chris Farrands and Roger Tooze, London: Routledge, pp. 1-9.

Taylor, Peter J. (1996) ‘The Modern Multiplicity of States', in Globalization: Theory and Practice, ed. Eleonore Kofman and Gillian Youngs, London: Pinter, pp. 99-108.

Tehranian, Majid and Kaharine Kia Tehranian (1997) 'Taming Modernity: Towards a New Paradigm', in International Communication and Globalization, ed. Ali Mohammadi, London: Sage, pp. 119-67.

Thomas, Sue (2004) Hello World: Travels in Virtuality, York: Raw Nerve Books.

Thussu, Daya Kishan and Des Freedman, (eds) (2003) War and the Media, London: Sage.

Toffler, Alvin (1971) Future Shock, London: Pan.

Tomlinson, John (1999) Globalization and Culture, Cambridge: Polity.

Tooze, J. Adam (1998) 'Imagining National Economies: National and International Economic Statistics 1900-1950', in Imagining Nations, ed. Geoffrey Cubitt, Manchester: Manchester University Press, pp. 212-28.

Tooze, Roger and Christopher May (2002a) 'Authority and Markets: Interpreting the Work of Susan Strange', in Authority and Markets: Susan Strange's Writings on International Political Economy, ed. Roger Tooze and Christopher May, New York: Palgrave Macmillan, pp. 1-16.

Tooze, Roger and Christopher May (eds) (2002b) Authority and Markets: Susan Strange's Writings on International Political Economy, New York: Palgrave Macmillan.

Tumber, Howard and Jerry Palmer (2004) Media at War: The Iraq Crisis, London: Sage.

UNAIDS (2004) 'A Global Overview of the AIDS Epidemic', Chapter 2 in 2004 Report on the Global AIDS Epidemic. Accessed online 17 May 2006 at <http://www.unaids.org/bangkok2004/GAR2004_html/GAR2004_03_en.htm\#Fi gure1>.

United Nations Conference on Trade and Development (UNCTAD) (2005) World 


\section{Bibliography}

Investment Report 2005) Transnational Corporations and the Transnationalization of R\&D, New York: United Nations.

United Nations (UN) Department of Economic and Social Affairs Population Division (2004) World Urbanization Prospects. The 2003 Revision, Data Tables and Highlights, UN: New York. Accessed online 10 August 2006 at <http://www. un.org/esa/population/publications/wup2003/2003Highlights.pdf>.

United Nations Development Programme (UNDP) (1998) Human Development Report, Oxford: Oxford University Press.

United Nations Development Programme (UNDP) (2002) Human Development Report: Deepening Democracy in a Fragmented World, Oxford: Oxford University Press.

United Nations Development Programme (UNDP) (2003) Human Development Report: Millennium Development Goals: A Compact Among Nations to End Human Poverty, Oxford: Oxford University Press.

United Nations Development Programme (UNDP) (2005) Human Development Report: International Cooperation at a Crossroads, Oxford: Oxford University Press.

US Census Bureau (2005) Computer and Internet Use in the United States: 2003, Washington: US Department of Commerce Economics and Statistics Administration. Accessed online 20 May 2006 at <http://www.census.gov/ prod/2005 pubs/p23-208.pdf $>$.

Wachowski, Andy and Larry Wachowski (2003) Matrix Reloaded, Warner Bros. Pictures in association with Village Roadshow Pictures and NPV Entertainment: A Silver Pictures Production.

Walby, Sylvia (1990) Theorizing Patriarchy, Oxford: Blackwell.

Walker, R. B. J. (1993) Inside/Outside: International Relations as Political Theory, Cambridge: Cambridge University Press.

Waltz, Kenneth. N. (1979) Theory of International Politics, New York: McGrawHill.

Webster, Frank (2002) Theories of the Information Society, 2nd edn, London: Routledge.

Webster, Frank (ed.) (2003) The Information Society Reader, London: Routledge.

Webster, Juliet (1995) 'What do we Know about Gender and Information Technology at Work? A Discussion of Selected Feminist Research', European Journal of Women's Studies 2: 315-34.

Webster, Juliet (1999) 'Technological Work and Women's Prospects in the Knowledge Economy: An Agenda for Research', Information, Communication and Society 2, 2: 201-221.

Whitaker, Chico (2006) 'The World Social Forum: Where do We stand and Where are We Going', in Global Civil Society 2005/6, ed. Marlies Glasius, Mary Kaldor, Helmut Anheier, London: Sage, pp. 66-72.

Wild, Leni (2005) 'Politics Remains a Man's World', Article on the Institute for Public Policy Research website. Accessed online 2 November 2005 at <http://www.ippr. org.uk/articles/archive.asp?id=1555\&fID=55>.

Williams, Kimberle Crenshaw (1994) 'Mapping the Margins: Intersectionality, Identity, and Violence Against Women of Color', in The Public Nature of Private Violence, ed. Martha Albertson Fineman and Rixanne Mykitiuk, London: Routledge, pp. 93-118.

Williams, Bruce A. (2003) 'The New Media Environment, Internet Chatrooms, and 
Public Discourse After 9/11', in War and the Media, ed. Daya Kishan Thussu and Des Freedman, London: Sage, pp. 176-89.

Williams, Howard, Moorhead Wright and Tony Evans (1993) A Reader in International Relations and Political Theory, Georgetown, ONT: University of British Columbia Press.

Wilson, Ara (2000) 'Patriarchy: Feminist Theory', in Routledge International Encyclopedia of Women: Global Issues and Women's Knowledge, vol. 2, ed. Cheris Kramarae and Dale Spender, London: Routledge, pp. 1493-7.

Winston, Brian (1998) Media, Technology and Society. A History: From the Telegraph to the Internet, London: Routledge.

World Bank (1998/9) World Development Report: Knowledge for Development, Oxford: Oxford University Press.

World Bank (1997) World Development Report: The State in a Changing World, Oxford: Oxford University Press.

World Bank (2006) 'China Quick Facts'. Accessed online 17 May 2006 at <http://web.worldbank.org/WBSITE/EXTERNAL/COUNTRIES/EASTASIAPACI FICEXT/CHINAEXTN/0, contentMDK: 20680895 pagePK: 1497618 piPK: 217854 theSitePK: 318950,00.html>.

World Health Organization (WHO) 'Environment and Health in China Today'. Accessed online 17 May 2006 at <http://www.wpro.who.int/china/sites/ehe/ overview.htm>.

World Summit on Information Society (WSIS) (2003) WSIS-03/Geneva/Doc/4-E (2003) 'Declaration of Principles. Building the Information Society: A Global Challenge in the New Millennium. Accessed online 6 April 2006 at <http:// www.itu.int/wsis/docs/geneva/official/dop.html>.

Young, Robert (1990) White Mythologies: Writing History and the West, London: Routledge.

Youngs, Gillian (1996) 'Dangers of Discourse: The Case of Globalization', in Globalization: Theory and Practice, ed. Eleonore Kofman and Gillian Youngs, London: Pinter, pp. 58-71.

Youngs, Gillian (1997a) 'Culture and the Technological Imperative: Missing Dimensions', in Technology, Culture and Competitiveness: Change and the World Political Economy, ed. Michael Talalay, Chris Farrands and Roger Tooze, London: Routledge, pp. 27-40.

Youngs, Gillian (1997b) 'Globalized Lives, Bounded Identities: Rethinking Inequality in Transnational Contexts', Development 40, 4: 15-21.

Youngs, Gillian (1997c) 'Political Economy, Sovereignty and Borders in Global Contexts', in Reclaiming Sovereignty, ed. Laura Brace and John Hoffman, London: Pinter, pp. 117-133.

Youngs, Gillian (1999a) International Relations in a Global Age: A Conceptual Challenge, Cambridge: Polity.

Youngs, Gillian (1999b) 'Virtual Voices: Real Lives', in Women@Internet, ed. Wendy Harcourt, London: Zed, pp. 55-68.

Youngs, Gillian (2000a) 'Breaking Patriarchal Bonds: Demythologizing the Public/Private', in Gender and Global Restructuring, ed. Marianne Marchand and Anne Sisson Runyan, London: Routledge, pp. 44-58.

Youngs, Gillian (2000b) 'Embodied Political Economy or an Escape from Disembodied Knowledge', in Political Economy, Power and the Body: Global Perspectives, ed. Gillian Youngs, London: Macmillan, pp. 11-30. 


\section{Bibliography}

Youngs, Gillian (2000c) 'Globalization, Technology and Consumption', in Political Economy, Power and the Body: Global Perspectives, ed. Gillian Youngs, London: Macmillan, pp. 75-93.

Youngs, Gillian (ed.) (2000d) Political Economy, Power and the Body: Global Perspectives, ed. Gillian Youngs, London: Macmillan.

Youngs, Gillian (2000e) 'Women Breaking Boundaries in Cyberspace', Asian Women 10: 1-18.

Youngs, Gillian (2001a) 'Globalization, Communication and Technology: Making the Democratic Links', Politica Internazionale, 1-2 (January-April), 217-26.

Youngs, Gillian (2001b) 'Theoretical Reflections on Networking in Practice: The Case of Women on the Net', in Virtual Gender: Technology, Consumption and Identity, ed. Eileen Green and Alison Adam, London: Routledge, pp. 84-99.

Youngs, Gillian (2001c) 'The Political Economy of Time in the Internet Era: Feminist Perspectives and Challenges', Information, Communication and Society 4, 1: 14-33.

Youngs, Gillian (2002a) 'Feminizing Cyberspace: Rethinking Technoagency', in Rethinking Empowerment: Gender and Development in a Global/Local World, ed. Jane L. Parpart, Shirin Rai and Kathleen Staudt, London: Routledge, pp. 79-94.

Youngs, Gillian (2002b) 'Globalization and the Internet', in The Media Book, ed. Chris Newbold, Oliver Boyd-Barrett and Hilda Van Den Bulck, London: Arnold, pp. 373-90.

Youngs, Gillian (2004a) 'Cyberspace: The New Feminist Frontier?' Essays in Feminism and Media, ed. Katharine Ross and Carolyn Byerly, Oxford: Blackwell, pp. 185-208.

Youngs, Gillian (2004b) 'Gender, Equality and Globalization', in Globalisation and Equality, ed. Keith Horton and Haig Patan, London: Routledge, pp. 114-28.

Youngs, Gillian (2005) 'Ethics of Access: Globalization, Feminism and Information Society', Journal of Global Ethics 1, 1: 69-84.

Youngs, Gillian (2006a) 'Feminist International Relations in the Age of the War on Terror: Ideologies, Religions and Conflict', International Feminist Journal of Politics 8, 1: 3-18.

Youngs, Gillian (2006b) 'Gender and Technology: The Internet in Context', in The Ideology of the Internet: Concepts, Policies, Uses, ed. Katharine Sarikakis and Daya Kishan Thussu, New York: Hampton Press (IAMCR series).

Yuval-Davis, Nira (1997) Gender and Nation, London: Sage.

Zalewski, Marysia (2000) 'Missing Mother? Reproductive Technologies into the 21st Century', in Political Economy, Power and the Body: Global Perspectives, ed. Gillian Youngs, London: Macmillan, pp. 112-31. 


\section{Index}

abstraction 6, 55-6, 113

activism 48, 62, 93, 143

advertising 52

Afghanistan 130

aid 4

AIDS see HIV/AIDS

air travel 149

Aljazeera 82

Amnesty International (AI) 133

anarchy 39,82 ; anarchic informational sphere $83,86,88$

Anderson, Benedict 37

Angola: oil 103

anti-globalization movement see globalization

ARPANET see Internet

art 50

Association for Progressive

Communications Women's

Networking Support Programme

(APCWNSP) 123

atomic bombs see weapons

audience see Internet

Australia: ICTs 104

authority 4

Bangladesh: GEM 103

BBC 79, 82

Berlin Wall 28

Berners-Lee, Tim 12, 43-5

binary oppositions 38,46 ; particular versus universal 113; rationality versus irrationality 65-6, 114; subject/object 108;

'technology/nontechnology' 120; virtual versus real 47

blogging 90-1, 93; and authorship 91

Bolivia 102

boundaries 4, 13, 16-17, 35, 81, 90; and cities 51; and digital market
137-42; and inequality 77, 147; cross-boundary 53, 88; organism and machine 56

Britain 27; see also communications

business to business (B2B) 11

business to customer (B2C) 11

call centres 67

capital 25-6, 30-1, 33; and domination of the world 93

capitalism 63, 92, 106, 115, 150;

industrial and post-industrial

capitalism 112, 120; 'male-dominant capitalism'56; 'noncapitalist forms of economy' 64; world capitalist system 28; see also rationalization

car 2, 149

Caribbean 101-2

Castells, Manuel 52

censorship 17

CERN 12, 43

change 3, 5-6, 9

childcare: and men 119

child deaths 99-100, 102; gender differences 100

China 24, 130; and hegemony 127, 133-7; communications 69, 72; culture of censorship 86, 132-3; economic growth $8-9,14,18,23$, 29, 80, 94-7, 103, 105, 144; exports 11, 96; Gini index 101-2; globalization 10-11; health 101; hyper development and environmental impact 101; income inequality 101 ; information economy 96, 103; inward investment 94; leapfrogging 133-5; manufacturing 9; oil 9; outward investment 95-6; trade deficit and surplus 96; uneven development 
100-1, 134-5; water and sanitation 101; see also Internet censorship

Chomsky, Noam 131

Church 7

citizenship 16, 24, 32-4, 36, 48, 78-80, 90, 136; and Internet 83, 88; cybercitizens 89

city $1-2,15-16,49-50,151$; and consumption 50; as hub of finance, corporate and cultural activity 50; global cities 15-16, 50, 111; megacities 15; pollution 101

civil society: global 93

class see socio-economic status

clocks 66

Cockburn, Cynthia 120

Cohen, Benjamin 33-4

Cold War/post-Cold War 7, 28, 43, 130-1

colonialism/postcolonialism 23, 27, 31, $60,62,77$; postcolonial critiques $38-9$

commodities 25

common sense 6

Commonwealth of Independent States (CIS): poverty 8,68

communications $14,23,52-3,70$; and the built environment 49;

broadband 73, 104; few-to-many 84-5; infrastructures $12,19,69$, 107; international 7 ; many-to-many 84; mobile 2, 12, 17, 40-1, 73; networks 9, 17 ; satellite 7,12 ; synchronous/asynchronous 51,111 , 147; telegraph 41; telephone 41,51 ; vertical/horizontal 16-17, 77, 81-2, 84-6, 88, 90-1, 94; video conferencing

Communism 24; see also, information and communication technologies and China

computers $1,7,13,48$; computermediated communication 46,53 ; computer-mediated spaces 45 connectivity 43-5, 51, 88, 110; and inequalities 143-51

consumption see production

continuities/discontinuities $31,35,49$, 65-6, 69, 131; see also technology control 1-2, 7, 16-17, 56; and technology 139-41

convergence 54

criminality see terrorism

cultural imperialism 35 currencies 26-34; individual experience of the market 35 ; post-national (regional) era of 30, 33-4

'cyber dissidents' 133

cyberspace 16,48

cyberstalking 142

cyborg 14, 56-7

Cyprus: GEM 102

databases 45

Darby, Philip 60

DAWN 123

decentralization 77-8

defense 12, 27, 116, 133; militaryindustrial complex 131-2

Deibert, Ronald 41

democratic: accountability 79,81 ; debate and WSF 93; deficits 79, 81; elections 78; legitimacy 78-80; participation 79 ; political processes 78; transparency 79-81

desire: economy of 35

development 60, 70-3; complexities of 98, 106; leapfrogging $18,127-8$, 133-7; linear notion of $64-5,70$; sustainable 9, 149-50; uneven 18 , 62, 105-6

developing countries 4, 14-16, 18, 149

digital 2, 7, 13-14; access 18-19, 72; cultures 137; divides 17-18, 70-2, $77,106,104,121-2,136$; economy 52-3, 67, 69, 128, 134, 137-42; elite 74 ; future 72 ; human rights 147; time 66

'disembedded' practices 81

disembodied perspectives 55-6

disempowerment see empowerment/ disempowerment

dollar see USA

Donna Haraway 14

double and triple burdens 63-4

East Asia 8, 67, 72, 100; and FDI 96;

Gini index 102

Eastern Europe: Gini index 102; poverty $8,67-8$

economies see states and markets education 7, 91, 106; and digital divides 104; and information society 99; and training 97, 135; gender gaps 100, 106; global gaps 100; primary 70,99

Egypt: oil 103

embodied perspectives $55-6,112-5$ 
empowerment/disempowerment 3; of women 70-1, 124; political disempowerment 81

Enloe, Cynthia 62

environmental sustainability 70

Ethiopia: communications 69

European Central Bank 30

European Union (EU) 24, 82, 95; common market 30; euro 30-34; globalization 9-11; imports 96; integration 30-3; regional monetary system 32; share of world output 9; single European market 30; Treaty of European Union 30; Treaty of Rome 30

everyday experience $34,57,62-3,112$; and communications 54, 111; and gender 112-3; globalized 80

evolution see human

exchange 25, 49, 133; and speed 66; exchange rates 32-33; virtual 111 exogenous/endogenous see technology exploitation 47, 65, 106 extermination camps 47

factories 62

feminist critiques 38-9, 54-7, 64, 108-24; of science and technology 66

'feminist curiosity' 63

finance 5-7, 11-13, 31, 66; financial markets 33,111

firms 4, 11-13, 79, 132, 136; Chinese and Indian 96-7; place-based and virtual 52

First World War 27, 58

flexibilities 16, 52-3, 138

flows 52-5, 91; Internet 87

food 26-7

Foreign Direct Investment (FDI) 95-7, 105, 144; Africa 103

Foucault, Michel 36

friendships 48

Fukuyama, Francis 116

\section{G8 79}

Gates, Bill 43-4, 132

gender 38, 55, 59, 61, 62, 66, 108-24; development index (GDI) 109-10; empowerment measure (GEM) 102-3, 109-10; equality 70, 99; see also education and inequalities genetics 45,65 geoeconomic 31-2, 58 geography 16

geopolitics 11, 30-1; and amnesia 60

Ghana 101

Gibson, Katherine 64

Gini index 101

Gleick, James 110-11

globalization 4-5, 8-11, 13, 27-8, $31-4,49,60,66,74,86,113,116$, 129, 144; and technology 111; and

US hegemony 127-33; anti-

globalization movement 93; 107, 112, 141; competition 32; economic growth 95; financial 11-12, 15; global public goods 30; investment patterns 94; production 16; services 16; women's experience of 61-2; unevenness 67, 97-8; see also city, EU, USA and China

gold 25, 27; gold standard 4

Gordon, Colin 36

governance 64, 129

governmentality 36

Graham, Julie 64

Great Depression 33

The Guardian 82-3; 'Comment is Free' 90

Haraway, Donna 56

Harding, Sandra 65

haves and have nots 15, 18, 69, 127

health 70, 100, 106; healthcare 135; see also HIV/AIDS

hegemony 127-37; see also China and USA

history: alternative 58-9; and amnesia 60; and cities 50; and technology 42, 49; discourses and knowledge structures 59-66; 'end of history' thesis 116; feminist and postcolonial critiques 38-9, 58-66; injustices 106; international 58, 60; monopoly over the telling of time 59; national 24, 29-3, 79, 58

HIV/AIDS 70, 94, 98; and women 99, 102

Hobsbawm, Eric 130

holism 42, 44; 'ecological holism' 41

Hong Kong (China) 95

homogeneity 60-1

Hollywood film 35

hooks, bell 62

Human Development Report 8, 3, 18, 101-3, 144; Human Development Index (HDI) 97-8, 101, 109-10 
hunger and malnutrition 97, 100, 106, 144

Hutton, Will 32

human: creativity 46; destructiveness 46; evolution 42; machine interface 47-8, 53, 56-7; rights 46, 133, 147; see also interdependence

hyper realities 40

hypertext 44

identity $14,17,24,36$; sovereign 30 , 37-8; symbolic 33; see also gender, technology and women

ideology 28, 93, 147; patriarchal 117; see also neoliberalism

illiteracy see literacy

imagining 2-3, 34, 46-7, 87; and the city 51 ; and the cyborg; Europe as imagined future 32; 'imagined communities' 37; technological 106

IMF 60

income distribution: uneven (global) $71-2,101$

India 9, 18, 94, 95, 105;

communications 69; FDI 96;

information economy 96-7, 103;

leapfrogging 133-5; outsourcing to 134; outward investment 96; servicing and software work 72 ; uneven development 100, 134-5

industrialization $8,14,23,128$; industrial revolution 70

inequalities 17-19, 42, 50, 59, 62, 67-9, 72, 74; and working patterns 61 ; crisis of 107 ; gender $3,8,18$, 108-24; old patterns and new forms 92; reducing 102; rising 101-2; socio-economic 3 , 8; trading 48; within and between countries 104 infant mortality rates 68

information 44, 82, 84, 137-42; control of 77 ; democratization of 77 ; inclusion and exclusion 98 ; legitimacy of 84 ; rich and poor 85 ; state bureaucratic control of 36 ; society 45-6, 54-5, 65, 70-1, 78, 92, 103; see also China and India information technology see digital information and communication technologies (ICTs) 8, 10-11, 15, 19, 43, 49, 69-70, 111; access to 71 , 85 ; and inequalities 98 ; and social movements 107; and women 121-4; cutting across (transcending) boundaries $81,84,107$; in the developing world 94; networks 11 , 16,23 ; see also rationalization informercial 137

'inside/outside' 37-9, 83; and the Internet as a technological layer 89 instantaneity see time/space

'intellectual play' 118-9

interactivity $12,19,44,81-2,85,91$

interest rates 32

interdependence: human/machine 2-3, 14, 46, 139-40, 148; of currencies; of public and private 55; with environment 42

International Monetary Fund (IMF) 11, 95

Internet 12-13, 41, 43, 45, 49, 51, 87; and audience-specific choice 82 ; and hegemony 127-8, 132; ARPANET 12; as a neoliberal medium 132; as a new global paradigm 87; censorship 86, 91, 132-3; global access 73; political economy of access 84,88 ; originated and developed in USA and Europe 87, 91; transcending boundaries 83; women and time 121

Internet Service Providers (ISPs) 89

'intersectionality' 38

investment see globalization and North/South

Iraq 130

ISIS International Manila 123

Israel: gender equality rankings 109

Italy: GEM 102-3

Japan 95; communications 73-4; GEM 102 ; in relation to China's economic growth 9 ; oil 9

Journalists 84

\section{Kenya: WON 123}

Keohane, Robert 5

knowledge 3, 5-6, 8, 14, 16, 42, 45, $66,72,81,142$; economies 70 ; mobile and transmissible 78 ; society 6,13 ; states as knowledge communities 81 ; scientific base and hegemony 127-33

labour 25-6: divisions 117; manual and mental 116-7

land 25-6

Lang, Fritz 2

Latin 78 
Latin America: and Chinese investment 95-6; poverty $67,101-2$

leapfrogging see development

Lebanon: GDI 109

leisure see work

Lenovo 96-7

liberalism see neoliberalism

life expectancy 68

lifeworld 138, 140

liminal 47

literacy/illiteracy 78-9, 91, 135; and information society $99,127-8$; and women 91; digital literacy 135

locatedness 24

machines 1-2, 16, 25-6, 89, 139-40; war 1, 47; see also interdependence McLuhan, Marshall 14

macro-micro see micro-macro

malnutrition see hunger

manufacturing 11, 14-15, 61, 67;

Africa and Asia 103; see also China

Marcuse, Herbert 140

marginalization 39

marketing 43, 128

markets see states and markets

marriage 48, 115

masculinity: masculinist logics 112 ; masculinist perspectives 38-9, 54-5; masculinist power 109; masculinist sensitivities to space 113

mass communications 41

The Matrix 1, 3, 14, 16; Matrix

Reloaded 1-2, 46-7, 139, 149

means/ends 3

media: global 23, 41, 81, 82; mass media 79, 81, 83, 139; mediation 84-5; multimedia 54, 141; national 80-1; new media 40, 139; trust and legitimacy 84

mediation see technology

medieval Christendom see Church

merchant shipping 28

Metropolis 2-3, 14, 16, 46-7, 139, 149

micro/macro 4, 31, 43-4, 48, 53-4, $86-7,142$; and feminist critiques 54-5; and Internet 88

Middle East: poverty 67

migration 106

military see defense

Millennium Development Goals

(MDGs) 69-70

mining: Africa 103 mobile see communications

modernity/postmodernity 23, 60, 65-6, 69, 140; 'spatialized account of modernity' 61

modernization 60

money 23, 25-6; territorial 33; see also symbolic

multilateralism 30

Mumford, Lewis 49

Munck, Ronaldo 106

Namibia 99, 101

nationalism 31-2; 'methodological nationalism' 107

nature 56; mastery of 116

neoliberalism (liberalism) 4, 18, 60, 64, 131; and equal rights 92-3; and Internet 87-8, 91; and utopian visions 92; criticism of neoliberal values; ideology 18, 71, 92, 105; institutionalist varieties 4 ; interests 79; negative impacts 93; neoliberal synergy of democratic politics and economics $87-8,116$; opposition to 107 ; tensions relating to inequality $72,105,143-51$

neorealism 4

networks 51-3, 55, 69, 106, 111, 142;

business and trading 67

new social movements see social

NGOs 18, 84-5, 93, 141, 146-7

Nigeria: oil 103

nineteenth century 23, 27, 33, 115

North/South 50, 52, 60-2, 67, 91, 141; and neoliberalism 105-6; investment patterns 94; patterns of poverty across 100-1; technological imbalance between 103

Norway 101; gender equality rankings 109-10

OECD 82; Gini index 102

oil 103; oil crises 4; see also China, Japan and USA

online/offline 48-9, 141; and citizens

89 ; identities 83 ; information

spheres 86 ; news 93

ontology 37-8, 42, 56

oppression 14, 108

paedophiles 46, 88, 141

Pakistan: GDI 109

passivity 85

patents see technology 
patriarchy 18; and colonial settings 109; and time 116, 121; embedded 108, 114; patriarchal notions of production 117; patriarchal paradigms 112; patriarchal social value 117

Peru: GDI 109

place/space 3, 10, 13-14, 111; see also time/space

policy 4, 10; environments 146; policymakers 143

political: horizontal versus vertical practices 107 ; theory $36-8$; will 150

pollution 149

poor see rich

pornography 46 ; combating access to online child pornography 86, 88-9;

post-Cold War see Cold War postcolonialism see colonialism postmodernity see modernity poverty 50, 97, 106; global improvements and variations 100 power 1, 3-7, 15, 17, 66-7, 129, 146; and cities 49-51; and knowledge 36, 114; church 78; national versus regional 31; power politics 28 ; state power 29; unilateral power 28

print: culture 78,91 ; printing press 77-8; revolution 77-8; transformations 78

private/public $3,11,17,40,54-6$, 63-4; and broadcast media 53-4; and 'nontechnology/technology' 120; digital market 138-9, 148-9; in relation to gender and time 113-4, 117-8

production and consumption 5-9, 12-13, 15-16, 18, 25-6, 32, 46, 50-1, 55-6, 68-9, 80, 92, 95, 106, $111,114,116,147$; consumer identities 89 ; cultural products 52 ; division in relation to time 115-6; primary products 67 ; productive time $25,117-8$

public see private/public public sphere 79,82 ; global public sphere $79,81,83$; stretching of 77 , 80

race $38,59,62$; racism 38,56 rape and sexual harassment 109 rationality/irrationality see binary oppositions rationalization $16,23,36,116,138-9$, 150; and ICTs 50-1, 111; of capitalism 116; rational-actor model 113-4, 116

regionalization 31-2

religious/secular realms 78

research $6-7,42$

resistance 57,58

Rice, Condaleeza 38

rich/poor 8, 67-9, 72; global poverty reduction 67-8; technological lead of rich countries 103

rituals 47

robot 47

Rose, Hilary 117

rural/urban 15-16, 52

Russia 28

Saudi Arabia: GDI 109; GEM 103; see also Internet censorship

secular see religious

science $7,14,54$; male dominance of 18 ; see also knowledge and technology

Second World War 27-8, 30, 33, 58

security 5-7

services $8-10,13,15,30,50,61,138$; see also globalization, India and women

Shields, Rob 47

skills 19

Sino-Japanese conflict 58

Slater, David 60

Smith, Adam 24-6, 150

social: division of labour 50; justice, 62; movements 93, 106, 127, 141, 146; relations 3 ; reproduction 56,64 , 114, 117-8, 120; science 3, 58-9; transformations 7, 14, 19, 35, 40, $44,47,53,77$

socio-economic status $38,62,119,146$

South Asia: poverty 67, 72; Gini index

South Africa: poverty 8

South Korea: ICTs 104; Internet and mobile phones 73-4

Sovereignty 36 : geospatial 34 ; monetary 33; national currencies 31-4; territorial 37 ; see also identity space see place/space and time/space speed 18, 66-9, 106, 110-11; and digital economy 135-7

Spender, Dale 90-1

stakeholders 72

Stanley, Autumn 118 
state-centrism: Foucaultian critiques of 36-7; state-centric stasis 33; state-centric theories 4 states and markets $4-5,10-12,15,19$, 24, 33, 47, 58, 116, 147, 150-1; and cities 49-51; and hegemony 128-33; ; and media 54; democratic 78 ; 'enhanced power' of markets 134; global market 24; markets and women 115; regional integrated market 24; scientific state 6 ; states as information spheres 86 ; states resist informational anarchy 85-6; vertical structures of 82

stereotyped roles 119

stock exchanges (markets) 11, 50

Stockholm International Peace Research Institute (SIPRI) 130

Strange, Susan 3-7, 127-33

Sub-Saharan Africa 8, 15, 67-8, 72, 94, 135,145 ; bottom end of the development scale 97-8; Gini index 101; see also HIV/AIDS

superpowers 28

surveillance 16,88 ; self-surveillance and the Internet 88 ; online cultures of 89,149

sustainable development see development

Sweden: ICTs 104

symbolic $2,19,128,147$; and rationality 116; environment of ICTs 137-42, 137-42, 151; euro 30-3;

flows 52; role of money 26-33, 151; sovereignty 35 ; spaces 13 ;

symbolism of the state 39 ; territorial symbology 33-4; US dollar 29-30

Tanzania 100; WON 123

technology (and science) 2, 4, 7-9, 15, $40,43,60,65,87$; and power 56 ; and US power $28,127-37$; as 'embedded' 42; as masculine 65-6, 110, 112, 117, 124; 'brown goods' and 'white goods'; competition 7; continuities/discontinuities 2-3; domestic and reproductive technologies 120-1; exogenous/endogenous 3, 41-4; gendered technologies and gender identities 119-22; infrastructures 11 ; innovation $14,19,41,66,68,118$, 132, 134; inventions 3 ; mediation 12, 14, 17, 137-42; medical applications 56 ; military 46 ; nanotechnology 45 ; patents 7,14 , 65,103 ; software and hardware 12 , 44, 47, 138; technological determinism 45, 140; 'the technological imperative' 116 ; teleworking 149; unintended consequences 43

territoriality $10,16-17,24,31-3,36$, $38-9,41,80$; and cities 51; and networks 52

terrorism/criminality $17,86,142,147$; post 9/11 200186 ; online monitoring of 89

texts 59

Thatcher, Margaret 38

time/space 8, 16, 23-7, 29, 34, 39, 43, 87; and 24/7 Internet; division between work and leisure, production and consumption 115; feminist perspectives on the political economy of time 108, 111-24; gender matrix of time 111-5, 119; freedom in relation to time (contrasts between men and women) 115-22; historical and present time 112; instantaneity $7,11,111,116$, 121; multiple spatial framings 79 ; pre-industrial, agricultural seasonal time 67; state definition and control of 36, 37-8; time and evolution 116; time as a resource 117; time in the service of others 118; time-saving domestic appliances 120-1

trade 4, 12, 26-7, 31, 106

Trade-Related Intellectual Property Rights (TRIPS) 65

traditional practices 65

transatlanticism 27,30

transcendence see social transformations

transnational corporations (TNCs) see firms

transport 10, 53

Turkey: gender equality rankings 109 twentieth century $2,4-5,8-9,11,13$, $15,27,32,56,92,105$

twenty-first century 2, 4, 7-9, 27, 29, $32,50,59,71,128,139$

typewriter and wordprocessor: as gendered technologies 121

Uganda 99

UK: digital divides 104-5; GDI 109; 
military spending 130 ; sterling $31-3$; standing as a leading economy 32 ; treasury 32 ; women workers in 114 ; see also Britain

United Nations (UN) 82, 92; conferences 146

United Nations Development Programme (UNDP) 8

university sector 6

Universal Declaration of Human Rights 70

urban see $\mathrm{rural} / \mathrm{urban}$

USA: American dream 35; broadband 74; communications 69; digital divides 104; dollar 27-30, 32, 34-5; dominance in military and technological terms 129-30; entry into First and Second World Wars 27-8; exceptionalism 129-30; GDI 109; Gini index 101; globalization 10-11; hegemony 3-7, 9, 18, 28-9, 32 , 95, 127-33; imports 96 ; information economy 96; oil 9; unilateral power 28 ; women workers in 114; see also Internet and technology

utopia 46; and the information age 136,141

value 24-5, 29-30, 55, 64; global networks of 52 ; time 111,117 vertical/horizontal communications see communications virtual 12-13, 16-17, 19, 42, 52, 71, 140; and time 111; identities 53, 89; 'image' 47; market-place 52, 128, 137-42; mobility 149; platform 43; presence 47; reality and the web 67 ; worlds, communities and forums 48-9, 53, 122, 141, 147; see also binary oppositions and symbolic

wage: family 114, 117

Walker, Rob 37

war 47, 58; 'network wars' 131; on terror 86, 129, 131; 'star wars' 131; total war 27-9; see also First World War, Second World War and machines wealth 24, 27-8, 52, 92

The Wealth of Nations 24-6

weapons 27-8; atomic bombs 28

weblogs see blogging

western Europe 27

Westernization 60-1

Westphalian state system 33

Winston, Brian, 41

women 102; and alienation from their own time 119; and children's dependence on men 117; and information society 71 ; and invention 118-9; and online activism and policy work 124; as outsiders in the online world 124; in paid labour 61; voice 102; women's movements 18,124 ; women's service functions in the home and at work 119; women's socially constructed knowledge 121; women's time 118; women's time in the service of others 119-22; see also gender, education and technology

Women on the Net (WON) 122-4

work/leisure 2, 16, 48, 53-4, 110; commodification of work 115-6; division in relation to time 115 ; paid and unpaid 114-5, 116-7; see also labour

World Bank 60, 121

World Economic Forum (WEF) 79, 93

World Social Forum (WSF) 93; activism 94; and experimentation 93; utopian vision 93

World Summit on Information Society (WSIS) 17, 19, 69-72, 134; and marginalized and disadvantaged groups 71

World Trade Organization (WTO) 65, 79, 93

world wide web 12, 43-5; and 24-hour reality 67 ; and enduring identity 93-4

World Wide Web Consortium 44

Yemen: GEM 103

Zambia 99 